Utah State University

DigitalCommons@USU

\title{
Reliability-Based Underseepage Analysis in Levees Using Monte Carlo Simulation
}

Lourdes Polanco

Utah State University

Follow this and additional works at: https://digitalcommons.usu.edu/etd

Part of the Civil Engineering Commons

\section{Recommended Citation}

Polanco, Lourdes, "Reliability-Based Underseepage Analysis in Levees Using Monte Carlo Simulation" (2010). All Graduate Theses and Dissertations. 573.

https://digitalcommons.usu.edu/etd/573

This Thesis is brought to you for free and open access by the Graduate Studies at DigitalCommons@USU. It has been accepted for inclusion in All Graduate Theses and Dissertations by an authorized administrator of DigitalCommons@USU. For more information, please contact digitalcommons@usu.edu.

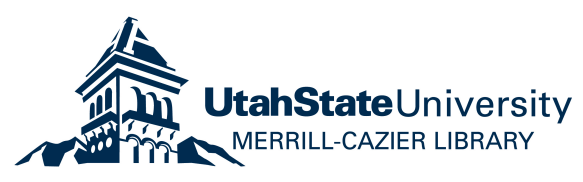




\title{
RELIABILITY BASED UNDERSEEPAGE ANALYSIS IN LEVEES USING MONTE CARLO SIMULATION
}

\author{
by \\ Lourdes Polanco \\ A thesis proposal submitted in partial fulfillment \\ of the requirements for the degree \\ of \\ MASTER OF SCIENCE \\ In \\ Civil and Environmental Engineering
}

Approved:

Dr. John Rice

Major Professor

Dr. Joseph Caliendo

Committee Member
Dr. Keri Ryan

Committee Member

Dr. Byron Burnham

Dean of Graduate Studies

UTAH STATE UNIVERSITY

Logan, Utah 


\begin{abstract}
Reliability-based Underseepage Analysis in Levees Using Monte Carlo Simulation
\end{abstract}

by

Lourdes Polanco, Master of Science

Utah State University, 2009

Major Professor: Dr. John Rice

Department: Civil and Environmental Engineering

A new method for assessing the potential for unsatisfactory levee performance due to underseepage is presented. Specifically, the method assesses the potential for the initiation of piping (the internal backward erosion of the foundation or embankment caused by seepage). Current assessment methods consist of deterministic seepage analyses and simplified reliability methods. Deterministic methods produce either a maximum hydraulic exit gradient or a Factor of Safety against piping but they do not account for high levels of uncertainty in soil properties and subsurface geometry that are inherent to many levee analyses. The most common simplified reliability approaches that are currently being used to analyze levees with regard to underseepage apply the First Order Second Moment (FOSM) Taylor Series method using the US Army Corps of Engineers "Blanket Theory" equation as the performance function. These methods take into account the uncertainty of the soil properties but are limited to simplified subsurface geometries and often do not model the actual mechanism responsible for levee failure due to underseepage piping. 
The proposed new method uses a Monte Carlo simulation to calculate the probability of unsatisfactory levee profile performance and can take into account complexities in subsurface geometry that cannot be assessed using the simplified reliability methods. The relationships between uncertainty of the soil parameters, the subsurface geometry, and the Factor of Safety against piping are defined through parametric variation analyses of a finite-element seepage model. The results of the parametric analyses are used to develop a series of equations that define the relationship between the various input parameters and the factor of safety. Using these equations, probability density functions for the various input parameters, and the computer program $@$ Risk which interfaces with Excel, a Monte Carlo analysis is performed to calculate the probability of unsatisfactory performance which represents the probability of initiating erosion given a river flood level. The results of the analysis represent a single node of the event tree. In order to assess failure potential, other points in the event tree will need to be assessed with calculations or judgment since it is only the first phase that is currently considered to be in the process of piping. The new method is demonstrated using actual data of levee profiles from the Natomas Basin in Sacramento, California as a case study. The case study highlights the benefits of reliability-based analyses over the Factor of Safety and demonstrates the importance of subsurface geometry in reliability calculations. 


\section{ACKNOWLEDGMENTS}

I would like to thank Dr. John Rice for introducing me to the wonderful world of levees, for guiding me throughout this research, and for his patience, support and constant counseling. I would also like to thank Dr. David Bowles and Dr. Sanjay Chauhan for their time and help.

I would also like to give special thanks to the Dominican Scholarship Program for giving me the opportunity of being here today. For their guidance and wisdom I thank God and my parents and last but not least, to my fiancé for always supporting me when I needed it the most. I would have never done it without all of you.

Lourdes Polanco 


\section{CONTENTS}

$\begin{array}{ll}\text { Page } & \text { Pat }\end{array}$

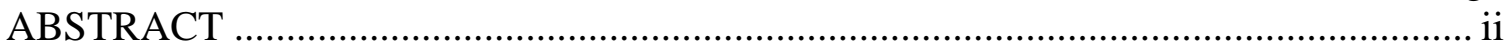

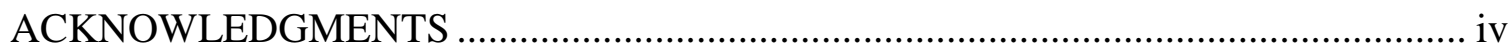

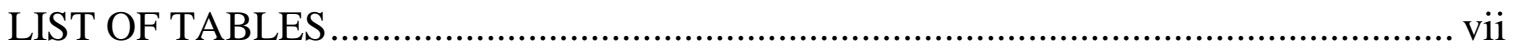

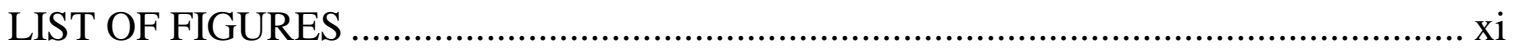

\section{CHAPTER}

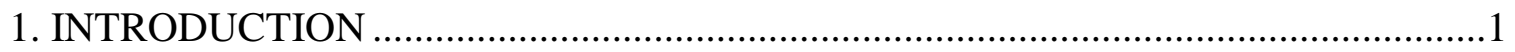

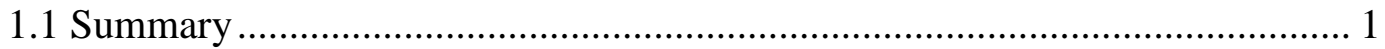

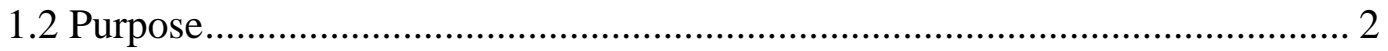

1.3 Research to be Undertaken .................................................................... 2

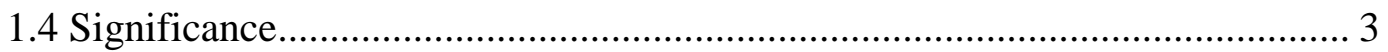

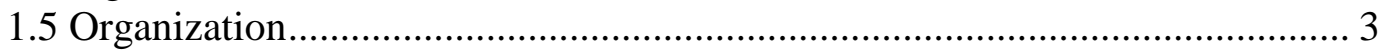

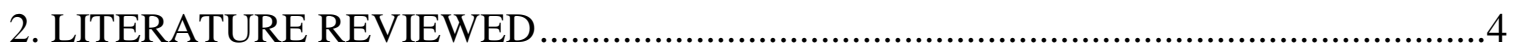

2.1 Reliability in Geotechnical Engineering ................................................... 4

2.2 Sources of Uncertainty: Epistemic Versus Aleatory ...................................... 7

2.3 Current Methods for Levee Reliability Underseepage Analysis ................... 9

2.4 Background of the Natomas Basin Area...................................................... 17

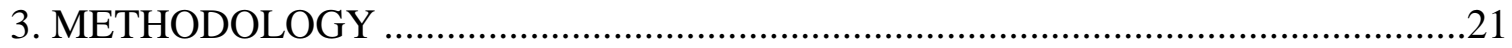

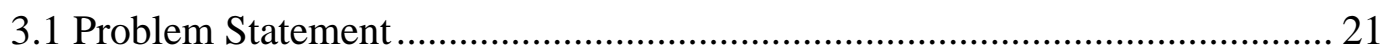

3.2 Failure Mechanism................................................................................ 22

3.3 Sources of Data: Profiles ................................................................... 26

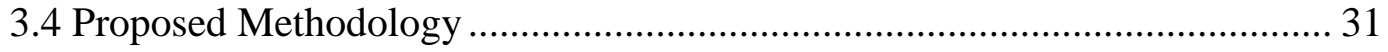

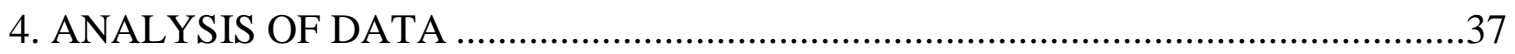

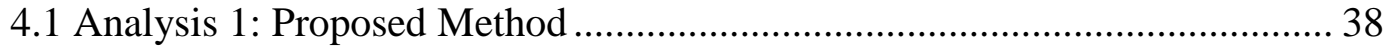

4.2 Analysis 2 Effective Stress Method with a Crack at the Toe of the Levee .... 40

4.3 Analysis 3: FEM and Monte Carlo Simulation with Blanket Theory Assumptions ................................................................................... 42

4.4 Analysis 4: Old Channel Model................................................................ 44

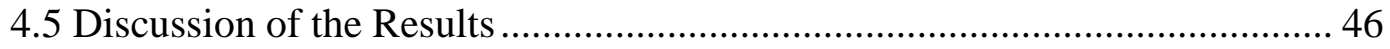

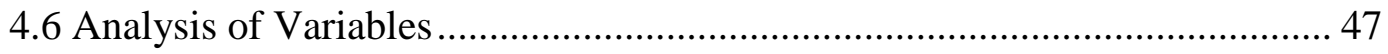




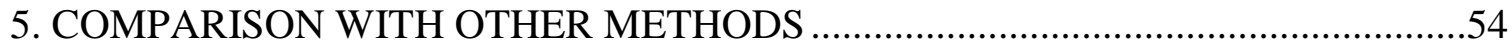

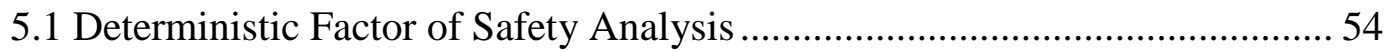

5.2 FOSM - Blanket Theory Simulation ............................................................ 56

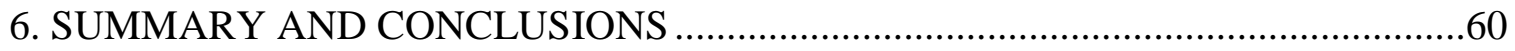

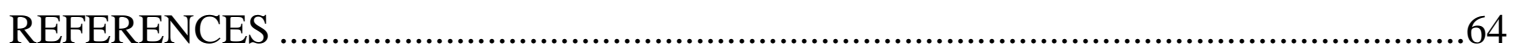

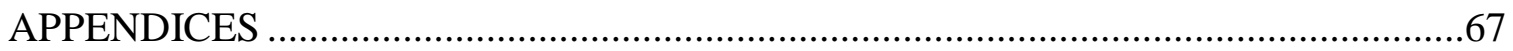

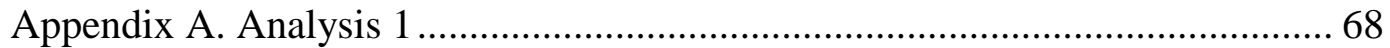

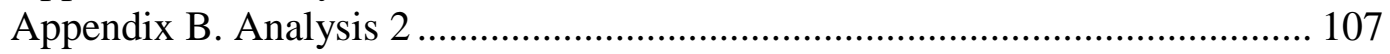

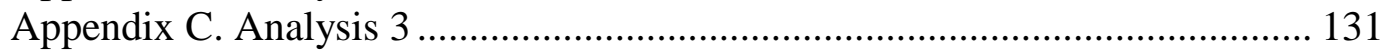

Appendix D. Analysis 4 ............................................................................. 140 


\section{LIST OF TABLES}

Table Page

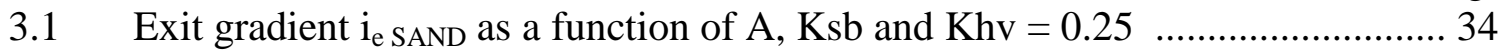

3.2 Uplift pressure of the sand $\mu_{\mathrm{S}}$ as a function of $\mathrm{A}, \mathrm{Ksb}$ and $\mathrm{Khv}=0.25 \ldots \ldots \ldots \ldots . . . .34$

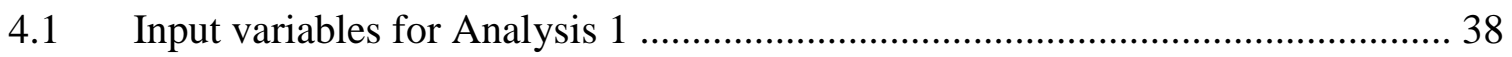

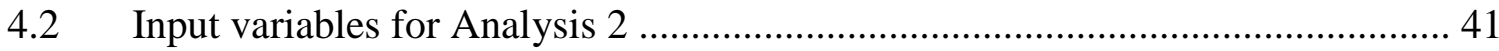

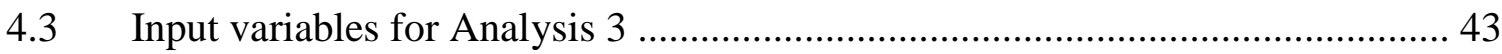

Input variables for Analysis 4.............................................................. 45

4.5 Regression analysis output summary for Analysis 1.................................. 49

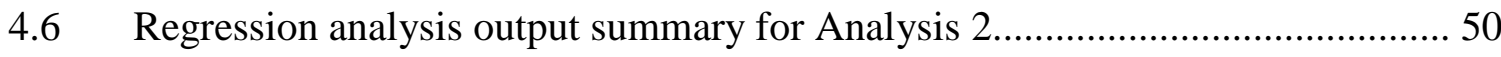

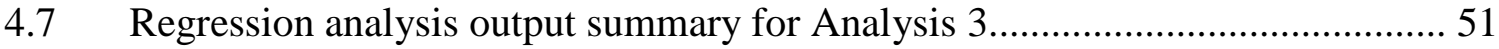

4.8 Regression analysis output summary for Analysis 4.................................... 52

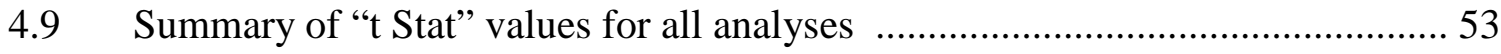

5.1 Summary input and output for the deterministic F.S. analysis ......................... 55

5.2 Analysis of levee section with MLV by Blanket Theory ................................ 58

5.3 FOSM Taylor Series method for levee section with Blanket Theory................ 59

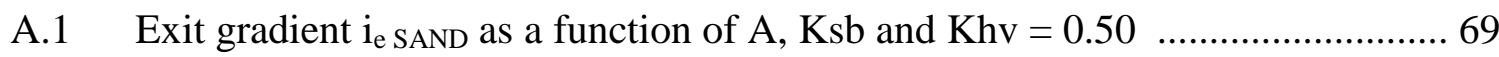

A.2 Polynomial Trendline Coefficients and Coefficient of Determination $\left(\mathrm{R}^{2}\right)$ for Family of Curves in Figure A.1 …............................................................... 71

A.3 Uplift (Pore) Pressure $\mu_{\text {SAND }}$ as a function of $\mathrm{A}, \mathrm{Ksb}$ and $\mathrm{Khv}=0.50 \ldots \ldots \ldots \ldots .72$

A.4 Polynomial Trendline Coefficients and Coefficient of Determination $\left(\mathrm{R}^{2}\right)$ for Family of Curves in Figure A.7 ................................................................ 74

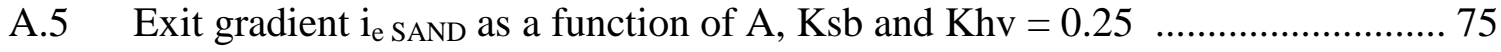


A.6 Polynomial Trendline Coefficients and Coefficient of Determination $\left(\mathrm{R}^{2}\right)$ for Family of Curves in Figure A.13 …............................................................ 78

A.7 Uplift (Pore) Pressure $\mu_{\text {SAND }}$ as a function of A, Ksb and Khv $=0.25 \ldots \ldots \ldots . . .78$

A.8 Polynomial Trendline Coefficients and Coefficient of Determination $\left(\mathrm{R}^{2}\right)$ for Family of Curves in Figure A.19 .............................................................. 81

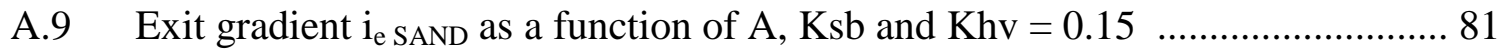

A.10 Polynomial Trendline Coefficients and Coefficient of Determination $\left(\mathrm{R}^{2}\right)$ for Family of Curves in Figure A.25 ......................................................... 85

A.11 Uplift (Pore) Pressure $\mu_{\text {SAND }}$ as a function of A, Ksb and Khv $=0.15 \ldots \ldots \ldots . . .85$

A.12 Polynomial Trendline Coefficients and Coefficient of Determination $\left(\mathrm{R}^{2}\right)$ for Family of Curves in Figure A.31 ......................................................... 88

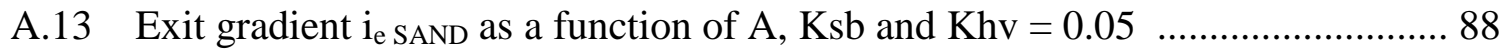

A.14 Polynomial Trendline Coefficients and Coefficient of Determination $\left(\mathrm{R}^{2}\right)$ for Family of Curves in Figure A.37 .............................................................. 91

A.15 Uplift (Pore) Pressure $\mu_{\text {SAND }}$ as a function of A, Ksb and Khv $=0.05 \quad \ldots \ldots \ldots . . . .92$

A.16 Polynomial Trendline Coefficients and Coefficient of Determination $\left(\mathrm{R}^{2}\right)$ for Family of Curves in Figure A.43 ........................................................... 94

A.17 Exit gradient $i_{\mathrm{e}}$ SAND as a function of $\mathrm{A}, \mathrm{Ksb}$ and $\mathrm{Khv}=0.005$.................... 95

A.18 Polynomial Trendline Coefficients and Coefficient of Determination $\left(\mathrm{R}^{2}\right)$ for Family of Curves in Figure A.49 .......................................................... 98

A.19 Uplift (Pore) Pressure $\mu_{\text {SAND }}$ as a function of A, Ksb and $\mathrm{Khv}=0.005 \quad \ldots \ldots \ldots . . .98$

A.20 Polynomial Trendline Coefficients and Coefficient of Determination $\left(\mathrm{R}^{2}\right)$ for Family of Curves in Figure A.55 ........................................................ 101

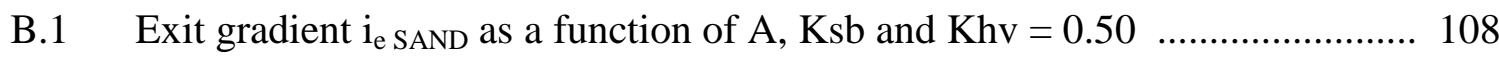

B.2 Polynomial Trendline Coefficients and Coefficient of Determination $\left(\mathrm{R}^{2}\right)$ for Family of Curves in Figure B.1 .......................................................... 111

B.3 Exit gradient $\mathrm{i}_{\mathrm{e} \text { SAND }}$ as a function of $\mathrm{A}, \mathrm{Ksb}$ and $\mathrm{Khv}=0.25 \ldots \ldots \ldots \ldots \ldots \ldots \ldots \ldots \ldots \ldots \ldots \ldots$ 
B.4 Polynomial Trendline Coefficients and Coefficient of Determination $\left(\mathrm{R}^{2}\right)$ for Family of Curves in Figure B.7 ............................................................ 114

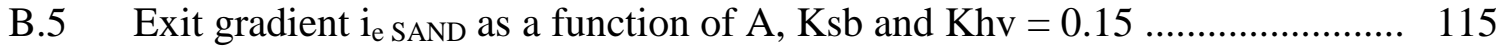

B.6 Polynomial Trendline Coefficients and Coefficient of Determination $\left(\mathrm{R}^{2}\right)$ for Family of Curves in Figure B.13 ......................................................... 118

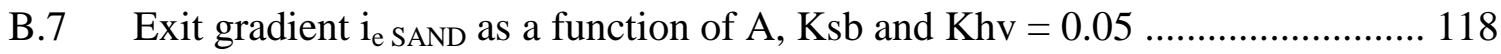

B.8 Polynomial Trendline Coefficients and Coefficient of Determination $\left(\mathrm{R}^{2}\right)$ for Family of Curves in Figure B.19....................................................... 121

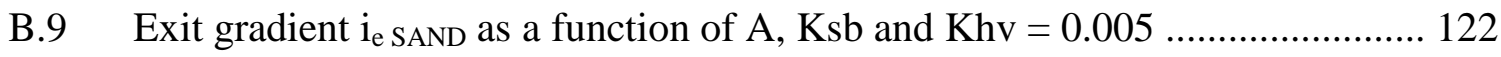

B.10 Polynomial Trendline Coefficients and Coefficient of Determination $\left(\mathrm{R}^{2}\right)$ for Family of Curves in Figure B.25

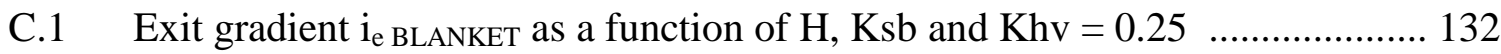

C.2 Polynomial Trendline Coefficients and Coefficient of Determination $\left(\mathrm{R}^{2}\right) \ldots \ldots .135$

D.1 Uplift (Pore) Pressure $\mu_{\text {SAND }}$ as a function of $h, K s b, K h v=0.25$ and $\mathrm{d}=175$,

D.2 Polynomial Trendline Coefficients and Coefficient of Determination $\left(\mathrm{R}^{2}\right)$ for Family of Curves in Figure D.1

D.3 Uplift (Pore) Pressure $\mu_{\text {SAND }}$ as a function of $h, K s b, K h v=0.25$ and $\mathrm{d}=150$ '

D.4 Polynomial Trendline Coefficients and Coefficient of Determination $\left(\mathrm{R}^{2}\right)$ for Family of Curves in Figure D.2

D.5 Uplift (Pore) Pressure $\mu_{\text {SAND }}$ as a function of $h, K s b, K h v=0.25$ and $\mathrm{d}=125^{\prime}$

D.6 Polynomial Trendline Coefficients and Coefficient of Determination $\left(\mathrm{R}^{2}\right)$ for Family of Curves in Figure D.3

D.7 Uplift (Pore) Pressure $\mu_{\text {SAND }}$ as a function of $h, K s b, K h v=0.25$ and $\mathrm{d}=100$ '

D.8 Polynomial Trendline Coefficients and Coefficient of Determination $\left(\mathrm{R}^{2}\right)$ for Family of Curves in Figure D.4

D.9 Uplift (Pore) Pressure $\mu_{\text {SAND }}$ as a function of $h, K s b, K h v=0.25$ and $\mathrm{d}=75$ 
D.10 Polynomial Trendline Coefficients and Coefficient of Determination $\left(\mathrm{R}^{2}\right)$ for Family of Curves in Figure D.5 …........................................................ 145

D.11 Uplift (Pore) Pressure $\mu_{\text {SAND }}$ as a function of $h, K s b, K h v=0.25$ and $\mathrm{d}=50$ '

D.12 Polynomial Trendline Coefficients and Coefficient of Determination $\left(\mathrm{R}^{2}\right)$ for Family of Curves in Figure D.6

D.13 Uplift (Pore) Pressure $\mu_{\text {SAND }}$ as a function of $h, K s b, K h v=0.25$ and $\mathrm{d}=25$,

D.14 Polynomial Trendline Coefficients and Coefficient of Determination $\left(\mathrm{R}^{2}\right)$ for Family of Curves in Figure D.7 


\section{LIST OF FIGURES}

Figure Page

2.1 Actual and simplification of the levee section for Blanket Theory analysis ...... 13

2.2 Natomas Levee Construction by hydraulic fill method ................................. 18

2.3 Dredge used in the Natomas Levees. Original construction method .................. 18

3.1 Schematic illustration of Effective Stress Method based on Blanket Theory.... 23

3.2 Schematic illustration of Total Stress Method ............................................. 25

3.3 East bank of the Sacramento River by URS ............................................... 28

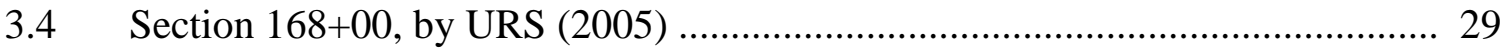

3.5 Levee section considered in the analyses (after URS, 2005) ......................... 29

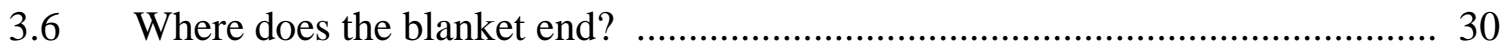

3.7 Family of curves representing relationship of Ksb, Khv, and A to $\mathrm{i}_{\mathrm{e}} \ldots \ldots \ldots \ldots \ldots . \ldots . \ldots . \ldots$

3.8 Family of curves representing relationship of Ksb, Khv, and A to $\mu \mathrm{s} \ldots \ldots \ldots \ldots . . . . .35$

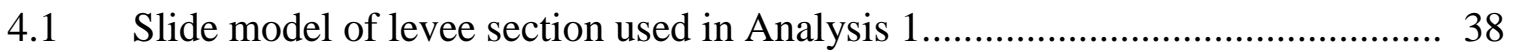

4.2 Cumulative ascending distribution function for the F.S. for Analysis 1.......... 40

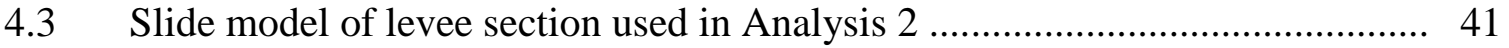

4.4 Cumulative ascending distribution function for the F.S. for Analysis 2.......... 42

4.5 Levee section used for FEM - Monte Carlo Simulation comparison with

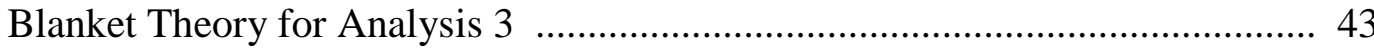

4.6 Cumulative ascending distribution function for the F.S. for Analysis 3 .......... 44

4.7 Levee section used in Analysis 4 ....................................................... 45

4.8 Cumulative ascending distribution function for the F.S. Analysis 4 ................ 46

5.1 Cumulative ascending distribution function for the deterministic F.S. ............. 56

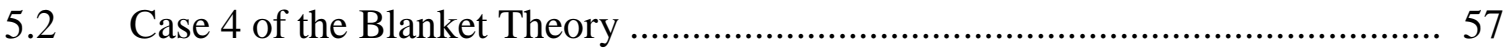


A.1 Family of curves representing relationship of A, Ksb, and Khv $=0.50$

to $i_{\mathrm{e}}$ SAND

A.2 Family of curves representing relationship of $\mathrm{A}, \mathrm{Ksb}=20$, and $\mathrm{Khv}=0.50$

to $\mathrm{i}_{\mathrm{e}} \mathrm{SAND}$

A.3 Family of curves representing relationship of $\mathrm{A}, \mathrm{Ksb}=65$, and $\mathrm{Khv}=0.50$

to $\mathrm{i}_{\mathrm{e}} \mathrm{SAND}$

A.4 Family of curves representing relationship of $\mathrm{A}, \mathrm{Ksb}=200$, and $\mathrm{Khv}=0.50$

to $i_{\mathrm{e}} \mathrm{SAND}$

A.5 Family of curves representing relationship of A, Ksb $=1300$, and Khv $=0.50$

to $i_{\mathrm{e}} \mathrm{SAND}$

A.6 Family of curves representing relationship of A, Ksb $=13000$, and $\mathrm{Khv}=0.50$

to $i_{\mathrm{e}} \mathrm{SAND}$

A.7 Family of curves representing relationship of A, Ksb, and $\mathrm{Khv}=0.50$

to $\mu_{\text {SAND }}$

A.8 Family of curves representing relationship of $\mathrm{A}, \mathrm{Ksb}=20$, and $\mathrm{Khv}=0.50$

to $\mu_{\text {SAND }}$

A.9 Family of curves representing relationship of $\mathrm{A}, \mathrm{Ksb}=65$, and $\mathrm{Khv}=0.50$

to $\mu_{\mathrm{SAND}}$

A.10 Family of curves representing relationship of $\mathrm{A}, \mathrm{Ksb}=200$, and $\mathrm{Khv}=0.50$

to $\mu_{\mathrm{SAND}}$

A.11 Family of curves representing relationship of $\mathrm{A}, \mathrm{Ksb}=1300$, and $\mathrm{Khv}=0.50$

to $\mu_{\text {SAND }}$

A.12 Family of curves representing relationship of $\mathrm{A}, \mathrm{Ksb}=13000$, and $\mathrm{Khv}=0.50$

to $\mu_{\mathrm{SAND}}$

A.13 Family of curves representing relationship of A, Ksb, and Khv $=0.25$

to $i_{\mathrm{e}} \mathrm{SAND}$

A.14 Family of curves representing relationship of, $\mathrm{A}, \mathrm{Ksb}=20$, and $\mathrm{Khv}=0.25$

to $i_{\mathrm{e}} \mathrm{SAND}$

A.15 Family of curves representing relationship of, $\mathrm{A}, \mathrm{Ksb}=65$, and $\mathrm{Khv}=0.25$

to $\mathrm{i}_{\mathrm{e}} \mathrm{SAND}$ 
A.16 Family of curves representing relationship of, $\mathrm{A}, \mathrm{Ksb}=200$, and

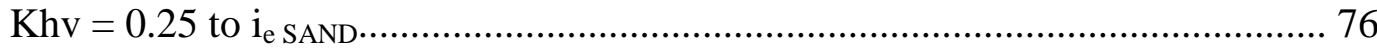

A.17 Family of curves representing relationship of A, Ksb $=1300$, and

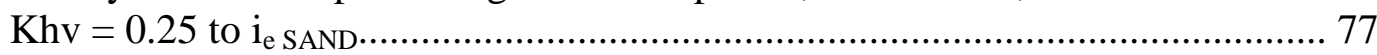

A.18 Family of curves representing relationship of A, Ksb $=13000$, and

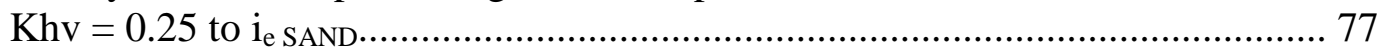

A.19 Family of curves representing relationship of A, Ksb, and Khv $=0.25$

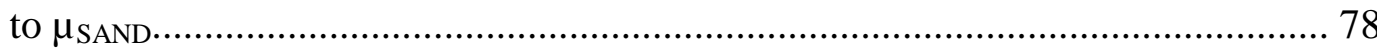

A.20 Family of curves representing relationship of $\mathrm{A}, \mathrm{Ksb}=20$, and

$\mathrm{Khv}=0.25$ to $\mu_{\mathrm{SAND}}$

A.21 Family of curves representing relationship of $\mathrm{A}, \mathrm{Ksb}=65$, and

$\mathrm{Khv}=0.25$ to $\mu_{\mathrm{SAND}}$

A.22 Family of curves representing relationship of A, Ksb $=200$, and

$\mathrm{Khv}=0.25$ to $\mu_{\mathrm{SAND}}$

A.23 Family of curves representing relationship of A, Ksb $=1300$, and

$\mathrm{Khv}=0.25$ to $\mu_{\mathrm{SAND}}$

A.24 Family of curves representing relationship of A, Ksb $=13000$, and

$\mathrm{Khv}=0.25$ to $\mu_{\mathrm{SAND}}$

A.25 Family of curves representing relationship of A, Ksb, and Khv $=0.15$

to $i_{\mathrm{e}} \mathrm{SAND}$

A.26 Family of curves representing relationship of $\mathrm{A}, \mathrm{Ksb}=20$, and

$\mathrm{Khv}=0.15$ to $\mathrm{i}_{\mathrm{e}} \mathrm{SAND}$

A.27 Family of curves representing relationship of $\mathrm{A}, \mathrm{Ksb}=65$, and

$\mathrm{Khv}=0.15$ to $\mathrm{i}_{\mathrm{e}} \mathrm{SAND}$

A.28 Family of curves representing relationship of $\mathrm{A}, \mathrm{Ksb}=200$, and

$\mathrm{Khv}=0.15$ to $\mathrm{i}_{\mathrm{e}} \mathrm{SAND}$

A.29 Family of curves representing relationship of $\mathrm{A}, \mathrm{Ksb}=1300$, and

$\mathrm{Khv}=0.15$ to $\mathrm{i}_{\mathrm{e}} \mathrm{SAND}$

A.30 Family of curves representing relationship of A, Ksb = 13000 and

$\mathrm{Khv}=0.15$ to $\mathrm{i}_{\mathrm{e}} \mathrm{SAND}$ 84

A.31 Family of curves representing relationship of A, Ksb, and Khv $=0.15$

to $\mu_{\mathrm{SAND}}$. 
A.32 Family of curves representing relationship of $\mathrm{A}, \mathrm{Ksb}=20$, and

$\mathrm{Khv}=0.15$ to $\mu_{\mathrm{SAND}}$

A.33 Family of curves representing relationship of $\mathrm{A}, \mathrm{Ksb}=65$, and

$\mathrm{Khv}=0.15$ to $\mu_{\mathrm{SAND}}$

A.34 Family of curves representing relationship of A, Ksb $=200$, and

$\mathrm{Khv}=0.15$ to $\mu_{\mathrm{SAND}}$

A.35 Family of curves representing relationship of $\mathrm{A}, \mathrm{Ksb}=1300$, and

$\mathrm{Khv}=0.15$ to $\mu_{\mathrm{SAND}}$.

A.36 Family of curves representing relationship of $\mathrm{A}, \mathrm{Ksb}=13000$, and

$\mathrm{Khv}=0.15$ to $\mu_{\mathrm{SAND}}$

A.37 Family of curves representing relationship of A, Ksb, and Khv $=0.05$

to $i_{\mathrm{e}}$ SAND.

A.38 Family of curves representing relationship of $\mathrm{A}, \mathrm{Ksb}=20$, and

$\mathrm{Khv}=0.05$ to $\mathrm{i}_{\mathrm{e}} \mathrm{SAND}$

A.39 Family of curves representing relationship of $\mathrm{A}, \mathrm{Ksb}=65$, and

$\mathrm{Khv}=0.05$ to $\mathrm{i}_{\mathrm{e}} \mathrm{SAND}$

A.40 Family of curves representing relationship of A, Ksb $=200$, and

$\mathrm{Khv}=0.05$ to $\mathrm{i}_{\mathrm{e}} \mathrm{SAND}$

A.41 Family of curves representing relationship of A, Ksb $=1300$, and

$\mathrm{Khv}=0.05$ to $\mathrm{i}_{\mathrm{e}} \mathrm{SAND}$

A.42 Family of curves representing relationship of $\mathrm{A}, \mathrm{Ksb}=13000$, and

$\mathrm{Khv}=0.05$ to $\mathrm{i}_{\mathrm{e}} \mathrm{SAND}$

A.43 Family of curves representing relationship of A, Ksb, and Khv $=0.05$

to $\mu_{\text {SAND. }}$

A.44 Family of curves representing relationship of $\mathrm{A}, \mathrm{Ksb}=20$, and

$\mathrm{Khv}=0.05$ to $\mu_{\mathrm{SAND}}$

A.45 Family of curves representing relationship of $\mathrm{A}, \mathrm{Ksb}=65$, and

$\mathrm{Khv}=0.05$ to $\mu_{\text {SAND }}$

A.46 Family of curves representing relationship of A, Ksb $=200$, and

$\mathrm{Khv}=0.05$ to $\mu_{\mathrm{SAND}}$

A.47 Family of curves representing relationship of A, Ksb $=1300$, and

$\mathrm{Khv}=0.05$ to $\mu_{\mathrm{SAND}}$ 
A.48 Family of curves representing relationship of A, Ksb $=13000$, and

$\mathrm{Khv}=0.05$ to $\mu_{\mathrm{SAND}}$.

A.49 Family of curves representing relationship of $\mathrm{A}, \mathrm{Ksb}$, and $\mathrm{Khv}=0.005$

to $i_{\mathrm{e}} \mathrm{SAND}$

A.50 Family of curves representing relationship of A, Ksb $=20$, and

$\mathrm{Khv}=0.005$ to $\mathrm{i}_{\mathrm{e}} \mathrm{SAND}$

A.51 Family of curves representing relationship of $\mathrm{A}, \mathrm{Ksb}=65$, and

$\mathrm{Khv}=0.005$ to $\mathrm{i}_{\mathrm{e}} \mathrm{SAND}$ 96

A.52 Family of curves representing relationship of $\mathrm{A}, \mathrm{Ksb}=200$, and

$\mathrm{Khv}=0.005$ to $\mathrm{i}_{\mathrm{e}} \mathrm{SAND}$

A.53 Family of curves representing relationship of A, Ksb $=1300$, and

$\mathrm{Khv}=0.005$ to $\mathrm{i}_{\mathrm{e}} \mathrm{SAND}$

A.54 Family of curves representing relationship of $\mathrm{A}, \mathrm{Ksb}=13000$, and

$\mathrm{Khv}=0.005$ to $\mathrm{i}_{\mathrm{e}} \mathrm{SAND}$

A.55 Family of curves representing relationship of A, Ksb and Khv $=0.005$

to $\mu_{\mathrm{SAND}}$

A.56 Family of curves representing relationship of $\mathrm{A}, \mathrm{Ksb}=20$, and

$\mathrm{Khv}=0.005$ to $\mu_{\mathrm{SAND}}$

A.57 Family of curves representing relationship of $\mathrm{A}, \mathrm{Ksb}=65$, and

$\mathrm{Khv}=0.005$ to $\mu_{\mathrm{SAND}}$

A.58 Family of curves representing relationship of $\mathrm{A}, \mathrm{Ksb}=200$, and

$\mathrm{Khv}=0.005$ to $\mu_{\mathrm{SAND}}$

A.59 Family of curves representing relationship of A, Ksb $=1300$, and

$\mathrm{Khv}=0.005$ to $\mu_{\mathrm{SAND}}$

A.60 Family of curves representing relationship of A, Ksb $=13000$, and

$\mathrm{Khv}=0.005$ to $\mu_{\mathrm{SAND}}$

A.61 Excel spreadsheet for Analysis 1 102

A.62 Flow Chart for Excel Spreadsheet for Analysis 1 103

A.63 Probability Density Function for geometric variable A 104

A.64 Probability Density Function for soil variable $\mathrm{Kb}$ 104 
A.65 Probability Density Function for soil variable Ks …................................ 105

A.66 Probability Density Function for soil variable Khv …............................... 105

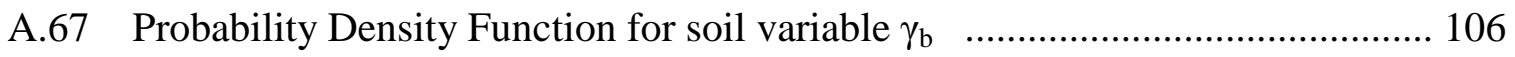

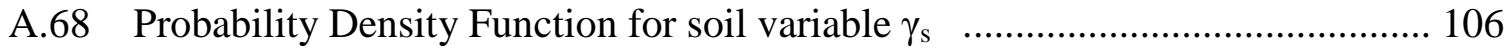

B.1 Family of curves representing relationship of A, Ksb, and Khv $=0.50$

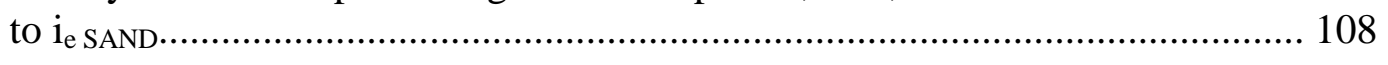

B.2 Family of curves representing relationship of A, Ksb $=20$, and

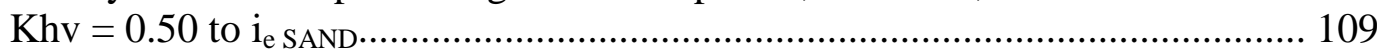

B.3 Family of curves representing relationship of $\mathrm{A}, \mathrm{Ksb}=65$, and

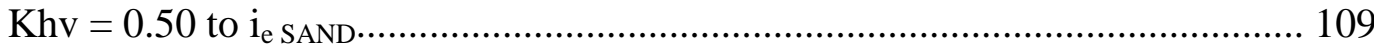

B.4 Family of curves representing relationship of A, Ksb $=200$, and

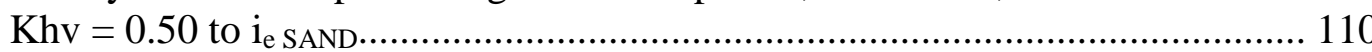

B.5 Family of curves representing relationship of $\mathrm{A}, \mathrm{Ksb}=1300$, and

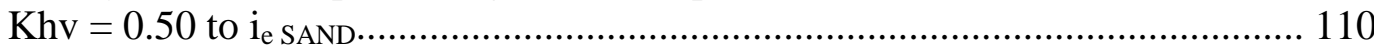

B.6 Family of curves representing relationship of A, Ksb $=13000$, and

$\mathrm{Khv}=0.50$ to $\mathrm{i}_{\mathrm{e}} \mathrm{SAND}$

B.7 Family of curves representing relationship of A, Ksb, and Khv $=0.25$

to $i_{\mathrm{e}} \mathrm{SAND}$

B.8 Family of curves representing relationship of $\mathrm{A}, \mathrm{Ksb}=20$, and

$\mathrm{Khv}=0.25$ to $\mathrm{i}_{\mathrm{e}} \mathrm{SAND}$

B.9 Family of curves representing relationship of $\mathrm{A}, \mathrm{Ksb}=65$, and

$\mathrm{Khv}=0.25$ to $\mathrm{i}_{\mathrm{e}} \mathrm{SAND}$

B.10 Family of curves representing relationship of A, Ksb $=200$, and

$\mathrm{Khv}=0.25$ to $\mathrm{i}_{\mathrm{e}} \mathrm{SAND}$

B.11 Family of curves representing relationship of A, Ksb $=1300$, and

$\mathrm{Khv}=0.25$ to $\mathrm{i}_{\mathrm{e}} \mathrm{SAND}$

B.12 Family of curves representing relationship of $\mathrm{A}, \mathrm{Ksb}=13000$, and

$\mathrm{Khv}=0.25$ to $\mathrm{i}_{\mathrm{e}} \mathrm{SAND}$

B.13 Family of curves representing relationship of A, Ksb and Khv $=0.15$

to $i_{\mathrm{e}} \mathrm{SAND}$ 
B.14 Family of curves representing relationship of $\mathrm{A}, \mathrm{Ksb}=20$, and

$\mathrm{Khv}=0.15$ to $\mathrm{i}_{\mathrm{e}} \mathrm{SAND}$

B.15 Family of curves representing relationship of $\mathrm{A}, \mathrm{Ksb}=65$, and

$\mathrm{Khv}=0.15$ to $\mathrm{i}_{\mathrm{e}} \mathrm{SAND}$

B.16 Family of curves representing relationship of $\mathrm{A}, \mathrm{Ksb}=200$, and

$\mathrm{Khv}=0.15$ to $\mathrm{i}_{\mathrm{e}} \mathrm{SAND}$

B.17 Family of curves representing relationship of $\mathrm{A}, \mathrm{Ksb}=1300$, and

$\mathrm{Khv}=0.15$ to $\mathrm{i}_{\mathrm{e}} \mathrm{SAND}$

B.18 Family of curves representing relationship of A, Ksb $=13000$, and

$\mathrm{Khv}=0.15$ to $\mathrm{i}_{\mathrm{e}} \mathrm{SAND}$

B.19 Family of curves representing relationship of A, Ksb, and

$\mathrm{Khv}=0.05$ to $\mathrm{i}_{\mathrm{e}} \mathrm{SAND}$

B.20 Family of curves representing relationship of $\mathrm{A}, \mathrm{Ksb}=20$, and

$\mathrm{Khv}=0.05$ to $\mathrm{i}_{\mathrm{e}}$ SAND

B.21 Family of curves representing relationship of $\mathrm{A}, \mathrm{Ksb}=65$, and

$\mathrm{Khv}=0.05$ to $\mathrm{i}_{\mathrm{e}} \mathrm{SAND}$

B.22 Family of curves representing relationship of $\mathrm{A}, \mathrm{Ksb}=200$, and

$\mathrm{Khv}=0.05$ to $\mathrm{i}_{\mathrm{e}} \mathrm{SAND}$

B.23 Family of curves representing relationship of $\mathrm{A}, \mathrm{Ksb}=1300$, and

$\mathrm{Khv}=0.05$ to $\mathrm{i}_{\mathrm{e}} \mathrm{SAND}$

B.24 Family of curves representing relationship of A, Ksb = 13000, and

$\mathrm{Khv}=0.05$ to $\mathrm{i}_{\mathrm{e}} \mathrm{SAND}$

B.25 Family of curves representing relationship of A, Ksb, and, Khv $=0.005$

to $i_{\mathrm{e}}$ SAND

B.26 Family of curves representing relationship of $\mathrm{A}, \mathrm{Ksb}=20$, and

$\mathrm{Khv}=0.005$ to $\mathrm{i}_{\mathrm{e}} \mathrm{SAND}$

B.27 Family of curves representing relationship of $\mathrm{A}, \mathrm{Ksb}=65$, and $\mathrm{Khv}=0.005$ to $\mathrm{i}_{\mathrm{e}} \mathrm{SAND}$

B.28 Family of curves representing relationship of $\mathrm{A}, \mathrm{Ksb}=200$, and $\mathrm{Khv}=0.005$ to $\mathrm{i}_{\mathrm{e}} \mathrm{SAND}$ 
B.29 Family of curves representing relationship of A, Ksb $=1300$, and $\mathrm{Khv}=0.005$ to $\mathrm{i}_{\mathrm{e}} \mathrm{SAND}$

B.30 Family of curves representing relationship of A, Ksb $=13000$, and

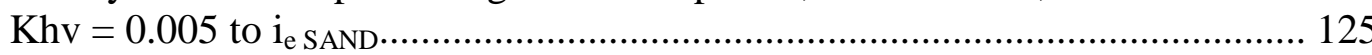

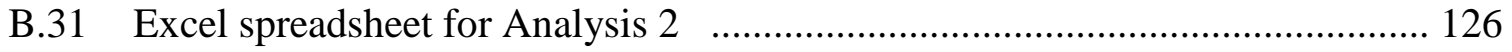

B.32 Flow Chart for Excel Spreadsheet for Analysis 2 .................................... 127

B.33 Probability Density Function for geometric variable A …........................... 128

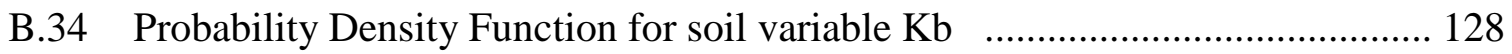

B.35 Probability Density Function for soil variable Ks f.................................... 129

B.36 Probability Density Function for soil variable Khv …................................ 129

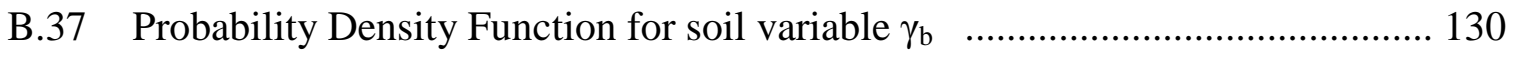

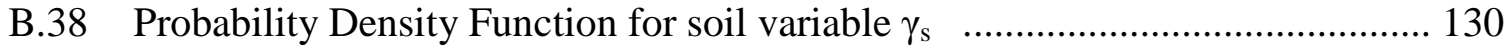

C.1 Family of curves representing relationship of $\mathrm{H}, \mathrm{Ksb}$, and $\mathrm{Khv}=0.25$

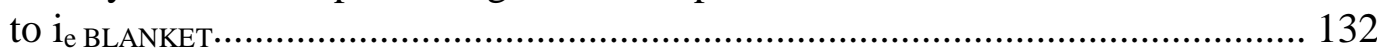

C.2 Exit Gradient ( $\mathrm{i}_{\mathrm{e} \text { BLANKET }}$ ) vs. Blanket Thickness $(\mathrm{H})$ for $\mathrm{Ksb}=20$, and $\mathrm{Khv}=0.25$

C.3 Exit Gradient ( $\left.\mathrm{i}_{\mathrm{e} \text { BLANKET }}\right)$ vs. Blanket Thickness $(\mathrm{H})$ for $\mathrm{Ksb}=63$, and $\mathrm{Khv}=0.25$

C.4 Exit Gradient ( $\mathrm{i}_{\mathrm{e} \text { BLANKET }}$ ) vs. Blanket Thickness $(\mathrm{H})$ for Ksb $=201$, and $\mathrm{Khv}=0.25$

C.5 Exit Gradient ( $\mathrm{i}_{\mathrm{e} \text { BLANKET }}$ ) vs. Blanket Thickness $(\mathrm{H})$ for $\mathrm{Ksb}=634$, and $\mathrm{Khv}=0.25$

C.6 Exit Gradient ( $\left.\mathrm{i}_{\mathrm{e} \text { BLANKeT }}\right)$ vs. Blanket Thickness $(\mathrm{H})$ for Ksb $=2006$, and $\mathrm{Khv}=0.25$

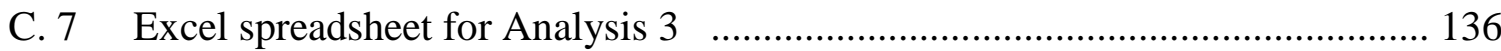

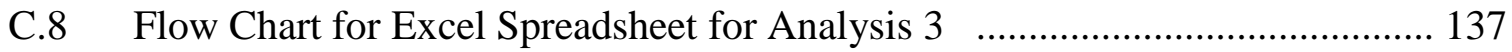

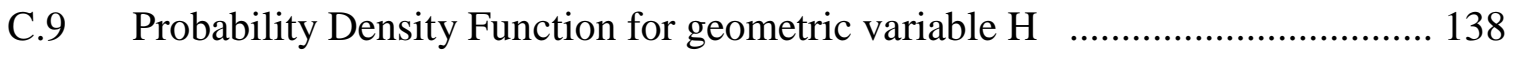

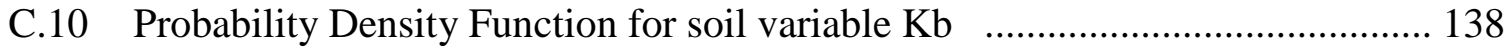


C.11 Probability Density Function for soil variable Ks .................................... 139

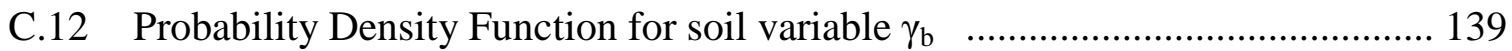

D.1 Family of curves representing relationship of $\mathrm{h}, \mathrm{Ksb}, \mathrm{Khv}=0.25$, and $\mathrm{d}=175^{\prime}$ to $\mu_{\mathrm{SAND}}$

D.2 Family of curves representing relationship of $\mathrm{h}, \mathrm{Ksb}, \mathrm{Khv}=0.25$, and

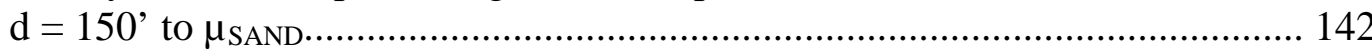

D.3 Family of curves representing relationship of h, Ksb, Khv $=0.25$, and $\mathrm{d}=125^{\prime}$ to $\mu_{\mathrm{SAND}}$

D.4 Family of curves representing relationship of $\mathrm{h}, \mathrm{Ksb}, \mathrm{Khv}=0.25$, and $\mathrm{d}=100$ ' to $\mu_{\mathrm{SAND}}$

D.5 Family of curves representing relationship of $\mathrm{h}, \mathrm{Ksb}, \mathrm{Khv}=0.25$, and $\mathrm{d}=75^{\prime}$ to $\mu_{\text {SAND. }}$.

D.6 Family of curves representing relationship of $\mathrm{h}, \mathrm{Ksb}, \mathrm{Khv}=0.25$, and $\mathrm{d}=50$ ' to $\mu_{\mathrm{SAND}}$. 146

D.7 Family of curves representing relationship of h, Ksb, Khv $=0.25$, and $\mathrm{d}=25^{\prime}$ to $\mu_{\mathrm{SAND}}$.

D.8 Excel spreadsheet for Analysis 4 148

D.9 Flow Chart for Excel Spreadsheet for Analysis 4

D.10 Probability Density Function for geometric variable d 150

D.11 Probability Density Function for geometric variable h

D.12 Probability Density Function for soil variable $\gamma_{\mathrm{b}}$

D.13 Probability Density Function for soil variable $\mathrm{Kb}$ 151

D.14 Probability Density Function for soil variable Ks 


\section{CHAPTER 1}

\section{INTRODUCTION}

\section{$\underline{1.1 \text { Summary }}$}

Levees are embankments designed to prevent the flooding of a river into an adjacent landward floodplain. They are exposed to different types of failure modes depending on the behavior of the river and the areas that surround them. One of the most important failure modes is underseepage where an open path called a "pipe" forms under the levee leading it to instability. This failure mode has been a concern around the Sacramento River in California for many years and has recently received more attention after New Orleans' flood event in 2005. Because levees are long structures, the analyses get to be complex and variable but engineers have been simulating them as simple as possible, sometimes making them unrealistic.

When underseepage flows beneath the levee, two conditions can occur:

1. The water may seep out gently doing no harm to the levee, or

2. Where critical combinations of water levels, soil types and foundation stratigraphy are present, the water can erode the soil, beginning at the seepage exit point and progressing towards the water side of the levee (piping).

More and more, geotechnical engineers are trying to incorporate reliability analyses into geotechnical engineering. Since geotechnical engineering is one of the newest areas/branches of engineering, and there is still plenty of research to be done, it is still somewhat hard and sometimes complicated to combine reliability calculations with geotechnical engineering analyses. 
Current methods for analyzing the likelihood of levee failure due to underseepage are based on calculating the Factor of Safety as the ratio of critical hydraulic gradient to hydraulic exit gradient. Factors of Safety (F.S.) have been analyzed both deterministically and probabilistically. Probabilistic methods have been applied to the exit gradient approach using the U.S. Army Corps of Engineers "Blanket Theory" equation and a First-Order Second-Moment (FOSM) Taylor series method.

Since the current reliability-based underseepage method has its shortfalls and limitations, a proposed method is presented. The proposed method incorporates the effects of more complex subsurface geometry using the Finite Element Method (FEM) Seepage Program Slide along with the program @ Risk to develop the reliability analysis by way of a Monte Carlo simulation.

\section{$\underline{1.2 \text { Purpose }}$}

The intent of this research is to develop an improved reliability-based method for assessing underseepage potential in levees that will take into account uncertainties of more complex subsurface geometry and soil variables uncertainty as well as better ways to model the mechanism responsible for underseepage failure. The results of the new/proposed method will be compared with the Factor of Safety and existing reliability methods and the benefits of the proposed method will be demonstrated.

\section{$\underline{1.3 \text { Research to be Undertaken }}$}

A case study involving two levee reaches along the east bank of the Sacramento River in California will be performed to demonstrate the new method. Actual subsurface data will be used in the case studies. 


\subsection{Significance}

This research is the first step of many planned research projects that are designed to improve the way seepage related erosion is analyzed. In this first phase a new method to analyze reliability-based underseepage in levees is developed. Work done during these developments will provide insight into some of the deficiencies of the current reliabilitybased underseepage method. Our proposed method assesses some of these problems, while further research will be needed for further development of the method.

\section{$\underline{1.5 \text { Organization }}$}

This thesis encompasses six chapters. Chapter 1 is the Introduction. Chapter 2 discusses the literature reviewed in conjunction with this study. It discusses reliability in geotechnical engineering, the current methods used for reliability-based underseepage analysis in levees, and gives a brief history of the area chosen for the case study demonstrating the method developed for this research. Chapter 3 is a discussion of the proposed methodology. First it presents a problem statement, then it talks about the failure mechanisms associated with underseepage along with the sources of data, and finally it explains with detail the steps of the proposed method. Chapter 4 presents the case study analyses done to demonstrate the proposed method mentioning the significance of each analysis. Chapter 5 compares the proposed method with current methods. It also presents a regression analysis that was done in order to assess the significance of the variables in the proposed method. Chapter 6 presents the conclusions and recommendations. 


\section{CHAPTER 2}

\section{LITERATURE REVIEWED}

This chapter summarizes current information and methods used for reliability based underseepage analysis in levees. Limited information can be found about this topic since the same deterministic method and probabilistic approach have been used to analyze underseepage in levees and not much research has been done. The topics that are discussed in this chapter are:

1. Reliability in geotechnical engineering

2. Sources of Uncertainty: Epistemic versus Aleatory

3. Current Methods for Levee Reliability Underseepage Analysis

4. Background of the Natomas Basin Area

\subsection{Reliability in Geotechnical Engineering}

Reliability analysis was introduced into civil engineering by Milton Harr. He published a book in 1925 and stated that civil engineering (back then) was facing the necessity of prediction in its analysis and designs because the engineering community was realizing that there was "significant variability" in the data that was being used (Harr, 1987).

Engineers such as G. Baecher, J. Christian, K. Phoon, G. Fenton, D. Griffiths, D. Wolff, M. Harr, M. Duncan, among others, have been pioneers of integrating probabilistic methods into geotechnical engineering. Despite this, geotechnical engineers have not taken advantage of reliability analysis because the concepts come from fields of probability and statistics that geotechnical engineers often do not understand well, 
creating confusion and difficulties (Baecher and Christian, 2003). Another reason is that engineers are concerned with the level of confidence associated with probabilistic methods.

Baecher and Christian (2003) were the first to publish a textbook directed toward students and practitioners aimed specifically at Reliability in Geotechnical Engineering. It can be said that geotechnical reliability has emerged somewhat from the field of Reliability in Structural Engineering. The knowledge of the rising structural reliability in the early 1970's began to leak into geotechnical engineering research and Baecher and Christian's book is based on this early work. Recently, others like Fenton and Griffiths (2008) and Phoon (2008) have published books with more recent data and new methods.

One of the biggest advantages of reliability calculations is that the uncertainties in input variables and the associated effects on the probability of unsatisfactory performance can be quantified. This is very useful for geotechnical engineering analysis since there is so much uncertainty with most of the material properties and subsurface geometry that are used to approach geotechnical designs. Although the geotechnical engineering community is aware of this disadvantage, most designs are still being analyzed based on the most likely value (MLV) of the variables (deterministic approach).

Phoon (2008) mentions that probability methods can be used for design criteria and this is probably much more reliable than just using the current available methods which are based on a deterministic Factor of Safety (F.S). As mentioned, even though there is a high potential for uncertainty in geotechnical engineering variables, it is interesting that the designs are assessed deterministically mainly by looking at a F.S. 
instead of evaluating the probability of failure, the cost of failure and the consequences of failure (Fenton and Griffiths, 2008).

It is true that many considerations and much conservatism goes into calculating a F.S. but not everyone knows and understands this information. For instance, if we say on the news that a levee design has a F.S. equal to 3, it is very probable that the relevance of this value is not understood by most people. But, if that information is changed to a probabilistic language, for example, saying that there is a 35 percent chance that the levee will fail in a 50 year period, perhaps more people will better understand the information.

According to Phoon (2008), one of the frequent criticisms of reliability analysis applied to geotechnical engineering is that the judgment of experts will be put aside, and it is his belief that this is not so. Experience and judgment are always going to be needed in any area of engineering, but intuition or estimation are not things that all humans have and this is the part that reliability analysis takes care of. Examples of this situation are given by Baecher and Christian (2003) and by Duncan (2000). Baecher and Christian (2003) state that even technically qualified people do poorly in a gambling table because this way of thinking is not natural in our mind and world. Duncan's (2000) example states that studies have shown that there is a tendency of underestimating the values of geotechnical engineering variables proving once again that even experienced engineers do not have good methods of estimation.

With reliability-based calculations it is possible to evaluate the combined effects of uncertainties associated with the various input variables and assess the probability of unsatisfactory performance based on these uncertainties. Furthermore, the output information can be presented in a way that provides a better understanding of the design, 
and helps assess where the largest uncertainties come from. However, it is important to mention that each reliability analysis is unique because it is modeled as viewed by the analyst. Undoubtedly, each analysis will have the mark of its owner reflecting the way uncertainty was represented along with the assumptions and limitations of the program (Modarres, 1993).

\subsection{Sources of Uncertainty: Epistemic Versus Aleatory}

There are two schools of thoughts when it comes to probability, one called the frequentist approach and the other one called the degree-of-believe approach. So now, in a deeper context, we can say that probability is associated with an event that suggests either "likelihood" or "degree of certainty." Each approach depends on and is related to how "uncertainty" is defined. Since each probability is unique in its own way, this is the main reason why a reliability analysis is also unique; with a possibility of differing from individual to individual even though the same problem is analyzed (Baecher and Christian, 2003; Hartford and Baecher, 2007; Modarres, 1993).

The concept underlying the frequentist approach is that the probability of an uncertain event will be obtained by its "relative frequency" of previous observations. This approach is a property of nature regardless of anyone's knowledge of it. Hartford and Baecher (2007) point out that two analysts with enough and same data of a problem should end up having the same results. Since frequentist probability is established on the basis of limited frequency, Devore (2000) considers that its applicability is limited to repeatable situations under similar conditions. 
The word random is the word that has been used over the years to described this approach but nowadays the word "aleatory" is more commonly used and accepted. Some authors like Bartoszyński and Niewiadomska-Bugaj (2008) and Devore (2000) talk about this approach as the objective interpretation of probability. Others, like Baecher and Christian (2003) and Hartford and Baecher (2007) refer to it (being more specific for geotechnical engineering) as natural variability or aleatory uncertainty.

On the other hand, the perception of the degree-of-believe approach is that probability is "a measure of state of knowledge" in other words, it is the certainty of an approach or the degree of believe in the occurrence of an event. Based on this and unlike the frequentist approach, this probability is the point of view or judgment of the individual. Hartford and Baecher (2007) consider that with this approach, two analysts with enough and same data of a problem can end up having different results and both be correct.

Some authors like DeGroot (1975) and Bartoszyński and Niewiadomska-Bugaj (2008) refer to this approach as the subjective approach and others like Baecher and Christian (2003) and Hartford and Baecher (2007) refer to it as "knowledge uncertainty" or "epistemic uncertainty." Uncertainty is the word that has been used to describe this approach.

In engineering, it can be said that probability is a practical view and it depends on its application. The way the analyst decides whether the problem is assumed to be aleatory or epistemic will affect the results and the meaning of these results. As Hartford and Baecher (2007) and Baecher and Christian (2003) mention, if the uncertainty is 
considered to be aleatory then the probability refers to a "temporal or spatial fraction", and if it is taken as epistemic, the probability refers to "a chance of complete failure."

At the end, in engineering practice, uncertainty is believed to be a mix between the two approaches but it is still very important to separate one from each other. Due to all the terminology that has arisen over the years, Hartford and Baecher (2007) and Baecher and Christian (2003) have developed a table of terms to describe the meaning of uncertainty based on each approach. It is important to mention that each term that they mention has also a particular meaning depending on its usage.

Geotechnical engineering analysis can be interpreted as any of these approaches but it appears that geotechnical engineers feel more comfortable with the degree-of believe approach (epistemic) than with the frequentist approach (aleatory) (Baecher and Christian, 2003). It is the author's hypothesis that this situation is due to the costs that associated with getting enough valuable data for the geotechnical analysis. As Fenton and Griffiths (2008) say, in an ideal world we would be able to do as many field-data explorations and laboratory tests as we could and then perform our designs with high self-assurance but this is unlikely because of economic restrictions.

\section{$\underline{2.3 \text { Current Methods for Levee Reliability Underseepage Analysis }}$}

Current methods for analyzing the likelihood of levee failure due to underseepage consist of calculating factors of safety based on the ratio of critical gradients of the soil and hydraulic exit gradients calculated using the finite-element method or other seepage analyses. Probabilistic methods have been applied to the exit gradient approach using the U.S. Army Corps of Engineers "Blanket Theory" equation (USACE, 2000, 2005) along 
with the First Order-Second Moment Taylor Series Method (FOSM) (Wolff et al., 1996; Crum 1996; Wolff, 2008).

Wolff (2008) talks about the reliability of levee systems and gives a historic review of the research that has been done over the years until the present day. In 1994, Wolff prepared a report for the U.S. Army Corps of Engineers with the purpose of evaluating the reliability of existing levees. Later, in 1999, the report was added as Appendix B in the USACE`s Engineer Technical Letter ETL 1110-2-556 (Wolff, 2008). The methods and equations for the seepage analysis and probabilistic seepage analysis used on this report are based on a First-Order Second-Moment (FOSM) Taylor Series analysis using the "Blanket Theory" equation as the performance function. It is the author's understanding that reliability based underseepage analysis for levees has been performed using this method since it was developed, thus it is currently the most commonly used method for probabilistic levee underseepage assessment.

These methods do not realistically model the underseepage failure mechanism in levees and the uncertainty associated with their performance. These methods force the uncertainty variables to be either a normal or lognormal distribution and limit the levee geometry to a very simplified case. Hence, a new method is proposed herein modeling a failure mechanism that more closely follows the erosion process using a Monte Carlo simulation for the reliability analysis.

\subsubsection{Deterministic factor of safety}

Despite its limitations, the deterministically calculated Factor of Safety is currently the most common method used by engineers to assess underseepage. The F.S. with respect to the initiation of piping is generally defined by the equation: 


$$
\text { F.S. }=\frac{i_{\mathrm{C}}}{\mathrm{i}_{\mathrm{e}}}
$$

where $i_{c}=$ the critical gradient, and $i_{\mathrm{e}}=$ the exit gradient .

The critical gradient $\left(i_{c}\right)$ is the gradient needed to initiate erosion in the soil and usually varies from about 0.80 to 1.0 (Mansur, Postol, and Salley, 2000), depending on the unit weight of the soil. The exit gradient $\left(i_{\mathrm{e}}\right)$ is the gradient at the point of erosion calculated with Finite Element Analysis and it is a function of the subsurface geometry and the permeability of the subsurface soils.

The calculated F.S. against underseepage failure is used to provide a theoretical design margin of stability and its acceptable value is related to the lack of confidence in the design process and input parameters. In theory, if the F.S. is greater than 1.0 the system is stable and will not fail, and if the F.S. is less than 1.0 the system is unstable and is expected to fail. However, the acceptable F.S. is a specified margin above 1.0 to deal with uncertainty and to provide a margin of safety. Generally, for levee underseepage a F.S. greater than 3.0 is considered acceptable.

The limitation of the F.S. method is that it does not take into account the uncertainty and variability of the input variables. As Duncan (2000) mentions, engineers usually use the same factor of safety, applying it to conditions that involve a wide range of uncertainty. This approach is not reasonable as the same Factor of Safety can represent different levels of reliability.

\subsubsection{Blanket theory}

The "Blanket Theory" is a simplified method for analyzing underseepage in levees and it provides closed-form equations for calculating the factor of safety. The 
equations assume two continuous soil layers in the levee foundation, each having constant thickness and horizontal boundaries. The top layer is considered a semi-pervious soil called "the blanket" (either silt or clay), and the layer below is considered pervious (sand and gravel) (USACE, 2005). The permeability is assumed to be horizontal for the pervious layer from the waterside model boundary to the landside model boundary, vertical for the blanket layer from the waterside levee toe to the waterside model boundary, and vertical for the landside blanket layer from the landside levee toe to the landside boundary condition.

In addition, the levee itself, like the blanket underneath it, is assumed to be impervious. The thickness and permeability of the riverside and landside top stratum may be different (URS, 2007). An example of a levee section simplified for use in the Blanket Theory is shown on Figure 2.1. Figure 2.1a presents the actual levee section as defined by subsurface exploration. Figure $2.1 \mathrm{~b}$ presents the same levee section simplified as required by the Blanket Theory.

Wolff (2008) gives a great explanation of the Blanket Theory along with an example of its use. This method was developed by the USACE to model simplified foundation conditions of levees so it is reasonable to say that the method is limited in the flexibility of the subsurface geometry of the levees. Given that the Blanket Theory simplifies the levee geometry extremely, it does not model a realistic state of nature of many levees.

Another limitation is that it calculates the F.S. using a hydraulic gradient in the blanket, assuming the silt and clay is the eroding material (Wolff et al., 1996; Crum, 1996). In most cases the erosion occurs at the top of the sand layer through a crack or 
defect in the blanket. The failure mode to be considered for this proposed method will be explained in the methodology.

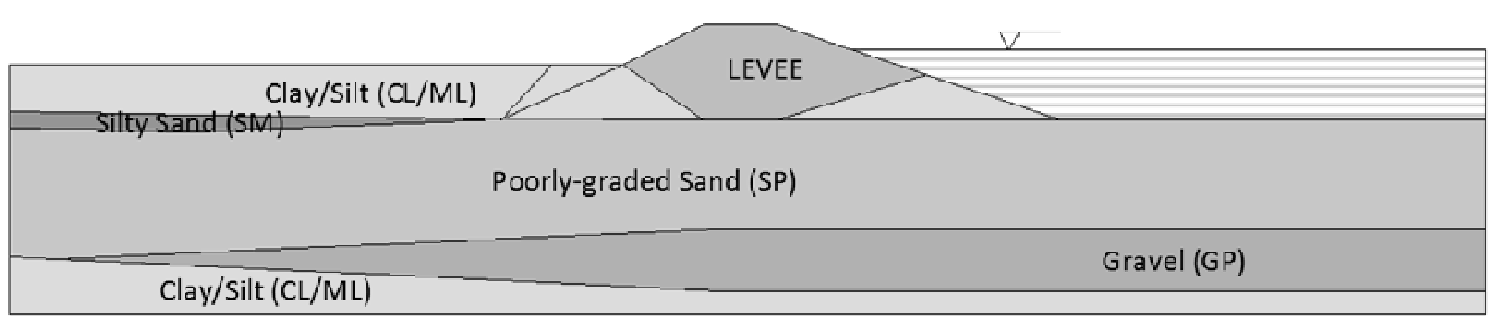

(a) Actual levee section

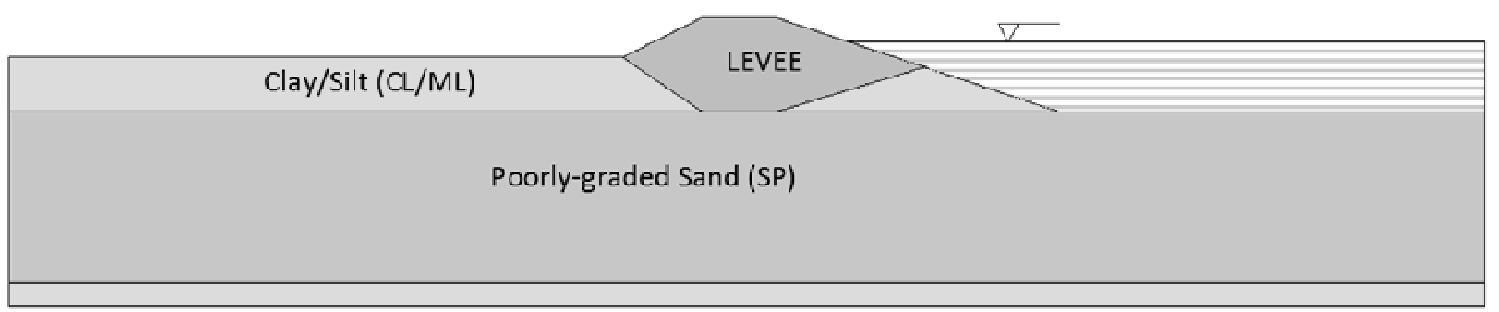

(b) Simplified levee section

Figure 2.1 Actual and simplification of the levee section for Blanket Theory analysis.

\subsubsection{First Order-Second Moment}

(FOSM) Taylor Series Method

Most authors agree that the FOSM Taylor Series method is the simplest reliability method available and it requires few calculations. The method is well explained by Harr (1987), Duncan (2000), Baecher and Christian (2003), and Sleep and Duncan (2008).

The method includes the uncertainty of the variables into an assessment of probability of failure. Using only the first terms of Taylor's series expansion ("first order"), the first two moments ("second moment") of the performance function are estimated (the expected value and variance). When using the Taylor Series method, $2 \mathrm{~N}+1$ calculations of the Factor of Safety are required, where $\mathrm{N}$ is the number of variables. 
An advantage of the Taylor Series method is that it allows the engineer to see how significant each variable is to the overall probability of failure. It is therefore easy to see which variables have the largest effect on the factor of safety. According to Baecher and Christian (2003), this is very useful and many other methods do not make this information available.

Steps and assumptions for this method are listed below:

1. Identify the variables that have uncertainties large enough to significantly affect the probability of failure.

2. Assume a normal or lognormal probability density function distribution for each variable.

3. Estimate the standard deviation $(\sigma)$ and most likely value (MLV) for each variable.

4. Calculate F.S. using the MLVs of all variables: F FLV

5. Compute two F.S. for each variable with the values of the remaining variables equal to their MLVs: one F.S. with the variable increased by one standard deviation $(\mathrm{F}+)$ and one F.S. with the variable decreased by one standard deviation from its most likely value (F-). Using the values of $\mathrm{F}+$ and $\mathrm{F}$-, compute values of $\Delta \mathrm{F}$ (the difference between $\mathrm{F}+$ and $\mathrm{F}-$ ) for each variable.

6. Compute the standard deviation $(\sigma)$ and coefficient of variation $(\mathrm{COV})$ of the factor of safety.

$$
\sigma_{\mathrm{F}}=\sqrt{\left(\frac{\Delta \mathrm{F}_{1}}{2}\right)^{2}+\left(\frac{\Delta \mathrm{F}_{2}}{2}\right)^{2}+\left(\frac{\Delta \mathrm{F}_{3}}{2}\right)^{2}}, \quad \operatorname{COV}=\frac{\sigma_{\mathrm{F}}}{\mathrm{F}_{\mathrm{MLV}}}
$$

7. Determine reliability index $(\beta) . \quad \beta=\frac{\mathrm{F}_{\mathrm{MLV}}-1}{\sigma_{\mathrm{FS}}}$ 
8. Determine the value of probability of failure, $\mathrm{P}_{\mathrm{f}}$, using published tables or using the Excel function NORMSDIST(x). $\mathrm{P}_{\mathrm{f}}=1-\operatorname{NORMSDIST}(\beta)$

9. Analyze the results to determine the relative contribution of the significant variables.

\subsubsection{Monte Carlo simulation}

Monte Carlo simulation is a process where random values are generated for each uncertain input variable in order to calculate a defined problem. The term Monte Carlo references games of chance in Monte Carlo, Monaco (Fenton and Griffiths, 2008). With this method, random values of the input variables are selected from probability density functions (PDFs) of the variables. These values are plugged into the performance function to obtain a result. This process is repeated many times using different values for the input variables. The range and distribution of input variable values is determined from the variable's PDFs. After performing a significant number of repetitions, the results define a probability distribution of the performance variable (Factor of Safety or other). Hartford and Baecher (2007), mention that it is important to consider that each trial only gives one result no matter how many input variables are used, therefore, adding more input variables will not increase the number of trials necessary nor the accuracy of the results. The accuracy of the results will mainly depend on the number of trials that the analyst considered necessary to ensure a desired level of confidence. Also, Hartford and Baecher (2007) state that the method is adequate for nonlinear problems or when it involves different types of PDFs for all the uncertain variables.

Back in the days, a big concern of the method was that it was very timeconsuming since it had a slow convergence due to all the repetitions that were necessary. 
Currently, this is not a big issue because of the advances in the computer industry. However, Haldar and Mahadevan (2000) argue that some analyses that involve Finite Element Analysis might not be reasonable to analyze with this method because they might become time consuming. Despite the time-consuming issue, it is the author's belief that this is a practical engineering method since not all methods are straightforward and fast but might improve the estimation of the results.

\subsubsection{Pros and cons of FOSM Taylor Series}

and Monte Carlo simulation methods

As already mentioned, the FOSM Taylor Series Method is a simple method that includes the uncertainty of the variables into the results. Despite its simplicity, it is very limited in its application. An advantage of the Taylor Series method is that it allows the engineer to see how significant each variable is to the overall factor of safety.

One of the most important assumptions, which becomes the biggest limitation, is that not only the Factor of Safety but all the input variables are assumed to have a normal or lognormal distribution. Sleep and Duncan (2008) consider this to be inaccurate since the distribution of the Factor of Safety is difficult to predict. Additionally, it is not reasonable to think that all cases will have variables with normal or log-normal distributions (Haldar and Mahadevan, 2000).

The method is generally only accurate for small variability and small nonlinearity (Fenton and Griffiths, 2008), hence significant error could be generated by ignoring higher order terms (Haldar and Mahadevan, 2000). If values of the variables result in non-linear behavior beyond the standard deviation, an additional error may occur. Moreover, the method only considers the mean and standard deviation of the variables 
instead of taking into account the entire probability density function of all the variables. Also, it is prone to error when more than one failure mode is modeled (Baecher and Christian, 2003), and the reliability index $(\beta)$ is not accurate when the performance function is outlined differently but with similar equivalent terms (Haldar and Mahadevan, 2000).

On the other hand, Monte Carlo Simulation is a relative straightforward method that can be used to analyze complex problems. It is very useful when the input variables of the performance functions are independent and can not be expressed by the normal or log-normal PDFs (Baecher and Christian, 2003). Another advantage is that more than one failure mode can be assessed with this method.

According to most authors, the biggest disadvantage is that the convergence can be slow and the large number of calculations necessary.

\subsection{Background of the Natomas Basin Area}

Since the mid-1800 the Natomas Basin in Sacramento, California has faced high risk for flooding. The Basin is surrounded by long levees, which include the American River North and Sacramento River South levees, the Natomas East Main Drainage Canal, the Natomas Cross Canal, and part of the Sacramento River (North) levee.

According to the California Department of Conservation (2007), Native Americans settled in the oak woodlands, grasslands, and along the marshland banks of the Sacramento River. Beginning early last century, much of the basin was drained for agriculture and levees were built for flood protection. The cores of today's levees are often somewhat the levees built by farmers and settlers as much as 150 years ago. Early 
levees were not constructed to current engineering standards, and little care was given to the suitability of foundation soils (see Figures 2.2 and 2.3). These remnants of the past often make today's levees unreliable.

Before the construction of the levees, the Sacramento River used to work as a meandering channel and it is for this reason that we find variations on its banks. In some areas we can find that the foundation of the levee is an erodable material or a cohesive material or a combination of both. Since the foundations of the levees were not treated as they should have, there have been multiple failures along the levees of the central Valley.

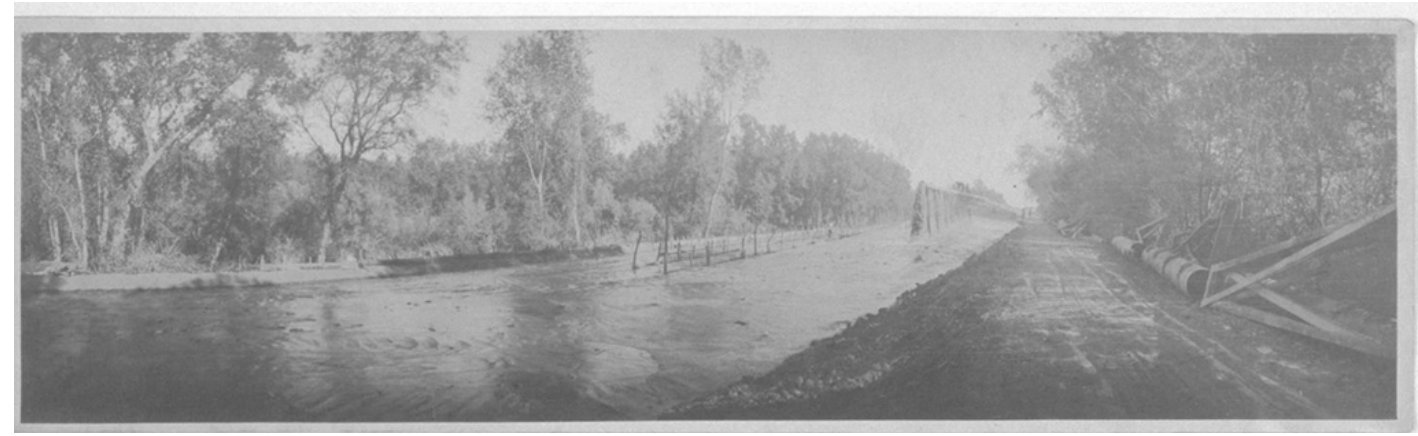

Figure 2.2 Natomas Levee Construction by hydraulic fill method. (Photo from online archive of California UCBerkley.library, 2009)

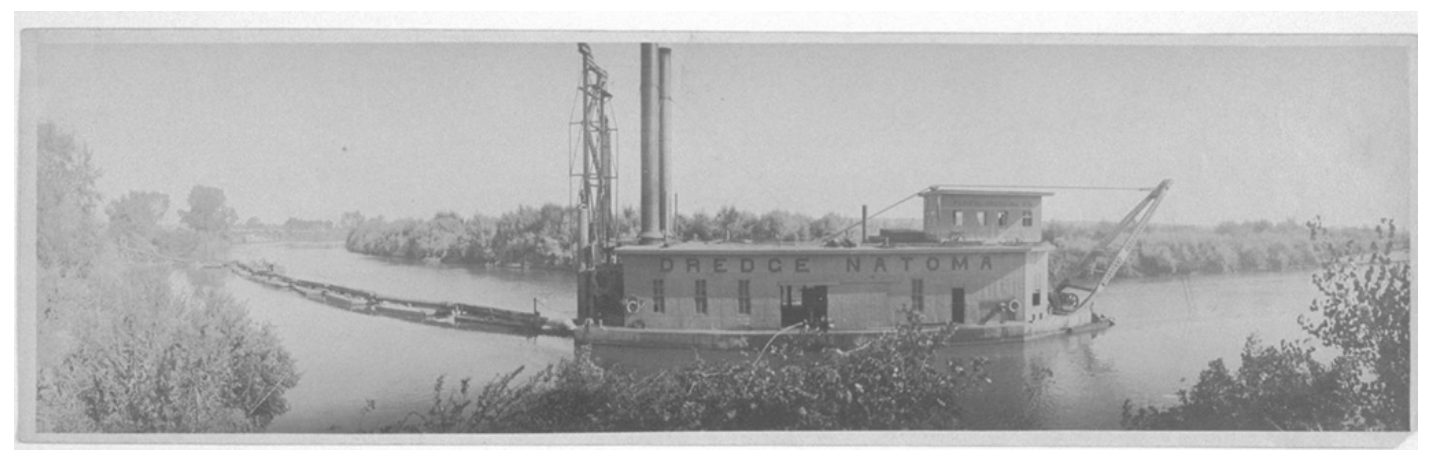

Figure 2.3 Dredge used in the Natomas Levees. Original construction method. (Photo from online archive of California UCBerkley.library, 2009) 
Urban development began in the area when Sacramento Municipal Airport (now Sacramento International Airport) was built in the 1960's. Changes in this area are predominantly conversions from irrigated farming to urban development. Most of the changes are associated with residential and commercial development in the northern portion of the City of Sacramento, as well as additions to Sacramento International Airport.

Since urban development increased around this area, flood events started to be a big concern. Folsom Dam was designed to reduce flood flows in the American River to a flow rate that could be safely carried by the downstream levees. Construction of Folsom Dam began in 1950 and in the design of the dam engineers used historic flow records and statistical analyses to predict the size and frequency of occurrence of large floods. A flood history-overview of the Sacramento Area can be found at SAFCA (2008a).

Despite this effort, Folsom Dam exceeded its normal flood control storage capacity during an event in 1986 and several areas of the levees nearly collapsed under the strain of the storm. The quantity of water flowing out of the Sierra Nevada Mountains during large floods appears to be increasing and in response to this area's vulnerability to catastrophic flooding the Sacramento Area Flood Control Agency (SAFCA) was formed in 1989 (SAFCA, 2008b). After this flood event, research has been done by the U.S. Army Corps of Engineers (USACE) to analyze the susceptibility and stability of the levees that surround the Natomas Basin.

Since 2001 there has been an effort to evaluate the geotechnical conditions of these levees with regard to seepage, stability, seismic stability and erosion. The analyses concerning underseepage have been made according to the USACE (2000) and USACE 
(2005) where the Blanket Theory is used and a Factor of Safety is calculated. After the New Orleans' flood event in 2005, the State of California became alarmed from the disastrous situation and started to take the Natomas Basin area more seriously (Boyle, 2006). In January 1st, 2008, a $\$ 400$ million flood control project to protect Sacramento's Natomas Basin was approved by SAFCA (California Planning and Development Report, 2008). Currently research and construction is being done to strengthen levees, and make them less susceptible to failure. 


\section{CHAPTER 3}

\section{METHODOLOGY}

\section{$\underline{\text { 3.1 Problem Statement }}$}

Current methods for analyzing the likelihood of levee failure due to underseepage are based on calculating the Factor of Safety as the ratio of critical hydraulic gradient to hydraulic exit gradient. Factors of Safety (F.S.) have been analyzed both deterministically and probabilistically. The biggest limitation of deterministic analyses is that they do not consider the uncertainty of the input variables. Probabilistic methods have been applied to the exit gradient approach using the U.S. Army Corps of Engineers "Blanket Theory" equation and a First-Order Second-Moment (FOSM) Taylor series method. This probabilistic approach has two significant shortfalls: 1) the Blanket Theory equation limits the analyses to very simplified subsurface geometries, and 2) the exit gradient approach does not model the actual failure mechanisms responsible for underseepage failures in many cases.

With reliability-based calculations it is possible to evaluate the combined effects of uncertainties associated with the various input variables and assess the probability of unsatisfactory performance based on these uncertainties. The calculated probabilities of unsatisfactory performance for a number of levee reaches can be directly compared, unlike factors of safety where the uncertainty of the input variables has not been taken into account.

The proposed method will model the actual failure mechanism and consider the effects of more complex subsurface geometry on the calculated reliability in order to 
approach a realistic state of nature of the levees. The failure mechanism to be considered has been explained by Mansur, Postol, and Salley, (2000), Guy et al. (2007), McCook (2007), and Halpin and Ferguson (2007), and will be explained later on.

To incorporate the effects of more complex subsurface geometry into the analyses, the proposed method will utilize the Finite Element Method (FEM) Seepage Program Slide. Successive FEM analyses will be performed varying the values of the input variables within the range of possible values. The result of these analyses will be used to develop curves or surfaces defining the relationship between the input variables and the calculated exit gradient or uplift pressure. The exit gradients or uplift pressures are then used to calculate a F.S. Using the curves and the computer program @ Risk, the probability of unsatisfactory performance will be calculated by way of a Monte Carlo simulation.

\section{$\underline{3.2 \text { Failure Mechanism }}$}

The Blanket Theory assumes that failure (piping) will occur when the upward seepage gradient is equal to the critical gradient of the subsurface soil. The Factor of Safety is defined as the ratio between the critical gradient $\left(i_{c}\right)$ and the calculated exit gradient of the blanket (ie $\mathrm{BLANKET}_{\mathrm{B}}$ ).

$$
\text { F.S. }=\frac{\mathrm{i}_{\mathrm{c}}}{\mathrm{i}_{\mathrm{e}_{\text {BLANKET }}}}
$$

Essentially, the failure mechanism of the Blanket Theory focuses on a hydraulic gradient in the blanket reflecting backward erosion in the blanket. The critical gradient $\left(i_{c}\right)$ is generally taken to be a function of the saturated buoyant unit weight of the soil $\left(\gamma_{b}\right)$ and the unit weight of the water, or 


$$
\mathrm{i}_{\mathrm{c}}=\frac{\gamma_{\mathrm{b}}}{\gamma_{\mathrm{w}}}
$$

This method is called the Effective Stress Method or Upward Stress Method and is the general definition used to calculate the F.S. against piping. See Figure 3-1 for a schematic illustration. Figure 3-1.a illustrates initiation of the mechanism when $i_{\mathrm{e}}$ BLANKET is greater than $i_{c}$. Figure 3-1.b illustrates progress (backward erosion) in the blanket towards the sand.

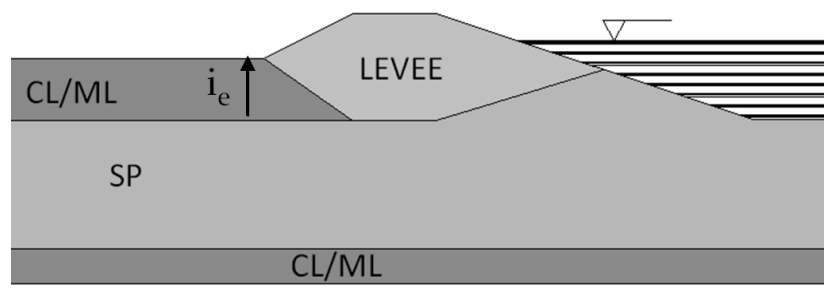

(a) Initiation

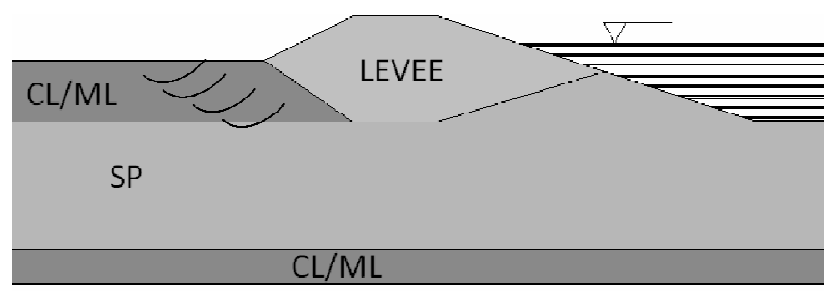

(b) Progression

Figure 3.1 Schematic illustration of Effective Stress Method based on Blanket Theory. 
It is the author's belief that this failure mechanism is not the actual underseepage failure mechanism that occurs in this type of levee section. As mentioned, the proposed (actual) failure mechanism has been explained by Mansur, Postol, and Salley (2000), Guy et al. (2007), McCook (2007), and Halpin and Ferguson (2007), and is as follows: 1) high pressures in the sand (pervious substratum) cause the blanket (impervious substratum) to heave resulting in a crack in the blanket, 2) concentrated flow in the crack results in high gradients in the sand at the base of the crack, 3) erosion of the sand initiates, and 4) erosion progresses towards the river in the sand (backward erosion).

The method to analyze this mechanism is called the Total Stress Method where the Factor of Safety is defined as the ratio of the total vertical pressure at the base of the blanket (impervious layer) divided by the uplift pressure of the water in the sand $\left(\mu_{S}\right)$ (pervious layer) at the base of the blanket.

$$
\text { F.S. }=\frac{H \gamma_{b}}{\left(h_{O}+H\right) \times \gamma_{w}}
$$

where $\mathrm{H}=$ thickness of overlying soil blanket, $\gamma_{\mathrm{b}}=$ saturated unit weight of overlying soil column (blanket), $\mathrm{h}_{\mathrm{o}}=$ head above ground at toe, in feet of water head, and $\gamma_{\mathrm{w}}=$ unit weight of water McCook (2007).

Figure 3-2 shows a schematic illustration of the Total Stress Method. Figure 3.2.a shows high pressures in the sand that affect the blanket. Figure 3.2.b represents how the blanket heaves due to high pressures in the sand. Figure 3.2.c shows the developing of a crack in the blanket resulting in high gradients in the sand at the base of the crack. Figure 3.2.d represents the initiation of erosion of the sand and progression towards the river. 


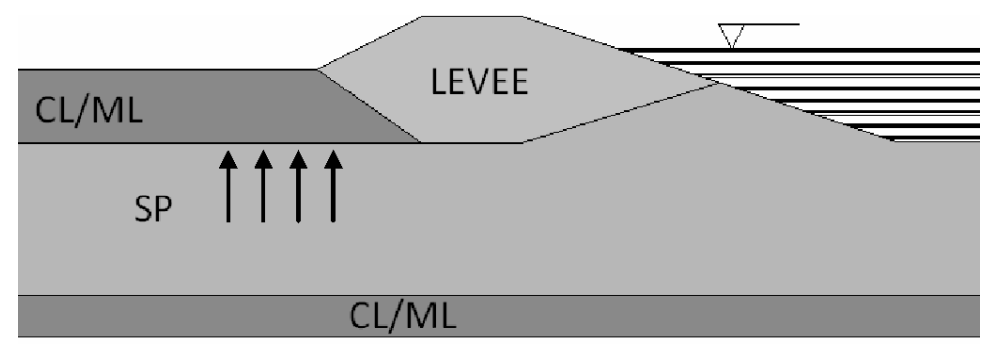

(a) Initiation, high pressures in the sand

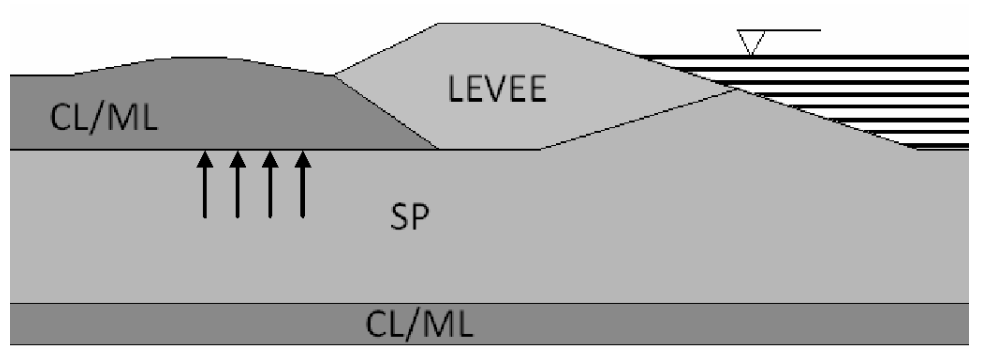

(b) Heave of the blanket

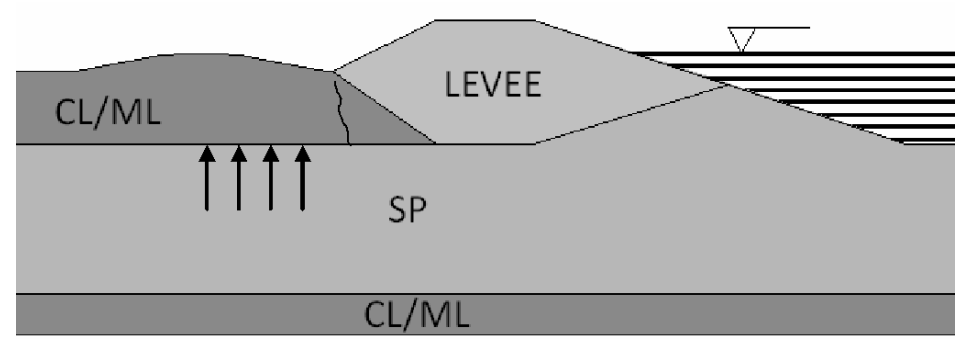

(c) Developing of crack

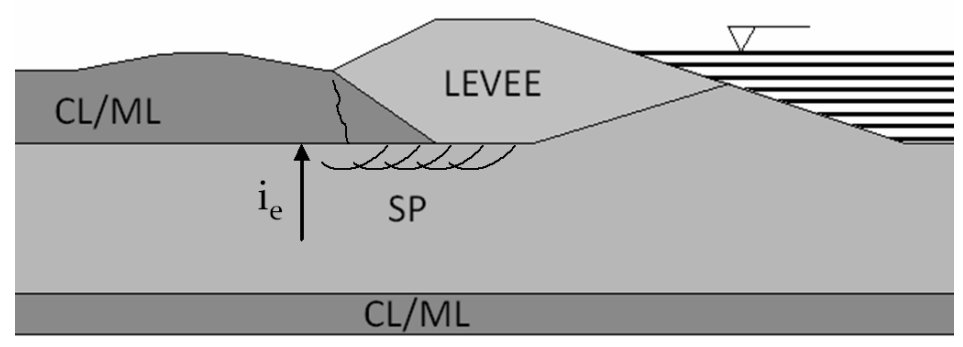

(d) Erosion of the sand initiates at the base of the crack and progresses towards the river Figure 3.2 Schematic illustration of Total Stress Method. 
A separate effective stress seepage analysis can be performed to assess whether the sand will erode once the heaving has occurred and a crack formed. In most cases the heaving (total stress analysis) will have a lower F.S. than the sand erosion, making the heaving, the controlling mechanism.

The total stress method is a more realistic approach since it is very unlikely that any erosion will occur in the blanket (impervious layer) because of its engineering properties. Holtz and Kovacs (1981) point out that seepage forces affect sands more than clays because sands are cohesionless, whereas clay soils have more resistance against seepage because they are cohesive.

\section{$\underline{3.3 \text { Sources of Data: Profiles }}$}

A geotechnical risk-based analysis was performed by the Army Corps of Engineers in 2007 as part of the flood protection system of the Natomas Levee (USACE, 2007). The primary goal was to gather and review all available data to analyze and identify critical reaches for each unit and their probability of failure for different river stages; performance functions considered for the risk analyses included slope stability and seepage. The reliability analysis was based on the FOSM Taylor series method with the "Blanket Theory" as the performance function.

According to USACE (2007), the Natomas Basin flood protection system (Figure 3-3) consists of nearly 26 miles of levees. To perform the reliability analysis the levees were divided in four major units: (1) Levee Unit 1, 18.6 miles long, located along the east bank of the Sacramento River; (2) Levee Unit 2, 2.3 miles long, located along the north bank of the American River; (3) Levee Unit 3, 17.3 miles long, located along the west 
bank of the Natomas East Canal and Pleasant Grove Creek Canal; and (4) Levee Unit 4, 4.4 miles long, located along the south bank of the Natomas Cross Canal.

For the purpose of this study, a section (reach) along Levee Unit 1 between Levee Miles 2 and 3 (shown in Figure 3-3) was selected based on a deterministically calculated exit gradient, drilled borings, and foundation soil profile. A sketch of the section by URS (2005) is presented as Figure 3-4. As part of the Army Corps of Engineers analysis in 2007, more borings were made and as a result of all of the borings together the section was revised to the section presented in Figure 3-5.

Based on the information available in 2005 by URS, the section presented in Figure 3-4 was developed. Although no subsurface data was available directly under the levee, the blanket was assumed to be continuous under the levee. Additional borings drilled as part of the 2007 study are shown in the section in Figure 3-5. One of the 2007 borings drilled through the levee encountering no blanket but, a boring drilled 300 feet inland encountered a blanket. So the most important question with regard to seepage and piping analysis on this section is "where does the blanket end?"

Based on this question, the author has concluded that the blanket could end anywhere between borings B1 and B2 in Figure 3-6. Notice that borings B1 and B2 are also shown in Figure 3-5.

Since the blanket could end before or after the levee toe, there are two possible failure mechanisms that could occur: (1) piping of sand at the ground surface where the blanket ends before the levee toe and, (2) uplift of the blanket layer where the blanket ends below the levee. For mechanism 1, the piping potential will be analyzed using the Effective Stress Method and, for mechanism 2, the Total Stress Method will be used. 


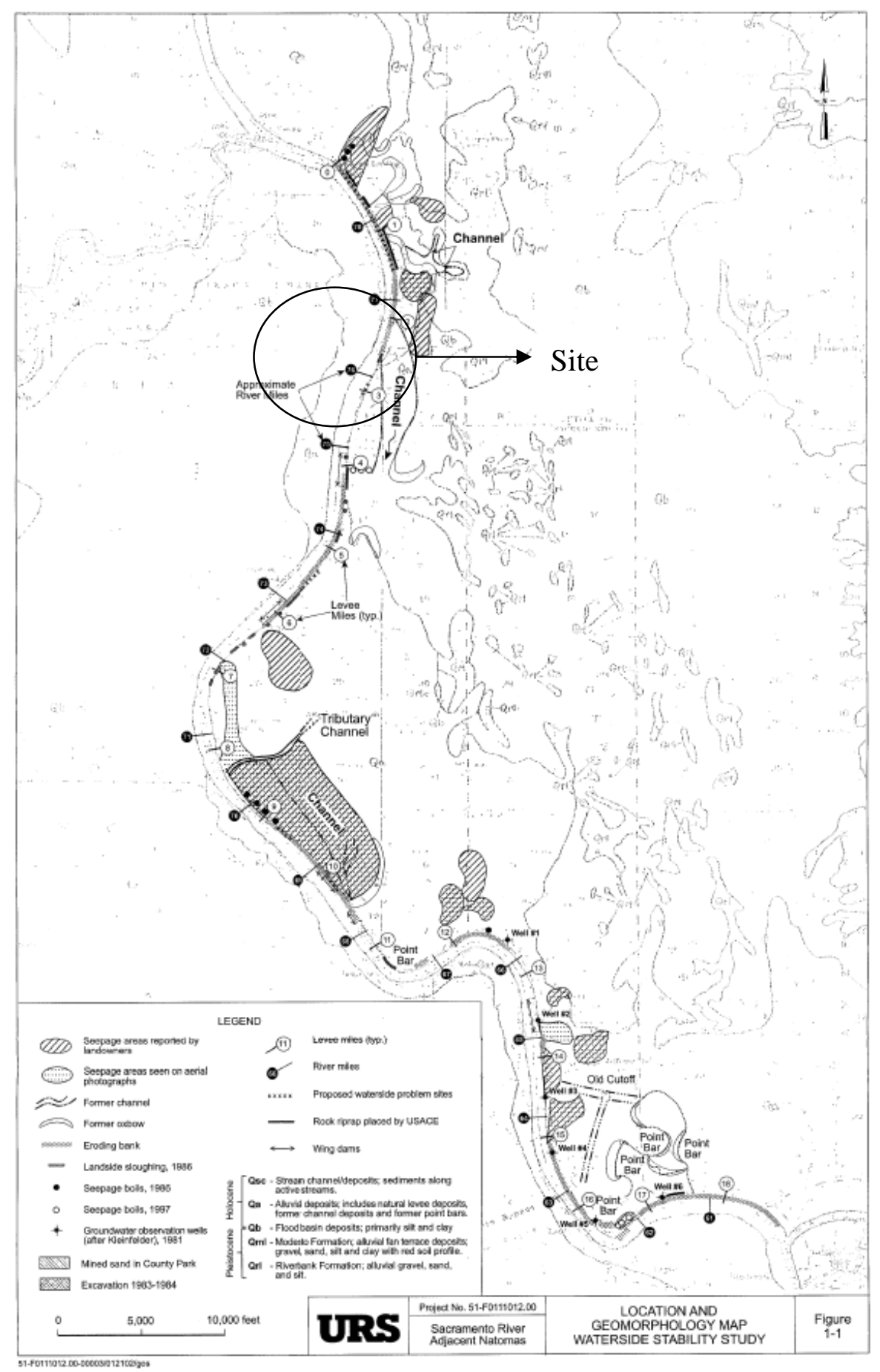

Figure 3.3 East bank of the Sacramento River by URS. 


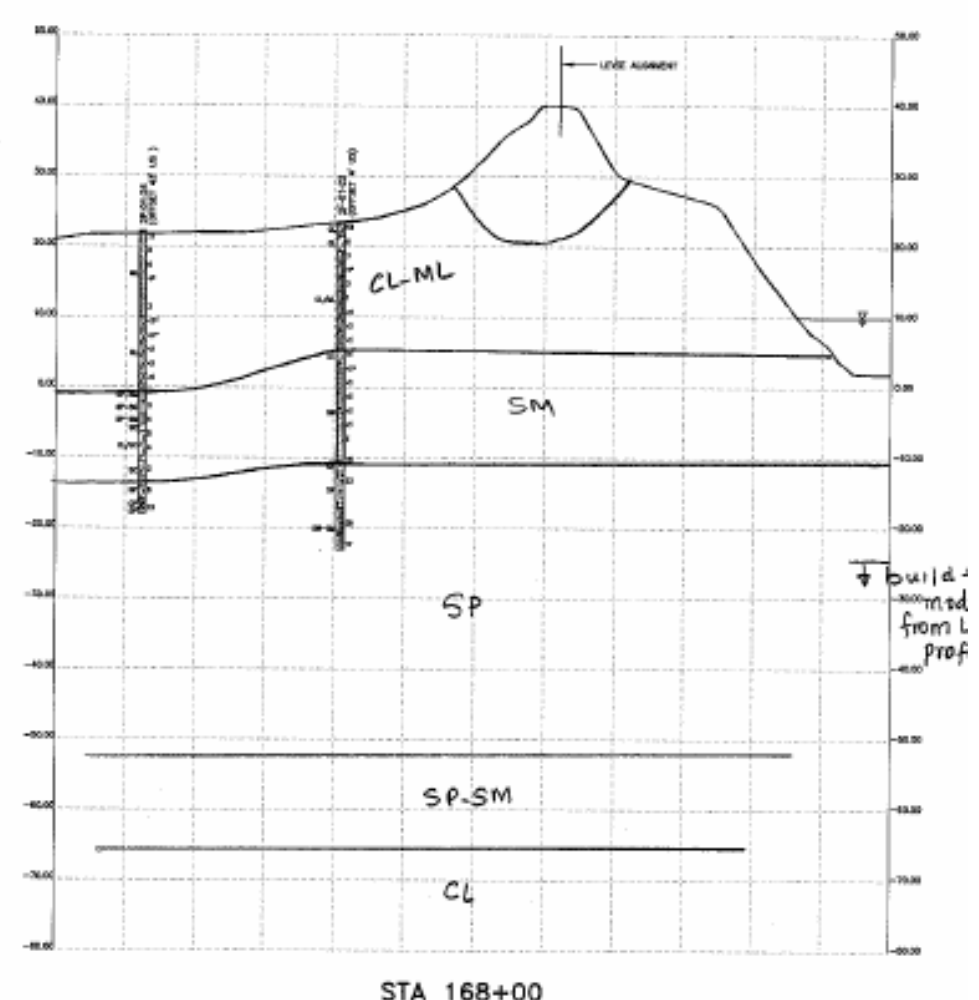

Figure 3.4 Section 168+00, by URS (2005).

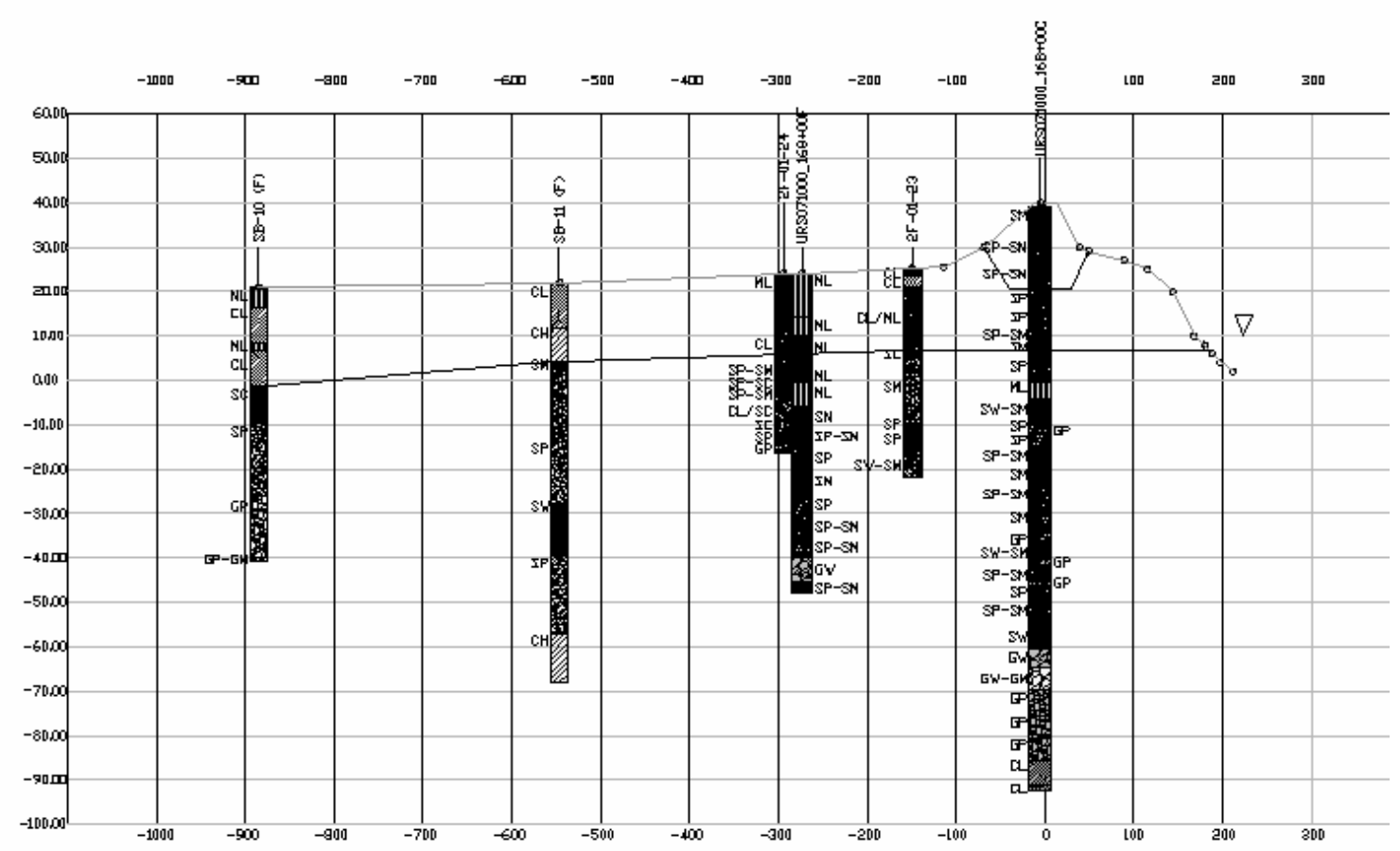

Figure 3.5 Levee section considered in the analyses (after URS, 2005). 


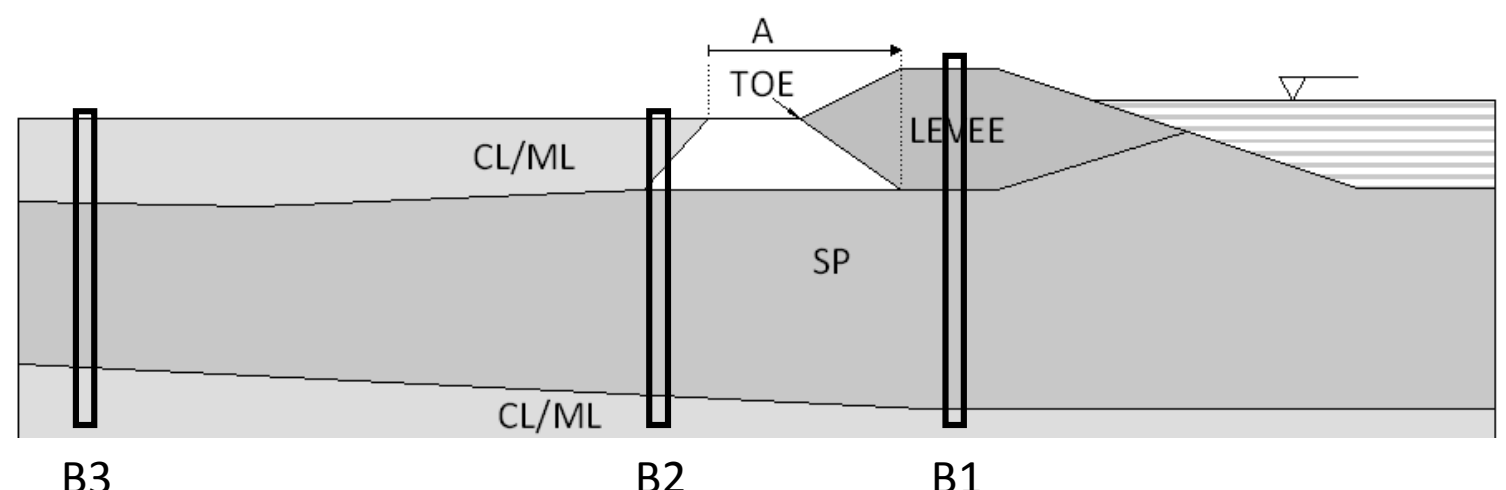

Figure 3.6 Where does the blanket end?

It is very important to note that the Effective Stress Method will only be used where the sand (which is the erodable soil) is at the ground surface and the critical mechanism is the exit gradient in the sand. This differs from the Blanket Theory where the Effective Stress Method is used when the blanket is at the ground surface implying that the blanket is the eroding soil. This is done because the author believes that this failure mechanism should reflect backward erosion in the sand towards the river. The Total Stress Method will be used where the blanket is at the ground surface and the critical mechanism is heave and cracking of the blanket which will allow for sand erosion. Analyses will be performed to check that sand erosion will occur if heave and cracking occurs first.

When the end of blanket is very close to the levee toe but under the levee toe, a combined mechanism will be assumed. In this case, both the gradient and the uplift pressure will be taken and the F.S. will be interpolated between the F.S. of the gradient and the F.S. of the uplift pressure. 


\subsection{Proposed Methodology}

For each reach, general steps of the proposed methodology are as follows:

1. Define a variable or variables in the levee profile to represent geometry variations in the subsurface.

2. Define the soil variables.

3. Define the probability density function (PDF) for each variable.

4. Develop the FEM analysis profile.

5. Perform FEM analyses to assess effects of parameter variation.

6. Develop family of curves or surfaces defining the effects of parameter variation.

7. Develop equations fitting the family of curves or surfaces.

8. Develop Excel spreadsheet to calculate F.S. given a value for each parameter.

9. Run @ Risk for Monte Carlo simulation using the Excel spreadsheet to calculate the probability of unsatisfactory performance.

Step 1. Identify geometric variables. Since one of the benefits of this method is to represent a more realistic state of nature of the levees, the first step is to identify a variable or variables in the levee profile that represent the geometry variation in the subsurface such as the location of the blanket pinching out. These variables are called "geometric variables."

Step 2. Identify soil variables. Another set of variables are the soil variables such as the permeability ratio (Ksb) (the ratio of the permeability of the sand $(\mathrm{Ks})$ and the permeability of the blanket $(\mathrm{Kb})$ ), the anisotropy ratio (Khv) (the horizontal to vertical 
ratio of the permeability of the sand), the unit weight of the blanket $\left(\gamma_{b}\right)$, and the unit weight of the sand $\left(\gamma_{\mathrm{s}}\right)$. These variables are called "soil variables." It is only necessary to input the permeability of the sand, the permeability of the blanket, and the anisotropy ratio of the sand. Because the variation in the hydraulic regime (hydraulic pressures and gradients) is a function of $\mathrm{Ksb}$ and not the individual permeabilities of the sand and blanket, only one of the permeabilities will need to be changed setting the other one equal to its most likely value.

Step 3. Define PDF for each variable. Once the variables have been identified, the probability density functions (PDF) for each variable are defined. The probability density function of the variables are selected by judgment and published papers (Baecher and Christian (2003), Harr (1987), and Sleep and Duncan (2008)). According to Baecher and Christian (2003), for engineering practice, the permeability of the soils is usually assumed to be a lognormal distribution. The anisotropy ratio (Khv) has also been assumed to be a lognormal distribution. For the unit weights of the soils, normal distributions have been assumed. For the geometric variable "A" (see Figure 3.6), which defines where the blanket could end or where the blanket pinches out, a trapezoidal distribution has been assumed. The "A" variable first reflects an increasing probability of occurrence at the beginning (from left to right) then a uniform probability when it gets close to the levee toe and, finally a decreasing probability when it gets under the levee toe (also from left to right) all of this between the defined ranges.

For each variable an array of 5 to 10 values is selected to encompass the entire range of the variables' PDF. These values will be used later in the FEM analysis (Step 5) to define the relationship between the variables and the F.S. 
Step 4. Develop the FEM analysis profile. After the variables have been defined, a FEM analysis profile is developed. It is important to draw the section with boundaries defining all the possible geometry variations that can occur within the range of variations of the geometric variables. Doing so avoids re-discretization (changing of the FEM mesh) when the geometry is changed. Changes in the mesh can affect local results near the location of the mesh changes.

Step 5. Perform FEM analyses. The profile is then analyzed for all possible combinations of the different geometry variations and soil variables that were specified in Step 3. The FEM results are assessed, selecting the highest exit gradient in the sand (i $\left.i_{\mathrm{eSAND}}\right)$ if the blanket ends before the levee toe or the uplift pressure of the sand ( $\left.\mu_{\mathrm{SAND}}\right)$ at the base of the blanket if the blanket ends after the levee toe.

Step 6. Develop family of curves or surfaces. The results of the FEM analysis are plotted with respect to the exit gradient or uplift pressure. The relationships are represented by family of curves or surfaces that will allow us to estimate (by interpolation) the $\mathrm{i}_{\mathrm{ESAND}}$ or the $\mu_{\mathrm{SAND}}$ under a wide range of geometric and soil variables represented by the probability density functions (PDF).

Tables 3.1 and 3.2, and Figures 3-7 and 3-8 show an example of a family of surfaces. In this example, Table 3-2 and Figure 3-7 represent the numeric relationship between the geometric variable "A" which is where the blanket could pinch out, the permeability ratio "Ksb", and the anisotropy ratio "Khv" with the calculated exit gradient in the sand " $i_{e}$ SAND". Table 3-3 and Figure 3-8 represent the numeric relationship between the geometric variable "A", calculated uplift pressure of the sand " $\mu_{\mathrm{S}}$ " at the base of the blanket, and the anisotropy ratio "Khv". 
Table 3.1 Exit gradient $\mathrm{i}_{\mathrm{e}}$ SAND as a function of $\mathrm{A}, \mathrm{Ksb}$ and $\mathrm{Khv}=0.25$

\begin{tabular}{|c|c|c|c|c|c|}
\hline $\mathbf{A s b}$ & $\mathbf{2 0}$ & $\mathbf{6 3}$ & $\mathbf{2 0 1}$ & $\mathbf{6 3 4}$ & $\mathbf{2 0 0 6}$ \\
\hline-76 & 0.453 & 0.476 & 0.484 & 0.486 & 0.487 \\
-68.75 & 0.481 & 0.512 & 0.524 & 0.528 & 0.529 \\
-61.5 & 0.527 & 0.576 & 0.595 & 0.602 & 0.604 \\
-54.25 & 0.623 & 0.713 & 0.749 & 0.762 & 0.766 \\
-47 & 0.763 & 0.928 & 0.998 & 1.023 & 1.03 \\
\hline
\end{tabular}

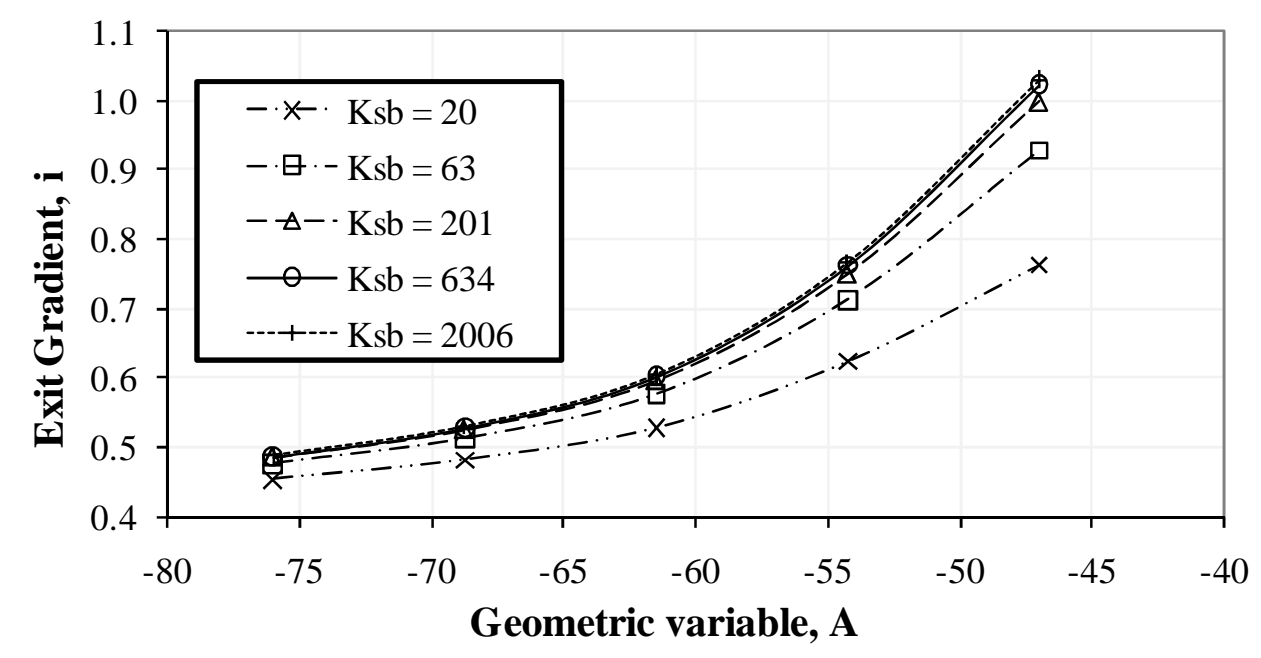

Figure 3.7 Family of curves representing relationship of $\mathrm{Ksb}, \mathrm{Khv}$, and $\mathrm{A}$ to $\mathrm{i}_{\mathrm{e}}$.

Table 3.2 Uplift pressure of the sand $\mu_{\mathrm{S}}$ as a function of $\mathrm{A}, \mathrm{Ksb}$ and $\mathrm{Khv}=0.25$

\begin{tabular}{|c|c|c|c|c|c|}
\hline Ksb & $\mathbf{2 0}$ & $\mathbf{6 3}$ & $\mathbf{2 0 1}$ & $\mathbf{6 3 4}$ & $\mathbf{2 0 0 6}$ \\
\hline-43 & 627.569 & 776.17 & 850.501 & 878.79 & 888.444 \\
-39 & 930.496 & 1056.632 & 1114.164 & 1135.349 & 1142.503 \\
-31 & 1379.494 & 1481.699 & 1525.025 & 1540.552 & 1545.784 \\
-23 & 1710.716 & 1800.452 & 1837.373 & 1850.419 & 1854.788 \\
-15 & 1967.447 & 2049.645 & 2083.011 & 2094.695 & 2098.581 \\
\hline
\end{tabular}




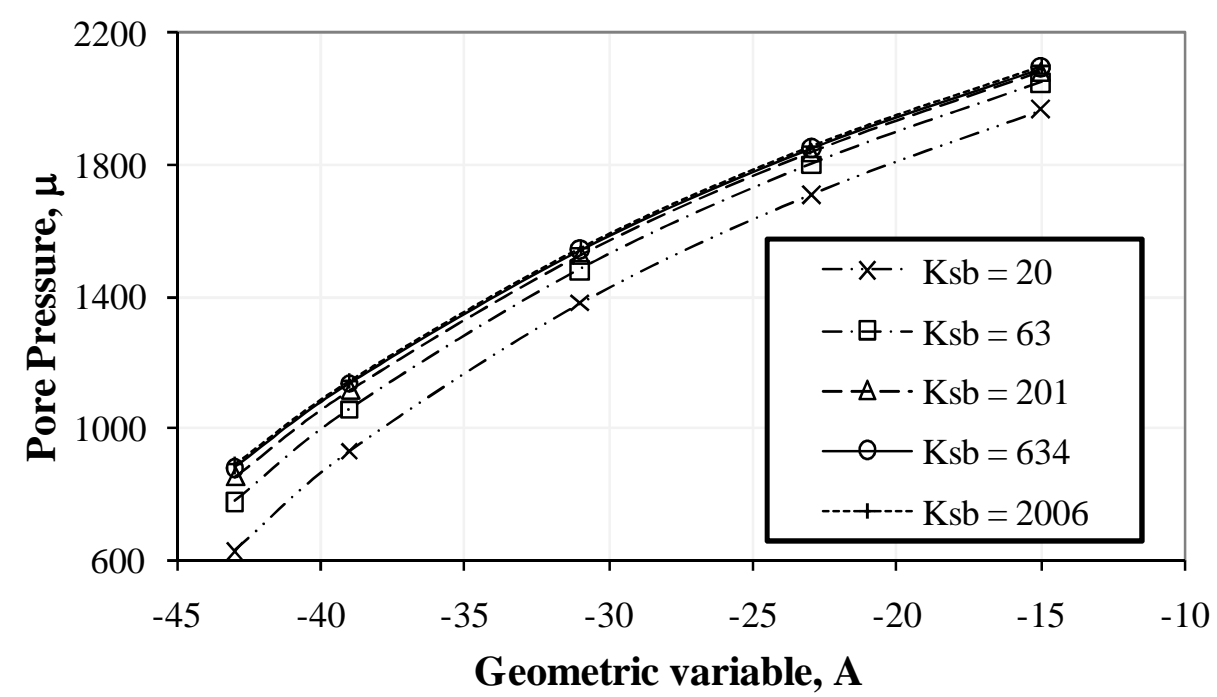

Figure 3.8 Family of curves representing relationship of Ksb, Khv, and A to $\mu$ s.

Notice that each curve represents a relationship between the geometric variable A and the exit gradient, $i_{\mathrm{e}}$, or pore pressure, $\mu_{\mathrm{s}}$, for a constant value of Ksb. If the analyst wants to add uncertainty to the anisotropy ratio, another set of FEM analyses must be made in order to present this in the reliability analysis.

Step 7. Develop equations. Equations describing the curves for step 5 are developed through a polynomial curve fitting method in Excel. The equations are up to a $6^{\text {th }}$ order polynomial curve fitting determined by the "least squares" method by means of linear regression analysis. Using these equations, and interpolation between them, the F.S. can be calculated for the profile given any combination of variables within the defined ranges. 
Step 8. Develop Excel spreadsheet. Having the distribution of all the variables (including the ones that were not used to calculate the exit gradient or uplift pressure) and the family of curves or surfaces, a "macro" together with an input sheet should be created in Excel in order to calculate the F.S. given a set of values for the variables.

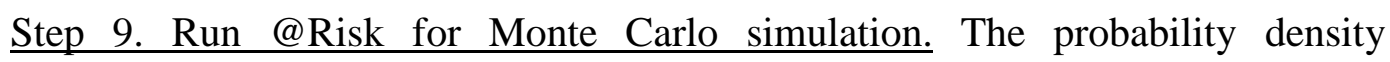
distributions of the variables are input into the Excel spreadsheet and, using the program @Risk, a Monte Carlo simulation is run. The program @ Risk randomly takes values from the PDFs of the variables and, using the family of curves or surfaces calculates a F.S. for each combination of variables. This process is repeated many times resulting in a probability density function that defines the relationship between the F.S. and probability of occurrence.

The result of the analysis represents the probability of initiating erosion given a river flood level, hence, it is only the first phase in the development of the process of piping. Foster and Fell (2008) explain that it is helpful and practical to consider the failure mode process (in general) of internal erosion and piping into four phases: initiation of erosion, continuation of erosion, progression to form a pipe, and formation of a breach. These phases are represented in a sequence of events (event trees). The probability of the analysis described above represents one single node of the event tree. In order to assess failure, other points in the event tree will need to be assessed with calculations or by judgment.

This proposed method is based on the actual failure mechanism explained above but for purposes of comparison with other methods it will be also applied using the failure mechanism assumed by the Blanket Theory. 


\section{CHAPTER 4}

\section{ANALYSIS OF DATA}

Four example cases are presented herein to demonstrate the use of the proposed method in a variety of analyses. All the cases are analyzed with the Finite Element Analysis and Monte Carlo simulation method described in Chapter 4. In Analyses 1 and 2, a complex levee section similar to the one shown in Figure 3.6 will be analyzed. Analysis 1 models the levee section with the realistic failure mechanism discussed in Chapter 3, using the Effective Stress Method where the blanket ends before the levee toe (piping of sand at the ground surface) and the Total Stress Method where the blanket ends below the levee toe (uplift of the blanket layer). Analysis 2 models the levee section by means of the Effective Stress Method but in this case blanket layer has a crack at the toe of the levee to model erosion through the blanket layer. Analysis 3 models a simple levee section assuming the same failure mechanism and simplified geometry as the Blanket Theory. The results of this analysis will be used to make a comparison with the current reliability method (FOSM - Blanket Theory) in Chapter 5. Analysis 4 models a hypothetical levee section with a different subsurface geometry to demonstrate the flexibility of the proposed method. Analyses of the variables are performed for each of the analyses by means of a multiple regression analysis in order to show the effects of variation of each variable with respect to the F.S. 


\subsection{Analysis 1: Proposed Method}

A model levee section similar to the section presented in Figures 3.5 and 3.6 is shown in Figure 4.1. The section has been modeled with the proposed failure mechanism and methodology described in Chapter 3. It was analyzed with a closed seepage exit (no flow-boundary) on the landside boundary of the model. The geometric and soil variables used in this example are presented in Table 4.1.

This section is more complex than sections that could be analyzed using Blanket Theory. As seen in Figure 4.1 and Table 4.1, the geometric variable that has been chosen is the horizontal coordinate of the location where the blanket could pinch out denoted as "A". The probability density function for this variable is assumed to be trapezoidal.

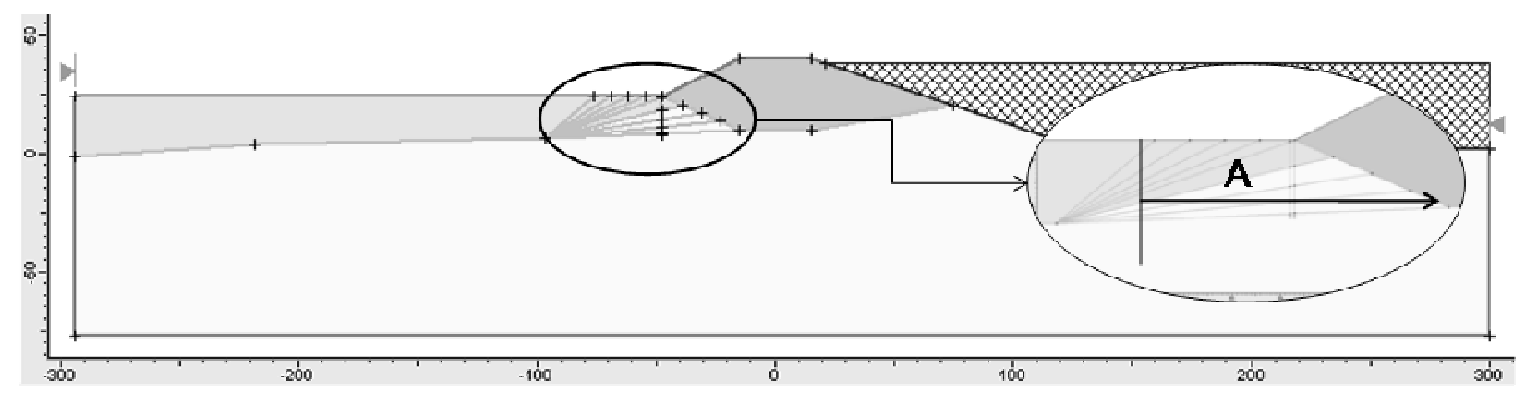

Figure 4.1 Slide model of levee section used in Analysis 1.

Table 4.1 Input variables for Analysis 1

\begin{tabular}{|c|c|c|c|c|c|}
\hline Variable & MLV & $\boldsymbol{\sigma}$ & MIN & MAX & Type of distribution \\
\hline $\log (\mathrm{Kb})$ & -6.00 & 0.67 & -7.00 & -5.10 & Normal \\
$\log (\mathrm{Ks})$ & -3.00 & 0.67 & -3.80 & -2.00 & Normal \\
$\log (\mathrm{Kh} / \mathrm{Kv})$ & -0.60 & 0.163 & -2.30 & -0.30 & Normal \\
$\mathrm{A}$ & -47 & - & -76 & -15 & Trapezoidal \\
$\gamma_{\mathrm{b}}$ & 120 & 5.000 & 110 & 130 & Normal \\
$\gamma_{\mathrm{s}}$ & 130 & 5.000 & 120 & 140 & Normal \\
\hline
\end{tabular}


The variability of the permeabilities have been modeled using normal distributions of the log of the permeability values. In the spreadsheet the antilog of the $\log$ of the permeabilities is taken to perform the calculations. The same thing is done to the anisotropy ratio "Khv". The input variable " $\gamma_{\mathrm{s}}$ " (unit weight of the sand) is used to calculate the critical gradient and contributes to the F.S. (along with the calculated exit gradient, $i_{\mathrm{e}}$ ) when the sand layer is exposed at the ground surface. The input variable " $\gamma_{\mathrm{b}}$ " (unit weight of the blanket) is used to calculate the pressure at the base of the blanket and contributes to the F.S. (along with the calculated $\mu_{\mathrm{s}}$ ) when the blanket is below the levee toe. Both, $\gamma_{\mathrm{b}}$ and $\gamma_{\mathrm{s}}$ are assumed to have normal distributions.

The failure mechanisms considered are: (1) piping of sand at the ground surface where the blanket ends before the levee toe and, (2) uplift of the blanket layer where the blanket ends below the levee. For mechanism 1, the piping potential will be analyzed using the Effective Stress Method (calculating $\mathrm{i}_{\mathrm{e}}$ in the sand) and, for mechanism 2, the Total Stress Method will be used (calculating the water pressure, $\mu_{\mathrm{s}}$, at the base of the blanket).

The Excel spreadsheet, probability density functions for each input variable, family of curves, and developed equations for this case are presented in Appendix A. With the help of the developed Excel spreadsheet, a Monte Carlo simulation is performed using the program @ Risk. The cumulative ascending distribution function for the F.S. given by @Risk is presented below as Figure 4.2. As can be seen, the probability of unsatisfactory performance (that the F.S. is less than 1.0) is equal to 70.4 percent. 


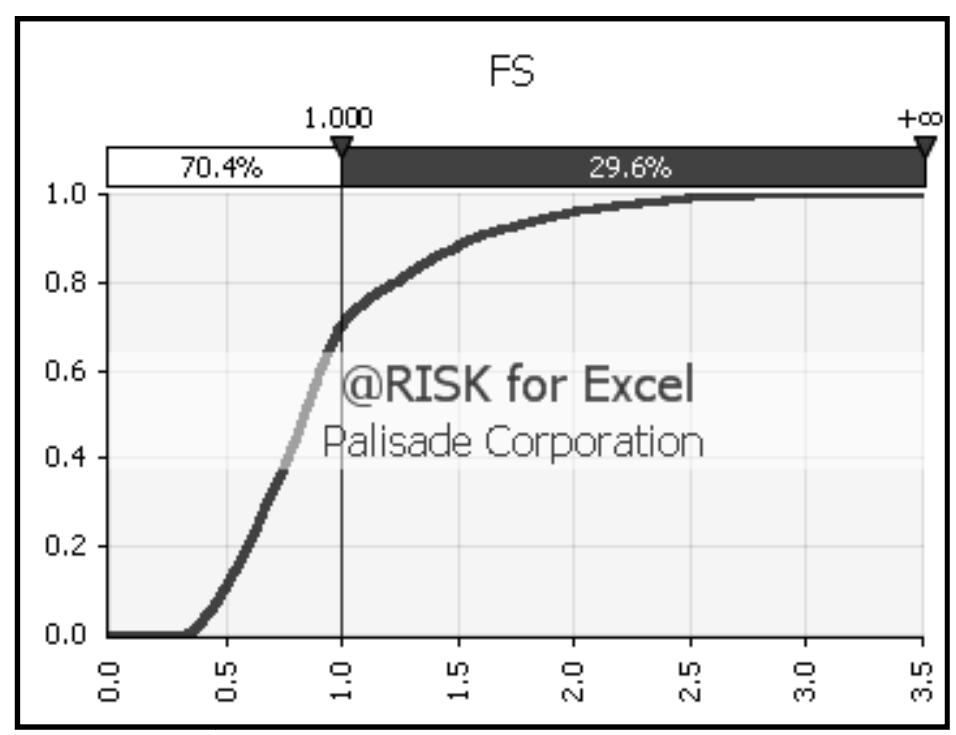

Figure 4.2 Cumulative ascending distribution function for the F.S. for Analysis 1.

\subsection{Analysis 2 Effective Stress Method with a Crack at the Toe of the Levee}

The same levee section as that analyzed in Section 4.1 has been re-analyzed with a crack through the blanket layer at the levee toe. In this case, the section presented as Figure 4.3 has been modeled only with the Effective Stress Method as described in the proposed methodology. However, in contrast to the Blanket Theory, the calculated exit gradient $\left(\mathrm{i}_{\mathrm{e}}\right)$ is measured in the sand at the base of the crack (and not at the surface of the blanket). The geometric and soil variables involved in this analysis are presented in Table 4.2 .

The failure mechanisms considered are: (1) piping of sand at the ground surface where the blanket ends before the levee toe and, (2) piping of the sand through the crack where the blanket ends below the levee. For both mechanisms, piping potential will be analyzed using the Effective Stress Method (calculating $i_{\mathrm{e}}$ in the sand). 


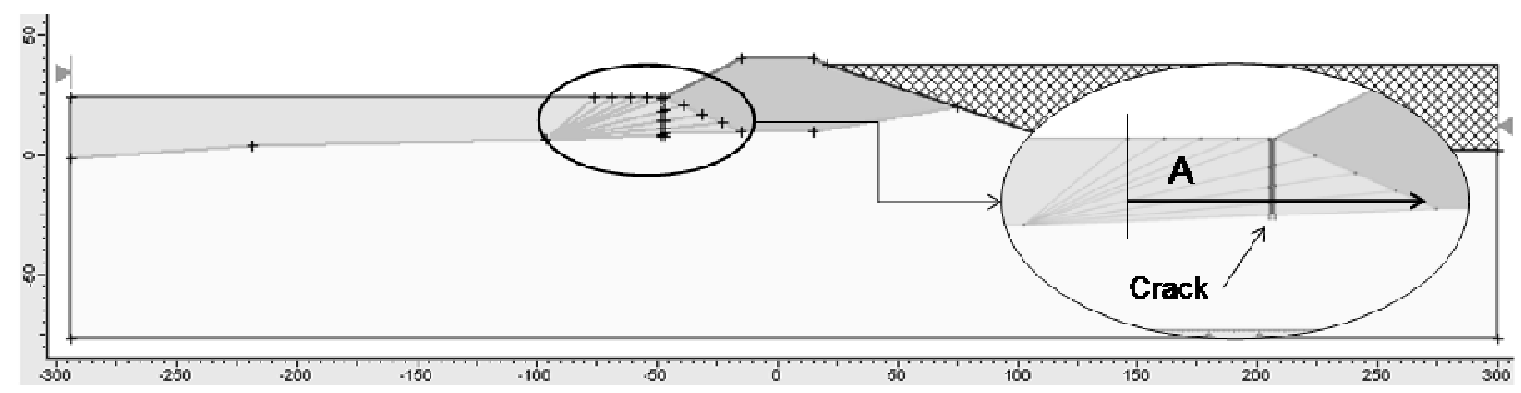

Figure 4.3 Slide model of levee section used in Analysis 2.

Table 4.2 Input variables for Analysis 2

\begin{tabular}{|c|c|c|c|c|c|}
\hline Variable & MLV & $\boldsymbol{\sigma}$ & MIN & MAX & Type of distribution \\
\hline $\log (\mathrm{Kb})$ & -6.00 & 0.67 & -7.00 & -5.10 & Normal \\
$\log (\mathrm{Ks})$ & -3.00 & 0.67 & -3.80 & -2.00 & Normal \\
\hline $\log (\mathrm{Kh} / \mathrm{Kv})$ & -0.60 & 0.163 & -2.30 & -0.30 & Normal \\
$\mathrm{A}$ & -47 & - & -76 & -15 & Trapezoidal \\
$\gamma_{\mathrm{s}}$ & 130 & 5.000 & 120 & 140 & Normal \\
\hline
\end{tabular}

The Excel spreadsheet, probability density function for each input variable, family of curves, and developed equations for this case are presented in Appendix B. With the help of the developed Excel spreadsheet, a Monte Carlo simulation is performed with the program @Risk. The cumulative ascending distribution function for the F.S. given by @Risk is presented below as Figure 4.4. As it can be seen, the probability of unsatisfactory performance that the F.S. is less than 1.0 is equal to 75.1 percent. The fact that the probabilities of unsatisfactory performance for Analyses 1 and 2 are very similar is largely coincidental, as they model very different failure mechanisms when the blanket ends beneath the levee toe. 


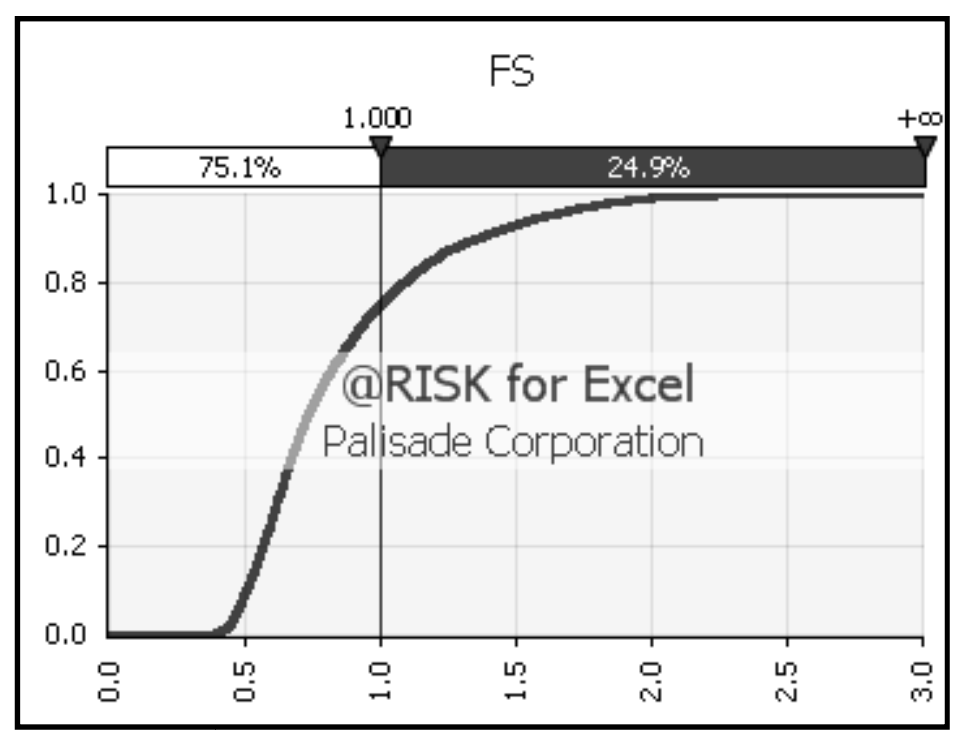

Figure 4.4 Cumulative ascending distribution function for the F.S. for Analysis 2.

\subsection{Analysis 3: FEM and Monte Carlo Simulation with Blanket Theory Assumptions}

A simple levee section was analyzed using Finite Element Analysis and Monte Carlo simulation. In order to make this analysis comparable to the First-Order SecondMoment (FOSM) Taylor Series with Blanket Theory method, the failure mechanism was assumed to be an Effective Stress Method Case (as in the Blanket Theory). It was analyzed with a closed seepage exit (no-flow boundary) on the landside boundary of the model. The geometric and soil variables involved in this example are presented in Table 4.3 and the simple levee section is shown in Figure 4.5.

The geometric variable analyzed is the thickness of the blanket " $\mathrm{H}$ " (equivalent to " $\mathrm{z}_{\mathrm{b} 1}$ " in the "FOSM - Blanket Theory" example, see Table 5.2, Section 5.2) as shown in Figure 4.1. The anisotropy ratio is not presented as a variable because the section will be analyzed assuming that the anisotropy ratio is equal to its most likely value $(\mathrm{Khv}=0.25)$ like would be done using the FOSM - Blanket Theory. Normal distributions have been 
assumed for all the input variables as would be done using the FOSM - Blanket Theory methodd. The variability of the permeabilities have been modeled assuming normal distributions of the log of the permeability values. In the spreadsheet, the antilogs of the $\log$ of the permeabilities are taken to perform the calculations. The input variable " $\gamma_{\mathrm{b}}$ " (unit weight of the blanket) is used to calculate the critical gradient and is assumed to be represented with a normal distribution.

The Excel spreadsheet, probability density function for each input variable, family of curves, and developed equations for this case are presented in Appendix C. With the help of the developed Excel spreadsheet, a Monte Carlo simulation was performed with the program @ Risk. The cumulative ascending distribution function for the F.S. given by @ Risk is presented in Figure 4.6. The probability of unsatisfactory performance (that the F.S. is less than 1.0) is equal to 20.3 percent.

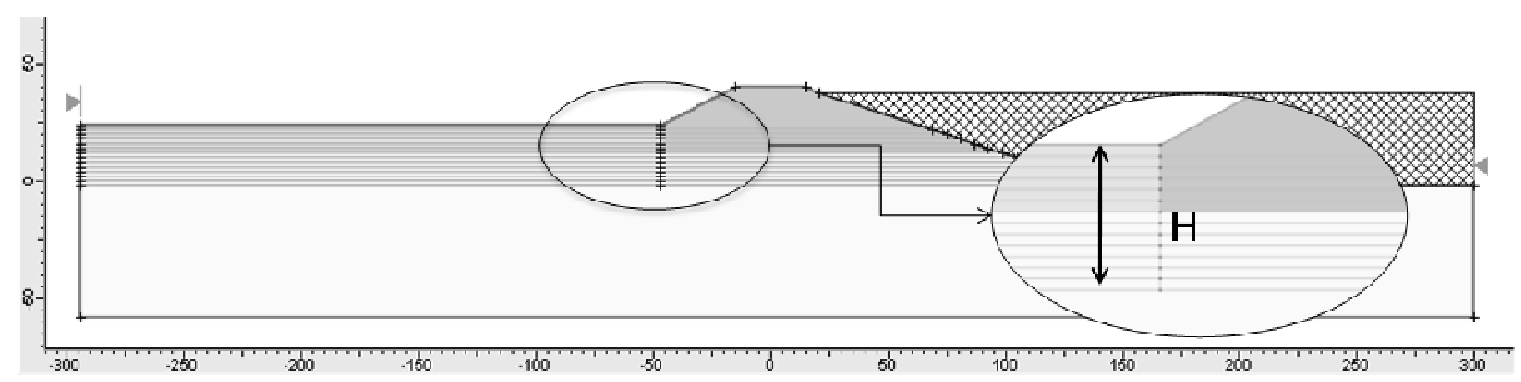

Figure 4.5 Levee section used for FEM - Monte Carlo Simulation comparison with Blanket Theory for Analysis 3.

Table 4.3 Input variables for Analysis 3

\begin{tabular}{|c|c|c|c|c|c|}
\hline Variable & MLV & $\boldsymbol{\sigma}$ & MIN & MAX & Type of distribution \\
\hline $\log (\mathrm{Kb})$ & -6.00 & 1.00 & -7.00 & -5.10 & Normal \\
$\log (\mathrm{Ks})$ & -3.00 & 1.00 & -3.80 & -2.00 & Normal \\
$\mathrm{H}$ & 14 & 8.00 & 2 & 26 & Normal \\
$\gamma_{\mathrm{b}}$ & 120 & 5.00 & 110 & 130 & Normal \\
\hline
\end{tabular}




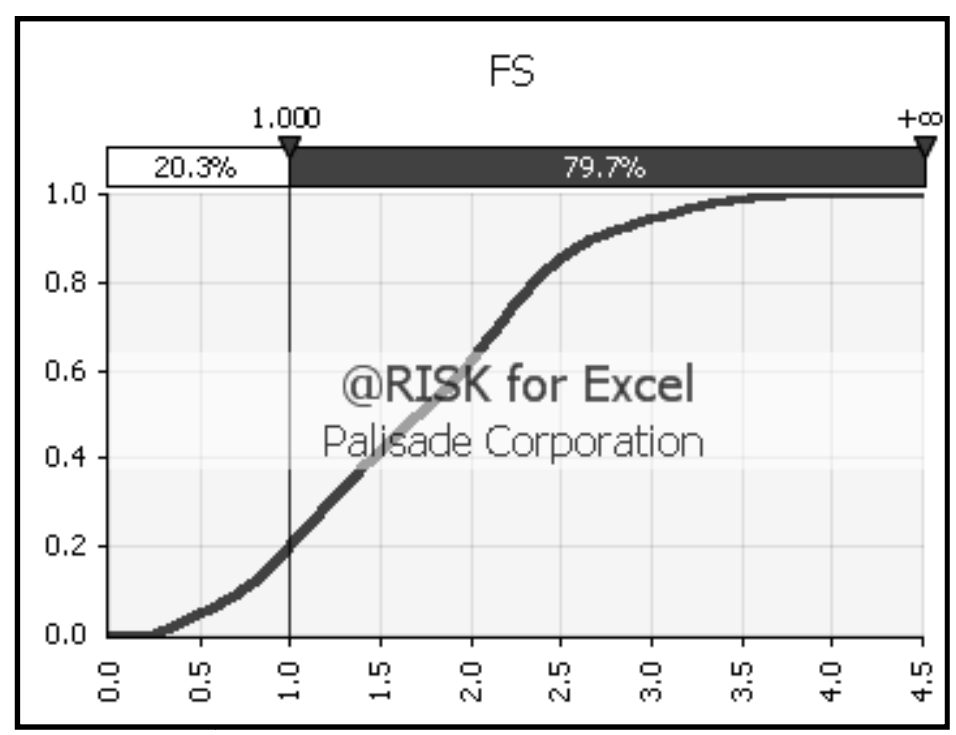

Figure 4.6 Cumulative ascending distribution function for the F.S. for Analysis 3.

\subsection{Analysis 4: Old Channel Model}

This case presents a hypothetical levee section based loosely on conditions observed within the Natomas Basin. The analysis is designed to model a buried channel or point bar in the blanket with uncertainty in the depth and location of the channel. It was analyzed using the proposed method using the Finite Element Analysis and Monte Carlo simulation. The model has a closed seepage exit (no-flow boundary) on the landside boundary of the model. The geometric and soil variables involved in this example are presented in Table 4.4 and the levee section is shown in Figure 4.7.

Two geometric variables were used to define the geometric variation of the profile: (1) the thickness of the channel "h" and, (2) the distance of the channel "d" taken from the landside of the levee to the levee itself (from left to right) as shown in Figure 4.7. The probability density function for these variables is uniform, indicating equal potential for all depths and locations of the channel within the range of possible values. 
The probability density functions of the permeabilities and unit weights are the same as used in the proposed analysis.

The failure mechanism considered is uplift of the blanket layer using the Total Stress Method. The Excel spreadsheet, probability density function for each input variable, family of curves, and developed equations for this case are presented in Appendix D. With the help of the developed Excel spreadsheet, a Monte Carlo simulation is performed with the program @ Risk. The cumulative ascending distribution function for the F.S. given by @ Risk is presented below as Figure 4.8. As it can be seen, the probability of unsatisfactory performance (that the F.S. is less than 1.0) is equal to 56.7 percent.

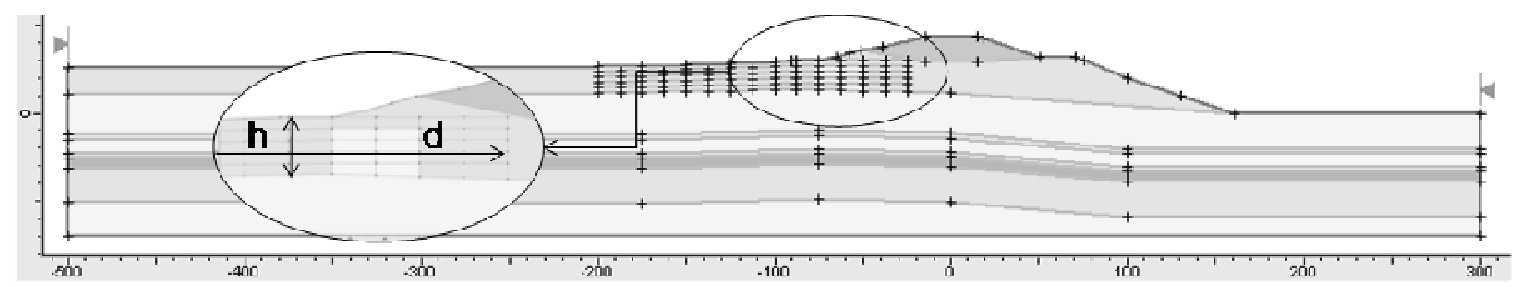

Figure 4.7 Levee section used in Analysis 4.

Table 4.4 Input variables for Analysis 4

\begin{tabular}{|c|c|c|c|c|c|}
\hline Variable & MLV & $\boldsymbol{\sigma}$ & MIN & MAX & Type of distribution \\
\hline $\log (\mathrm{Kb})$ & -6.00 & 0.67 & -7.00 & -5.10 & Normal \\
\hline $\log (\mathrm{Ks})$ & -3.00 & 0.67 & -3.80 & -2.00 & Normal \\
\hline$\gamma_{\mathrm{b}}$ & 120 & 4.80 & 110 & 130 & Normal \\
\hline $\mathrm{d}$ & - & - & 25 & 175 & Uniform \\
\hline $\mathrm{h}$ & - & - & 0 & 12 & Uniform \\
\hline
\end{tabular}




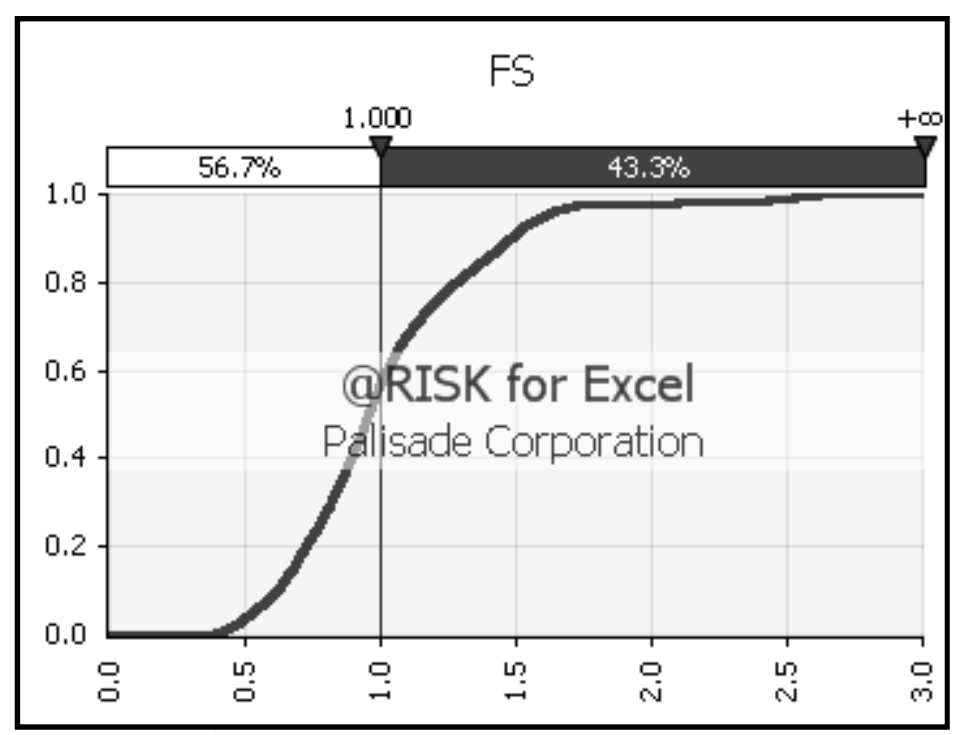

Figure 4.8 Cumulative ascending distribution function for the F.S. Analysis 4.

\section{$\underline{4.5 \text { Discussion of the Results }}$}

The objective of Analysis 1 (Section 4.1) is to demonstrate the ability of the proposed method to incorporate variability in complex geometric subsurface configurations, and assess multiple failure modes. These abilities make the proposed method more accurate when compared to the Blanket Theory with FOSM Taylor Series Method. The result of the analysis represents the probability of occurrence of a single node of an event tree that describes the chain of events that need to happen for a failure to occur.

In Analysis 2 (Section 4.2), the crack at the levee toe simulates a preexisting crack that may be the result of previous uplifting, tree root or any other source of a defect. It's the author's belief that the only way there could be erosion through the blanket is if a crack forms in the blanket. The crack could also represent the condition just following the condition in Section 4.1 (Analysis 1) where uplift of the blanket results in a crack. The fact that the probabilities of unsatisfactory performance for Analyses 1 and 2 are very 
similar is largely coincidental, as they model very different failure mechanisms when the blanket ends beneath the levee toe.

In order to make a comparison between the FOSM - Blanket Theory method and the proposed method, a simple levee section was analyzed in Section 4.3 (Analysis 3). It can be said that this is the way that the levee sections from Analyses 1 and 2 would be analyzed, using the Blanket Theory equation. From here it can be seen that the probabilities of occurrence for Analyses 1 and 2 are much larger from that in Analysis 3. As we will see in Section 4.6, the difference is due to the geometric variables, thus showing the benefits of the flexibility of the proposed method.

Analysis 4 demonstrates the flexibility of the proposed method in modeling a variety of complex geometries. The method is flexible enough to allow more than one geometric variable to be modeled. This analysis can represent uncertainty in the height of the channel or where it might be situated with respect to the levee toe.

\subsection{Analysis of Variables}

Multiple regression analyses were performed using Excel in order to assess the relative effects changes that the variables have on the F.S. for the various analyses. The functional form equation for Analysis 1 is as follows:

$$
\begin{aligned}
\log (\text { F.S. })= & \beta_{0}+\beta_{1} \log \left(\mathrm{A}^{2}\right)+\beta_{2} \log (\mathrm{Kb})+\beta_{3} \log (\mathrm{Ks}) \\
& +\beta_{4} \log (\mathrm{Khv})+\beta_{5} \log \left(\gamma_{\mathrm{b}}\right)+\beta_{6} \log \left(\gamma_{\mathrm{s}}\right)+\varepsilon_{\mathrm{i}}
\end{aligned}
$$

where $\beta_{0}$ is the F.S. intercept value in the equation, $\beta_{1}$ is the coefficient that will describe the size of the effect of $A^{2}, \beta_{2}$ is the coefficient that will describe the size of the effect of $\mathrm{Kb}, \beta_{3}$ is the coefficient that will describe the size of the effect of $\mathrm{Ks}, \beta_{4}$ is the coefficient 
that will describe the size of the effect of $\mathrm{Khv}, \beta_{5}$ is the coefficient that will describe the size of the effect of $\gamma_{b}, \beta_{6}$ is the coefficient that will describe the size of the effect of $\gamma_{s}$, and $\varepsilon_{\mathrm{i}}$ is the error term called the regression residual. It should be noted that the variable A is squared in Equation 5. This is because the plot of A values versus F.S. is shaped more like a parabola than a straight line like the other variables.

Since this is a multiple regression analysis, the coefficients tell us how much the F.S. is expected to either increase or decrease when one of the variables increases or decreases by a value of one, while holding the other variables constant. Taking this into account, all the coefficients are assumed to be positive except the coefficient $\beta_{3}$ which has been assumed negative. The summary output for the regression analysis is shown as Table 4.5.

The objective of the regression analysis is to reject the hypothesis that each variable has absolutely no effect on the F.S. In order to reject the hypothesis the P-value should be 5 percent or less and, as seen in Table 4.5, all the P-values are very small. This means that there is a probability of 1.0 that the variables have some effect on the F.S. Another way to check this will be looking at the Significance F which is the P-value of the ANOVA analysis. The terms "Lower 95\%" and "Upper 95\%" in Table 4.5 represent the confidence level intervals of the coefficients.

Notice that the assumptions made for the coefficients were correct. Even though the coefficient $\beta_{6}$ (which corresponds to $\gamma_{s}$ ) has the highest value with respect to the other coefficients, results suggest that the variable A has a greater effect in the variation of the F.S. This is due to the value of the "t Stat" which is the ratio between the coefficient and its standard error. Since the standard error is a measure of the variation of the coefficient 
Table 4.5 Regression analysis output summary for Analysis 1

\begin{tabular}{lr}
\hline \multicolumn{2}{c}{ Regression Statistics } \\
\hline Multiple R & 0.387942777 \\
R Square & 0.150499598 \\
Adjusted R Square & 0.149478768 \\
Standard Error & 0.173576551 \\
Observations & 5000 \\
\hline
\end{tabular}

ANOVA

\begin{tabular}{lccccc}
\hline & df & SS & MS & F & Significance F \\
\hline Regression & 6 & 26.6511177 & 4.44185295 & 147.42871 & $1.0188 \mathrm{E}-172$ \\
Residual & 4993 & 150.433194 & 0.03012882 & & \\
Total & 4999 & 177.084311 & & & \\
\hline
\end{tabular}

Coefficients

\begin{tabular}{|c|c|c|c|c|c|c|}
\hline & & Standard & & & & \\
\hline & Coefficients & Error & t Stat & P-value & Lower $95 \%$ & Upper $95 \%$ \\
\hline Intercept & -3.338814 & 0.423915 & -7.876138 & $4.11 \mathrm{E}-15$ & -4.169873 & -2.507754 \\
\hline $\log \left(A^{2}\right)$ & 0.222157 & 0.008685 & 25.580591 & 9.91E-136 & 0.205131 & 0.239182 \\
\hline $\log (\mathrm{Kb})$ & 0.025921 & 0.005148 & 5.035595 & 4.93E-07 & 0.015829 & 0.036012 \\
\hline $\log (\mathrm{Ks})$ & -0.033789 & 0.005368 & -6.293911 & $3.36 \mathrm{E}-10$ & -0.044313 & -0.023264 \\
\hline $\log (\mathrm{Khv})$ & 0.188550 & 0.016249 & 11.603678 & $9.76 \mathrm{E}-31$ & 0.156694 & 0.220405 \\
\hline $\log \left(\gamma_{\mathrm{b}}\right)$ & 0.376604 & 0.135428 & 2.780841 & $5.44 \mathrm{E}-03$ & 0.111105 & 0.642103 \\
\hline $\log \left(\gamma_{\mathrm{s}}\right)$ & 0.919036 & 0.146739 & 6.263060 & $4.09 \mathrm{E}-10$ & 0.631363 & 1.206709 \\
\hline
\end{tabular}

resulting from changes in the variable, it can be considered analogous to the standard deviation of a variable. Thus, the "t Stat" of a coefficient can be considered analogous to the coefficient of variation of a variable. Therefore, based on the "t Stat" value, it can be said that the geometric variable A has a greater effect in the variation of the F.S. Similar multiple regression analyses were preformed for Analyses 2 through 4. Details and results of these analyses are presented below.

The functional form equation for Analysis 2 is: 


$$
\begin{aligned}
\log (\text { F.S. })= & \beta_{0}+\beta_{1} \log \left(\mathrm{A}^{2}\right)+\beta_{2} \log (\mathrm{Kb})+\beta_{3} \log (\mathrm{Ks}) \\
& +\beta_{4} \log (\mathrm{Khv})+\beta_{5} \log \left(\gamma_{\mathrm{b}}\right)+\beta_{6} \log \left(\gamma_{\mathrm{s}}\right)+\varepsilon_{\mathrm{i}}
\end{aligned}
$$

where $\beta_{0}$ is the F.S. intercept value in the equation, $\beta_{1}$ is the coefficient that will describe the size of the effect of $A^{2}, \beta_{2}$ is the coefficient that will describe the size of the effect of $\mathrm{Kb}, \beta_{3}$ is the coefficient that will describe the size of the effect of $\mathrm{Ks}, \beta_{4}$ is the coefficient that will describe the size of the effect of Khv, $\beta_{5}$ is the coefficient that will describe the size of the effect of $\gamma_{\mathrm{b}}, \beta_{6}$ is the coefficient that will describe the size of the effect of $\gamma_{\mathrm{s}}$, and $\varepsilon_{\mathrm{i}}$ is the error term.

Table 4.6 Regression analysis output summary for Analysis 2

\begin{tabular}{|c|c|c|c|c|c|}
\hline & $\mathrm{df}$ & SS & MS & $\mathrm{F}$ & Significance $\mathrm{F}$ \\
\hline Regression & 5 & 110.818427 & 22.163685 & 5488.6361 & 0 \\
\hline Residual & 4994 & 20.1662931 & 0.0040381 & & \\
\hline Total & 4999 & 130.98472 & & & \\
\hline
\end{tabular}

\begin{tabular}{lr}
\hline \multicolumn{2}{c}{ Regression Statistics } \\
\hline Multiple R & 0.9198048 \\
R Square & 0.84604087 \\
Adjusted R Square & 0.84588673 \\
Standard Error & 0.06354608 \\
Observations & 5000 \\
\hline
\end{tabular}

Coefficients

\begin{tabular}{lcccccc}
\hline & \multicolumn{3}{c}{ Standard } & & Lower & Upper \\
& Coefficients & Error & $\mathrm{t}$ Stat & P-value & $95 \%$ & $95 \%$ \\
\hline Intercept & -5.50947 & 0.11085 & -49.70289 & 0.000000 & -5.72678 & -5.29216 \\
$\log \left(\mathrm{A}^{2}\right)$ & 0.49361 & 0.00318 & 155.30914 & 0.000000 & 0.48737 & 0.49984 \\
$\log (\mathrm{Kb})$ & 0.03066 & 0.00188 & 16.27333 & $4.65 \mathrm{E}-58$ & 0.02696 & 0.03435 \\
$\log (\mathrm{Ks})$ & -0.03104 & 0.00196 & -15.79950 & $6.58 \mathrm{E}-55$ & -0.03489 & -0.02718 \\
$\log (\mathrm{Khv})$ & 0.37235 & 0.00929 & 40.07330 & $1.01 \mathrm{E}-304$ & 0.35413 & 0.39056 \\
$\log (\mathrm{ys})$ & 1.95327 & 0.05159 & 37.86306 & $5.06 \mathrm{E}-276$ & 1.85214 & 2.05441 \\
\hline
\end{tabular}


The functional form equation for Analysis 3 is:

$$
\log (\mathrm{F} . \mathrm{S} .)=\beta_{0}+\beta_{1} \log (\mathrm{H})+\beta_{2} \log (\mathrm{Kb})+\beta_{3} \log (\mathrm{Ks})+\beta_{4} \log \left(\gamma_{\mathrm{b}}\right)+\varepsilon_{\mathrm{i}}
$$

where $\beta_{0}$ is the intercept value in the equation, $\beta_{1}$ is the coefficient that will describe the size of the effect of $\mathrm{H}, \beta_{2}$ is the coefficient that will describe the size of the effect of $\mathrm{Kb}$, $\beta_{3}$ is the coefficient that will describe the size of the effect of Ks, $\beta_{4}$ is the coefficient that will describe the size of the effect of $\gamma_{b}$, and $\varepsilon_{i}$ is the error term.

Table 4.7 Regression analysis output summary for Analysis 3

\begin{tabular}{lr}
\hline \multicolumn{2}{c}{ Regression Statistics } \\
\hline Multiple R & 0.99325912 \\
R Square & 0.98656368 \\
Adjusted R Square & 0.986558303 \\
Standard Error & 0.027174426 \\
Observations & 10000 \\
\hline
\end{tabular}

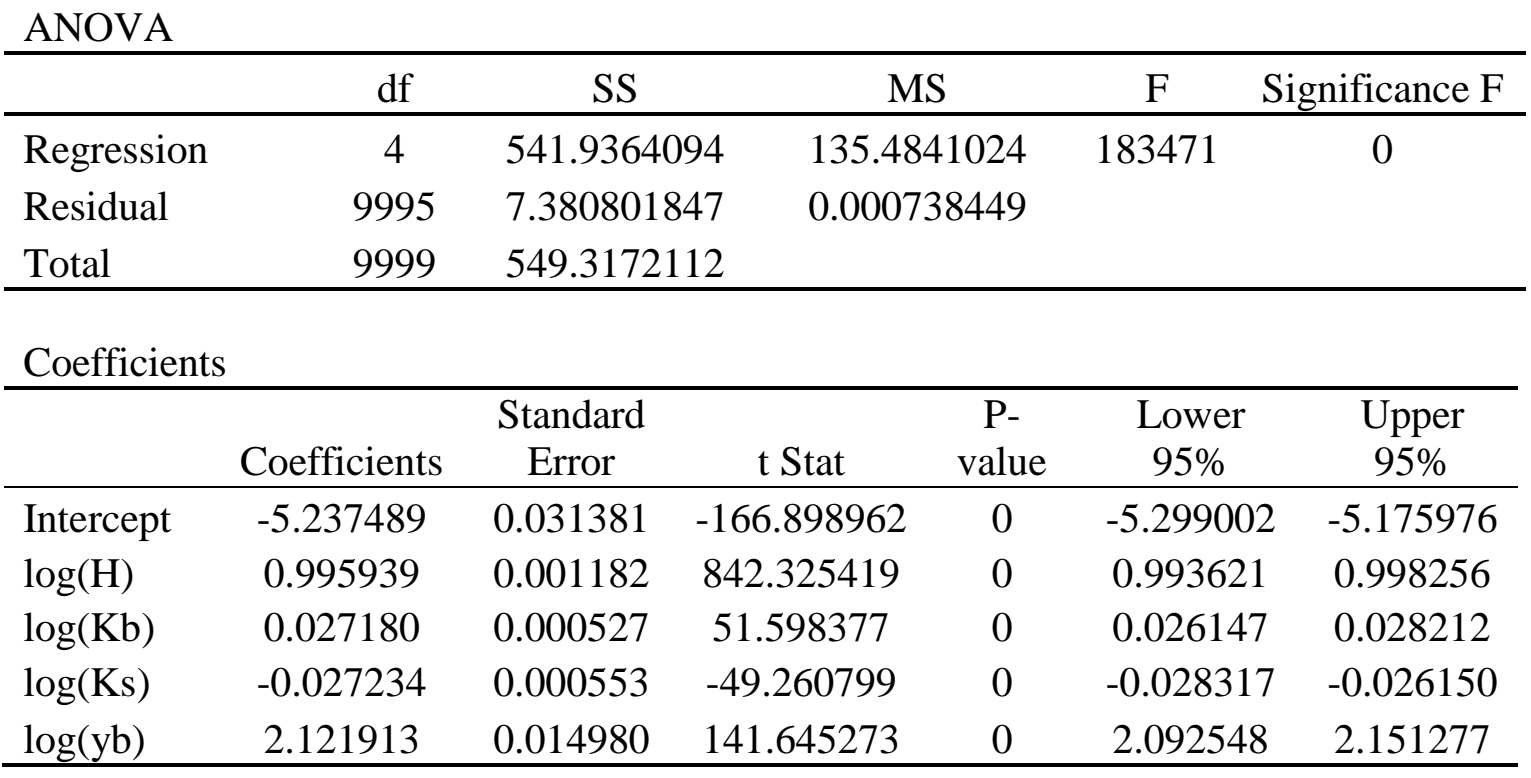


The functional form equation for Analysis 4 is:

$$
\begin{aligned}
\log (\text { F.S. })= & \beta_{0}+\beta_{1} \log (d)+\beta_{2} \log (\mathrm{h})+\beta_{3} \log \left(\gamma_{\mathrm{b}}\right) \\
& +\beta_{4} \log (\mathrm{Kb})+\beta_{5} \log (\mathrm{Ks})+\varepsilon_{\mathrm{i}}
\end{aligned}
$$

where $\beta_{0}$ is the intercept value in the equation, $\beta_{1}$ is the coefficient that will describe the size of the effect of $d, \beta_{2}$ is the coefficient that will describe the size of the effect of $h, \beta_{3}$ is the coefficient that will describe the size of the effect of $\gamma_{b}, \beta_{4}$ is the coefficient that will describe the size of the effect of $\mathrm{Kb}, \beta_{5}$ is the coefficient that will describe the size of the effect of Ks, and $\varepsilon_{\mathrm{i}}$ is the error term.

Table 4.8 Regression analysis output summary for Analysis 4

\begin{tabular}{lr}
\hline \multicolumn{2}{c}{ Regression Statistics } \\
\hline Multiple R & 0.81296703 \\
R Square & 0.6609154 \\
Adjusted R Square & 0.6605759 \\
Standard Error & 0.0869201 \\
Observations & 5000 \\
\hline
\end{tabular}

ANOVA

\begin{tabular}{lccccc}
\hline & df & SS & MS & F & Significance F \\
\hline Regression & 5 & 73.5405269 & 14.708105 & 1946.77755 & 0 \\
Residual & 4994 & 37.7301856 & 0.0075551 & & \\
Total & 4999 & 111.270712 & & & \\
\hline
\end{tabular}

Coefficients

\begin{tabular}{lcccccc}
\hline & & Standard & & Lower & Upper \\
& Coefficients & Error & t Stat & P-value & $95 \%$ & $95 \%$ \\
\hline Intercept & -1.07811 & 0.14834 & -7.26784 & $4.22 \mathrm{E}-13$ & -1.368917 & -0.787296 \\
$\log (\mathrm{d})$ & -0.38426 & 0.00551 & -69.69998 & $0.00 \mathrm{E}+00$ & -0.395068 & -0.373452 \\
$\log (\mathrm{h})$ & -0.13563 & 0.00282 & -48.07798 & $0.00 \mathrm{E}+00$ & -0.141165 & -0.130103 \\
$\log (\mathrm{yb})$ & 1.04505 & 0.07067 & 14.78806 & $1.83 \mathrm{E}-48$ & 0.906507 & 1.183590 \\
$\log (\mathrm{Kb})$ & 0.09131 & 0.00258 & 35.42137 & $2.21 \mathrm{E}-245$ & 0.086258 & 0.096365 \\
$\log (\mathrm{Ks})$ & -0.09278 & 0.00269 & -34.52966 & $1.71 \mathrm{E}-234$ & -0.098048 & -0.087512 \\
\hline
\end{tabular}


A summary output for each Analysis is presented as Table 4.9. Results from the regression analyses show that the "t Stat" for the geometric variables $(\mathrm{A}, \mathrm{H}, \mathrm{d}$, and $\mathrm{h}$ ) are always greater than the other variables, therefore, it demonstrates that the geometric variables have a significant effect on the probability of underseepage related failure.

Table 4.9 Summary of "t Stat" values for all analyses (geometric variables in bold type)

\begin{tabular}{lcccc}
\hline & Analysis 1 & Analysis 2 & Analysis 3 & Analysis 4 \\
\hline $\log \left(\mathrm{A}^{2}\right)$ & $\mathbf{2 5 . 5 8 0 5 9}$ & $\mathbf{1 5 5 . 3 0 9 1 4}$ & - & - \\
$\log (\mathrm{Kb})$ & 5.03559 & 16.27333 & 51.59838 & 35.42137 \\
$\log (\mathrm{Ks})$ & -6.29391 & -15.79950 & -49.26080 & -34.52966 \\
$\log (\mathrm{Khv})$ & 11.60368 & 40.07330 & - & - \\
$\log (\mathrm{yb})$ & 2.78084 & - & 141.64527 & 14.78806 \\
$\log (\mathrm{ys})$ & 6.26306 & 37.86306 & - & - \\
$\log (\mathrm{H})$ & - & - & $\mathbf{8 4 2 . 3 2 5 4 2}$ & - \\
$\log (\mathrm{d})$ & - & - & - & $\mathbf{- 6 9 . 6 9 9 9 8}$ \\
$\log (\mathrm{h})$ & - & - & - & $\mathbf{- 4 8 . 0 7 7 9 8}$ \\
\hline
\end{tabular}




\section{CHAPTER 5}

\section{COMPARISON WITH OTHER METHODS}

This chapter presents a comparison between the analysis and results of the deterministic Factor of Safety method, the FOSM - Blanket Theory method and, the proposed FEM - Monte Carlo Simulation method.

For comparison purposes, the same levee section that was used in Analysis 3 (Section 4.3) is re-analyzed using the deterministic F.S. and FOSM - Blanket Theory. The goal is to demonstrate agreement between the FOSM - Blanket Theory method and the proposed method, and show the limitations of these methods.

\section{$\underline{5.1 \text { Deterministic Factor of Safety Analysis }}$}

A deterministic F.S. was calculated for the levee section used for the analysis using the proposed method in Section 4.3 (see Analysis 3, Figure 4.5) for comparison purposes between the methods. Finite Element Analysis was used to calculate the exit gradient in the blanket ( $\mathrm{i}_{\mathrm{e}}$ BLANKET) using the most likely values of the permeabilities, anisotropy ratio and thickness of the blanket layer. The most likely value of the unit weight of the blanket was used to calculate the critical gradient $\left(\mathrm{i}_{\mathrm{c}}\right)$. A summary input and results are presented as Table 5.1. The exit gradient, $\mathrm{i}_{\mathrm{e}}$ BLANKET, can be found in Appendix C, Table C.1. 
Table 5.1 Summary input and output for the deterministic F.S. analysis

\begin{tabular}{|l|r|}
\hline $\mathrm{Kb}$ & $6.48 \mathrm{E}-06 \mathrm{ft} / \mathrm{s}$ \\
\hline $\mathrm{Ks}$ & $1.03 \mathrm{E}-03 \mathrm{ft} / \mathrm{s}$ \\
\hline $\mathrm{KhV}$ SAND & 0.25 \\
$\mathrm{H}$ & $14.00 \mathrm{ft}$ \\
$\gamma_{\mathrm{b}}$ & $120 \mathrm{pcf}$ \\
\hline $\mathrm{i}_{\mathrm{e}}$ BLANKET & 0.532 \\
$\mathrm{i}_{\mathrm{c}}$ & 0.923 \\
\hline F.S. & 1.735 \\
\hline
\end{tabular}

It is obvious that calculations for the deterministic F.S. are very easy and straight forward however, it only provides a design margin for one level of reliability. The calculations do not take into account the uncertainty and variability of the input variables. The deterministic F.S. for this case is equal to 1.7. If the deterministic F.S. would be the only method taken into account to assess underseepage, it would probably not be acceptable since it is lower than 3.0 which is the F.S. considered acceptable.

Recalling the result of Analysis 3, the probability of unsatisfactory performance (that the F.S. is less than 1.0) is equal to 20.3 percent using FEM - Monte Carlo Simulation. This figure has been re-arranged to show that the probability of unsatisfactory performance (that the F.S. is less than 1.7) is equal to 50.4 percent (see Figure 5.1); a predictable result considering the F.S. was calculated using the most likely values of the variables. 


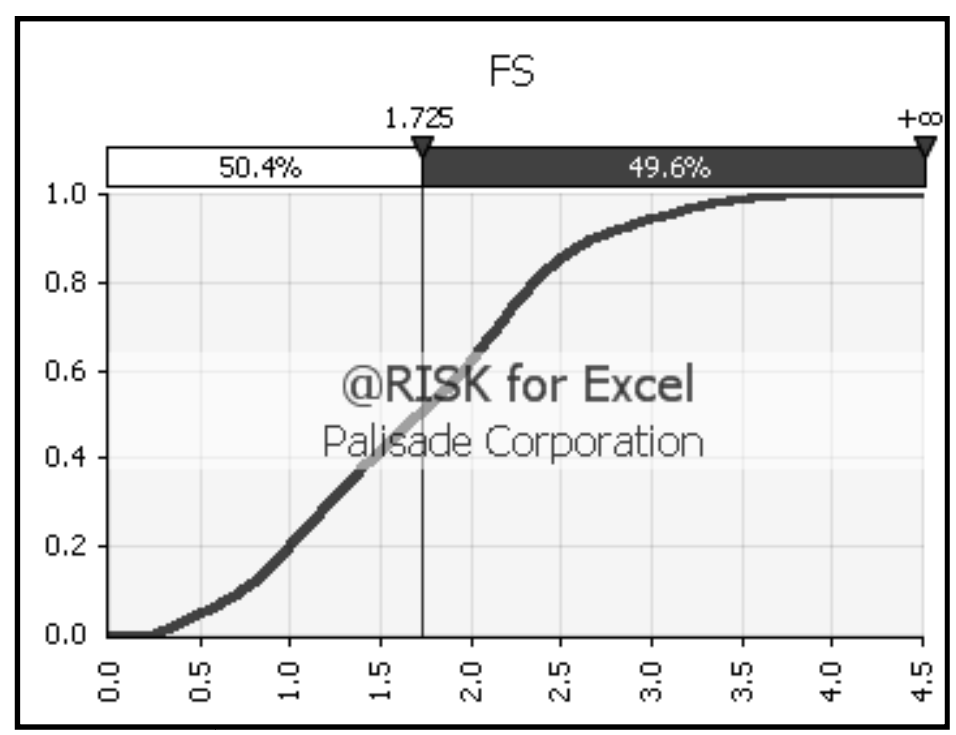

Figure 5.1 Cumulative ascending distribution function for the deterministic F.S.

\section{$\underline{5.2}$ FOSM - Blanket Theory Simulation}

Using the levee section analyzed in Section 4.3 (Analysis 3), a reliability-based analysis was performed using the FOSM - Blanket Theory method. The levee section from Section 4.3 is simplified so that the Blanket Theory equations can be applied with no further simplifications. This allows a direct comparison of the results between the proposed method and the FOSM - Blanket Theory method.

The Blanket Theory levee configuration is presented in Figure 5.2. The uncertain input variables are the blanket thickness $\left(\mathrm{z}_{\mathrm{bl}}\right)$, the foundation sand thickness (d), the vertical permeability of the top stratum (blanket) $\left(\mathrm{k}_{\mathrm{bl}}\right)$ and, the horizontal permeability of the pervious substratum (sand) $\left(\mathrm{k}_{\mathrm{f}}\right)$. 


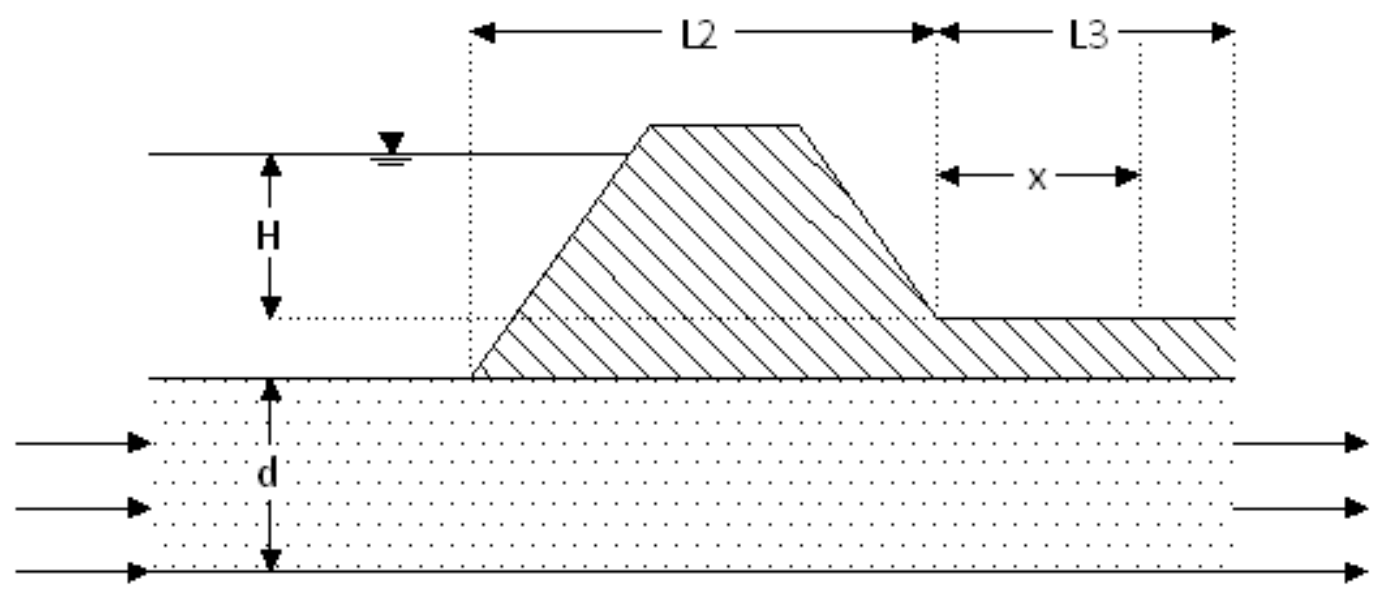

Figure 5.2 Case 4 of the Blanket Theory.

This analysis was performed using the closed form equation used in EM-1110-21913 (USACE, 2000) and an Excel Spreadsheet (shown as Table 5.2) was developed in order to make the calculations. The analysis of the F.S. using the most likely values for each variable resulted in a F.S. of 1.68 as noted in Table 5.2. In this case, since four uncertain variables have been chosen, nine calculations $(2 \mathrm{~N}+1)$ will be needed. Analyses are then made by using each variable by plus and minus one standard deviation while holding the other variables constant. These calculations are presented in Table 5.3. The probability of unsatisfactory performance based on this analysis is equal to 24 percent.

From Analysis 3 (Section 4.3), the probability of unsatisfactory performance (that the F.S. is less than 1.0) is equal to 20.3 percent. The results for both methods are very close. It is the authors' belief that the FOSM with Blanket Theory method gives a higher $\mathrm{P}_{(\mathrm{u})}$ because it only considers the mean and standard deviation of the variables instead of taking into account the full probability density function of all the variables as the FEM Monte Carlo method does (Analysis 3). 
Table 5.2 Analysis of levee section with MLV by Blanket Theory

\begin{tabular}{|c|c|c|c|}
\hline Parameter & Symbol & Value & Unit \\
\hline Net head on levee & $\mathrm{H}$ & 14 & $\mathrm{ft}$ \\
\hline Transformed thickness of landside top stratum & $\mathrm{z}_{\mathrm{bl}}$ & 14 & $\mathrm{ft}$ \\
\hline Thickness of pervious substratum & $\mathrm{d}$ & 60 & $\mathrm{ft}$ \\
\hline Horizontal permeability of pervious substratum & $\mathrm{k}_{\mathrm{f}}$ & $3.96 \mathrm{E}-02$ & $\mathrm{~cm} / \mathrm{s}$ \\
\hline Base width of levee and berm & $\mathrm{L}_{2}$ & 176 & $\mathrm{ft}$ \\
\hline Length of foundation and top stratum beyond landside levee toe & $\mathrm{L}_{3}$ & 247 & $\mathrm{ft}$ \\
\hline Horizontal permeability of top stratum & $\mathrm{k}_{\mathrm{bl}}$ & $6.48 \mathrm{E}-06$ & $\mathrm{ft} / \mathrm{s}$ \\
\hline Permeability ratio & $\mathrm{k}_{\mathrm{v}} / \mathrm{k}_{\mathrm{h}}$ & 0.25 & - \\
\hline Vertical permeability of top stratum & $\mathrm{k}_{\mathrm{bl}}$ & 8.42E-09 & $\mathrm{ft} / \mathrm{s}$ \\
\hline Horizontal permeability of pervious substratum & $\mathrm{k}_{\mathrm{f}}$ & $1.30 \mathrm{E}-03$ & $\mathrm{ft} / \mathrm{s}$ \\
\hline Factor & $\mathrm{c}$ & $8.78 \mathrm{E}-05$ & - \\
\hline Distance from landside levee toe to effective seepage exit & $\mathrm{x}_{3}$ & 247 & $\mathrm{ft}$ \\
\hline Distance from riverside levee toe to river & $\mathrm{L}_{1}$ & 0 & $\mathrm{ft}$ \\
\hline Distance from effective seepage entry to riverside levee toe 1 & $\mathrm{x}_{1}$ & 0 & $\mathrm{ft}$ \\
\hline Slope of hydraulic grade line beneath levee ${ }^{1}$ & $\mathrm{M}$ & 0.033 & - \\
\hline Shape factor & $\$$ & 0.13 & - \\
\hline Total amount of seepage passing beneath the levee & $\mathrm{Q}_{\mathrm{s}}$ & 1,669 & $\mathrm{gpd} / \mathrm{ft}$ \\
\hline Head beneath top stratum at landside levee toe & $\mathrm{h}_{\mathrm{o}}$ & 7.7 & $\mathrm{ft}$ \\
\hline Distance from landside levee toe & $\mathrm{x}$ & 0 & $\mathrm{ft}$ \\
\hline Head beneath top stratum at distance $\mathrm{x}$ from landside levee toe & $\mathrm{h}_{\mathrm{x}}$ & 7.7 & $\mathrm{ft}$ \\
\hline Upward gradient at landside toe of levee & $\mathrm{i}_{\mathrm{o}}$ & 0.55 & - \\
\hline Submerged unit weight of top stratum material & $\mathrm{g}_{\mathrm{z}}{ }^{\prime}$ & 57.6 & pcf \\
\hline Calculated Factor of Safety at levee toe & $\mathbf{F}_{\mathbf{0}}$ & 1.68 & - \\
\hline
\end{tabular}

On the other hand, notice that there is also agreement in that the blanket thickness, $\mathrm{z}_{\mathrm{bl}}$ which is the geometric variable $\mathrm{H}$ in Analysis 3, Section 4.3), has the greatest effect in the variation of the F.S. With the FEM - Monte Carlo analysis, the variable A has the greatest $\mathrm{t}$ Stat value. Likewise, in the FOSM - Blanket Theory method, the blanket thickness $\mathrm{z}_{\mathrm{bl}}$, has the greatest $\Delta \mathrm{F}$ value. 
Table 5.3 FOSM Taylor Series method for levee section with Blanket Theory

\begin{tabular}{|c|c|c|c|}
\hline Variable & Values & F.S. & $\Delta \mathbf{F}$ \\
\hline \multicolumn{4}{|l|}{ Blanket thickness $\left(\mathrm{z}_{\mathrm{bl}}\right)$} \\
\hline $\mathrm{MLV}+\sigma$ & $22 \mathrm{ft}$ & $\mathrm{F} 1+2.636$ & \multirow{2}{*}{1.917} \\
\hline MLV - $\sigma$ & $6 \mathrm{ft}$ & $\mathrm{F} 1+0.719$ & \\
\hline \multicolumn{4}{|l|}{ Foundation sand thickness (d) } \\
\hline $\mathrm{MLV}+\sigma$ & $80 \mathrm{ft}$ & $\mathrm{F} 2+1.709$ & \multirow{2}{*}{0.064} \\
\hline MLV - $\sigma$ & $40 \mathrm{ft}$ & $\mathrm{F} 2+1.645$ & \\
\hline \multicolumn{4}{|l|}{ Horizontal permeability of sand $\left(\mathrm{k}_{\mathrm{f}}\right)$} \\
\hline MLV $+\sigma$ & $3.96 \mathrm{E}-01 \mathrm{~cm} / \mathrm{s}$ & $\mathrm{F} 3+1.677$ & \multirow{2}{*}{0.000} \\
\hline MLV - $\sigma$ & $3.96 \mathrm{E}-03 \mathrm{~cm} / \mathrm{s}$ & $\mathrm{F} 3+1.677$ & \\
\hline \multicolumn{4}{|l|}{ Horizontal permeability of blanket $\left(\mathrm{k}_{\mathrm{bl}}\right)$} \\
\hline$M L V+\sigma$ & $6.48 \mathrm{E}-05 \mathrm{ft} / \mathrm{s}$ & $\mathrm{F} 4+1.678$ & \multirow{2}{*}{0.001} \\
\hline MLV - $\sigma$ & $6.48 \mathrm{E}-07 \mathrm{ft} / \mathrm{s}$ & $\mathrm{F} 4+1.677$ & \\
\hline \multicolumn{2}{|c|}{ With all variables assigned with their most likely values } & \multicolumn{2}{|c|}{ F.S. $=1.68$} \\
\hline & & \multicolumn{2}{|c|}{$\sigma_{\mathrm{FS}}=\mathbf{0 . 9 5 9}$} \\
\hline & & \multicolumn{2}{|c|}{$\mathrm{COV}_{\mathrm{FS}}=57 \%$} \\
\hline & & \multicolumn{2}{|c|}{$\beta=0.706$} \\
\hline & & \multicolumn{2}{|c|}{$P_{(u)}=24.00 \%$} \\
\hline
\end{tabular}




\section{CHAPTER 6}

\section{SUMMARY AND CONCLUSIONS}

Current methods for analyzing the likelihood of levee failure due to underseepage consist of calculating Factors of Safety based on the ratio of the critical gradients of the soil and hydraulic exit gradients. Probabilistic methods have been applied to the exit gradient approach using the U.S. Army Corps of Engineers "Blanket Theory" equation along with the First Order-Second Moment Taylor Series Method (FOSM). These methods do not reflect a realistic state of nature of the levees and the uncertainty associated with their performance. They force the uncertainty variables to be either a normal or lognormal distribution and, limit the levee geometry to a very simplified case.

A new method is proposed that models the erosion process with a more accurate failure mechanism, allows the incorporation of more complex subsurface geometry and uses a Monte Carlo simulation for the reliability analysis. Four analyses were presented to demonstrate the ability of the proposed method.

In Analysis 1, two possible failure mechanisms were considered: 1) piping of sand at the ground surface where the blanket ends before the levee toe and, 2) where the blanket ends below the levee, uplift and cracking of the blanket layer followed by subsequent erosion of the underlying sand. For the first mechanism, the piping potential was analyzed using the Effective Stress Method and, for the second mechanism, the Total Stress Method was used. The result of the analysis represents the probability of the blanket layer heaving, a critical step in the event tree that needs to happen for a failure to occur. 
Analysis 2 used a similar profile to that used in Analysis 1, only with a crack through the blanket layer at the levee toe. The erosion was modeled solely with the Effective Stress Method as described in the proposed methodology. In contrast to the Blanket Theory, the calculated exit gradient $\left(\mathrm{i}_{\mathrm{e}}\right)$ was measured in the sand at the base of the crack (and not at the blanket). The crack at the levee toe simulates a preexisting defect due to a rotting tree root, rodent burrow or other defect. It could also represent the condition just following the condition in Analysis 1 where uplift of the blanket results in the crack. The fact that the probabilities of unsatisfactory performance for Analyses 1 and 2 are very similar is largely coincidental, as they model very different failure mechanisms when the blanket ends beneath the levee toe.

Analysis 3 modeled a levee section to reflect the simplifying assumptions required by the Blanket Theory method. This model was analyzed using the FEM Monte Carlo Simulation method so the results could be compared with a FOSM - Blanket Theory method analysis on the same model. The results for both methods were very close (probabilities of failure between 20.3 and 24.0). This comparison shows that the proposed method gives similar results to the FOSM - Blanket Theory method. The FOSM Blanket Theory method gives a higher $\mathrm{P}_{(\mathrm{u})}$ because it only considers the mean and standard deviation of the variables instead of taking into account the full probability density function of all the variables as the FEM - Monte Carlo method does (Analysis 3).

Analysis 4 presents a hypothetical levee section based loosely on conditions observed within the Natomas Basin. The analysis is designed to model a buried channel or point bar in the blanket with uncertainty in the depth and location of the channel. The 
failure mechanism considered was uplift of the blanket layer using the Total Stress Method.

In order to assess the relative effects changes that the variables have on the F.S. for the various analyses, multiple regression analyses were performed using Excel. Results from the regression analyses show that the "t Stat" for the geometric variables (A, $\mathrm{H}, \mathrm{d}$, and $\mathrm{h}$ ) are always greater compared to the other variables, demonstrating that the geometric variables have greater effect on the probability of underseepage failure.

The new method is capable of analyzing both mechanisms (Effective Stress Method and Total Stress Method) in one analysis. The proposed method considers the probability density function of all the variables contrary to the FOSM Taylor Series and Blanket Theory method that only takes into account the mean and standard deviation of the variables. It also applies FEM analysis instead of a closed-form solution (such as that used in the Blanket Theory method) which allows the method to incorporate the effects of more complex subsurface geometry. The Monte Carlo simulation is performed by means of the @ Risk program allowing the analyst to assume any type of distribution deemed appropriate for the input variables.

The result of the analyses represents the probability of initiating erosion given a river flood level, hence, it is only the first phase in the development of the process of piping and it represents one node of an event tree that describes the chain of events that need to happen for a piping failure to occur. In order to assess failure, other points in the event tree will need to be assessed with calculations or by judgment.

One of the shortfalls of the proposed method is that it can be labor intensive. Depending on how many variables are desired to be modeled in the levee profile analysis, 
the analysis can be performed in within a week. Recording either the exit gradient or pore pressure, developing the family of curves and, developing the equations can take between 2 or 3 days. The Excel spreadsheet can take between 1 or 2 days depending on how big the macro is. The @ Risk simulation does not take long.

Automation of the method may help to address this problem, but for now, as it is, it is useful for developing understanding the effects of complex levee geometry and failure mechanisms on levee reliability. 


\section{REFERENCES}

Baecher, Gregory B., and Christian, John T. 2003. Reliability and statistics in geotechnical engineering, John Wiley \& Sons Ltd, Chichester, England. 605 p.

Bartoszyński, Robert and Niewiadomska-Bugaj, Magdalena. 2008. Probability and Statistical Inference. John Wiley \& Sons Ltd, Hoboken, New Jersey. 647 p.

Boyle, Alan. 2006. Next New Orleans may be in California: Sacramento-San Joaquin Delta cited as 'scariest spot' for flooding. NBC. Retrieved January 16, 2009, from http://www.msnbc.msn.com/id/11427817/

California Department of Conservation. 2007. A brief history of the Natomas Basin. State of California. Retrieved January 16, 2009, from http://www.conservation.ca.gov/ dlrp/fmmp/trends/TimeSeriesImg/Pages/Sacramento_natomas.aspx

California Planning and Development Report. 2008. A \$400 million flood control project to protect Sacramento's Natomas Basin has been approved by the Sacramento Area Flood Control Authority. Article Archives. Retrieved January 16, 2009, from http://www.articlearchives.com/environment-natural-resources/land-usedevelopment/1562685-1.html

Crum, Douglas A. 1996. Reliability applied to levee seepage analysis. Probabilistic Mechanics and Structural Reliability: American Society of Civil Engineers (ASCE) Proceedings of the Seventh Specialty Conference, March, 1996, Worcester, Massachusetts, 1:946-949.

DeGroot, Morris H. 1975. Probability and Statistics. Addison-Wesley Publishing Company, Inc., Philippines. 624 p.

Devore, Jay L. 2000. Probability and statistics for Engineering and the Sciences. Duxbury Thomson Learning, Belmont, California. 775 p.

Duncan, Michael J. 2000. Factors of safety and reliability in geotechnical engineering. Journal of Geotechnical and Geoenvironmental Engineering, 126(4):307-316.

Dredge used in the Natomas Levees. Original construction method. Retrieved November 10, 2009, from http://sunsite.berkeley.edu/FindingAids/dynaweb/calher/rice/ figures/I0027755A.jpg

Fenton, D.V., and Griffiths, G.A. 2008. Risk assessment in geotechnical engineering. John Wiley \& Sons, Inc., Hoboken, New Jersey. 461 p.

Foster, M. and Fell, R. 2008. Risk Analysis for Dam Safety: A Unified Method for Estimating Probabilities of Failure of Embankment Dams by Internal Erosion and Piping. A report prepared for U.S. Department of the Interior Bureau of Reclamation, U.S. Army Corps of Engineers, URS, UNSW. 
Guy, Erich D., Carter, Sean C., Navin, Michael P., and Robinette, Michael D. 2007. Probabilistic stability analyses and remedial design concept for Bolivar Dam. Ohio River Valley Soils Seminar XXXVIII Proceedings: Civil Infrastructure and the role of Geotechnical Engineering, Louisville, Kentucky, 5-1 to 5-17.

Haldar, A., and Mahadevan, S. 2000. Probability, reliability and statistical methods in engineering design. John Wiley \& Sons, Inc., New York. 304 p.

Halpin, E., and Ferguson, K. 2007. US Army Corps of Engineers Dam Safety Program: Status and lessons in transitioning to risk informed approaches. Journal of Dam Safety 5(2):1-12.

Harr, M. E. 1987. Reliability-based design in civil engineering. McGraw-Hill, Inc., New York. 290 p.

Hartford, Desmond N.D., and Baecher, Gregory B. 2007. Risk and uncertainty in dam safety. Thomas Telford Publishing, London. 416 p.

Holtz, R. and Kovacs, W., 1981. An introduction to geotechnical engineering, Prentice Hall, Inc., Upper Saddle River, New Jersey. 733 p.

Mansur, C., Postol, G., and Salley, J.R. 2000. Performance of relief well systems along Mississippi river levees. Journal of Geotechnical and Environmental Engineering, 126(8):727-738.

McCook, Danny. 2007. A discussion of uplift computations for embankments and levees. Journal of Dam Safety, 5(1):1-9.

Modarres, M. 1993. What every engineer should know about reliability and risk analysis. Marcel Dekker, Inc., New York. 350 p.

Natomas Levee Construction by hydraulic fill method. Retrieved November 10, 2009, from http://sunsite.berkeley.edu/FindingAids/dynaweb/calher/rice/figures/ I0027756A.jpg

Phoon, Kok-Kwang. 2008. Reliability-based design in geotechnical engineering: Computations and Applications. Taylor and Francis Publishing, New York. 532 p.

Sacramento Area Flood Control Agency, SAFCA 2008a. Flood History / Overview. Retrieved January 16, 2009, from http://www.safca.org/floodrisk/index.html

Sacramento Area Flood Control Agency, SAFCA 2008b. Mission Statement \& About SAFCA. Retrieved January 16, 2009, from http://www.safca.org/

Sleep, Matthew, and Duncan, Michael J. 2008. Manual for geotechnical engineering reliability. Report of a study performed by the Virginia Tech Center for Geotechnical Practice and Research. Blacksburg, Virginia. 123 p. 
URS. 2007. Guidance Document for Geotechnical Analysis, Version 5: Urban levee geotechnical evaluation program. Document prepared for California Department of Water Resources. United States Army Corps of Engineers. Sacramento District, California.

URS. 2005. Final Geotechnical Report - Volume 2: Natomas general reevaluation report. American River watershed project (common features). United States Army Corps of Engineers. Sacramento District, California.

USACE. 2000. Design and Construction of Levees EM 1110-2-1913. Department of the Army, United States Army Corps of Engineers. Washington, District of Columbia.

USACE. 2005. ETL 1110-2-569, Engineering and Design: Design guidance for levee under seepage. Department of the Army, United States Army Corps of Engineers. Washington, District of Columbia.

USACE. 2007. Geotechnical Risk-Base Analysis for the Existing Condition, Natomas flood control project, levee system. United States Army Corps of Engineers, Sacramento District, California.

Wolff, D. 2008. Reliability of levee systems, p. 448-496. in Kok-Kwang Phoon (Ed.). Reliability-based design in geotechnical engineering. Taylor \& Francis Group, New York.

Wolff, T.F., Demsky, E.C., Schauer, J., and Perry, E. 1996. Reliability assessment of dike and levee embankments. American Society of Civil Engineers Geotechnical Special Publication 1:636-650. 
APPENDICES 
Appendix A. Analysis 1 
Table A.1 Exit gradient $\mathrm{i}_{\mathrm{e} \text { SAND }}$ as a function of $\mathrm{A}, \mathrm{Ksb}$ and $\mathrm{Khv}=0.50$

\begin{tabular}{|c|c|c|c|c|c|}
\hline & \multicolumn{5}{|c|}{$\mathbf{i}_{\mathbf{e} \text { SAND }}$} \\
\hline $\mathbf{A}$ & $\mathbf{K s b}=\mathbf{2 0}$ & $\mathbf{K s b}=\mathbf{6 5}$ & $\mathbf{K s b}=\mathbf{2 0 0}$ & $\mathbf{K s b}=\mathbf{1 3 0 0}$ & $\mathbf{K s b}=\mathbf{1 3 0 0 0}$ \\
\hline $\mathbf{- 7 6}$ & 0.419 & 0.439 & 0.453 & 0.462 & 0.463 \\
\hline $\mathbf{- 6 8 . 7 5}$ & 0.441 & 0.472 & 0.493 & 0.505 & 0.507 \\
\hline $\mathbf{- 6 1 . 5}$ & 0.479 & 0.532 & 0.566 & 0.585 & 0.588 \\
\hline $\mathbf{- 5 4 . 2 5}$ & 0.554 & 0.653 & 0.715 & 0.75 & 0.757 \\
\hline $\mathbf{- 4 7}$ & 0.844 & 1.246 & 1.517 & 1.679 & 1.709 \\
\hline
\end{tabular}

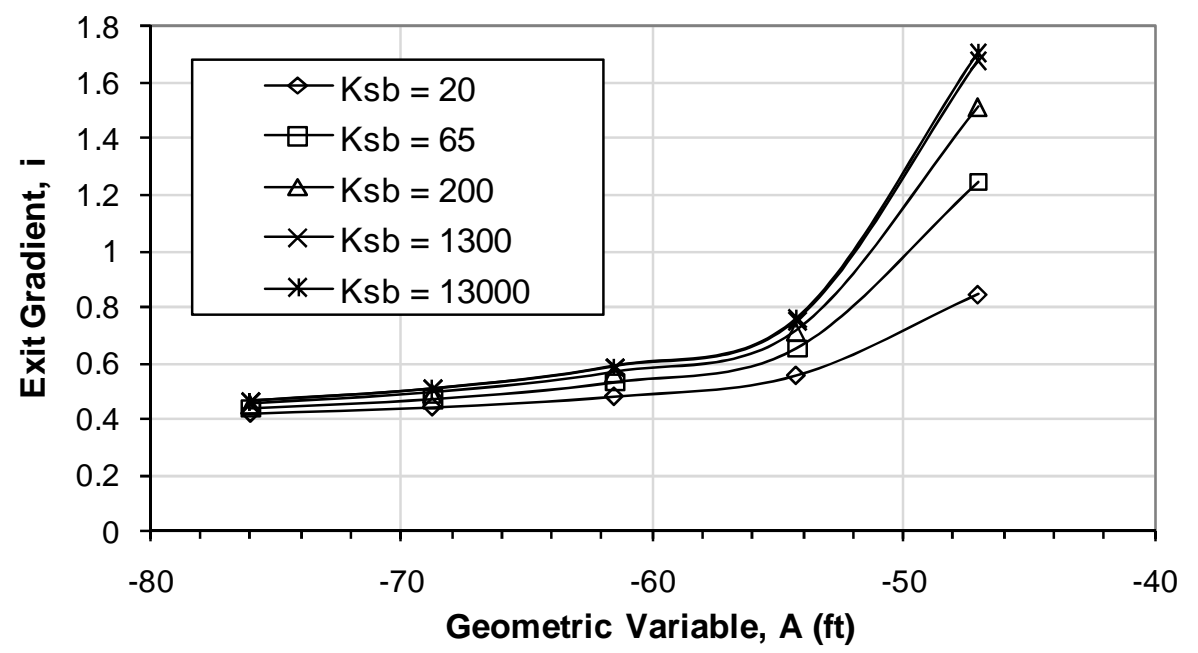

Figure A.1 Family of curves representing relationship of $\mathrm{i}_{\mathrm{e} S A N D}, \mathrm{~A}, \mathrm{Ksb}$ and, Khv $=0.50$.

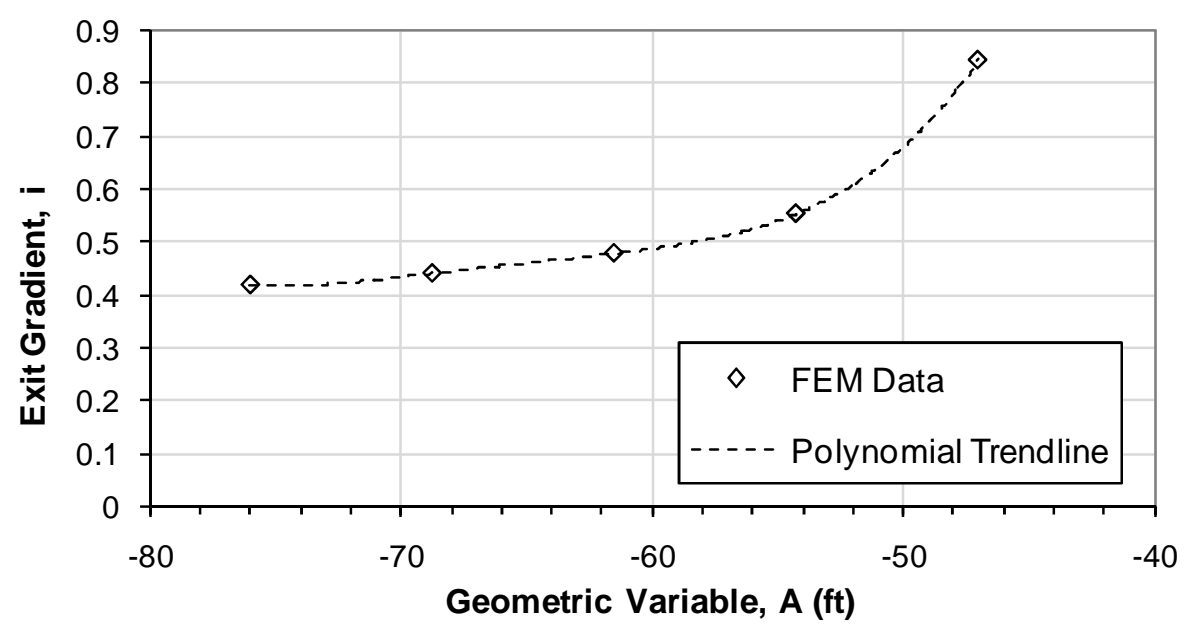

Figure A.2 Family of curves representing relationship of $\mathrm{i}_{\mathrm{e}} \mathrm{SAND}, \mathrm{A}, \mathrm{Ksb}=20$ and, $\mathrm{Khv}=0.50$. 


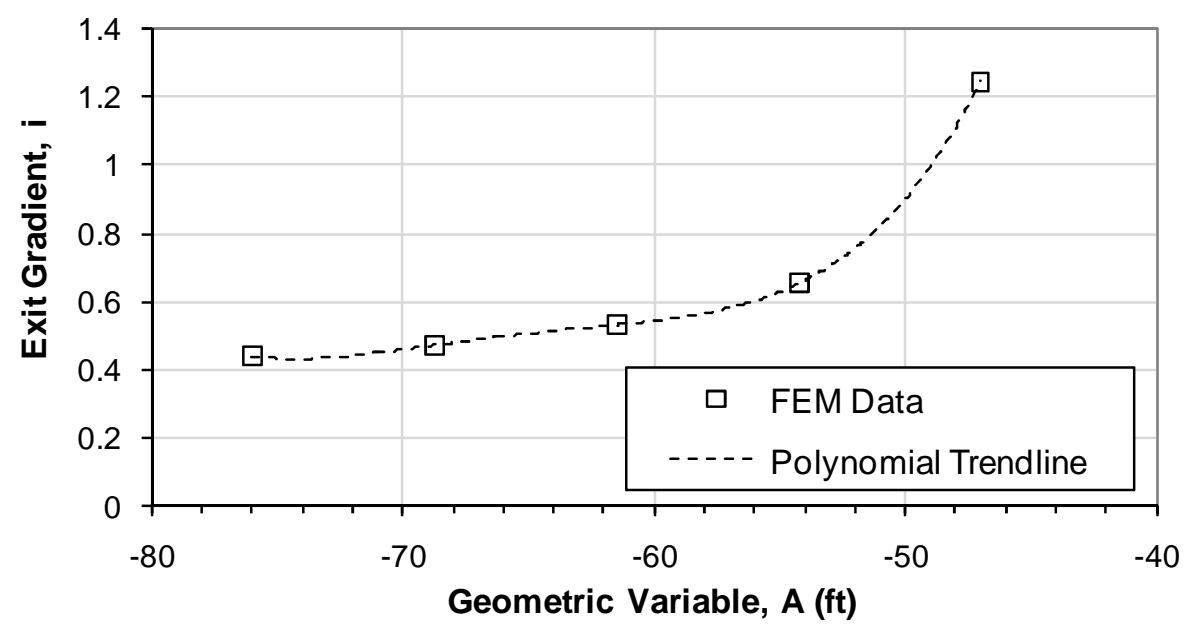

Figure A.3 Family of curves representing relationship of $\mathrm{i}_{\mathrm{e}}$ SAND $, \mathrm{A}, \mathrm{Ksb}=65$ and, $\mathrm{Khv}=0.50$.

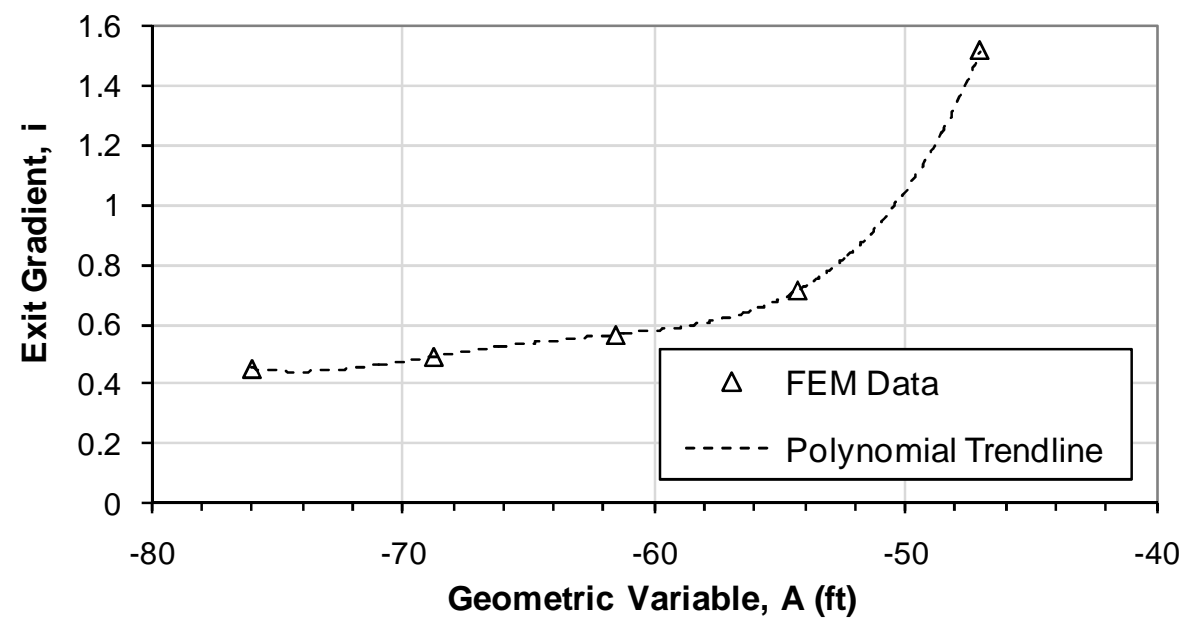

Figure A.4 Family of curves representing relationship of $\mathrm{i}_{\mathrm{e}}$ SAND, $\mathrm{A}, \mathrm{Ksb}=200$ and, $\mathrm{Khv}=0.50$. 


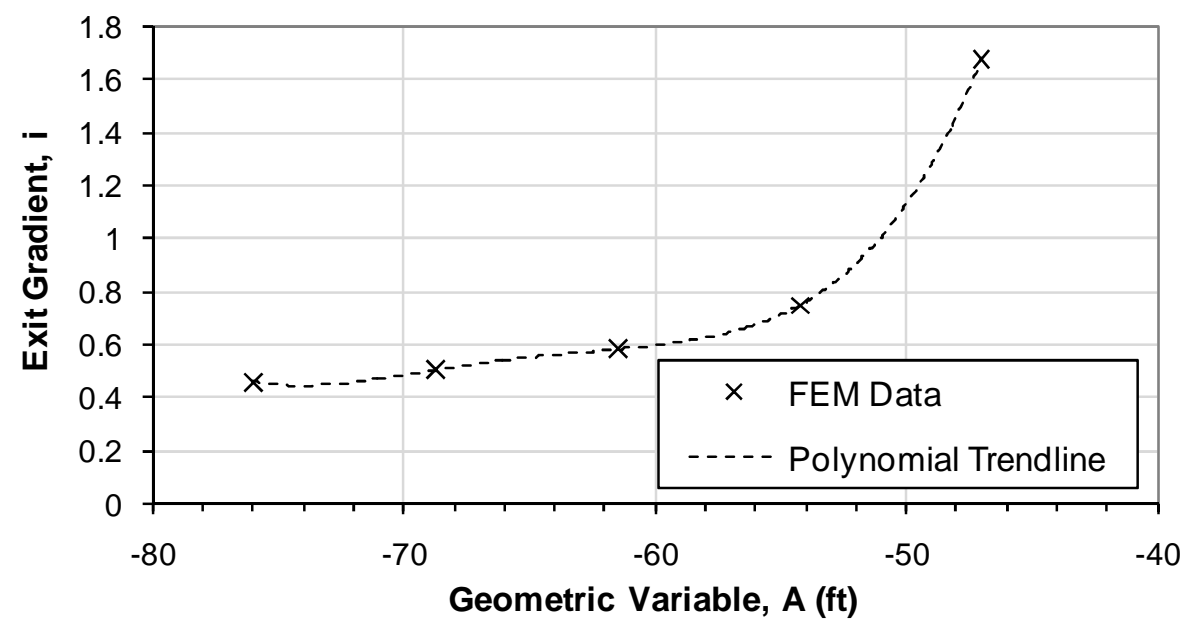

Figure A.5 Family of curves representing relationship of $\mathrm{i}_{\mathrm{e} S A N D}, \mathrm{~A}, \mathrm{Ksb}=1300$ and, Khv $=0.50$.

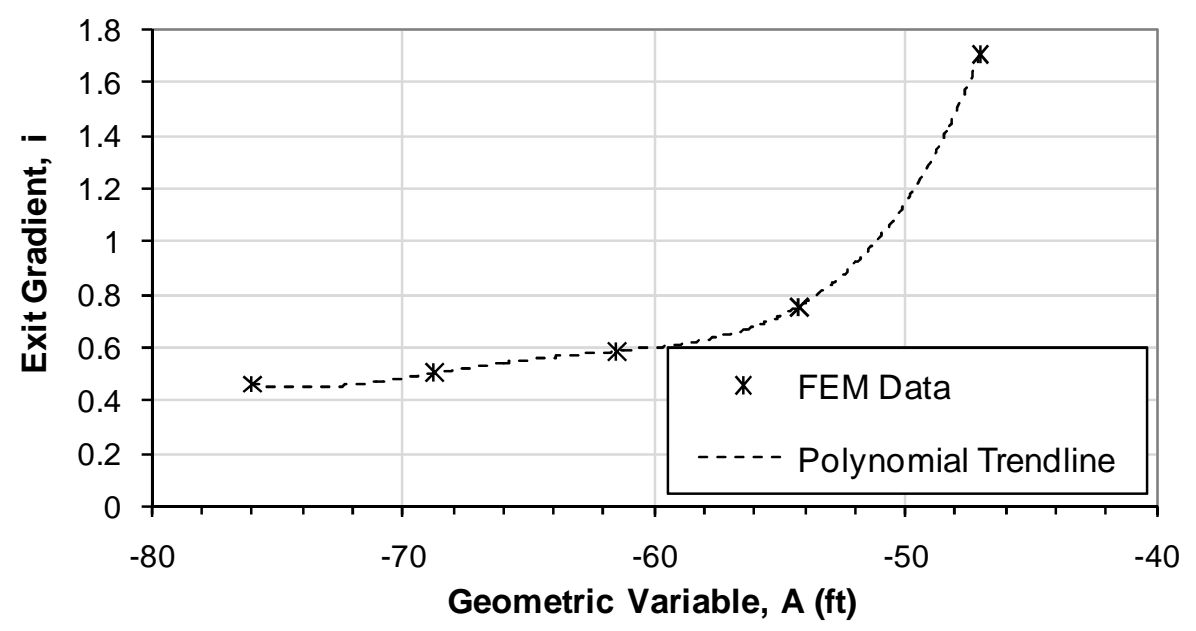

Figure A.6 Family of curves representing relationship of $\mathrm{i}_{\mathrm{e}}$ SAND, $\mathrm{A}, \mathrm{Ksb}=13000$ and, Khv $=0.50$.

Table A.2 Polynomial Trendline Coefficients and Coefficient of Determination $\left(\mathrm{R}^{2}\right)$ for Family of Curves in Figure A.1

\begin{tabular}{|c|c|c|c|c|c|c|}
\hline \multirow{2}{*}{ Ksb } & \multicolumn{6}{|c|}{$\mathbf{i}=\mathbf{a}_{\mathbf{4}} * \mathbf{A}^{\mathbf{4}}+\mathbf{a}_{\mathbf{3}} * \mathbf{A}^{\mathbf{3}}+\mathbf{a}_{\mathbf{2}} * \mathbf{A}^{\mathbf{2}}+\mathbf{a}_{\mathbf{1}} * \mathbf{A}+\mathbf{a}_{\mathbf{0}}$} \\
\cline { 2 - 8 } & $\mathbf{a}_{\mathbf{4}}$ & $\mathbf{a}_{\mathbf{3}}$ & $\mathbf{a}_{\mathbf{2}}$ & $\mathbf{a}_{\mathbf{1}}$ & $\mathbf{a}_{\mathbf{0}}$ & $\mathbf{R}^{\mathbf{2}}$ \\
\hline $\mathbf{2 0}$ & $2.368 \mathrm{E}-06$ & $6.260 \mathrm{E}-04$ & $6.199 \mathrm{E}-02$ & $2.730 \mathrm{E}+00$ & $4.567 \mathrm{E}+01$ & 1.00 \\
\hline $\mathbf{6 5}$ & $5.686 \mathrm{E}-06$ & $1.496 \mathrm{E}-03$ & $1.473 \mathrm{E}-01$ & $6.436 \mathrm{E}+00$ & $1.060 \mathrm{E}+02$ & 1.00 \\
\hline $\mathbf{2 0 0}$ & $8.053 \mathrm{E}-06$ & $2.117 \mathrm{E}-03$ & $2.081 \mathrm{E}-01$ & $9.077 \mathrm{E}+00$ & $1.489 \mathrm{E}+02$ & 1.00 \\
\hline $\mathbf{1 3 0 0}$ & $9.516 \mathrm{E}-06$ & $2.500 \mathrm{E}-03$ & $2.456 \mathrm{E}-01$ & $1.070 \mathrm{E}+01$ & $1.754 \mathrm{E}+02$ & 1.00 \\
\hline $\mathbf{1 3 0 0 0}$ & $9.712 \mathrm{E}-06$ & $2.552 \mathrm{E}-03$ & $2.508 \mathrm{E}-01$ & $1.094 \mathrm{E}+01$ & $1.792 \mathrm{E}+02$ & 1.00 \\
\hline
\end{tabular}


Table A.3 Uplift (Pore) Pressure $\mu_{\text {SAND }}$ as a function of A, Ksb and Khv $=0.50$

\begin{tabular}{|c|c|c|c|c|c|}
\hline \multirow{2}{*}{$\mathbf{A}$} & \multicolumn{5}{|c|}{$\boldsymbol{\mu}_{\text {SAND }}$} \\
\cline { 2 - 6 } & $\mathbf{K s b}=\mathbf{2 0}$ & $\mathbf{K s b}=\mathbf{6 5}$ & $\mathbf{K s b}=\mathbf{2 0 0}$ & $\mathbf{K s b}=\mathbf{1 3 0 0}$ & $\mathbf{K s b}=\mathbf{1 3 0 0 0}$ \\
\hline $\mathbf{- 3 9}$ & 707.80 & 920.00 & 1084.65 & 1194.30 & 1216.75 \\
\hline $\mathbf{- 3 1}$ & 1011.50 & 1210.00 & 1356.00 & 1450.80 & 1469.30 \\
\hline $\mathbf{- 2 3}$ & 1232.25 & 1422.80 & 1561.00 & 1650.00 & 1667.50 \\
\hline $\mathbf{- 1 5}$ & 1403.00 & 1588.80 & 1723.25 & 1809.25 & 1826.30 \\
\hline
\end{tabular}

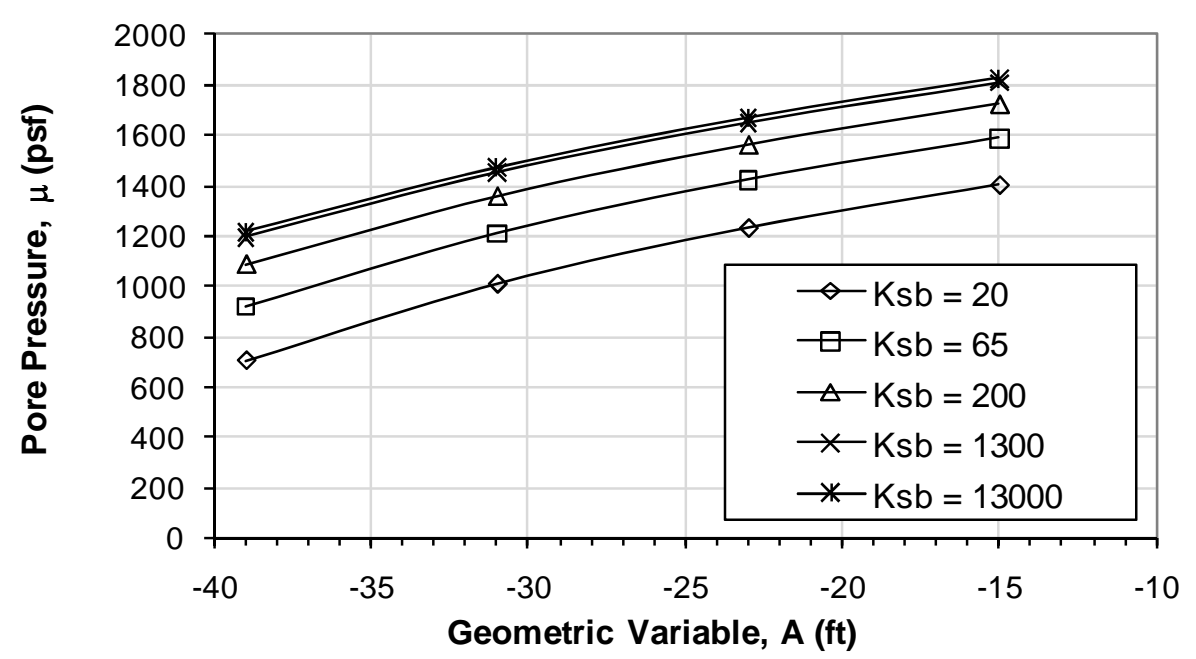

Figure A.7 Family of curves representing relationship of $\mu_{\mathrm{SAND}}, \mathrm{A}, \mathrm{Ksb}$ and, Khv $=0.50$.

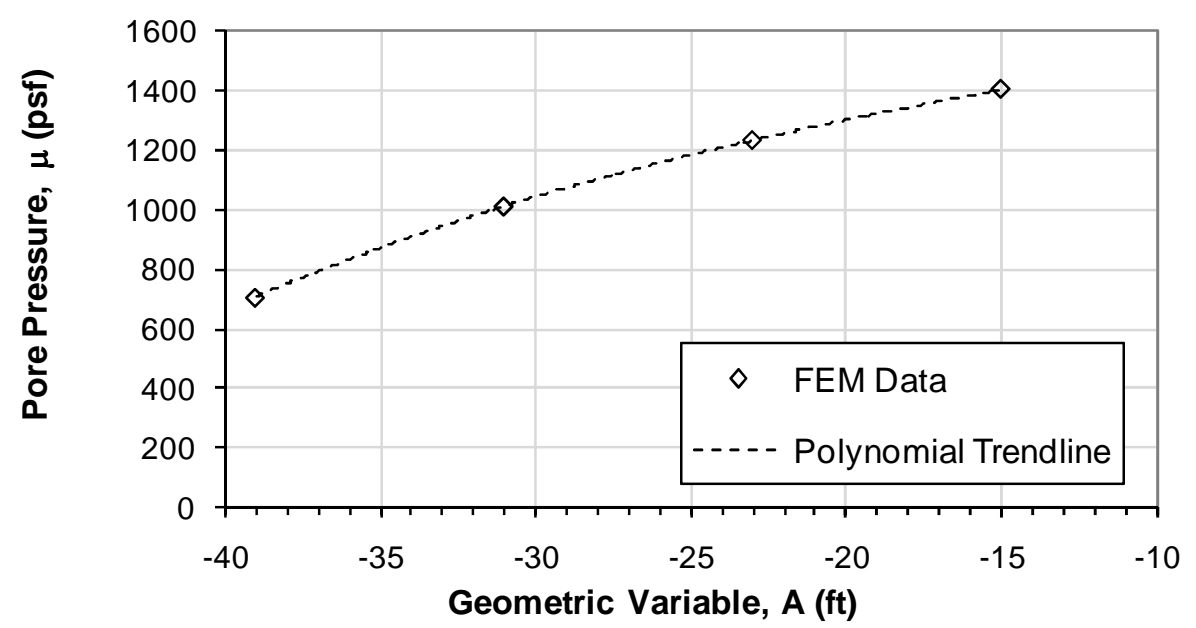

Figure A.8 Family of curves representing relationship of $\mu_{\mathrm{SAND}}, \mathrm{A}, \mathrm{Ksb}=20$ and, $\mathrm{Khv}=0.50$. 


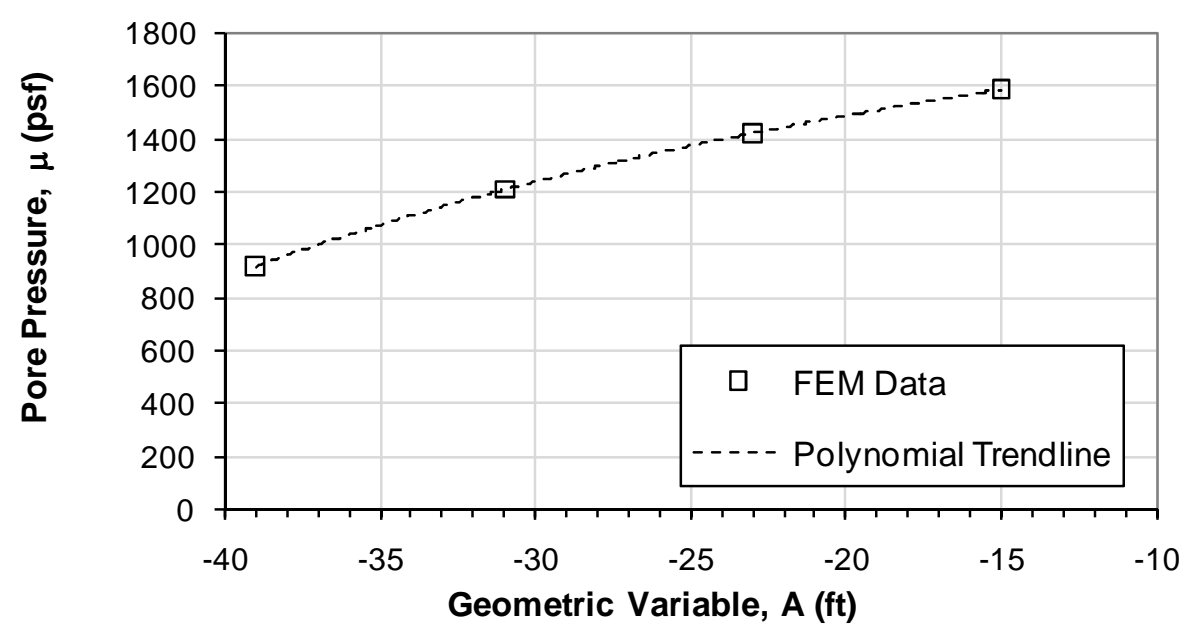

Figure A.9 Family of curves representing relationship of $\mu_{\mathrm{SAND}}, \mathrm{A}, \mathrm{Ksb}=65$ and, $\mathrm{Khv}=0.50$.

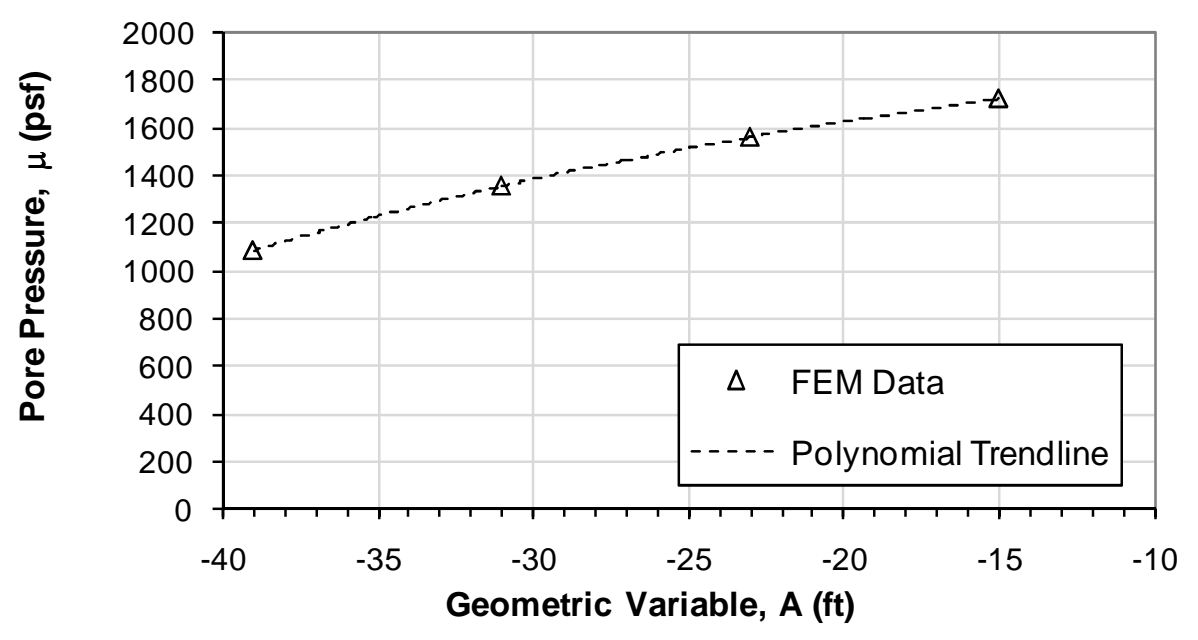

Figure A.10 Family of curves representing relationship of $\mu_{\mathrm{SAND}}, \mathrm{A}, \mathrm{Ksb}=200$ and, $\mathrm{Khv}=0.50$. 


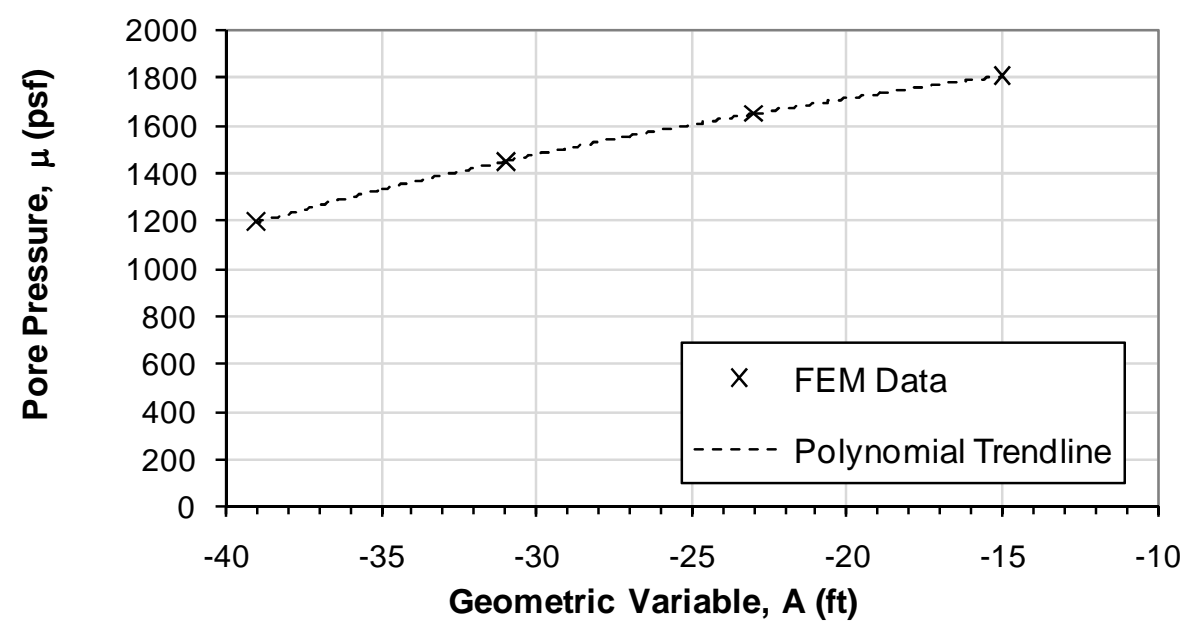

Figure A.11 Family of curves representing relationship of $\mu_{\mathrm{SAND}}, \mathrm{A}, \mathrm{Ksb}=1300$ and, $\mathrm{Khv}=0.50$.

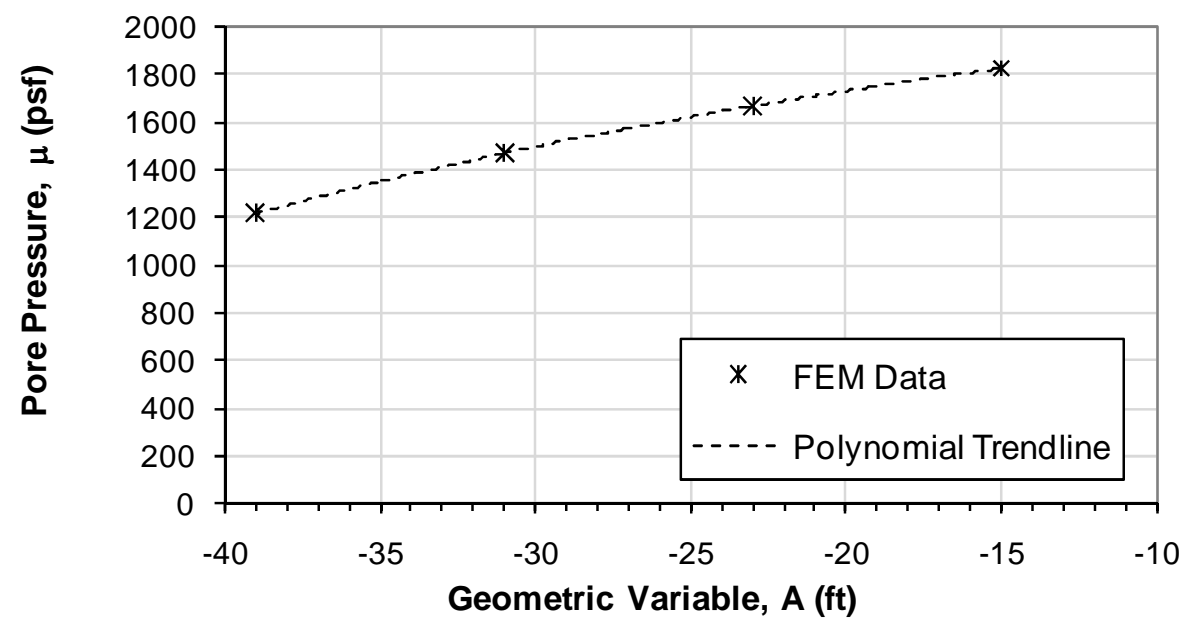

Figure A.12 Family of curves representing relationship of $\mu_{\mathrm{SAND}}, \mathrm{A}, \mathrm{Ksb}=13000$ and, Khv $=0.50$.

Table A.4 Polynomial Trendline Coefficients and Coefficient of Determination $\left(R^{2}\right)$ for Family of Curves in Figure A.7

\begin{tabular}{|c|c|c|c|c|c|}
\hline \multirow{2}{*}{ Ksb } & \multicolumn{5}{|c|}{$\boldsymbol{\mu}_{\mathbf{S}}=\mathbf{a}_{\mathbf{3}}{ }^{*} \mathbf{A}^{\mathbf{3}}+\mathbf{a}_{\mathbf{2}}{ }^{*} \mathbf{A}^{\mathbf{2}}+\mathbf{a}_{\mathbf{1}}{ }^{*} \mathbf{A}+\mathbf{a}_{\mathbf{0}}$} \\
\cline { 2 - 6 } & $\mathbf{a}_{\mathbf{3}}$ & $\mathbf{a}_{\mathbf{2}}$ & $\mathbf{a}_{\mathbf{1}}$ & $\mathbf{a}_{\mathbf{0}}$ & $\mathbf{R}^{\mathbf{2}}$ \\
\hline $\mathbf{2 0}$ & $1.073 \mathrm{E}-02$ & $3.495 \mathrm{E}-01$ & $2.284 \mathrm{E}+01$ & $1.703 \mathrm{E}+03$ & 1.00 \\
\hline $\mathbf{6 5}$ & $9.896 \mathrm{E}-03$ & $3.172 \mathrm{E}-01$ & $2.193 \mathrm{E}+01$ & $1.880 \mathrm{E}+03$ & 1.00 \\
\hline $\mathbf{2 0 0}$ & $7.682 \mathrm{E}-03$ & $1.961 \mathrm{E}-01$ & $1.929 \mathrm{E}+01$ & $1.994 \mathrm{E}+03$ & 1.00 \\
\hline $\mathbf{1 3 0 0}$ & $5.648 \mathrm{E}-03$ & $7.759 \mathrm{E}-02$ & $1.665 \mathrm{E}+01$ & $2.061 \mathrm{E}+03$ & 1.00 \\
\hline $\mathbf{1 3 0 0 0}$ & $4.870 \mathrm{E}-03$ & $2.798 \mathrm{E}-02$ & $1.556 \mathrm{E}+01$ & $2.069 \mathrm{E}+03$ & 1.00 \\
\hline
\end{tabular}


Table A.5 Exit gradient $i_{\mathrm{e}}$ SAND as a function of A, Ksb and $\mathrm{Khv}=0.25$

\begin{tabular}{|c|c|c|c|c|c|}
\hline \multirow{2}{*}{$\mathbf{A}$} & \multicolumn{5}{|c|}{$\mathbf{i}_{\mathbf{e}}$ SAND } \\
\cline { 2 - 6 } & $\mathbf{K s b}=\mathbf{2 0}$ & $\mathbf{K s b}=\mathbf{6 5}$ & $\mathbf{K s b}=\mathbf{2 0 0}$ & $\mathbf{K s b}=\mathbf{1 3 0 0}$ & $\mathbf{K s b}=\mathbf{1 3 0 0 0}$ \\
\hline $\mathbf{- 7 6}$ & 0.519 & 0.56 & 0.592 & 0.611 & 0.614 \\
\hline $\mathbf{- 6 8 . 7 5}$ & 0.543 & 0.604 & 0.647 & 0.673 & 0.677 \\
\hline $\mathbf{- 6 1 . 5}$ & 0.584 & 0.679 & 0.744 & 0.782 & 0.79 \\
\hline $\mathbf{- 5 4 . 2 5}$ & 0.663 & 0.826 & 0.94 & 1.009 & 1.022 \\
\hline $\mathbf{- 4 7}$ & 0.856 & 1.319 & 1.673 & 1.901 & 1.945 \\
\hline
\end{tabular}

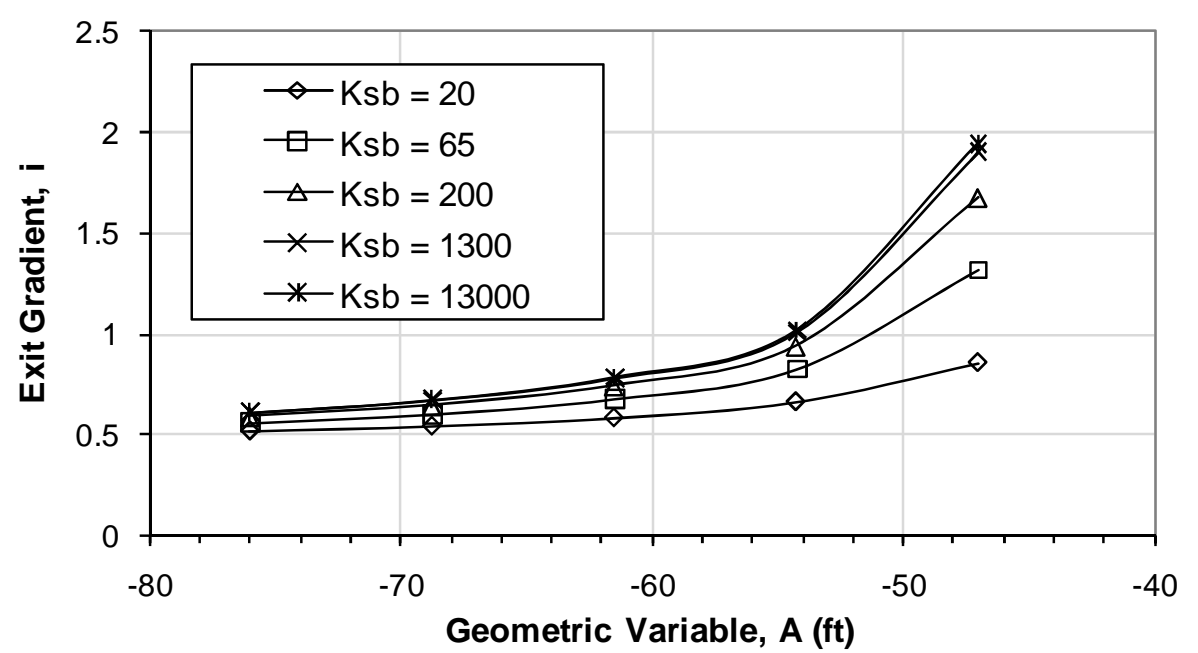

Figure A.13 Family of curves representing relationship of $\mathrm{i}_{\mathrm{e}}$ SAND, $\mathrm{A}, \mathrm{Ksb}$ and, $\mathrm{Khv}=0.25$.

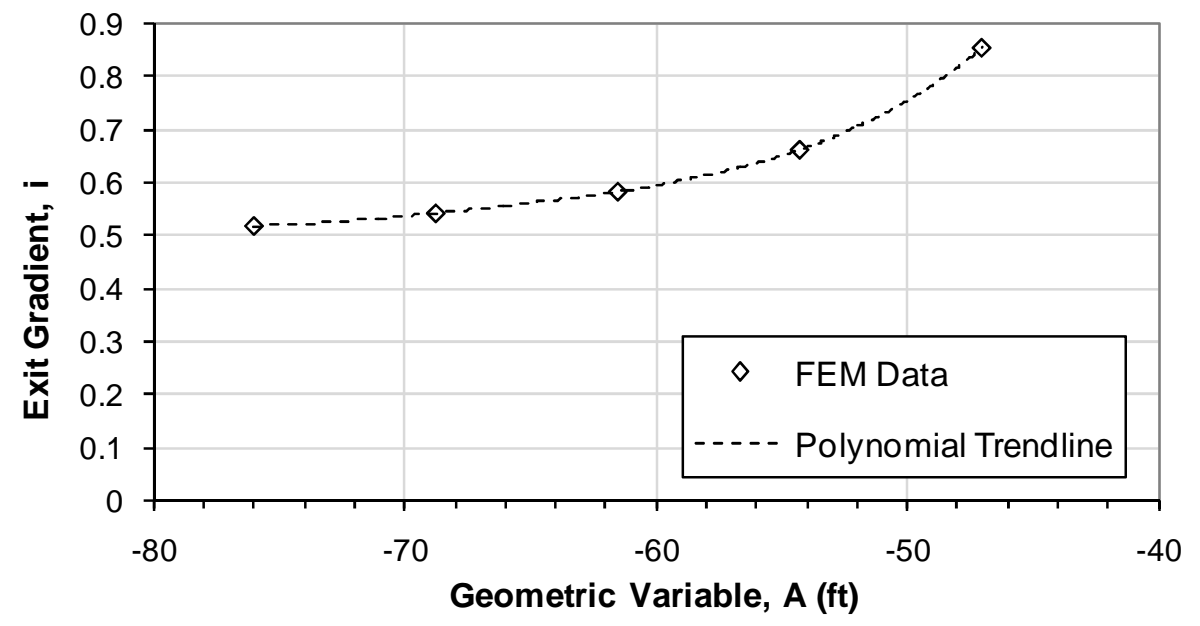

Figure A.14 Family of curves representing relationship of $\mathrm{i}_{\mathrm{e}}$ SAND $, \mathrm{A}, \mathrm{Ksb}=20$ and, $\mathrm{Khv}=0.25$. 


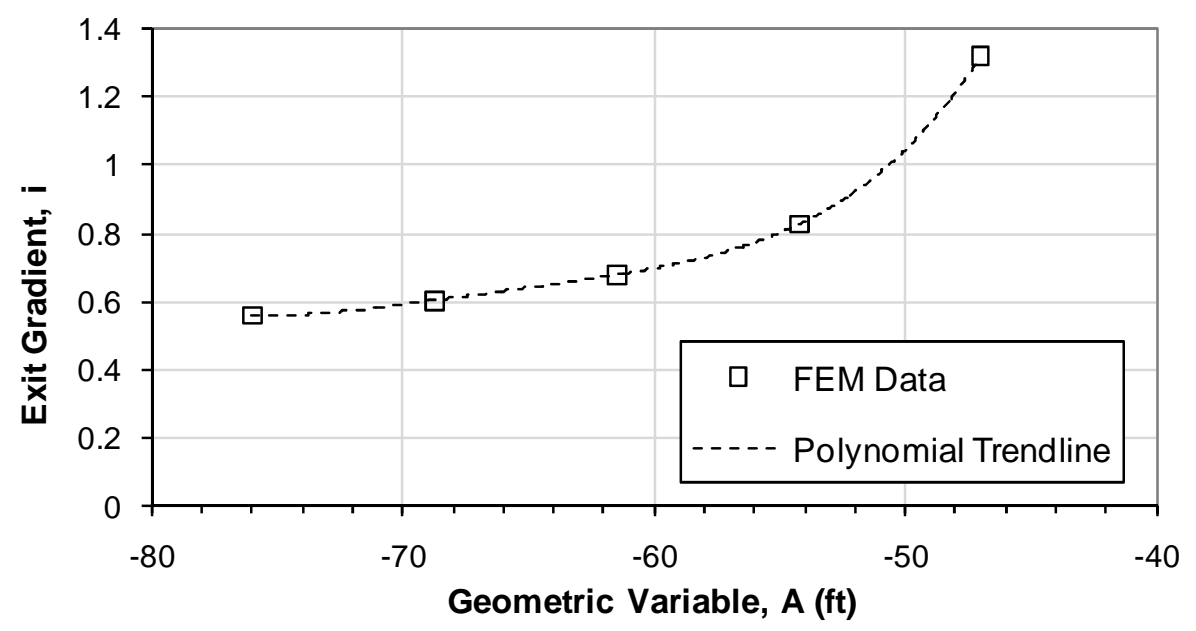

Figure A.15 Family of curves representing relationship of $\mathrm{i}_{\mathrm{e}} \mathrm{SAND}, \mathrm{A}, \mathrm{Ksb}=65$ and, $\mathrm{Khv}=0.25$.

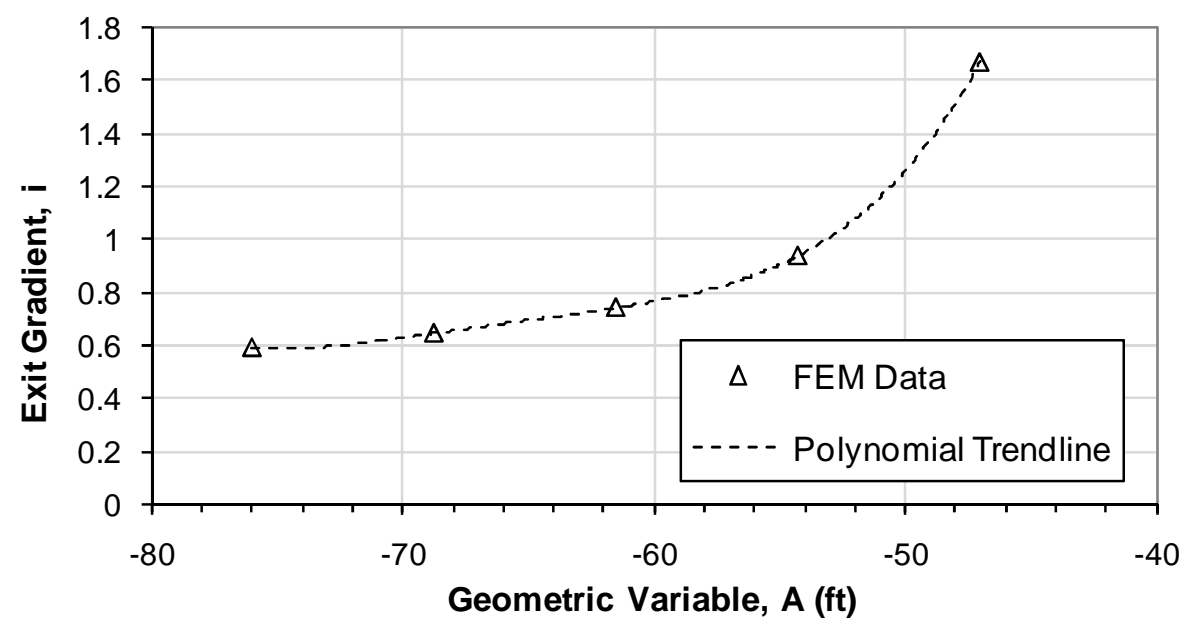

Figure A.16 Family of curves representing relationship of $\mathrm{i}_{\mathrm{e}}$ SAND, $\mathrm{A}, \mathrm{Ksb}=200$ and, $\mathrm{Khv}=0.25$. 


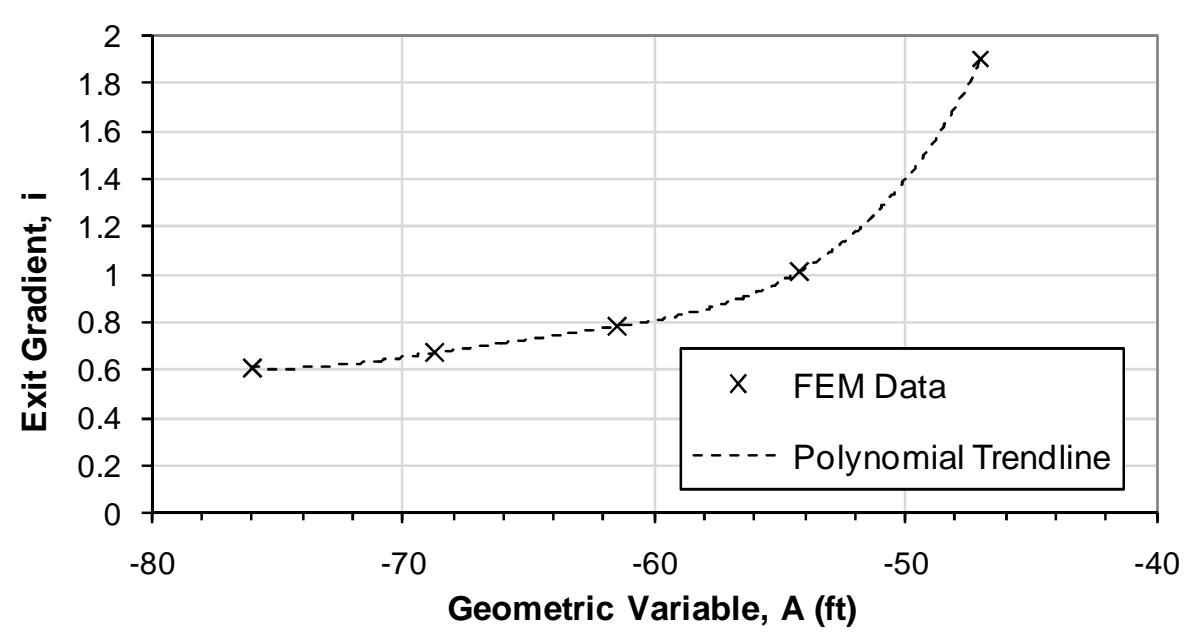

Figure A.17 Family of curves representing relationship of $\mathrm{i}_{\mathrm{e}} \mathrm{SAND}, \mathrm{A}, \mathrm{Ksb}=1300$ and, $\mathrm{Khv}=0.25$.

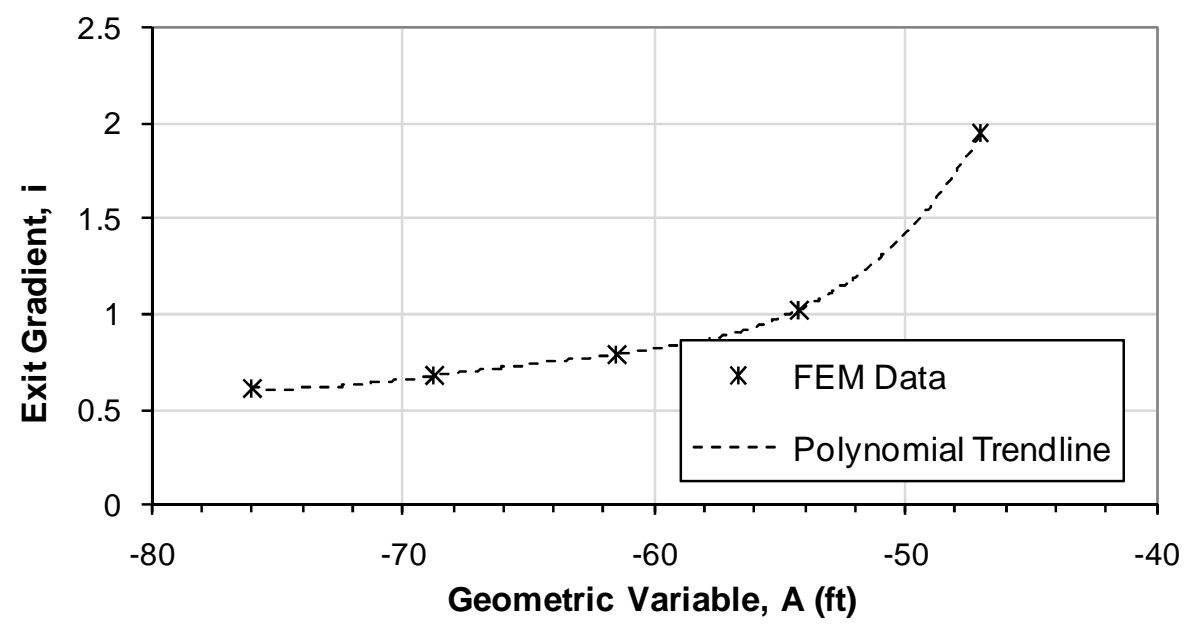

Figure A.18 Family of curves representing relationship of $\mathrm{i}_{\mathrm{e}} \mathrm{SAND}, \mathrm{A}, \mathrm{Ksb}=13000$ and, Khv $=0.25$. 
Table A.6 Polynomial Trendline Coefficients and Coefficient of Determination $\left(\mathrm{R}^{2}\right)$ for Family of Curves in Figure A.13

\begin{tabular}{|c|c|c|c|c|c|c|}
\hline \multirow{2}{*}{ Ksb } & \multicolumn{6}{|c|}{$\mathbf{i}=\mathbf{a}_{4} * \mathbf{A}^{4}+\mathbf{a}_{3} * \mathbf{A}^{3}+\mathbf{a}_{2} * \mathbf{A}^{2}+\mathbf{a}_{1} * A+\mathbf{a}_{0}$} \\
\hline & $\mathbf{a}_{4}$ & $\mathbf{a}_{3}$ & $\mathbf{a}_{2}$ & $\mathbf{a}_{1}$ & $\mathbf{a}_{0}$ & $\mathbf{R}^{2}$ \\
\hline 20 & $8.295 \mathrm{E}-07$ & $2.253 \mathrm{E}-04$ & $2.305 \mathrm{E}-02$ & $1.059 \mathrm{E}+00$ & $1.903 \mathrm{E}+01$ & 1.00 \\
\hline 65 & $3.514 \mathrm{E}-06$ & $9.333 \mathrm{E}-04$ & $9.295 \mathrm{E}-02$ & $4.124 \mathrm{E}+00$ & $6.958 \mathrm{E}+01$ & 1.00 \\
\hline 200 & $5.746 \mathrm{E}-06$ & $1.522 \mathrm{E}-03$ & $1.510 \mathrm{E}-01$ & $6.668 \mathrm{E}+00$ & $1.114 \mathrm{E}+02$ & 1.00 \\
\hline 1300 & 7.179E-06 & $1.901 \mathrm{E}-03$ & $1.886 \mathrm{E}-01$ & $8.320 \mathrm{E}+00$ & $1.387 \mathrm{E}+02$ & 1.00 \\
\hline 13000 & $7.586 \mathrm{E}-06$ & $2.006 \mathrm{E}-03$ & $1.987 \mathrm{E}-01$ & $8.755 \mathrm{E}+00$ & $1.457 \mathrm{E}+02$ & 1.00 \\
\hline
\end{tabular}

Table A.7 Uplift (Pore) Pressure $\mu_{\text {SAND }}$ as a function of A, Ksb and Khv $=0.25$

\begin{tabular}{|c|c|c|c|c|c|}
\hline \multirow{2}{*}{$A$} & \multicolumn{5}{|c|}{$\boldsymbol{\mu}_{\text {SAND }}$} \\
\cline { 2 - 6 } & $\mathbf{K s b}=\mathbf{2 0}$ & $\mathbf{K s b}=\mathbf{6 5}$ & $\mathbf{K s b}=\mathbf{2 0 0}$ & $\mathbf{K s b}=\mathbf{1 3 0 0}$ & Ksb = 13000 \\
\hline $\mathbf{- 3 9}$ & 662.95 & 880.725 & 1061.5 & 1189.5 & 1216 \\
\hline $\mathbf{- 3 1}$ & 975.81 & 1180.5 & 1339.3 & 1447.5 & 1469.500 \\
\hline $\mathbf{- 2 3}$ & 1201.37 & 1397.5 & 1547 & 1646.9 & 1667.000 \\
\hline $\mathbf{- 1 5}$ & 1374 & 1565.3 & 1710 & 1806.5 & 1826.000 \\
\hline
\end{tabular}

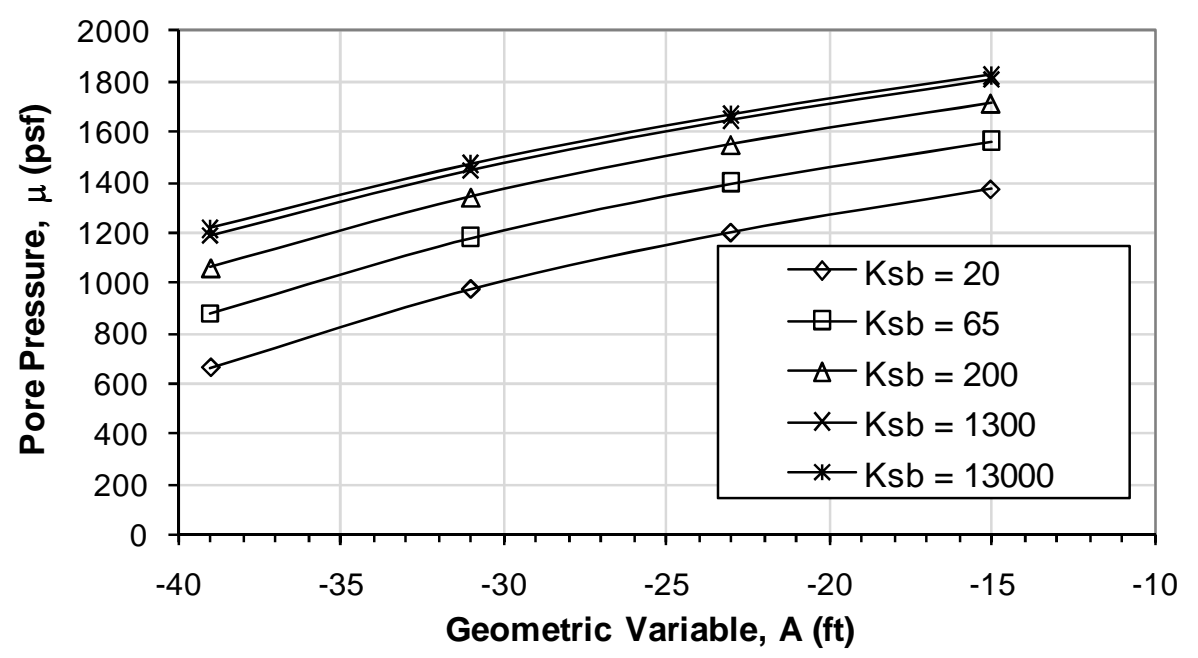

Figure A.19 Family of curves representing relationship between $\mu_{\mathrm{SAND}}$, A, Ksb and, Khv $=0.25$. 


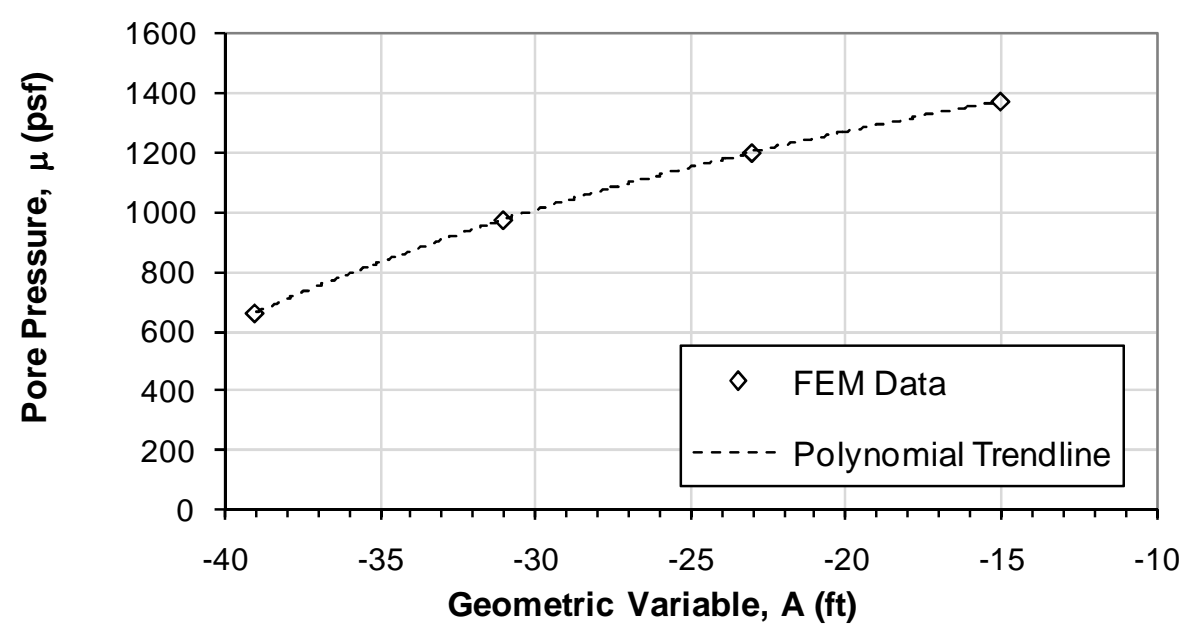

Figure A.20 Family of curves representing relationship of $\mu_{\text {SAND }}, A, K s b=20$ and, Khv $=0.25$.

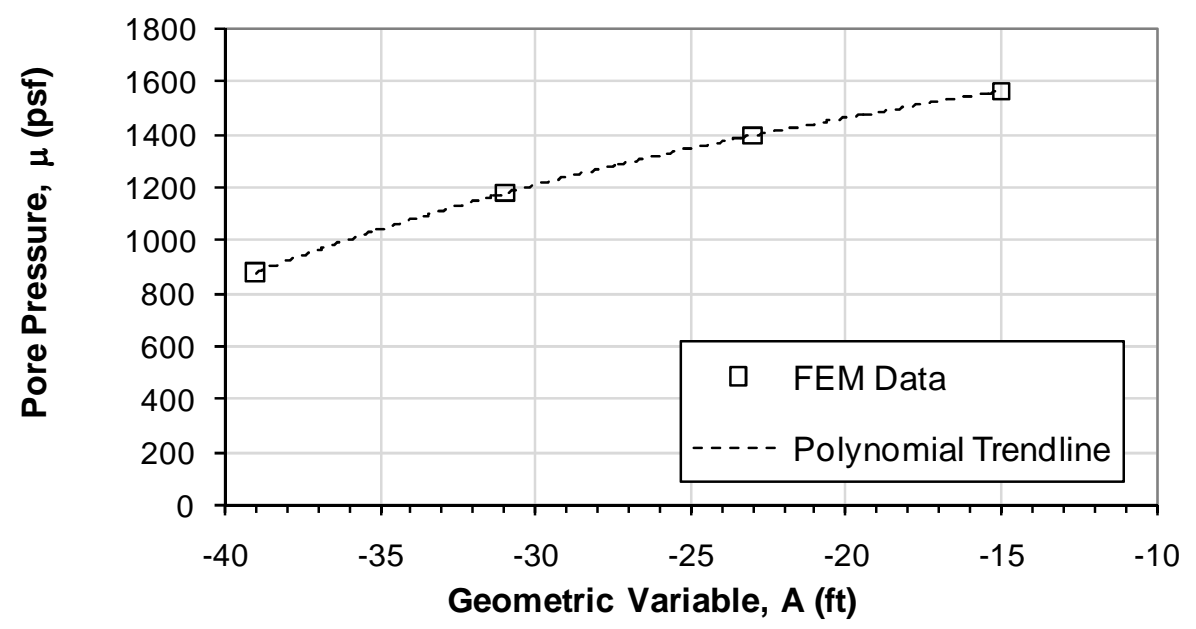

Figure A.21 Family of curves representing relationship of $\mu_{\mathrm{SAND}}, \mathrm{A}, \mathrm{Ksb}=65$ and, $\mathrm{Khv}=0.25$. 


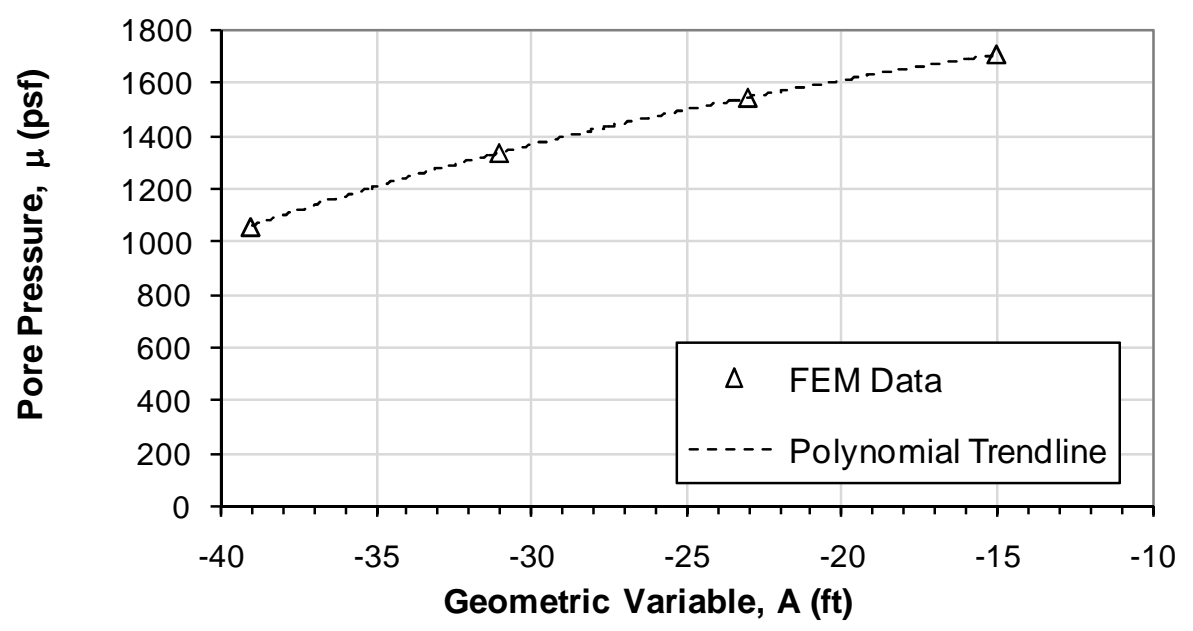

Figure A.22 Family of curves representing relationsh between $\mu_{\mathrm{SAND}}, \mathrm{A}, \mathrm{Ksb}=200$ and, $\mathrm{Khv}=0.25$.

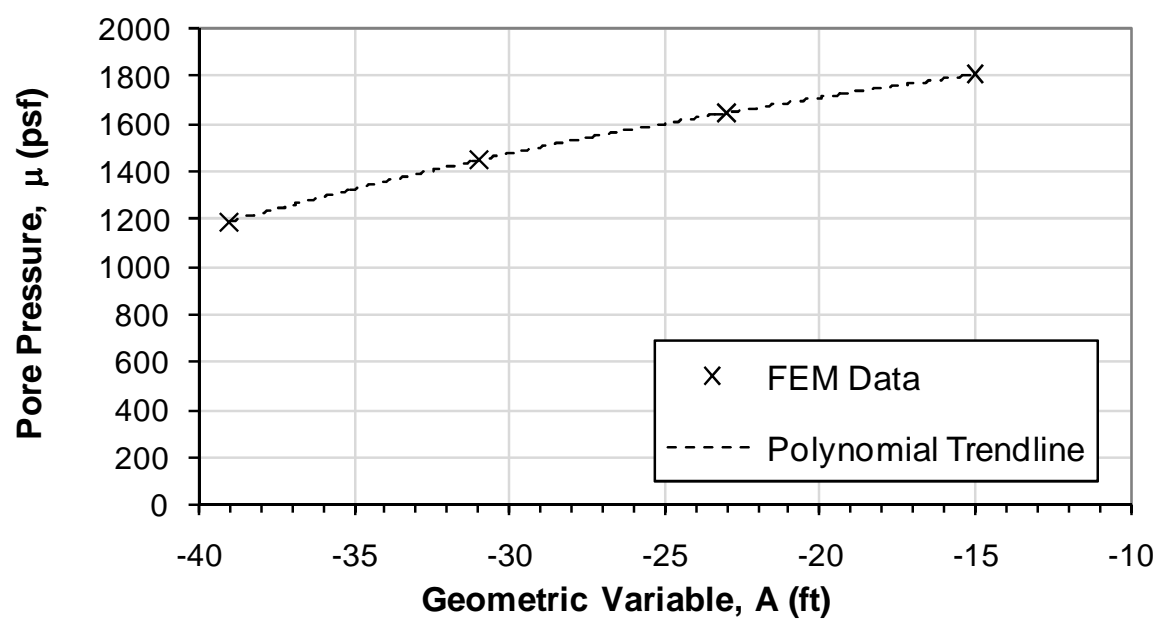

Figure A.23 Family of curves representing relationship of $\mu_{\text {SAND }}, \mathrm{A}, \mathrm{Ksb}=1300$ and, $\mathrm{Khv}=0.25$. 


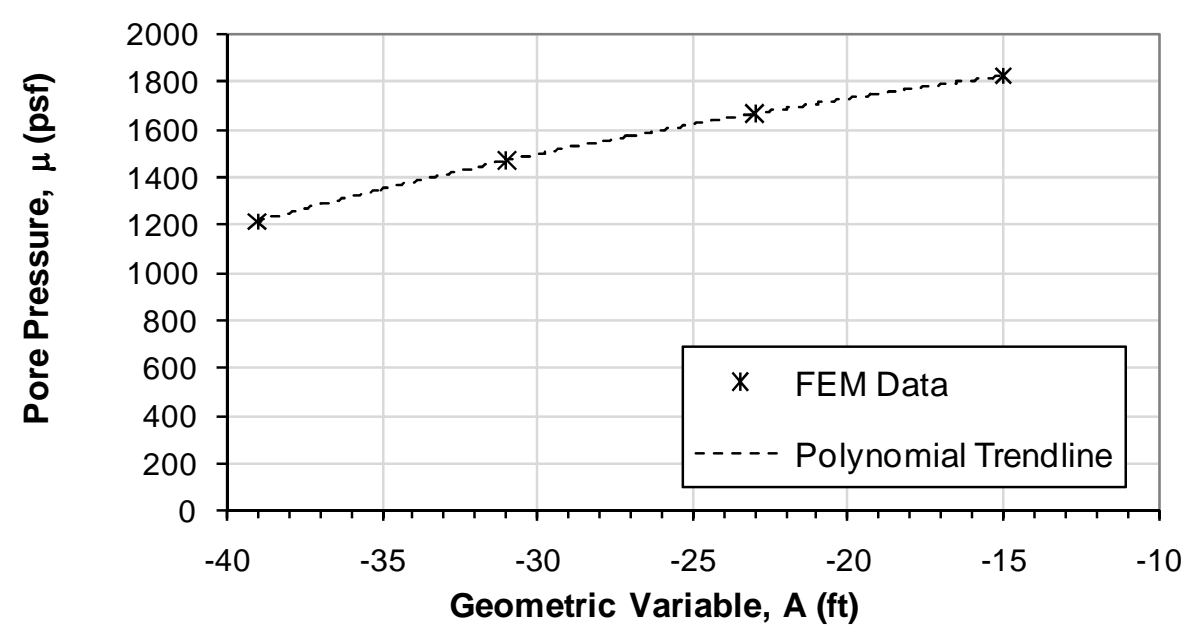

Figure A.24 Family of curves representing relationship of $\mu_{\mathrm{SAND}}, \mathrm{A}, \mathrm{Ksb}=13000$ and, $\mathrm{Khv}=0.25$.

Table A.8 Polynomial Trendline Coefficients and Coefficient of Determination $\left(\mathrm{R}^{2}\right)$ for Family of Curves in Figure A.19

\begin{tabular}{|c|c|c|c|c|c|}
\hline \multirow{2}{*}{ Ksb } & \multicolumn{5}{|c|}{$\boldsymbol{\mu}=\mathbf{a}_{\mathbf{3}} * \mathbf{A}^{\mathbf{3}}+\mathbf{a}_{\mathbf{2}} * \mathbf{A}^{\mathbf{2}}+\mathbf{a}_{\mathbf{1}} * \mathbf{A}+\mathbf{a}_{\mathbf{0}}$} \\
\cline { 2 - 6 } & $\mathbf{a}_{\mathbf{3}}$ & $\mathbf{a}_{\mathbf{2}}$ & $\mathbf{a}_{\mathbf{1}}$ & $\mathbf{a}_{\mathbf{0}}$ & $\mathbf{R}^{\mathbf{2}}$ \\
\hline $\mathbf{2 0}$ & $1.119 \mathrm{E}-02$ & $3.585 \mathrm{E}-01$ & $2.290 \mathrm{E}+01$ & $1.675 \mathrm{E}+03$ & 1.00 \\
\hline $\mathbf{6 5}$ & $1.093 \mathrm{E}-02$ & $3.698 \mathrm{E}-01$ & $2.301 \mathrm{E}+01$ & $1.864 \mathrm{E}+03$ & 1.00 \\
\hline $\mathbf{2 0 0}$ & $8.268 \mathrm{E}-03$ & $2.213 \mathrm{E}-01$ & $1.970 \mathrm{E}+01$ & $1.984 \mathrm{E}+03$ & 1.00 \\
\hline $\mathbf{1 3 0 0}$ & $6.120 \mathrm{E}-03$ & $1.113 \mathrm{E}-01$ & $1.745 \mathrm{E}+01$ & $2.064 \mathrm{E}+03$ & 1.00 \\
\hline $\mathbf{1 3 0 0 0}$ & $5.697 \mathrm{E}-03$ & $9.229 \mathrm{E}-02$ & $1.712 \mathrm{E}+01$ & $2.081 \mathrm{E}+03$ & 1.00 \\
\hline
\end{tabular}

Table A.9 Exit gradient $i_{\mathrm{e} \text { SAND }}$ as a function of $\mathrm{A}, \mathrm{Ksb}$ and $\mathrm{Khv}=0.15$

\begin{tabular}{|c|c|c|c|c|c|}
\hline \multirow{2}{*}{$A$} & \multicolumn{5}{|c|}{$\mathbf{i}_{\mathbf{e} \text { SAND }}$} \\
\cline { 2 - 6 } & $\mathbf{K s b}=\mathbf{2 0}$ & $\mathbf{K s b}=\mathbf{6 5}$ & $\mathbf{K s b}=\mathbf{2 0 0}$ & $\mathbf{K s b}=\mathbf{1 3 0 0}$ & $\mathbf{K s b}=\mathbf{1 3 0 0 0}$ \\
\hline $\mathbf{- 7 6}$ & 0.582 & 0.643 & 0.693 & 0.724 & 0.73 \\
\hline $\mathbf{- 6 8 . 7 5}$ & 0.606 & 0.692 & 0.76 & 0.801 & 0.809 \\
\hline $\mathbf{- 6 1 . 5}$ & 0.645 & 0.779 & 0.876 & 0.937 & 0.949 \\
\hline $\mathbf{- 5 4 . 2 5}$ & 0.719 & 0.944 & 1.114 & 1.222 & 1.244 \\
\hline $\mathbf{- 4 7}$ & 0.841 & 1.354 & 1.792 & 2.092 & 2.152 \\
\hline
\end{tabular}




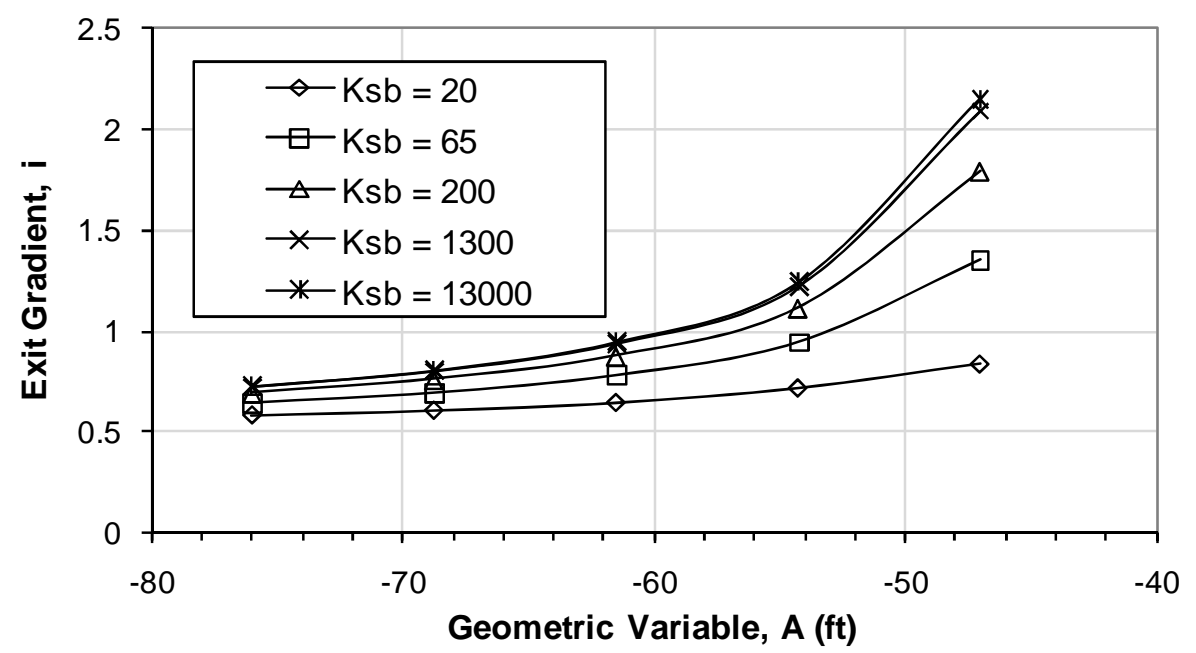

Figure A.25 Family of curves representing relationship of $\mathrm{i}_{\mathrm{e} \text { SAND }}, \mathrm{A}, \mathrm{Ksb}$ and, $\mathrm{Khv}=0.15$.

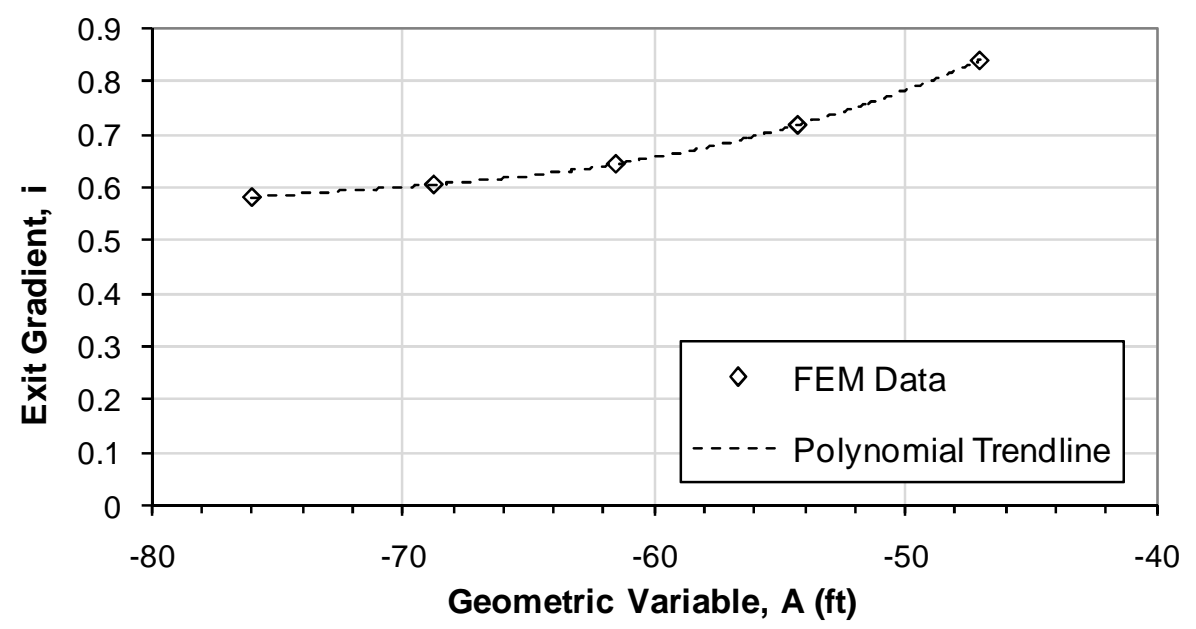

Figure A.26 Family of curves representing relationship of $\mathrm{i}_{\mathrm{e}}$ SAND, $\mathrm{A}, \mathrm{Ksb}=20$ and, $\mathrm{Khv}=0.15$. 


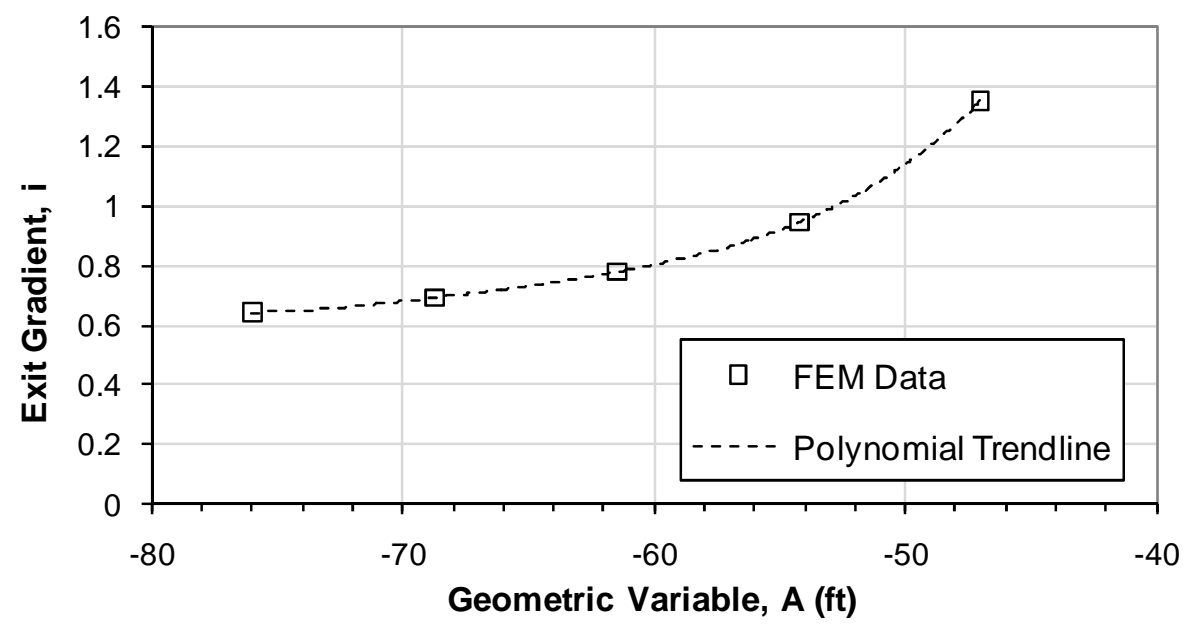

Figure A.27 Family of curves representing relationship of $\mathrm{i}_{\mathrm{e} \text { SAND }}, \mathrm{A}, \mathrm{Ksb}=65$ and, $\mathrm{Khv}=0.15$.

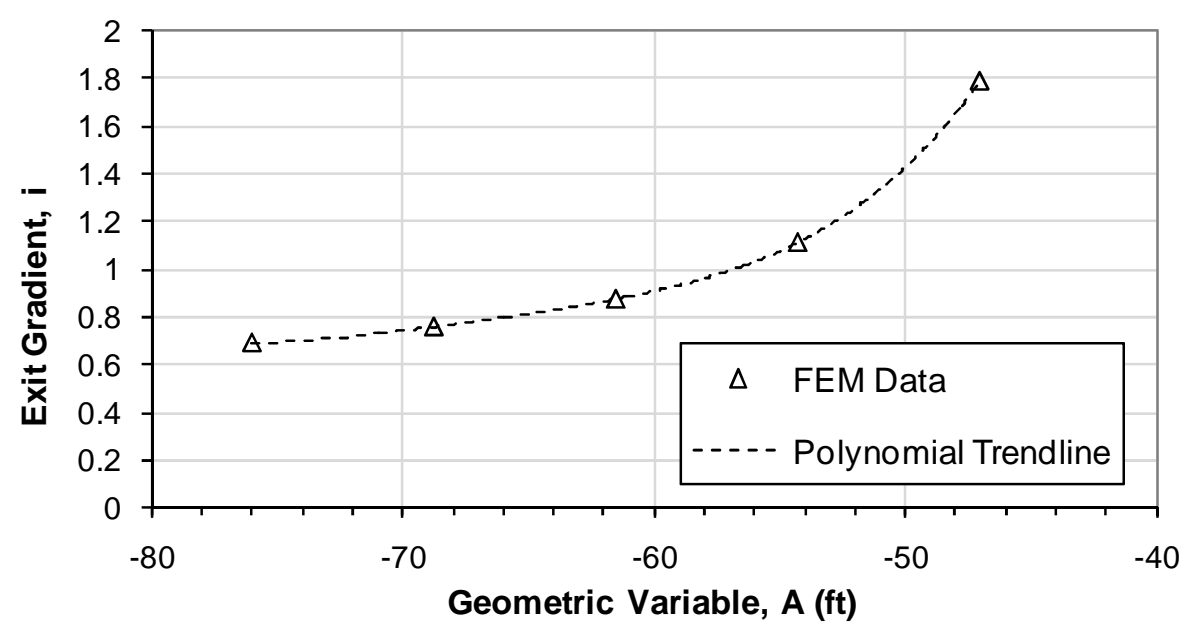

Figure A.28 Family of curves representing relationship of $\mathrm{i}_{\mathrm{e} \text { SAND }} \mathrm{A}, \mathrm{Ksb}=200$ and, $\mathrm{Khv}=0.15$. 


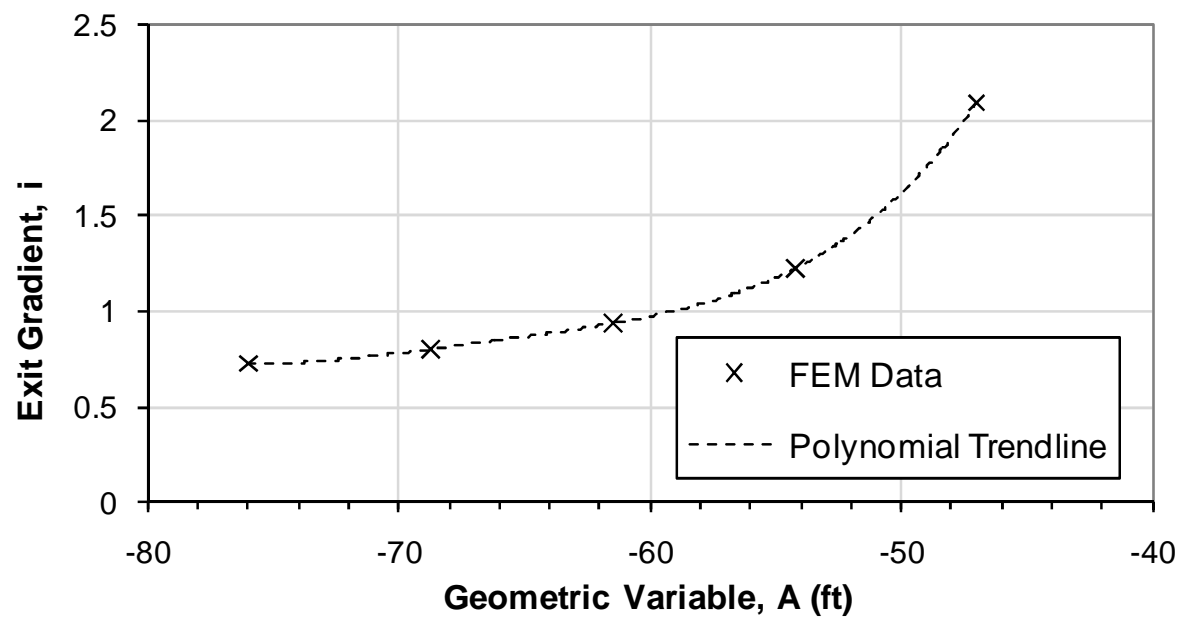

Figure A.29 Family of curves representing relationship of $\mathrm{i}_{\mathrm{e}} \mathrm{SAND}, \mathrm{A}, \mathrm{Ksb}=1300$ and, $\mathrm{Khv}=0.15$.

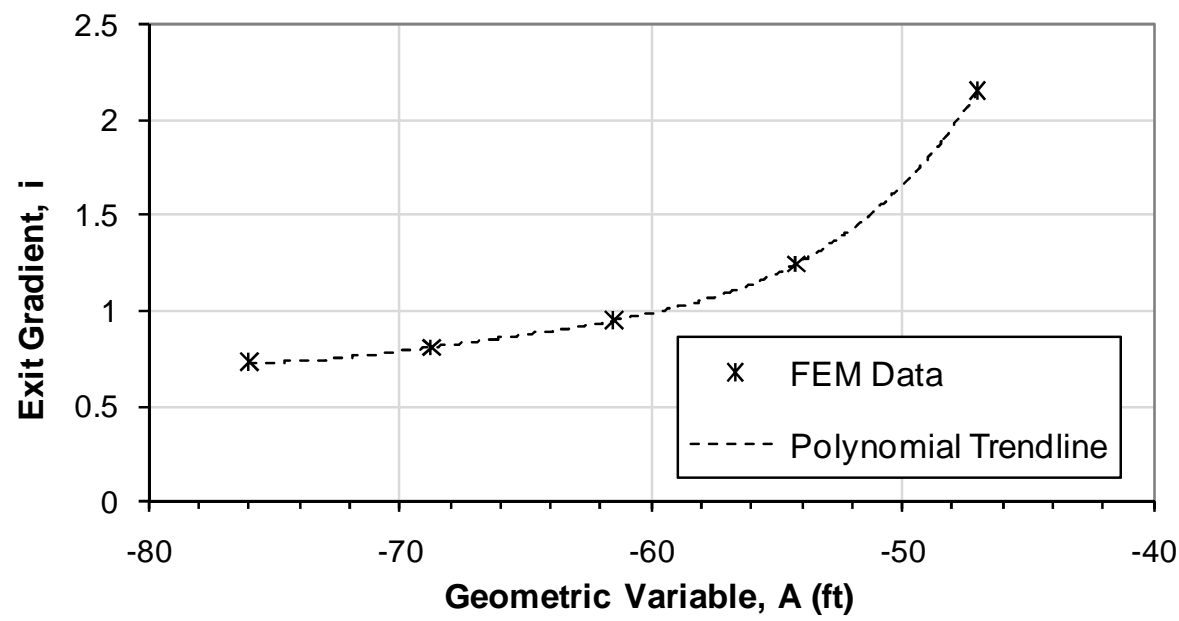

Figure A.30 Family of curves representing relationship of $\mathrm{i}_{\mathrm{e} \text { SAND }}, \mathrm{A}, \mathrm{Ksb}=13000$ and, $\mathrm{Khv}=0.15$. 
Table A.10 Polynomial Trendline Coefficients and Coefficient of Determination $\left(\mathrm{R}^{2}\right)$ for Family of Curves in Figure A.25

\begin{tabular}{|c|c|c|c|c|c|c|}
\hline \multirow{2}{*}{ Ksb } & \multicolumn{6}{|c|}{$i=a_{4} * A^{4}+a_{3} * A^{3}+a_{2} * A^{2}+a_{1} * A+a_{0}$} \\
\hline & $\mathbf{a}_{4}$ & $\mathbf{a}_{3}$ & $\mathbf{a}_{2}$ & $\mathbf{a}_{1}$ & $\mathbf{a}_{0}$ & $\mathbf{R}^{2}$ \\
\hline 20 & $-1.056 \mathrm{E}-07$ & $-1.875 \mathrm{E}-05$ & $-7.258 \mathrm{E}-04$ & $3.271 \mathrm{E}-02$ & $2.550 \mathrm{E}+00$ & 1.00 \\
\hline 65 & $1.915 \mathrm{E}-06$ & 5.164E-04 & $5.246 \mathrm{E}-02$ & $2.390 \mathrm{E}+00$ & $4.206 \mathrm{E}+01$ & 1.00 \\
\hline 200 & $3.695 \mathrm{E}-06$ & $9.944 \mathrm{E}-04$ & $1.006 \mathrm{E}-01$ & $4.547 \mathrm{E}+00$ & $7.850 \mathrm{E}+01$ & 1.00 \\
\hline 1300 & $5.218 \mathrm{E}-06$ & $1.399 \mathrm{E}-03$ & $1.408 \mathrm{E}-01$ & $6.324 \mathrm{E}+00$ & $1.081 \mathrm{E}+02$ & 1.00 \\
\hline 13000 & $5.490 \mathrm{E}-06$ & $1.471 \mathrm{E}-03$ & $1.480 \mathrm{E}-01$ & $6.647 \mathrm{E}+00$ & $1.135 \mathrm{E}+02$ & 1.00 \\
\hline
\end{tabular}

Table A.11 Uplift (Pore) Pressure $\mu_{\text {SAND }}$ as a function of A, Ksb and Khv $=0.15$

\begin{tabular}{|c|c|c|c|c|c|}
\hline \multirow{2}{*}{$\mathbf{A}$} & \multicolumn{5}{|c|}{$\boldsymbol{\mu}_{\text {SAND }}$} \\
\cline { 2 - 6 } & $\mathbf{K s b}=\mathbf{2 0}$ & $\mathbf{K s b}=\mathbf{6 5}$ & $\mathbf{K s b}=\mathbf{2 0 0}$ & $\mathbf{K s b}=\mathbf{1 3 0 0}$ & $\mathbf{1 3 0 0 0}$ \\
\hline $\mathbf{- 3 9}$ & 627.5 & 843.925 & 1038.825 & 1184.5 & 1215.3 \\
\hline $\mathbf{- 3 1}$ & 946.95 & 1153.6 & 1323.79 & 1444.09 & 1468.95 \\
\hline $\mathbf{- 2 3}$ & 1176.7 & 1375.65 & 1534.11 & 1644.1 & 1666.75 \\
\hline $\mathbf{- 1 5}$ & 1351.7 & 1545.25 & 1698.15 & 1803.94 & 1825.53 \\
\hline
\end{tabular}

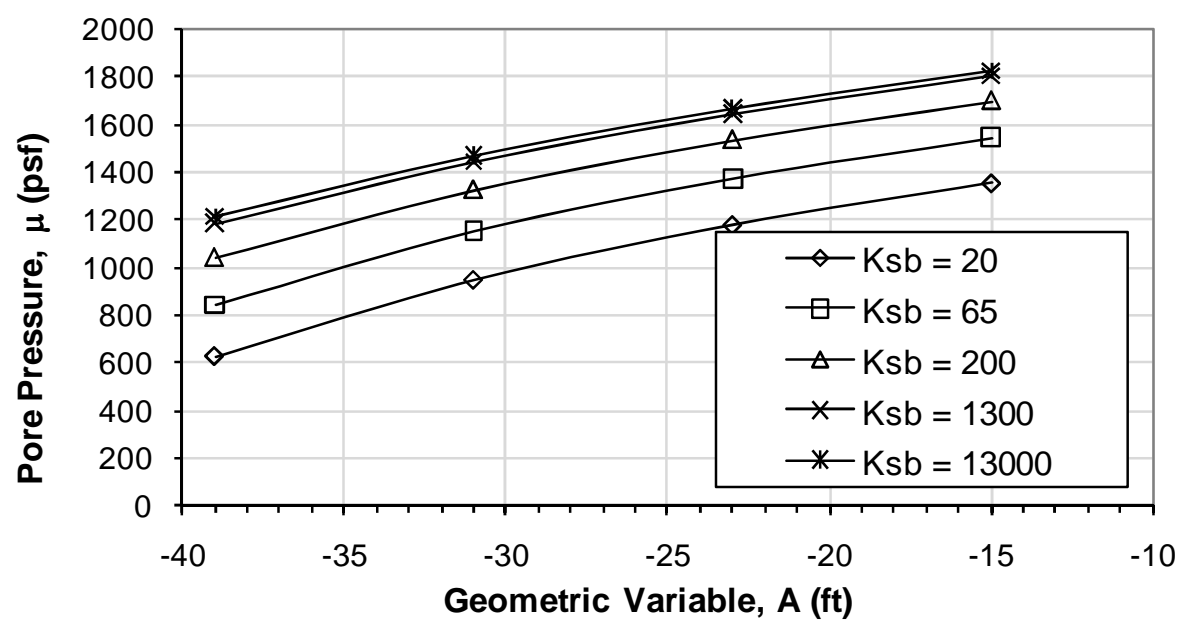

Figure A.31 Family of curves representing relationship of $\mu_{\text {SAND }}, A, K s b$ and, Khv $=0.15$. 


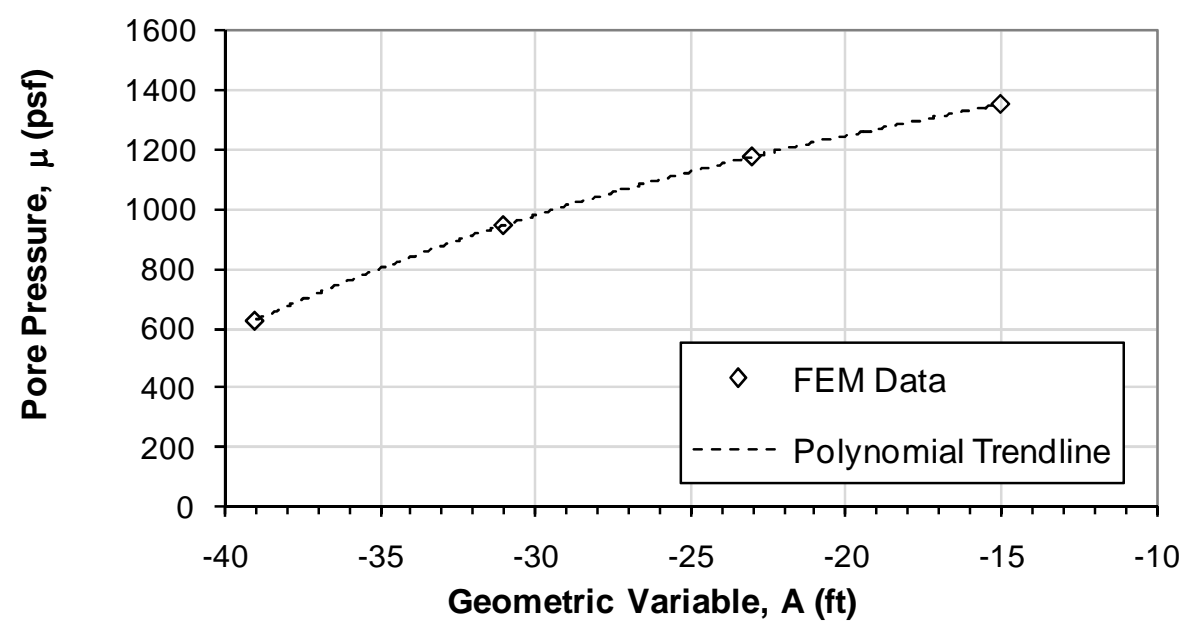

Figure A.32 Family of curves representing relationship of $\mu_{\text {SAND }}, A, K s b=20$ and, Khv $=0.15$.

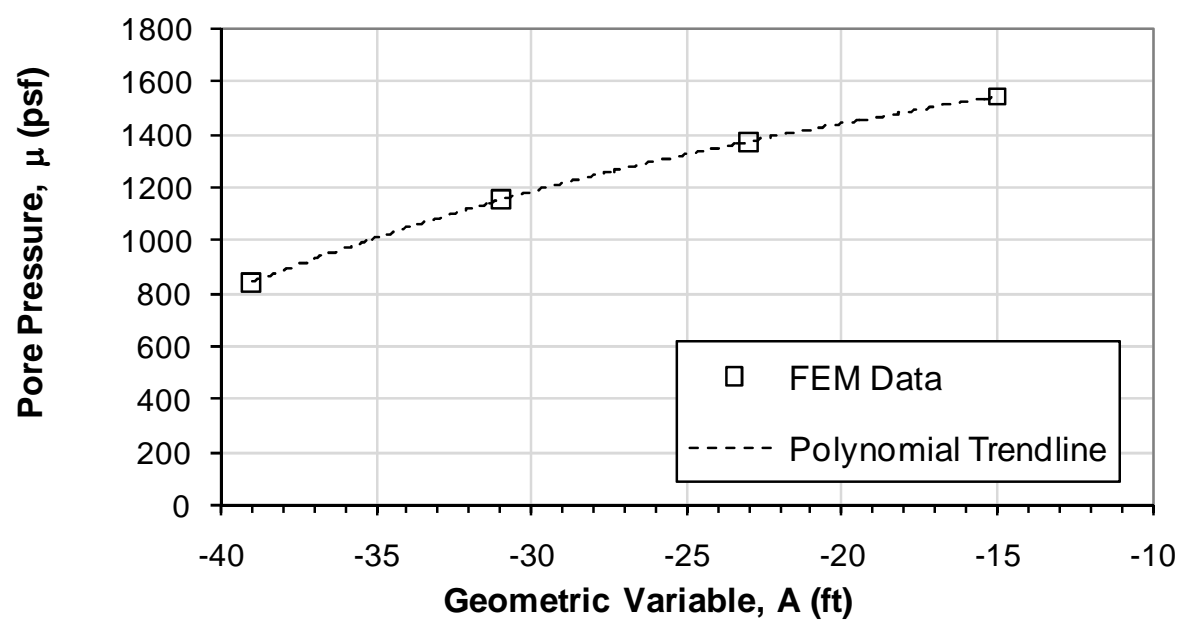

Figure A.33 Family of curves representing relationship of $\mu_{\mathrm{SAND}}, \mathrm{A}, \mathrm{Ksb}=65$ and, $\mathrm{Khv}=0.15$. 


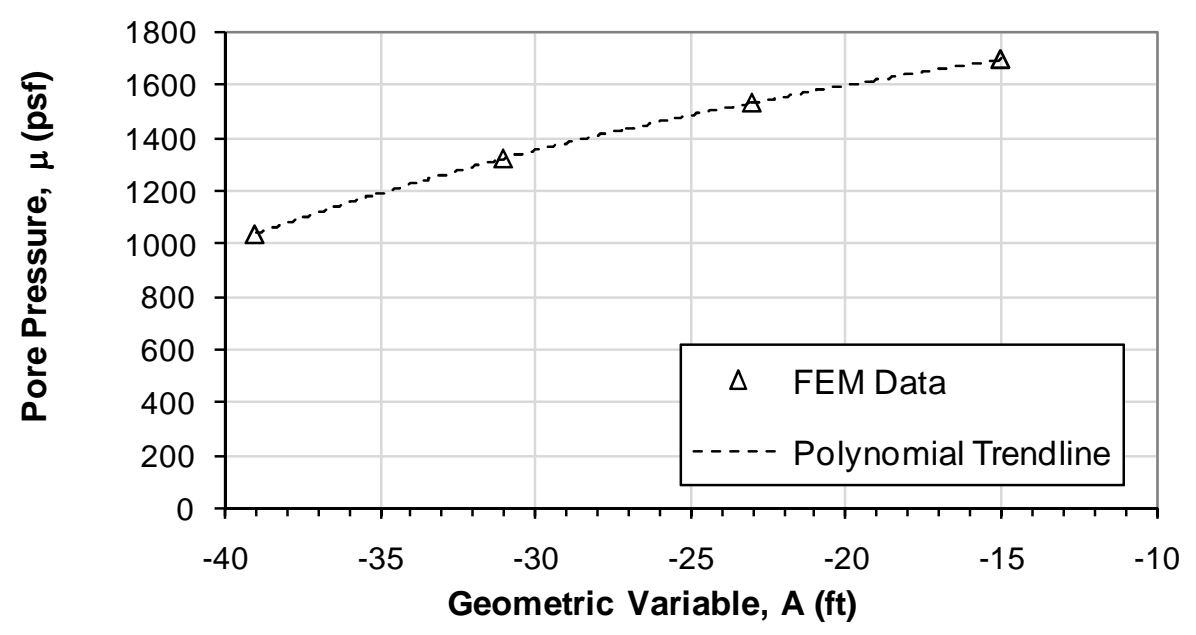

Figure A.34 Family of curves representing relationship of $\mu_{\text {SAND }}, \mathrm{A}, \mathrm{Ksb}=200$ and, $\mathrm{Khv}=0.15$.

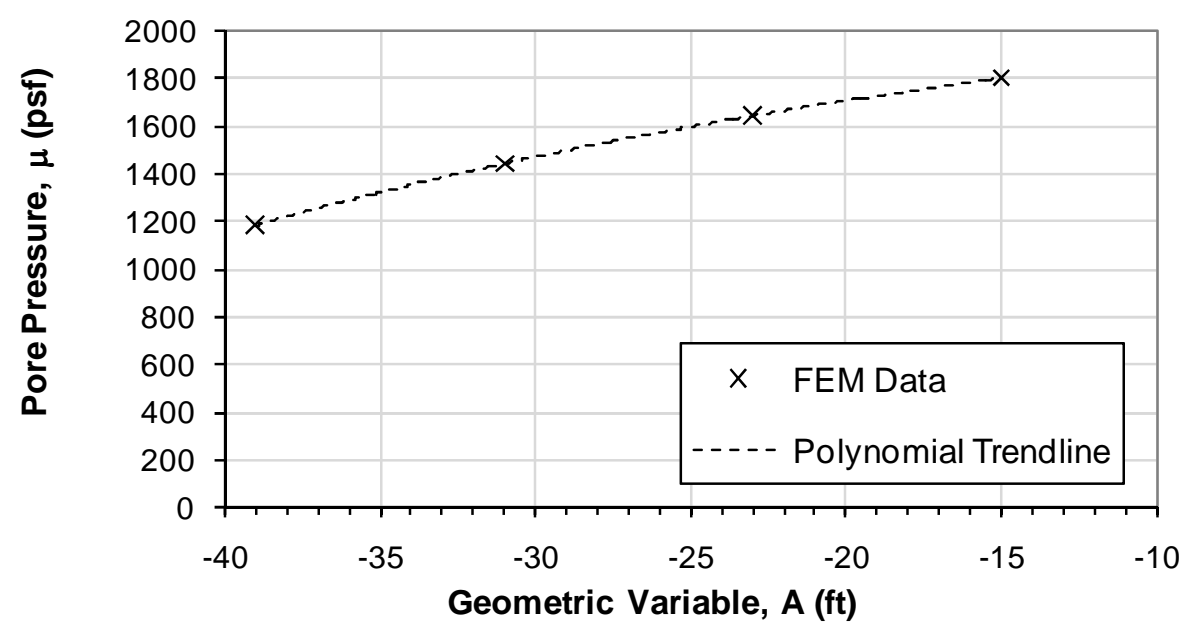

Figure A.35 Family of curves representing relationship of $\mu_{\mathrm{SAND}}, \mathrm{A}, \mathrm{Ksb}=1300$ and, $\mathrm{Khv}=0.15$. 


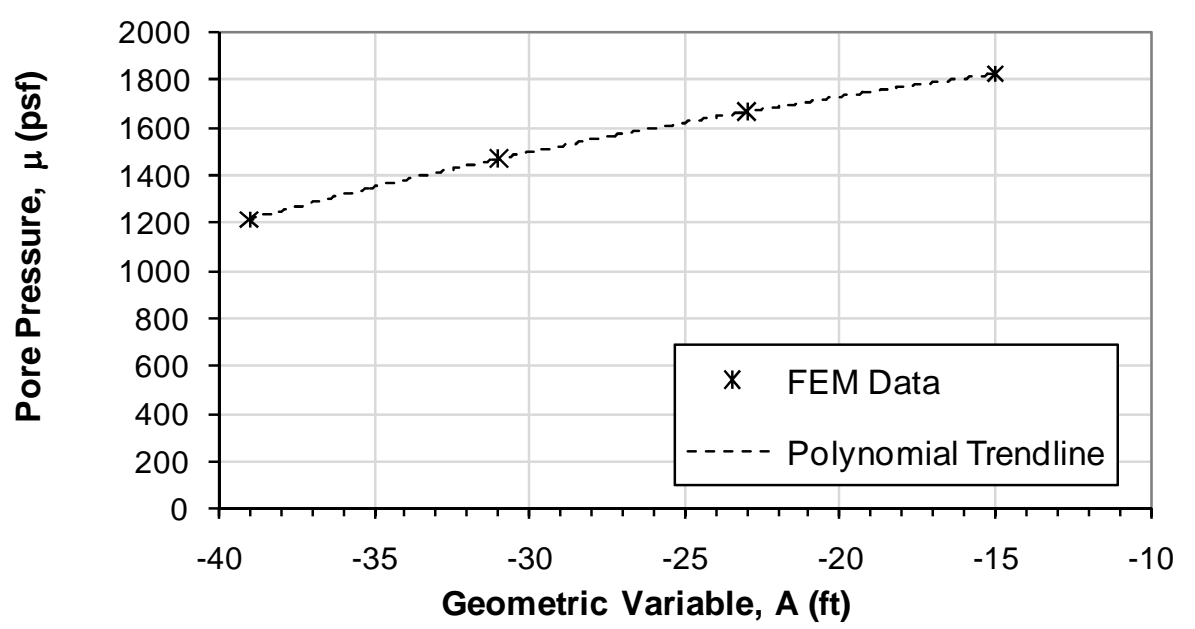

Figure A.36 Family of curves representing relationship of $\mu_{\mathrm{SAND}}, \mathrm{A}, \mathrm{Ksb}=13000$ and, $\mathrm{Khv}=0.15$.

Table A.12 Polynomial Trendline Coefficients and Coefficient of Determination $\left(\mathrm{R}^{2}\right)$ for Family of Curves in Figure A.31

\begin{tabular}{|c|c|c|c|c|c|}
\hline \multirow{2}{*}{ Ksb } & \multicolumn{5}{|c|}{$\boldsymbol{\mu}=\mathbf{a}_{\mathbf{3}} * \mathbf{A}^{\mathbf{3}}+\mathbf{a}_{\mathbf{2}} * \mathbf{A}^{\mathbf{2}}+\mathbf{a}_{\mathbf{1}} * \mathbf{A}+\mathbf{a}_{\mathbf{0}}$} \\
\cline { 2 - 6 } & $\mathbf{a}_{\mathbf{3}}$ & $\mathbf{a}_{\mathbf{2}}$ & $\mathbf{a}_{\mathbf{1}}$ & $\mathbf{a}_{\mathbf{0}}$ & $\mathbf{R}^{\mathbf{2}}$ \\
\hline $\mathbf{2 0}$ & $1.138 \mathrm{E}-02$ & $3.573 \mathrm{E}-01$ & $2.295 \mathrm{E}+01$ & $1.654 \mathrm{E}+03$ & 1.00 \\
\hline $\mathbf{6 5}$ & $1.145 \mathrm{E}-02$ & $3.803 \mathrm{E}-01$ & $2.307 \mathrm{E}+01$ & $1.844 \mathrm{E}+03$ & 1.00 \\
\hline $\mathbf{2 0 0}$ & $9.233 \mathrm{E}-03$ & $2.755 \mathrm{E}-01$ & $2.083 \mathrm{E}+01$ & $1.980 \mathrm{E}+03$ & 1.00 \\
\hline $\mathbf{1 3 0 0}$ & $6.313 \mathrm{E}-03$ & $1.218 \mathrm{E}-01$ & $1.767 \mathrm{E}+01$ & $2.063 \mathrm{E}+03$ & 1.00 \\
\hline $\mathbf{1 3 0 0 0}$ & $5.477 \mathrm{E}-03$ & $7.302 \mathrm{E}-02$ & $1.660 \mathrm{E}+01$ & $2.077 \mathrm{E}+03$ & 1.00 \\
\hline
\end{tabular}

Table A.13 Exit gradient $\mathrm{i}_{\mathrm{e}}$ SAND as a function of $\mathrm{A}, \mathrm{Ksb}$ and $\mathrm{Khv}=0.05$

\begin{tabular}{|c|c|c|c|c|c|}
\hline \multirow{2}{*}{$\mathbf{A}$} & \multicolumn{5}{|c|}{$\mathbf{i}_{\mathbf{e}}$ SAND } \\
\cline { 2 - 6 } & $\mathbf{K s b}=\mathbf{2 0}$ & $\mathbf{K s b}=\mathbf{6 5}$ & $\mathbf{K s b}=\mathbf{2 0 0}$ & $\mathbf{K s b}=\mathbf{1 3 0 0}$ & $\mathbf{K s b}=\mathbf{1 3 0 0 0}$ \\
\hline $\mathbf{- 7 6}$ & 0.667 & 0.769 & 0.874 & 0.947 & 0.962 \\
\hline $\mathbf{- 6 8 . 7 5}$ & 0.673 & 0.823 & 0.963 & 1.062 & 1.083 \\
\hline $\mathbf{- 6 1 . 5}$ & 0.684 & 0.914 & 1.115 & 1.264 & 1.295 \\
\hline $\mathbf{- 5 4 . 2 5}$ & 0.702 & 1.072 & 1.417 & 1.681 & 1.737 \\
\hline $\mathbf{- 4 7}$ & 0.768 & 1.256 & 1.897 & 2.442 & 2.564 \\
\hline
\end{tabular}




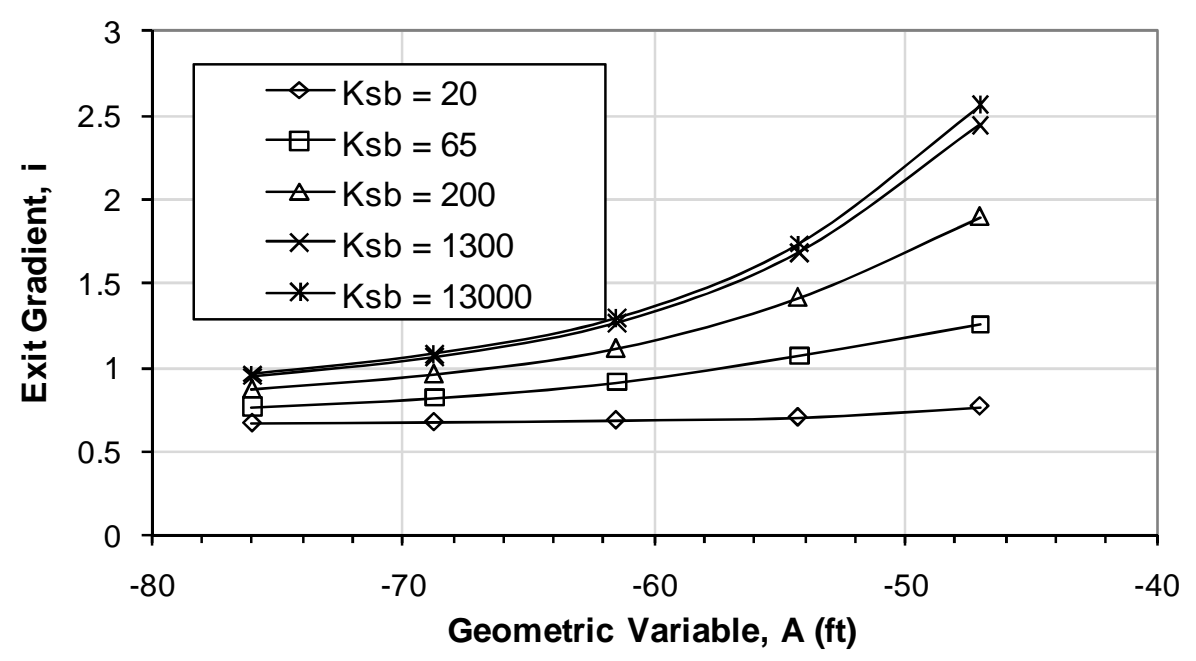

Figure A.37 Family of curves representing relationship of $\mathrm{i}_{\mathrm{e} S A N D}, \mathrm{~A}, \mathrm{Ksb}$ and, Khv $=0.05$.

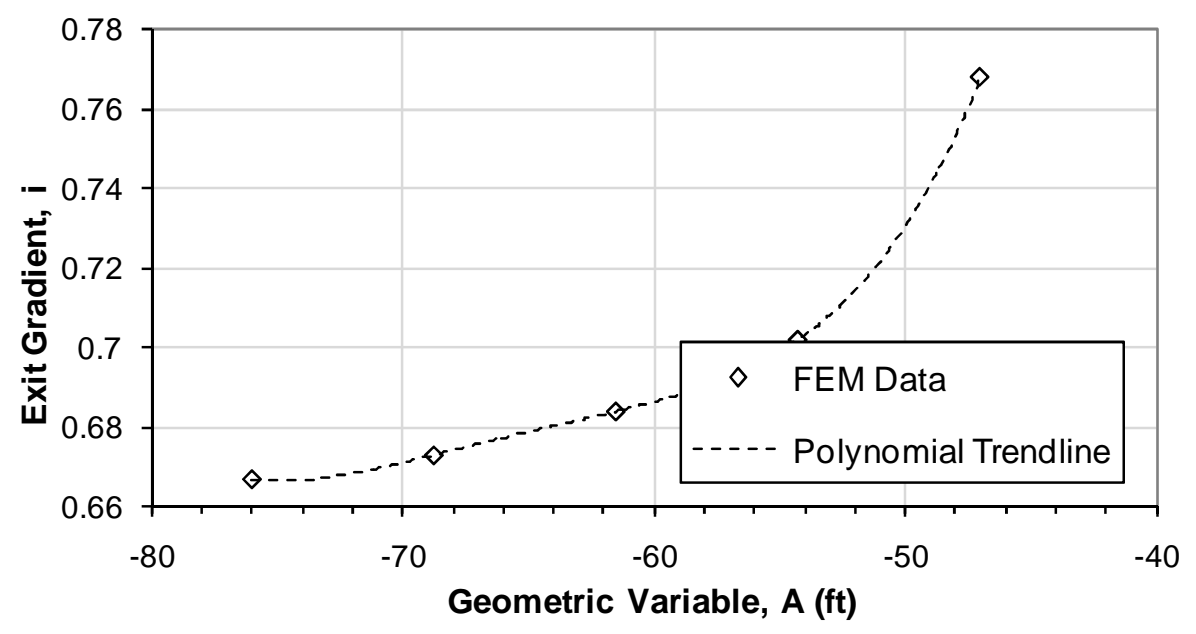

Figure A.38 Family of curves representing relationship between $\mathrm{i}_{\mathrm{e} \text { SAND }}, \mathrm{A}, \mathrm{Ksb}=20$ and, $\mathrm{Khv}=0.05$. 


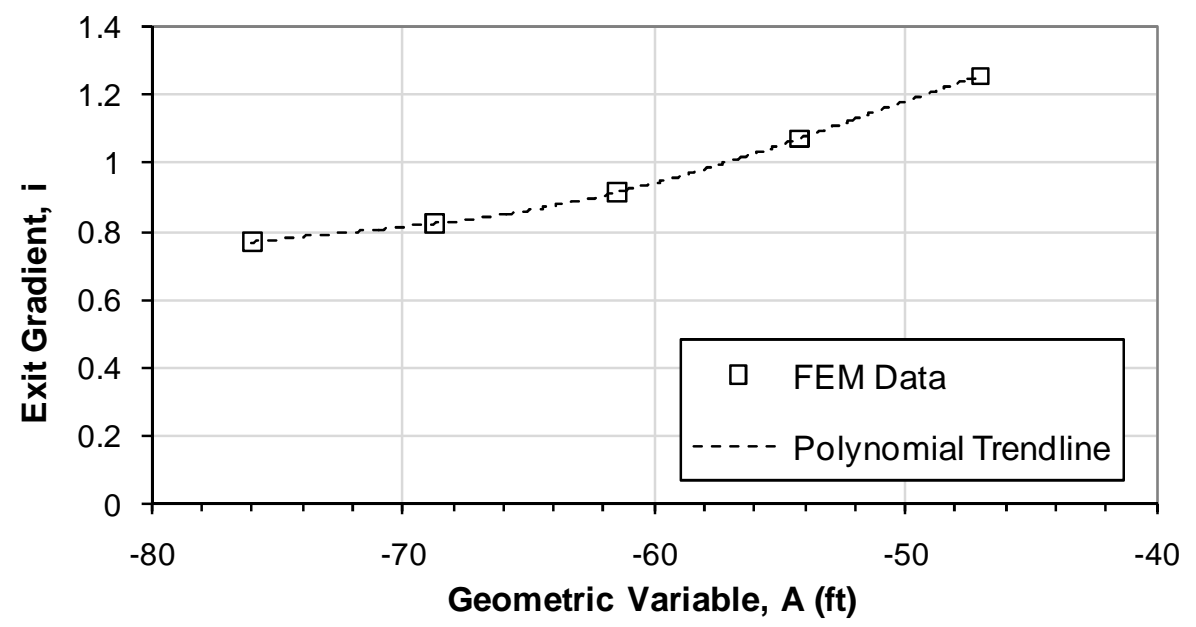

Figure A.39 Family of curves representing relationship of $\mathrm{i}_{\mathrm{e}}$ SAND $, \mathrm{A}, \mathrm{Ksb}=65$ and, $\mathrm{Khv}=0.05$.

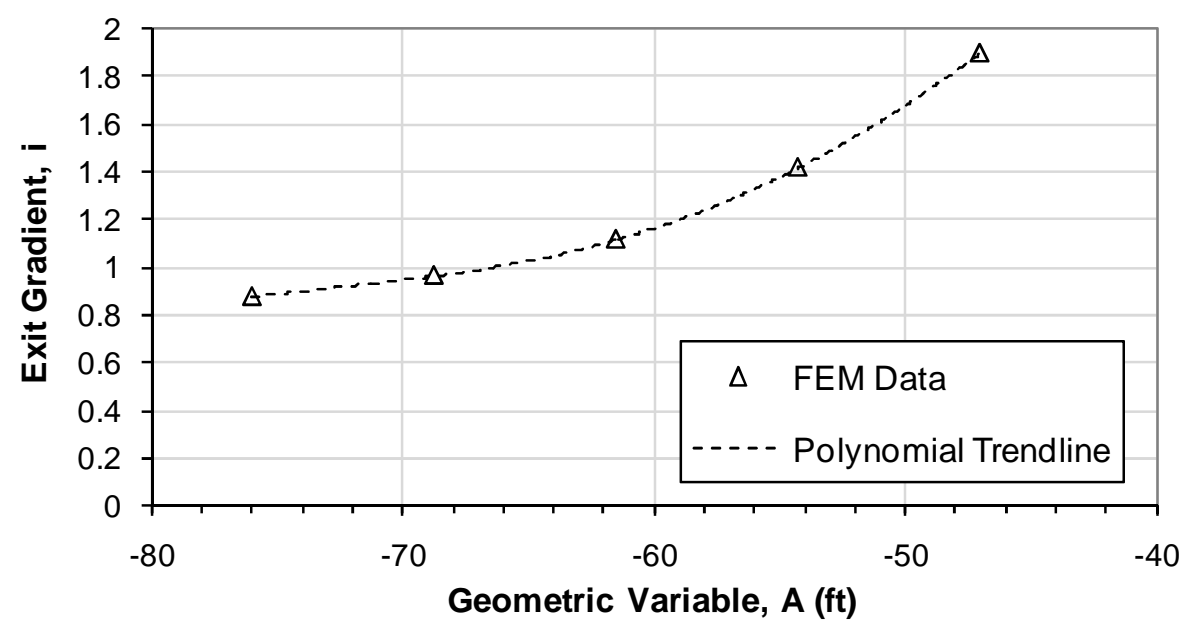

Figure A.40 Family of curves representing relationship of $\mathrm{i}_{\mathrm{e}}$ SAND, $\mathrm{A}, \mathrm{Ksb}=200$ and, $\mathrm{Khv}=0.05$. 


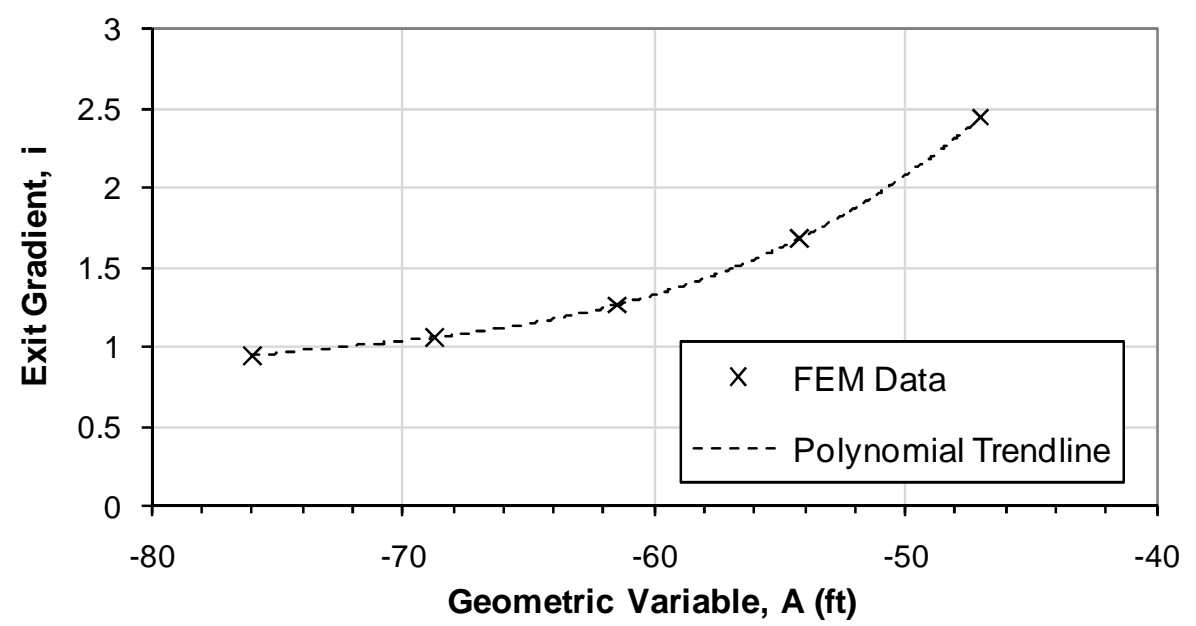

Figure A.41 Family of curves representing relationship of $\mathrm{i}_{\mathrm{e} S A N D}, \mathrm{~A}, \mathrm{Ksb}=1300$ and, $\mathrm{Khv}=0.05$.

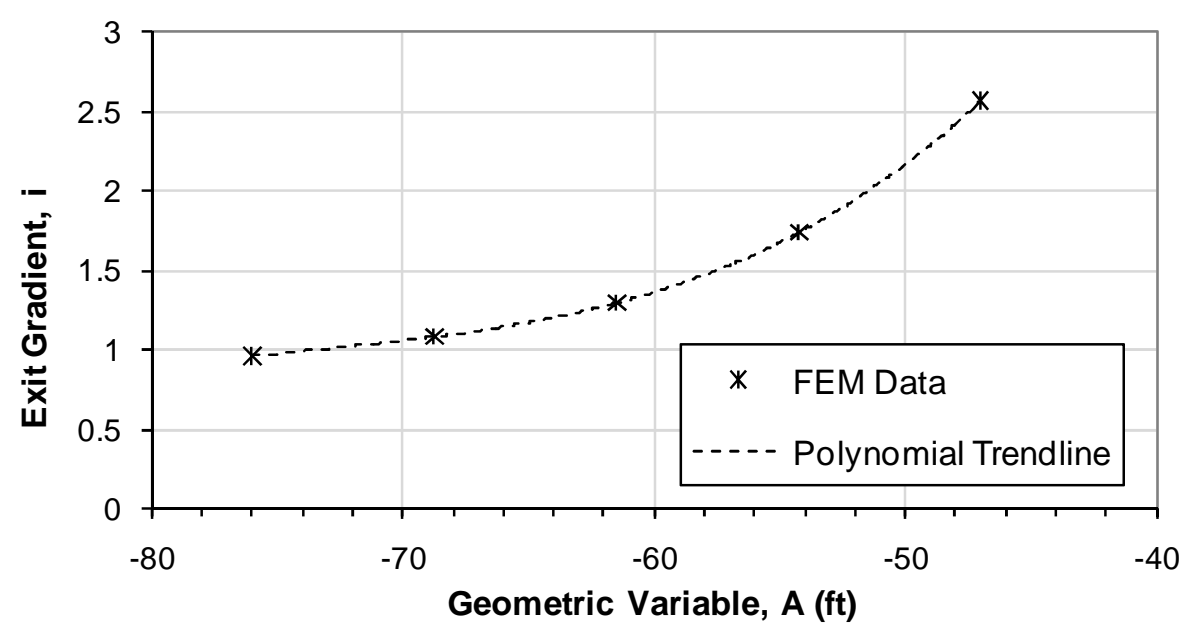

Figure A.42 Family of curves representing relationship of $\mathrm{i}_{\mathrm{e} \text { SAND, }} \mathrm{A}, \mathrm{Ksb}=13000$ and, $\mathrm{Khv}=0.05$.

Table A.14 Polynomial Trendline Coefficients and Coefficient of Determination $\left(\mathrm{R}^{2}\right)$ for Family of Curves in Figure A.37

\begin{tabular}{|c|c|c|c|c|c|c|}
\hline \multirow{2}{*}{ Ksb } & \multicolumn{6}{|c|}{$\mathbf{i}=\mathbf{a}_{\mathbf{4}} * \mathbf{A}^{\mathbf{4}}+\mathbf{a}_{\mathbf{3}} * \mathbf{A}^{\mathbf{3}}+\mathbf{a}_{\mathbf{2}} * \mathbf{A}^{\mathbf{2}}+\mathbf{a}_{\mathbf{1}} * \mathbf{A}+\mathbf{a}_{\mathbf{0}}$} \\
\cline { 2 - 8 } & $\mathbf{a}_{\mathbf{4}}$ & $\mathbf{a}_{\mathbf{3}}$ & $\mathbf{a}_{\mathbf{2}}$ & $\mathbf{a}_{\mathbf{1}}$ & $\mathbf{a}_{\mathbf{0}}$ & $\mathbf{R}^{\mathbf{2}}$ \\
\hline $\mathbf{2 0}$ & $5.882 \mathrm{E}-07$ & $1.541 \mathrm{E}-04$ & $1.512 \mathrm{E}-02$ & $6.598 \mathrm{E}-01$ & $1.151 \mathrm{E}+01$ & 1.00 \\
\hline $\mathbf{6 5}$ & $-1.071 \mathrm{E}-06$ & $-2.658 \mathrm{E}-04$ & $-2.405 \mathrm{E}-02$ & $-9.210 \mathrm{E}-01$ & $-1.128 \mathrm{E}+01$ & 1.00 \\
\hline $\mathbf{2 0 0}$ & $-8.898 \mathrm{E}-07$ & $-1.937 \mathrm{E}-04$ & $-1.408 \mathrm{E}-02$ & $-3.313 \mathrm{E}-01$ & $1.654 \mathrm{E}+00$ & 1.00 \\
\hline $\mathbf{1 3 0 0}$ & $1.508 \mathrm{E}-08$ & $5.991 \mathrm{E}-05$ & $1.276 \mathrm{E}-02$ & $9.429 \mathrm{E}-01$ & $2.473 \mathrm{E}+01$ & 1.00 \\
\hline $\mathbf{1 3 0 0 0}$ & $2.413 \mathrm{E}-07$ & $1.237 \mathrm{E}-04$ & $1.951 \mathrm{E}-02$ & $1.263 \mathrm{E}+00$ & $3.049 \mathrm{E}+01$ & 1.00 \\
\hline
\end{tabular}


Table A.15 Uplift (Pore) Pressure $\mu_{\text {SAND }}$ as a function of A, Ksb and Khv $=0.05$

\begin{tabular}{|c|c|c|c|c|c|}
\hline \multirow{2}{*}{$\mathbf{A}$} & \multicolumn{5}{|c|}{$\boldsymbol{\mu}_{\text {SAND }}$} \\
\cline { 2 - 6 } & $\mathbf{K s b}=\mathbf{2 0}$ & $\mathbf{K s b}=\mathbf{6 5}$ & $\mathbf{K s b}=\mathbf{2 0 0}$ & $\mathbf{K s b}=\mathbf{1 3 0 0}$ & $\mathbf{1 3 0 0 0}$ \\
\hline-39 & 548.658 & 743.427 & 965.35 & 1166.25 & 1213.95 \\
\hline $\mathbf{- 3 1}$ & 880.766 & 1081.77 & 1276.30 & 1433.10 & 1467.81 \\
\hline $\mathbf{- 2 3}$ & 1121.926 & 1319.53 & 1497.87 & 1635.65 & 1665.65 \\
\hline $\mathbf{- 1 5}$ & 1302.125 & 1495.38 & 1666.00 & 1796.69 & 1824.25 \\
\hline
\end{tabular}

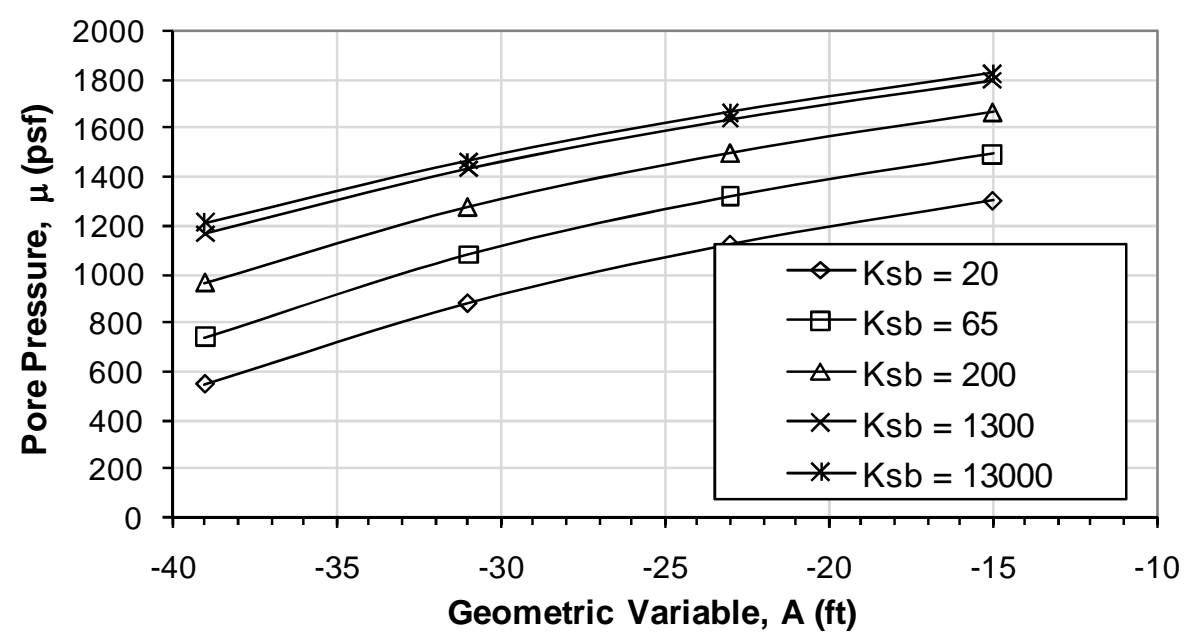

Figure A.43 Family of curves representing relationship of $\mu_{\text {SAND }}, A, K s b$ and, Khv $=0.05$.

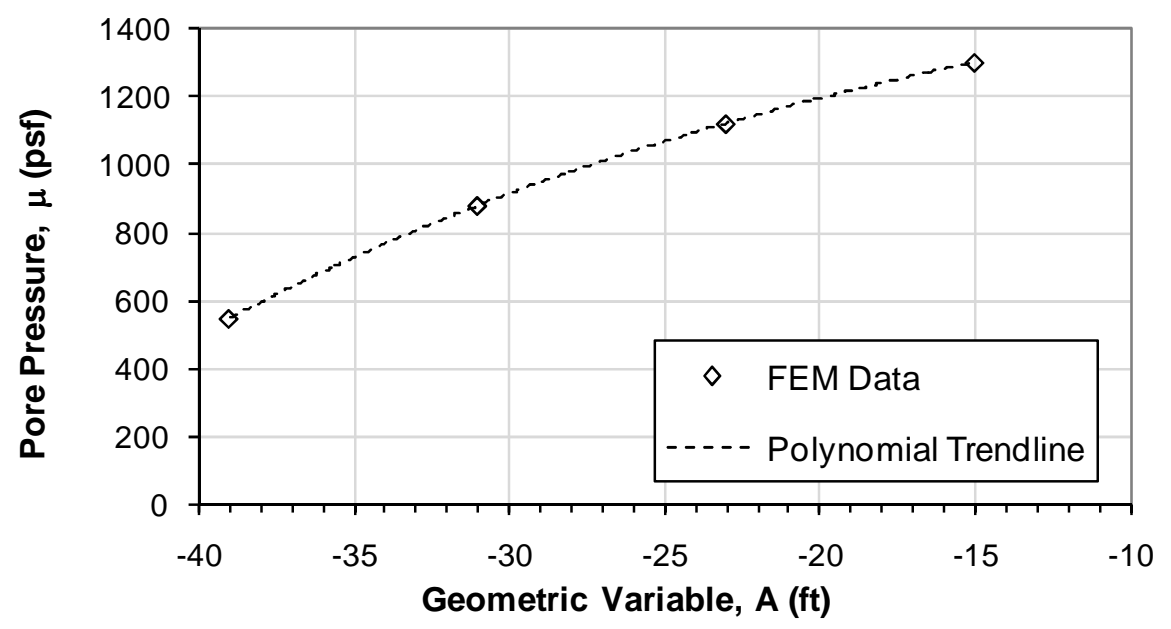

Figure A.44 Family of curves representing relationship of $\mu_{\mathrm{SAND}}, \mathrm{A}, \mathrm{Ksb}=20$ and, $\mathrm{Khv}=0.05$. 


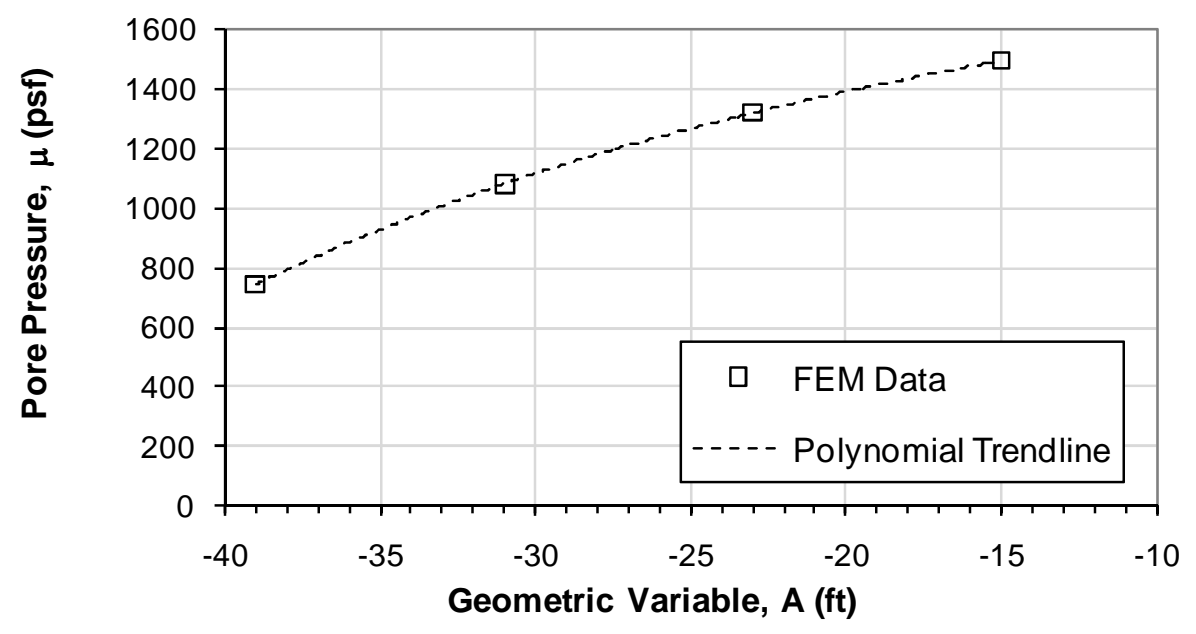

Figure A.45 Family of curves representing relationship of $\mu_{\text {SAND }}, A, K s b=65$ and, Khv $=0.05$.

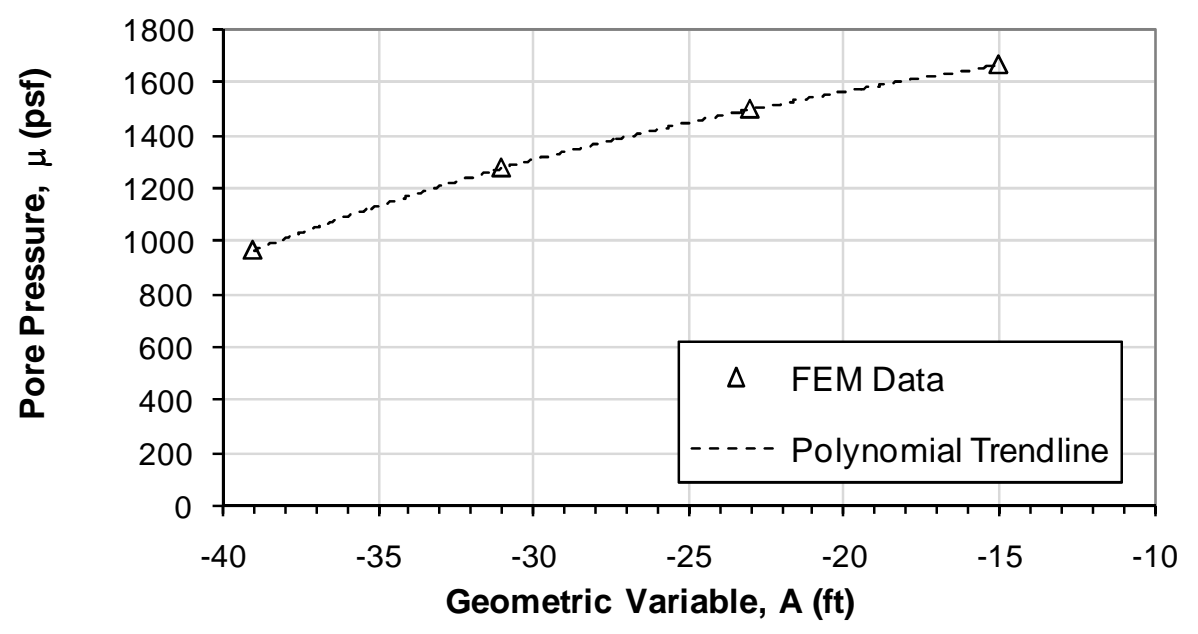

Figure A.46 Family of curves representing relationship of $\mu_{\mathrm{SAND}}, \mathrm{A}, \mathrm{Ksb}=200$ and, $\mathrm{Khv}=0.05$. 


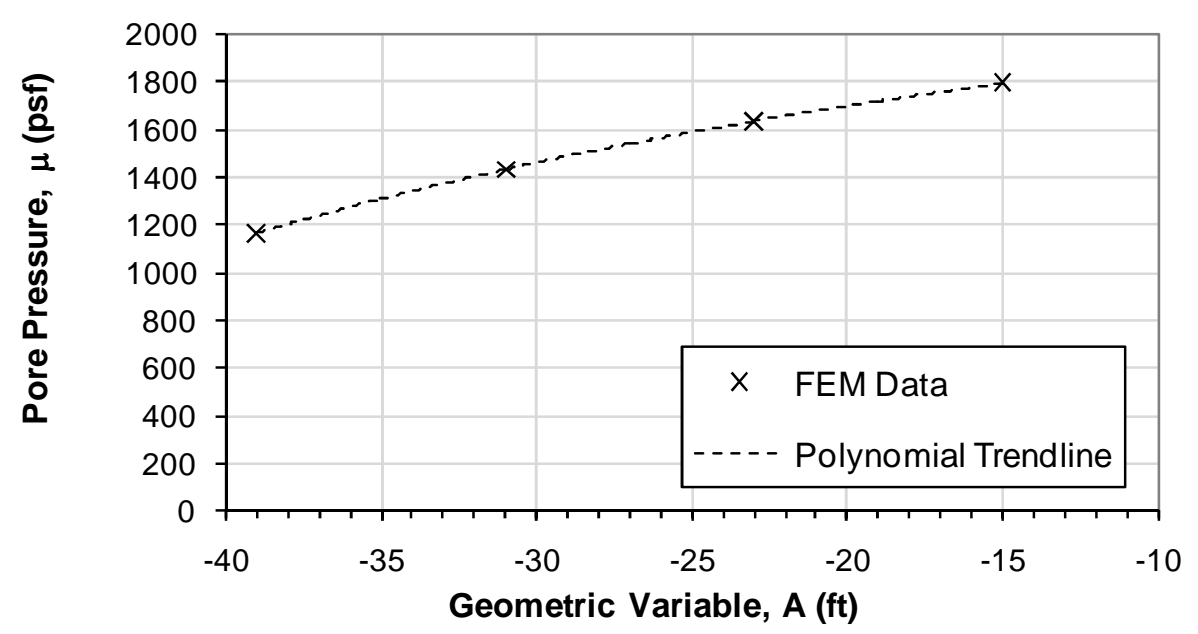

Figure A.47 Family of curves representing relationship of $\mu_{\mathrm{SAND}}, \mathrm{A}, \mathrm{Ksb}=1300$ and, $\mathrm{Khv}=0.05$.

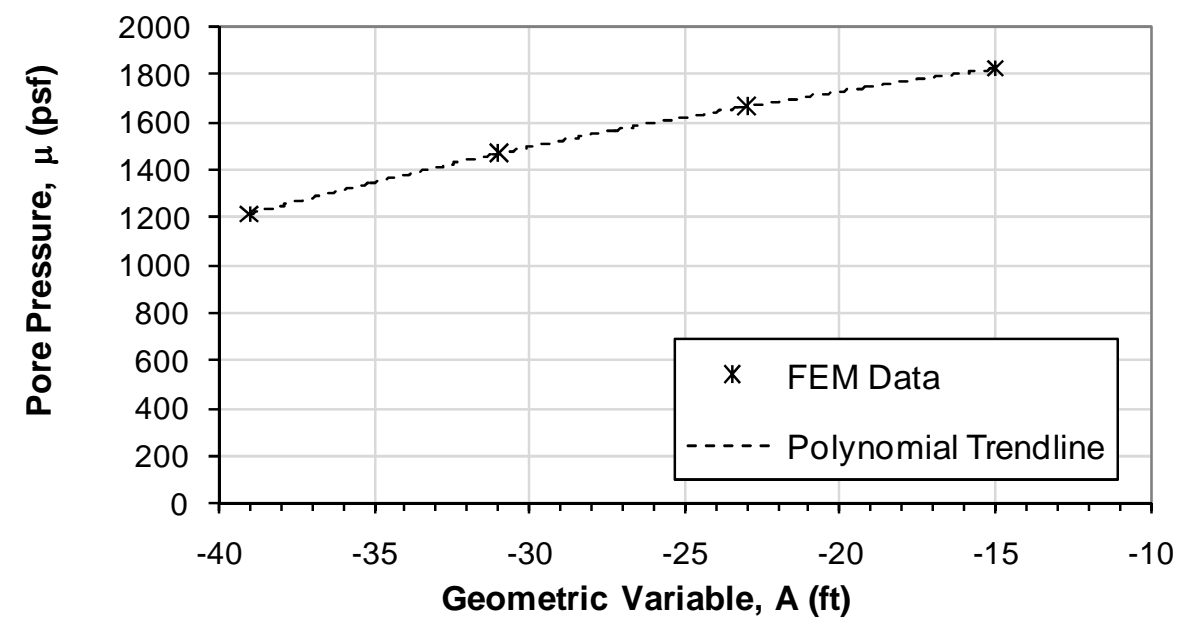

Figure A.48 Family of curves representing relationship of $\mu_{\text {SAND }}, \mathrm{A}, \mathrm{Ksb}=13000$ and, Khv $=0.05$.

Table A.16 Polynomial Trendline Coefficients and Coefficient of Determination $\left(\mathrm{R}^{2}\right)$ for Family of Curves in Figure A.43

\begin{tabular}{|c|c|c|c|c|c|}
\hline \multirow{2}{*}{ Ksb } & \multicolumn{5}{|c|}{$\boldsymbol{\mu}=\mathbf{a}_{\mathbf{3}} * \mathbf{A}^{\mathbf{3}}+\mathbf{a}_{\mathbf{2}} * \mathbf{A}^{\mathbf{2}}+\mathbf{a}_{\mathbf{1}} * \mathbf{A}+\mathbf{a}_{\mathbf{0}}$} \\
\cline { 2 - 6 } & $\mathbf{a}_{3}$ & $\mathbf{a}_{\mathbf{2}}$ & $\mathbf{a}_{\mathbf{1}}$ & $\mathbf{a}_{\mathbf{0}}$ & $\mathbf{R}^{\mathbf{2}}$ \\
\hline $\mathbf{2 0}$ & $9.761 \mathrm{E}-03$ & $1.973 \mathrm{E}-01$ & $1.929 \mathrm{E}+01$ & $1.580 \mathrm{E}+03$ & 1.00 \\
\hline $\mathbf{6 5}$ & $1.259 \mathrm{E}-02$ & $3.850 \mathrm{E}-01$ & $2.277 \mathrm{E}+01$ & $1.793 \mathrm{E}+03$ & 1.00 \\
\hline $\mathbf{2 0 0}$ & $1.170 \mathrm{E}-02$ & $3.897 \mathrm{E}-01$ & $2.297 \mathrm{E}+01$ & $1.962 \mathrm{E}+03$ & 1.00 \\
\hline $\mathbf{1 3 0 0}$ & $7.419 \mathrm{E}-03$ & $1.876 \mathrm{E}-01$ & $1.911 \mathrm{E}+01$ & $2.066 \mathrm{E}+03$ & 1.00 \\
\hline $\mathbf{1 3 0 0 0}$ & $5.457 \mathrm{E}-03$ & $6.996 \mathrm{E}-02$ & $1.649 \mathrm{E}+01$ & $2.074 \mathrm{E}+03$ & 1.00 \\
\hline
\end{tabular}


Table A.17 Exit gradient $\mathrm{i}_{\mathrm{e} \text { SAND }}$ as a function of $\mathrm{A}, \mathrm{Ksb}$ and $\mathrm{Khv}=0.005$

\begin{tabular}{|c|c|c|c|c|c|}
\hline \multirow{2}{*}{$A$} & \multicolumn{5}{|c|}{$\mathbf{i}_{\text {e SAND }}$} \\
\cline { 2 - 6 } & $\mathbf{K s b}=\mathbf{2 0}$ & $\mathbf{K s b}=\mathbf{6 5}$ & $\mathbf{K s b}=\mathbf{2 0 0}$ & $\mathbf{K s b}=\mathbf{1 3 0 0}$ & $\mathbf{K s b}=\mathbf{1 3 0 0 0}$ \\
\hline $\mathbf{- 7 6}$ & 0.644 & 0.728 & 0.96 & 1.231 & 1.308 \\
\hline $\mathbf{- 6 8 . 7 5}$ & 0.665 & 0.745 & 0.989 & 1.38 & 1.494 \\
\hline $\mathbf{- 6 1 . 5}$ & 0.685 & 0.763 & 1.029 & 1.613 & 1.797 \\
\hline $\mathbf{- 5 4 . 2 5}$ & 0.704 & 0.78 & 1.085 & 1.998 & 2.32 \\
\hline $\mathbf{- 4 7}$ & 0.723 & 0.798 & 1.065 & 2.327 & 2.864 \\
\hline
\end{tabular}

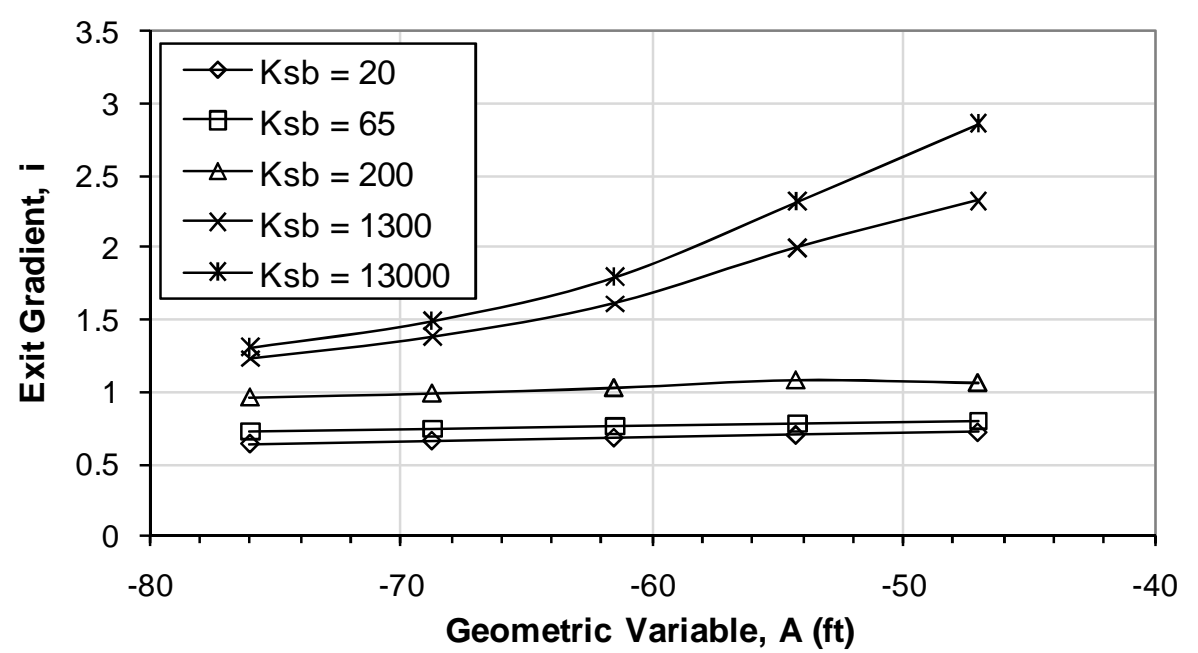

Figure A.49 Family of curves representing relationship of $\mathrm{i}_{\mathrm{e}}$ SAND, A, Ksb and, Khv $=0.005$.

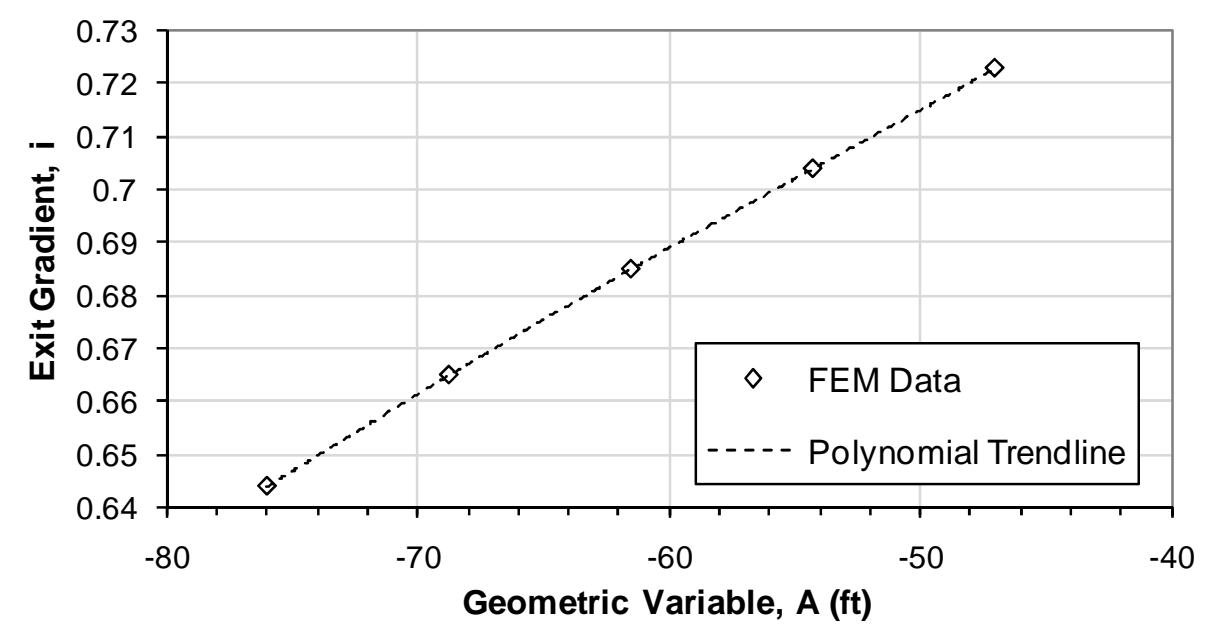

Figure A.50 Family of curves representing relationship of $\mathrm{i}_{\mathrm{e}}$ SAND, $\mathrm{A}, \mathrm{Ksb}=20$ and, $\mathrm{Khv}=0.005$. 


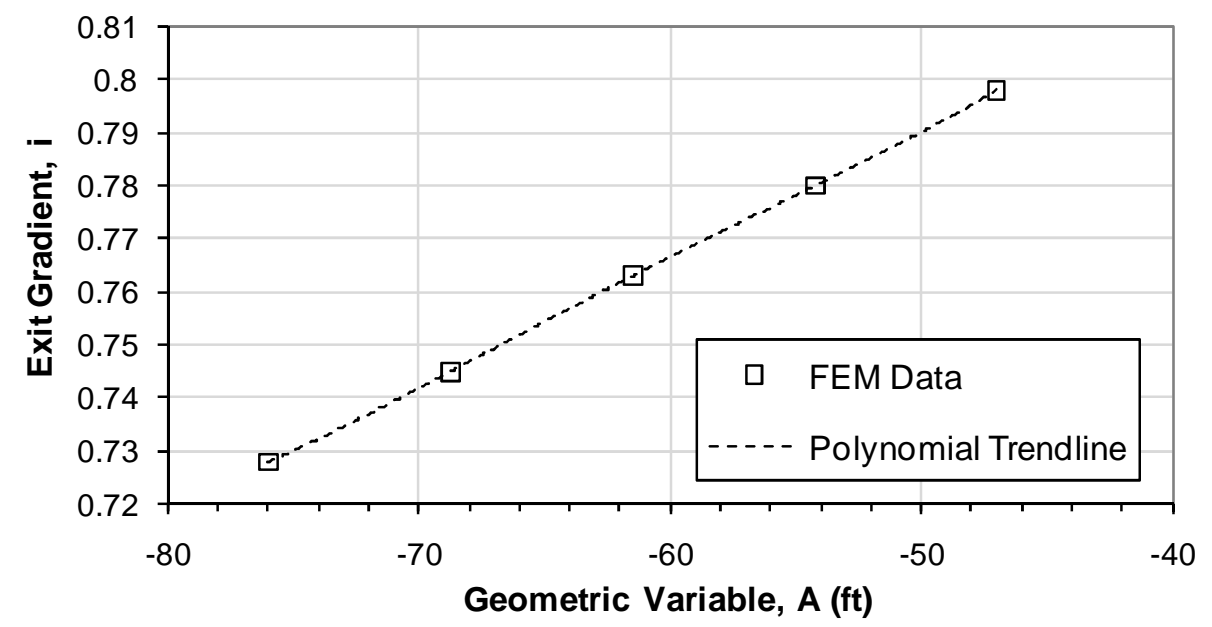

Figure A.51 Family of curves representing relationship of $\mathrm{i}_{\mathrm{e} \text { SAND }}, \mathrm{A}, \mathrm{Ksb}=65$ and, $\mathrm{Khv}=0.005$.

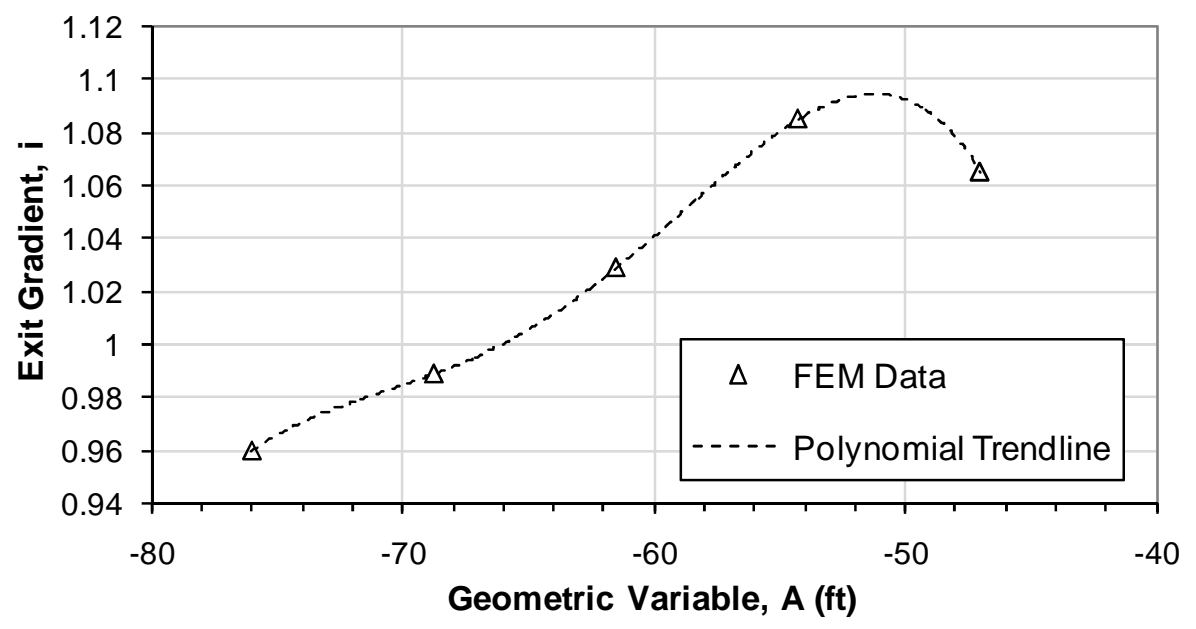

Figure A.52 Family of curves representing relationship of $\mathrm{i}_{\mathrm{e} \text { SAND }}, \mathrm{A}, \mathrm{Ksb}=200$ and, $\mathrm{Khv}=0.005$. 


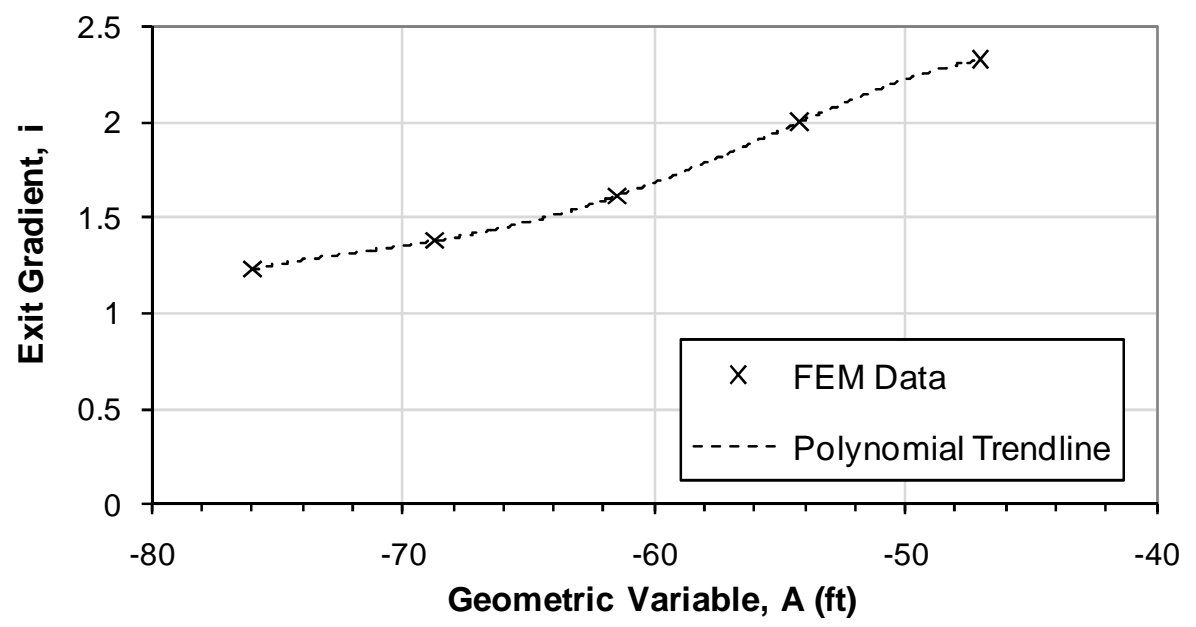

Figure A.53 Family of curves representing relationship of $\mathrm{i}_{\mathrm{e} \text { SAND }}, \mathrm{A}, \mathrm{Ksb}=1300$ and, Khv $=0.005$.

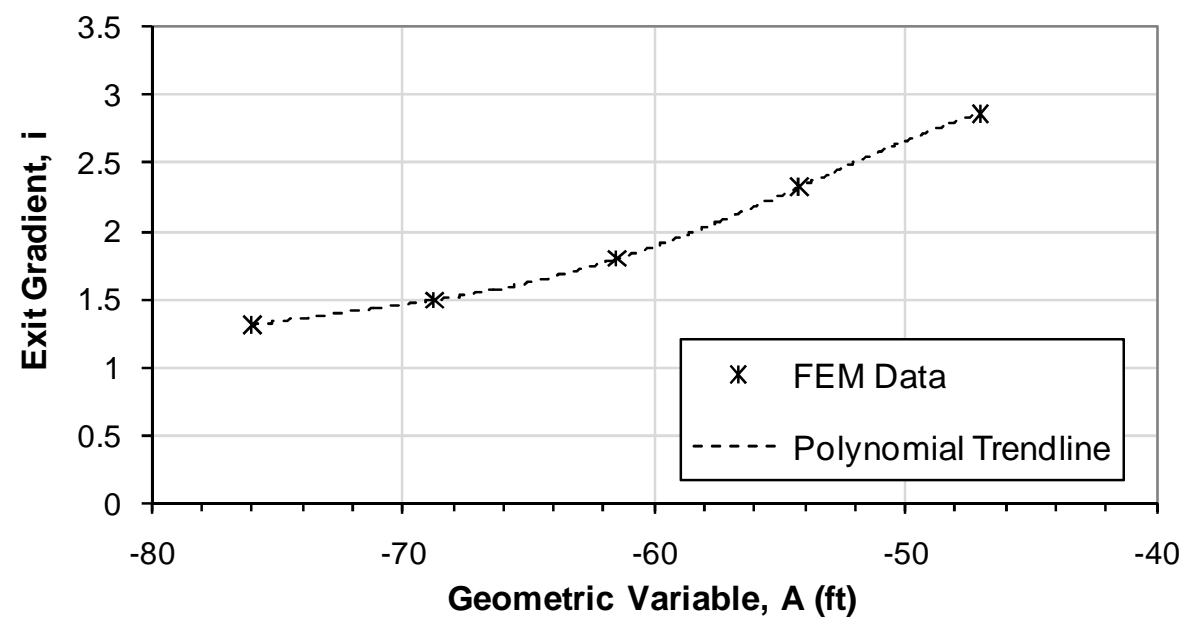

Figure A.54 Family of curves representing relationship of $\mathrm{i}_{\mathrm{e} \text { SAND }}, \mathrm{A}, \mathrm{Ksb}=13000$ and, Khv $=0.005$. 
Table A.18 Polynomial Trendline Coefficients and Coefficient of Determination $\left(\mathrm{R}^{2}\right)$ for Family of Curves in Figure A.49

\begin{tabular}{|c|c|c|c|c|c|c|}
\hline \multirow{2}{*}{ Ksb } & \multicolumn{6}{|c|}{$\mathbf{i}=\mathbf{a}_{\mathbf{4}} * \mathbf{A}^{\mathbf{4}}+\mathbf{a}_{\mathbf{3}} * \mathbf{A}^{\mathbf{3}}+\mathbf{a}_{\mathbf{2}} * \mathbf{A}^{\mathbf{2}}+\mathbf{a}_{\mathbf{1}} * \mathbf{A}+\mathbf{a}_{\mathbf{0}}$} \\
\cline { 2 - 7 } & $\mathbf{\mathbf { a } _ { 4 }}$ & $\mathbf{\mathbf { a } _ { 3 }}$ & $\mathbf{\mathbf { a } _ { 2 }}$ & $\mathbf{a}_{\mathbf{1}}$ & $\mathbf{a}_{\mathbf{0}}$ & $\mathbf{R}^{\mathbf{2}}$ \\
\hline $\mathbf{2 0}$ & $1.508 \mathrm{E}-08$ & $3.929 \mathrm{E}-06$ & $3.723 \mathrm{E}-04$ & $1.792 \mathrm{E}-02$ & $1.077 \mathrm{E}+00$ & 1.00 \\
\hline $\mathbf{6 5}$ & $6.032 \mathrm{E}-08$ & $1.484 \mathrm{E}-05$ & $1.356 \mathrm{E}-03$ & $5.698 \mathrm{E}-02$ & $1.726 \mathrm{E}+00$ & 1.00 \\
\hline $\mathbf{2 0 0}$ & $-1.463 \mathrm{E}-06$ & $-3.789 \mathrm{E}-04$ & $-3.648 \mathrm{E}-02$ & $-1.541 \mathrm{E}+00$ & $-2.299 \mathrm{E}+01$ & 1.00 \\
\hline $\mathbf{1 3 0 0}$ & $-4.162 \mathrm{E}-06$ & $-1.055 \mathrm{E}-03$ & $-9.844 \mathrm{E}-02$ & $-3.971 \mathrm{E}+00$ & $-5.604 \mathrm{E}+01$ & 1.00 \\
\hline $\mathbf{1 3 0 0 0}$ & $-4.555 \mathrm{E}-06$ & $-1.141 \mathrm{E}-03$ & $-1.049 \mathrm{E}-01$ & $-4.131 \mathrm{E}+00$ & $-5.585 \mathrm{E}+01$ & 1.00 \\
\hline
\end{tabular}

Table A.19 Uplift (Pore) Pressure $\mu_{\text {SAND }}$ as a function of A, Ksb and Khv $=0.005$

\begin{tabular}{|c|c|c|c|c|c|}
\hline \multirow{2}{*}{$\mathbf{A}$} & \multicolumn{5}{|c|}{$\boldsymbol{\mu}_{\text {SAND }}$} \\
\cline { 2 - 6 } & $\mathbf{K s b}=\mathbf{2 0}$ & $\mathbf{K s b}=\mathbf{6 5}$ & $\mathbf{K s b}=\mathbf{2 0 0}$ & $\mathbf{K s b}=\mathbf{1 3 0 0}$ & $\mathbf{1 3 0 0 0}$ \\
\hline $\mathbf{- 3 9}$ & 428.313 & 511.981 & 678.976 & 1038.39 & 1196.6 \\
\hline $\mathbf{- 3 1}$ & 759 & 875.911 & 1076.8 & 1365.58 & 1459.41 \\
\hline $\mathbf{- 2 3}$ & 1013.844 & 1166.52 & 1366.78 & 1596.31 & 1661.17 \\
\hline $\mathbf{- 1 5}$ & 1204.154 & 1368.08 & 1559.02 & 1764.93 & 1821.11 \\
\hline
\end{tabular}

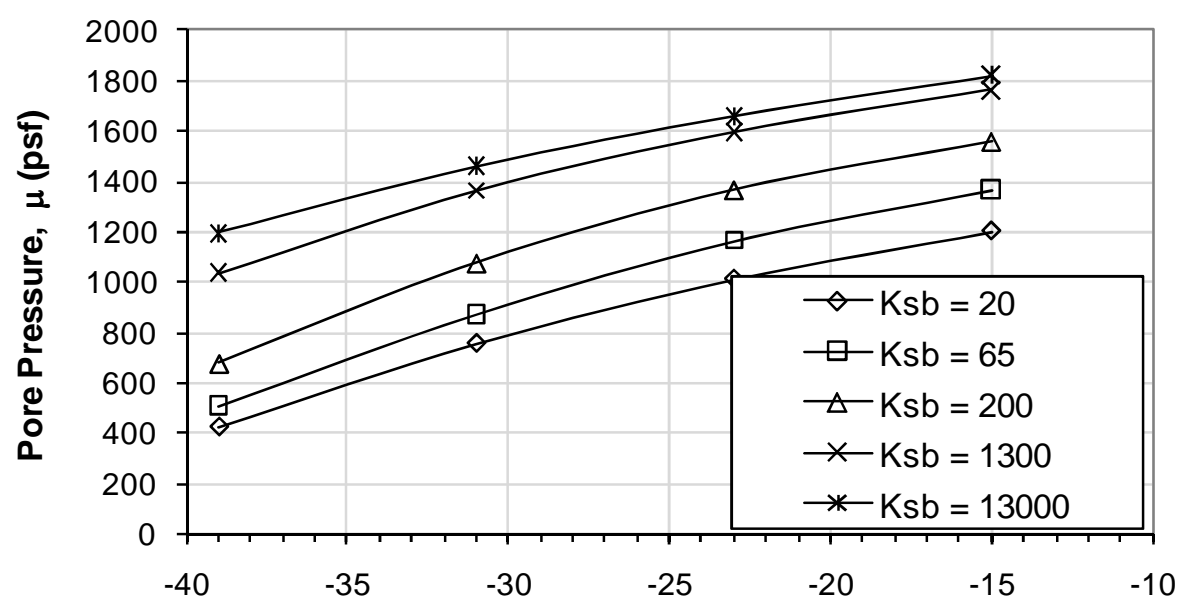

Figure A.55 Family of curves representing relationship of $\mu_{\mathrm{SAND}}, \mathrm{A}, \mathrm{Ksb}$ and, Khv $=0.005$. 


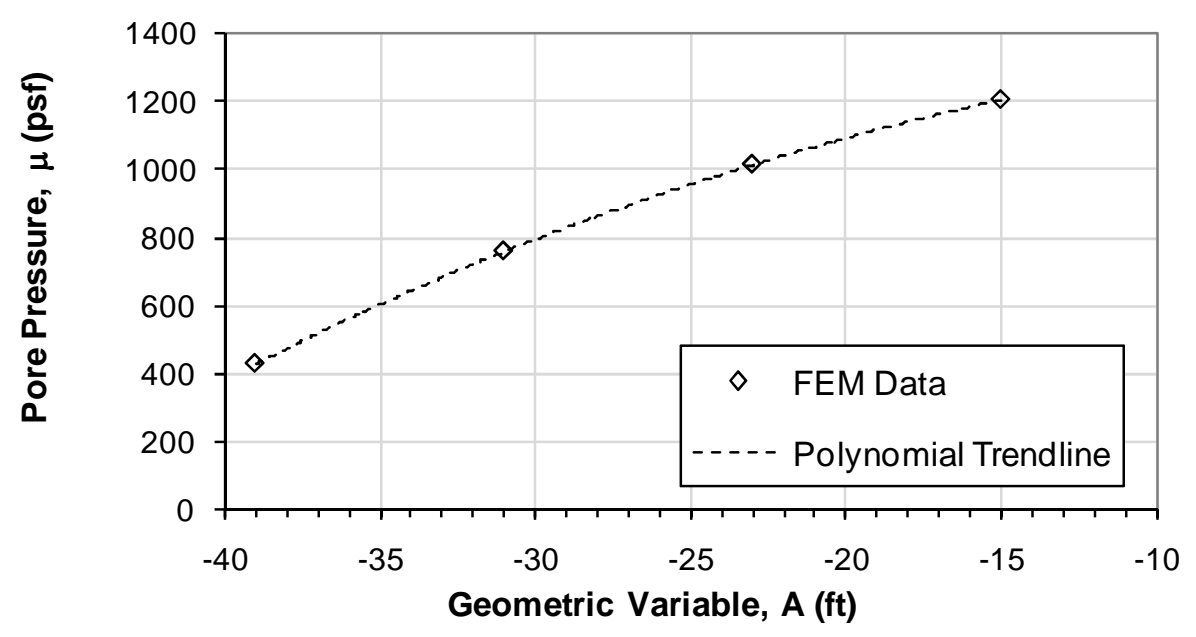

Figure A.56 Family of curves representing relationship of $\mu_{\text {SAND }}, \mathrm{A}, \mathrm{Ksb}=20$ and, $\mathrm{Khv}=0.005$.

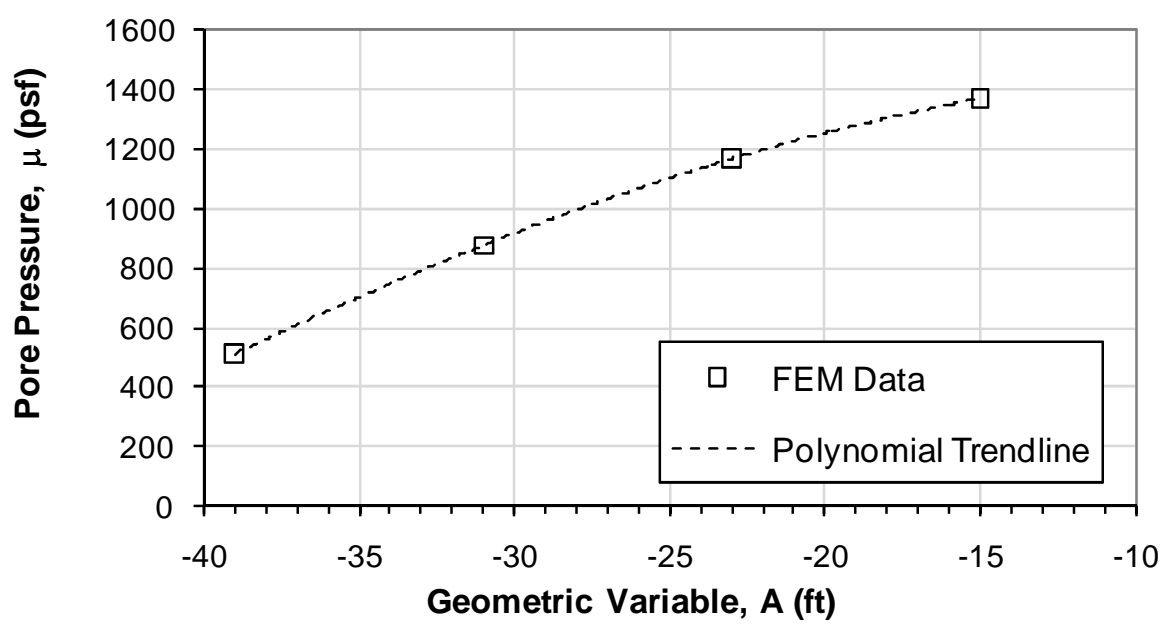

Figure A.57 Family of curves representing relationship of $\mu_{\mathrm{SAND}}, \mathrm{A}, \mathrm{Ksb}=65$ and, $\mathrm{Khv}=0.005$. 


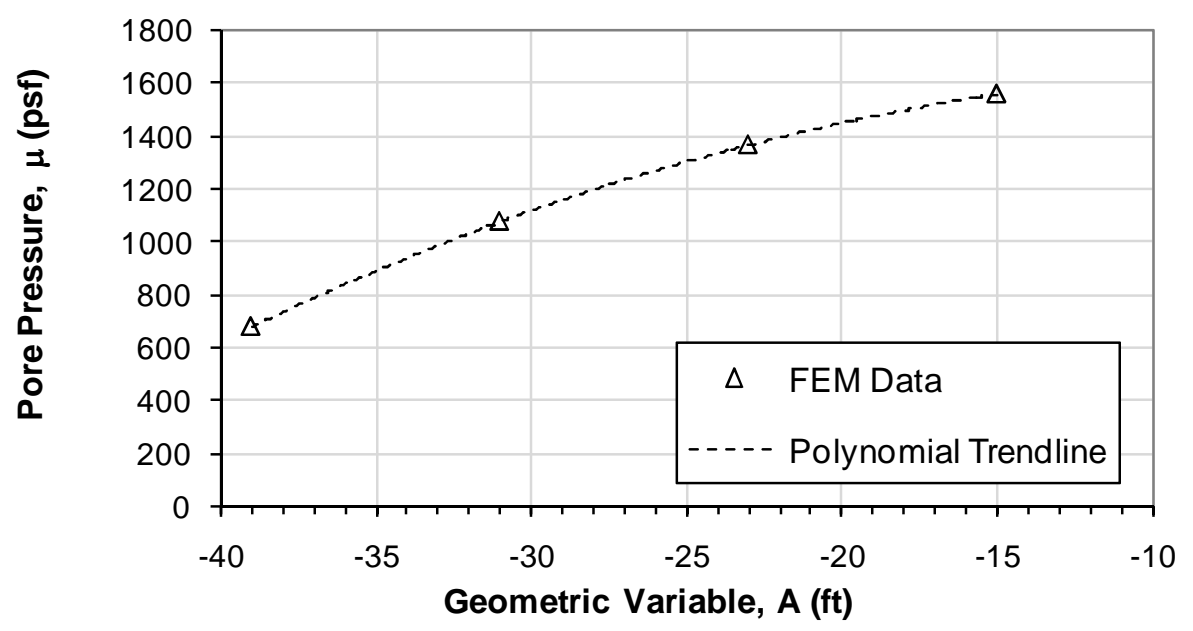

Figure A.58 Family of curves representing relationship of $\mu_{\mathrm{SAND}}, \mathrm{A}, \mathrm{Ksb}=200$ and, $\mathrm{Khv}=0.005$.

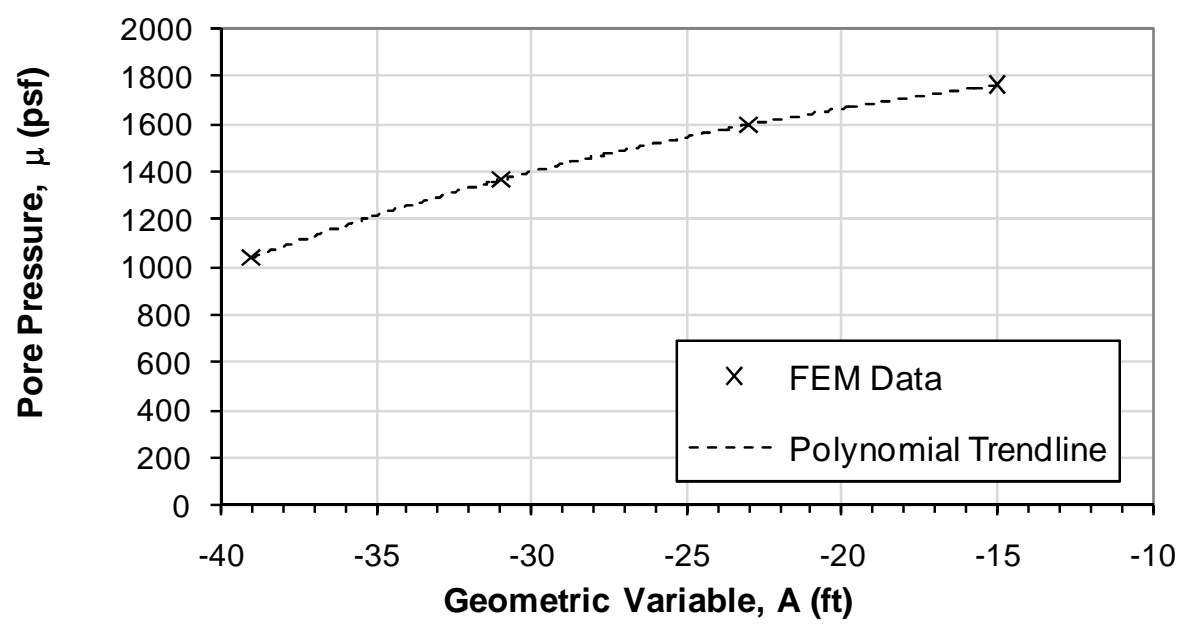

Figure A.59 Family of curves representing relationship of $\mu_{\mathrm{SAND}}, \mathrm{A}, \mathrm{Ksb}=1300$ and, Khv $=0.005$. 


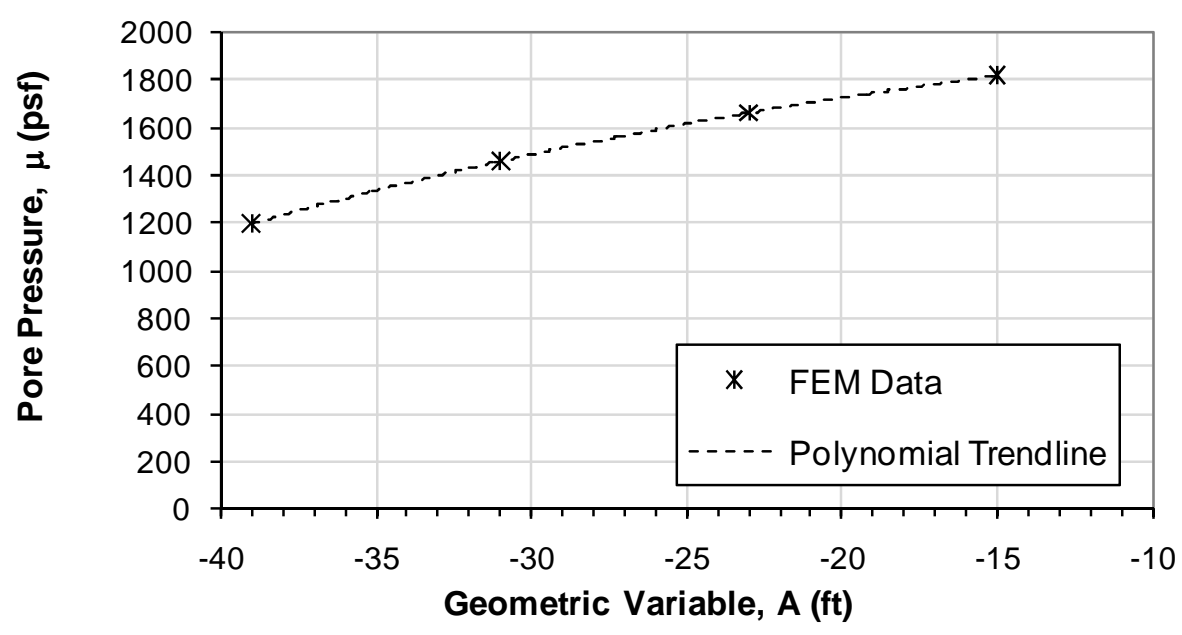

Figure A.60 Family of curves representing relationship of $\mu_{\text {SAND }}, \mathrm{A}, \mathrm{Ksb}=13000$ and, Khv $=0.005$.

Table A.20 Polynomial Trendline Coefficients and Coefficient of Determination $\left(\mathrm{R}^{2}\right)$ for Family of Curves in Figure A.55

\begin{tabular}{|c|c|c|c|c|c|}
\hline \multirow{2}{*}{ Ksb } & \multicolumn{5}{|c|}{$\boldsymbol{\mu}=\mathbf{a}_{\mathbf{3}} * \mathbf{A}^{\mathbf{3}}+\mathbf{a}_{\mathbf{2}} * \mathbf{A}^{\mathbf{2}}+\mathbf{a}_{\mathbf{1}} * \mathbf{A}+\mathbf{a}_{\mathbf{0}}$} \\
\cline { 2 - 6 } & $\mathbf{\mathbf { a } _ { 3 }}$ & $\mathbf{\mathbf { a } _ { 2 }}$ & $\mathbf{a}_{\mathbf{1}}$ & $\mathbf{a}_{\mathbf{0}}$ & $\mathbf{R}^{\mathbf{2}}$ \\
\hline $\mathbf{2 0}$ & $3.681 \mathrm{E}-03$ & $-2.502 \mathrm{E}-01$ & $1.024 \mathrm{E}+01$ & $1.426 \mathrm{E}+03$ & 1.00 \\
\hline $\mathbf{6 5}$ & $-5.116 \mathrm{E}-03$ & $-1.049 \mathrm{E}+00$ & $-9.030 \mathrm{E}+00$ & $1.451 \mathrm{E}+03$ & 1.00 \\
\hline $\mathbf{2 0 0}$ & $3.295 \mathrm{E}-03$ & $-5.362 \mathrm{E}-01$ & $3.579 \mathrm{E}-02$ & $1.691 \mathrm{E}+03$ & 1.00 \\
\hline $\mathbf{1 3 0 0}$ & $1.118 \mathrm{E}-02$ & $2.861 \mathrm{E}-01$ & $1.966 \mathrm{E}+01$ & $2.033 \mathrm{E}+03$ & 1.00 \\
\hline $\mathbf{1 3 0 0 0}$ & $6.267 \mathrm{E}-03$ & $1.058 \mathrm{E}-01$ & $1.712 \mathrm{E}+01$ & $2.075 \mathrm{E}+03$ & 1.00 \\
\hline
\end{tabular}




\begin{tabular}{c|c|c|c|c|} 
Variable & \multicolumn{1}{c}{ MLV } & \multicolumn{1}{c}{$\sigma$} & \multicolumn{1}{c}{ MAX } & \multicolumn{1}{c}{ MIN } \\
\cline { 2 - 5 } $\log ($ Kb $)$ & -6.00 & 0.67 & -5.10 & -7.00 \\
\cline { 2 - 5 } $\log ($ Ks $)$ & -3.00 & 0.67 & -2.00 & -3.80 \\
\cline { 2 - 5 } $\log ($ Khv $)$ & -0.60 & 0.163 & -0.30 & -2.30 \\
\cline { 2 - 5 }$A$ & -47 & - & -15 & -76 \\
\cline { 2 - 5 } yb & 120 & 5.000 & 130 & 110 \\
\cline { 2 - 5 } ys & 130 & 5.000 & 140 & 120 \\
\cline { 2 - 5 } & & & &
\end{tabular}

\begin{tabular}{|c|c|c|c|c|c|}
\hline$A$ & $\log (\mathrm{Kb})$ & $\log (\mathrm{Ks})$ & $\log (\mathrm{Khv})$ & $\mathrm{yb}$ & $\mathrm{ys}$ \\
\hline-41.75 & -5.16 & -2.26 & -0.35 & 119.55 & 130.45 \\
\hline
\end{tabular}

\begin{tabular}{|c|c|c|c|c|c|}
\hline $\mathrm{A}$ & $\log (\mathrm{Kb})$ & $\log (\mathrm{Ks})$ & $\log (\mathrm{Khv})$ & $\mathrm{yb}$ & $\mathrm{ys}$ \\
\hline-41.75 & -5.16 & -2.26 & -0.35 & 119.55 & 130.45 \\
\hline
\end{tabular}

\begin{tabular}{|c|c|c|c|c|c|}
\hline$A$ & Kb & Ks & Khv & yb & ys \\
\hline-41.75 & $7.00 \mathrm{E}-06$ & $5.55 \mathrm{E}-03$ & 0.45 & 119.55 & 130.45 \\
\hline
\end{tabular}

\begin{tabular}{|c|c|c|}
\hline Khv SP & $\mathrm{Kb}(\mathrm{ft} / \mathrm{s})$ & $\mathrm{Ksp}(\mathrm{ft} / \mathrm{s})$ \\
\hline 0.50 & $6.60 \mathrm{E}-05$ & 1.30E-03 \\
\hline 0.25 & $2.00 \mathrm{E}-05$ & \\
\hline 0.15 & $6.50 \mathrm{E}-06$ & \\
\hline 0.05 & $1.00 \mathrm{E}-06$ & \\
\hline 0.005 & $1.00 \mathrm{E}-07$ & \\
\hline
\end{tabular}

\begin{tabular}{|c|c|c|}
\hline$A(f t)$ & $z(f t)$ & $A u(f t)$ \\
\hline-39 & 5.535 & -43 \\
\hline-31 & 9.585 & \multicolumn{1}{|}{} \\
\hline-23 & 12.755 \\
\cline { 1 - 2 }-15 & 15.295 & \multicolumn{1}{|}{} \\
\hline
\end{tabular}

$$
\begin{aligned}
\mathrm{yw} & =62.4 \\
\mathrm{ic} & =1.09 \\
\mathrm{FS} & =0.42
\end{aligned}
$$

Figure A.61 Excel spreadsheet for Analysis 1. 


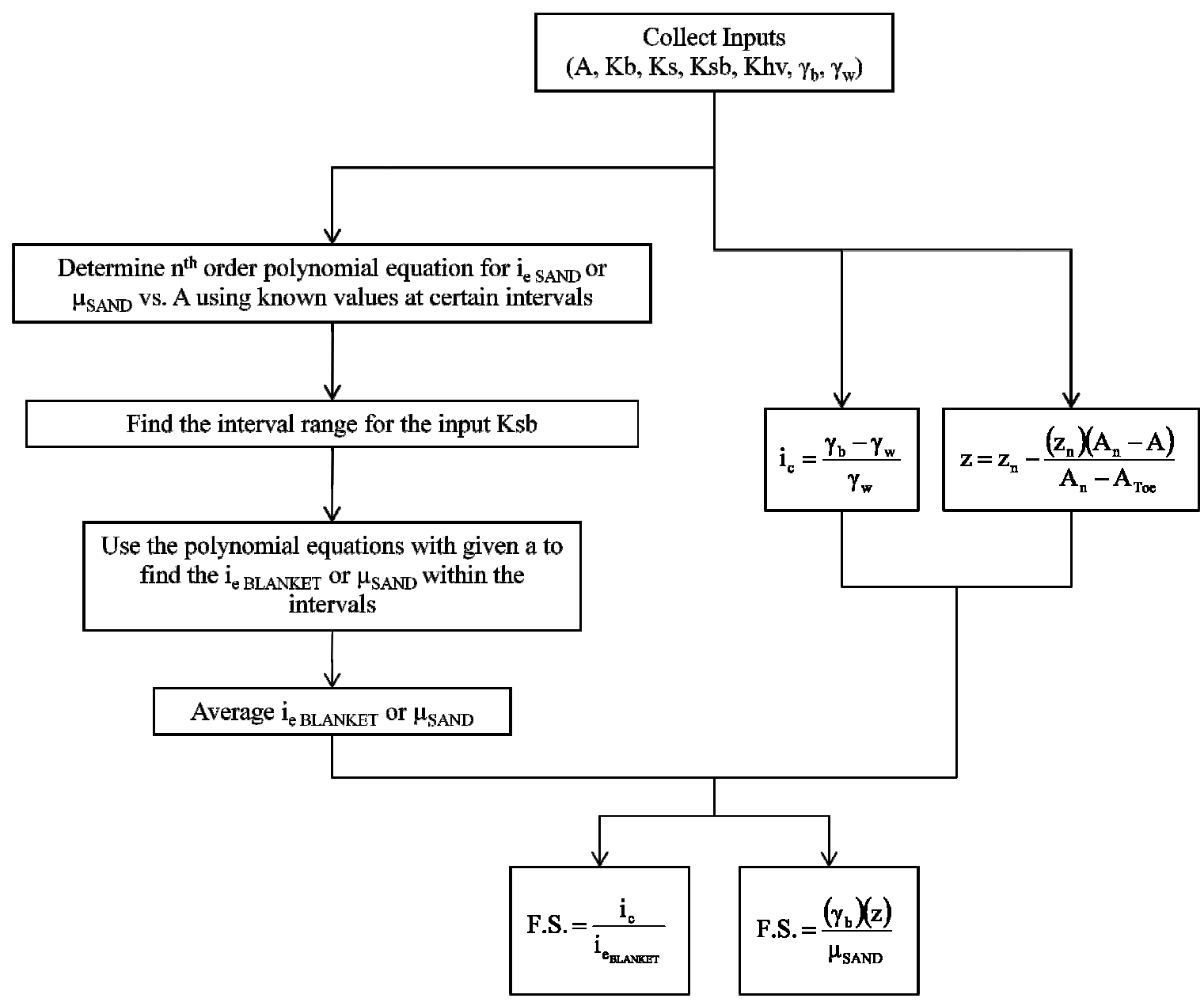

Figure A.62 Flow Chart for Excel Spreadsheet for Analysis 1. 


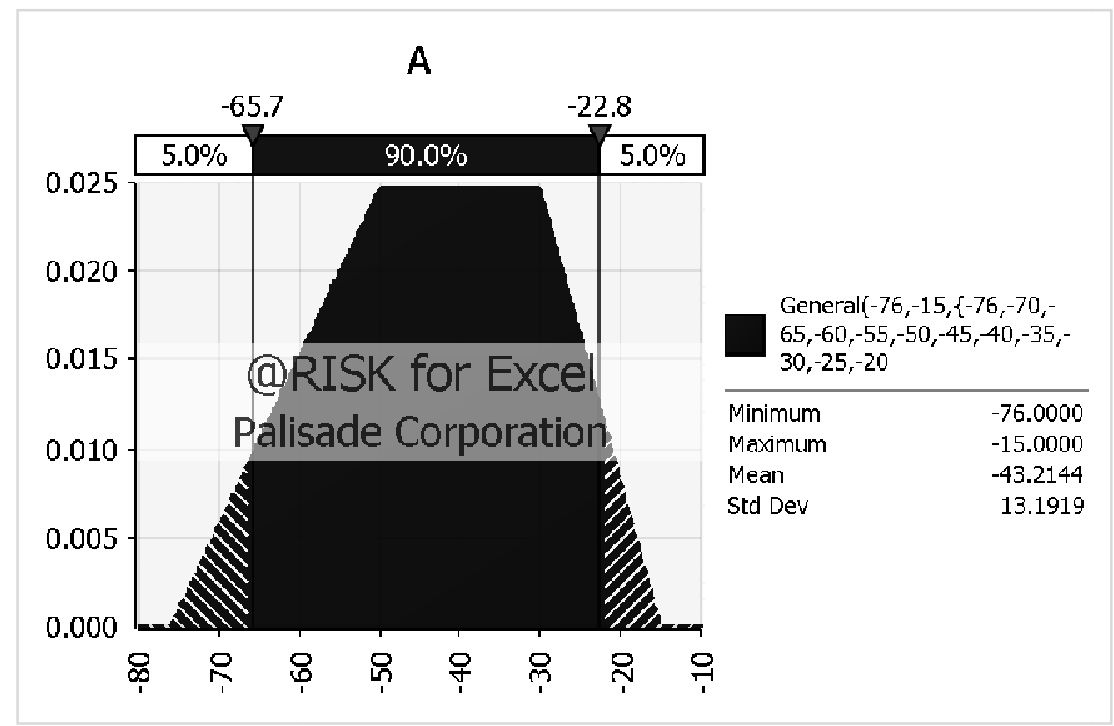

Figure A.63 Probability Density Function for geometric variable A.

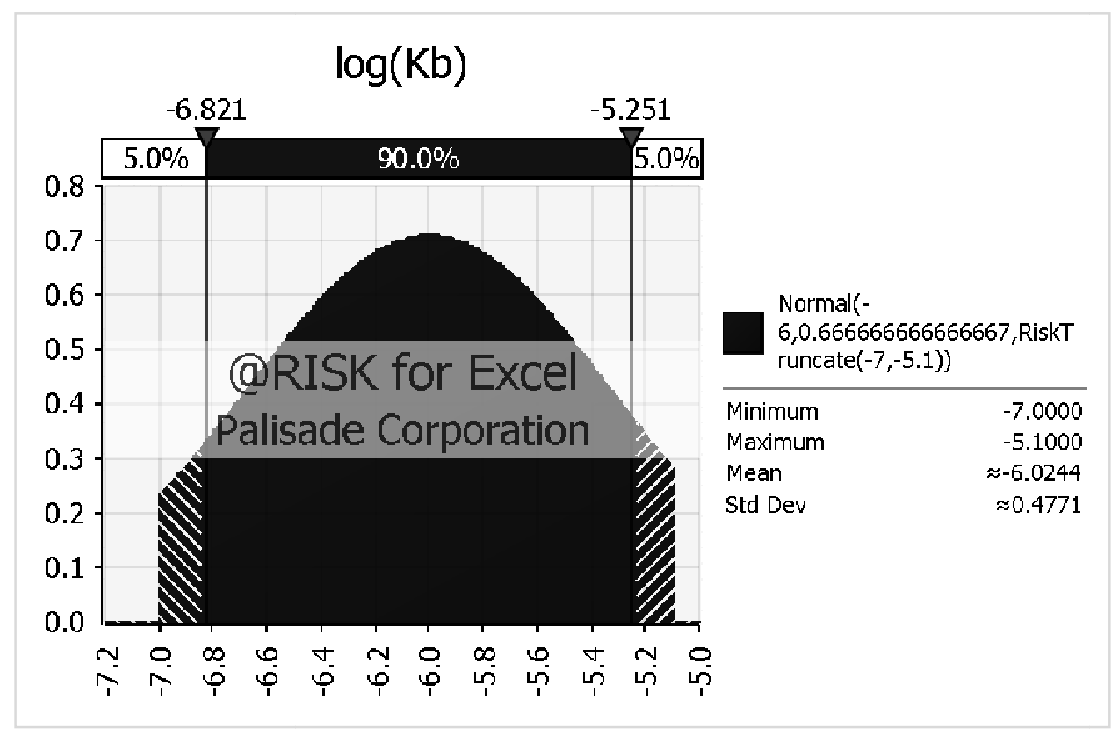

Figure A.64 Probability Density Function for soil variable $\mathrm{Kb}$. 


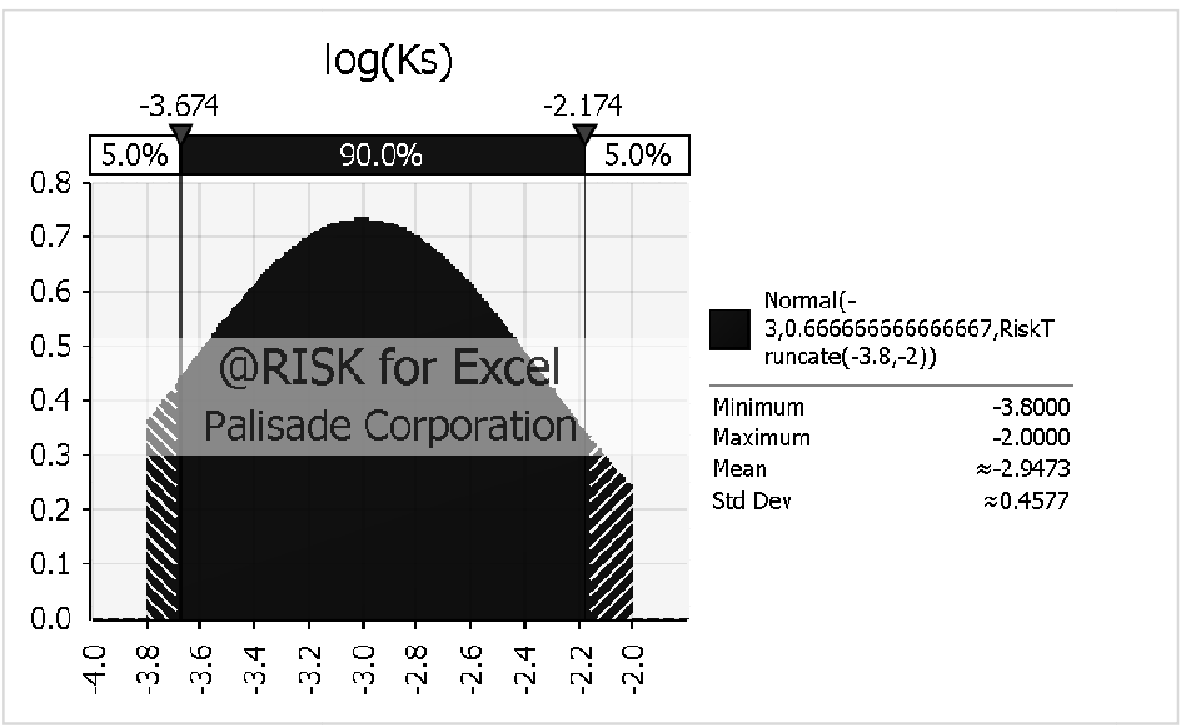

Figure A.65 Probability Density Function for soil variable Ks.

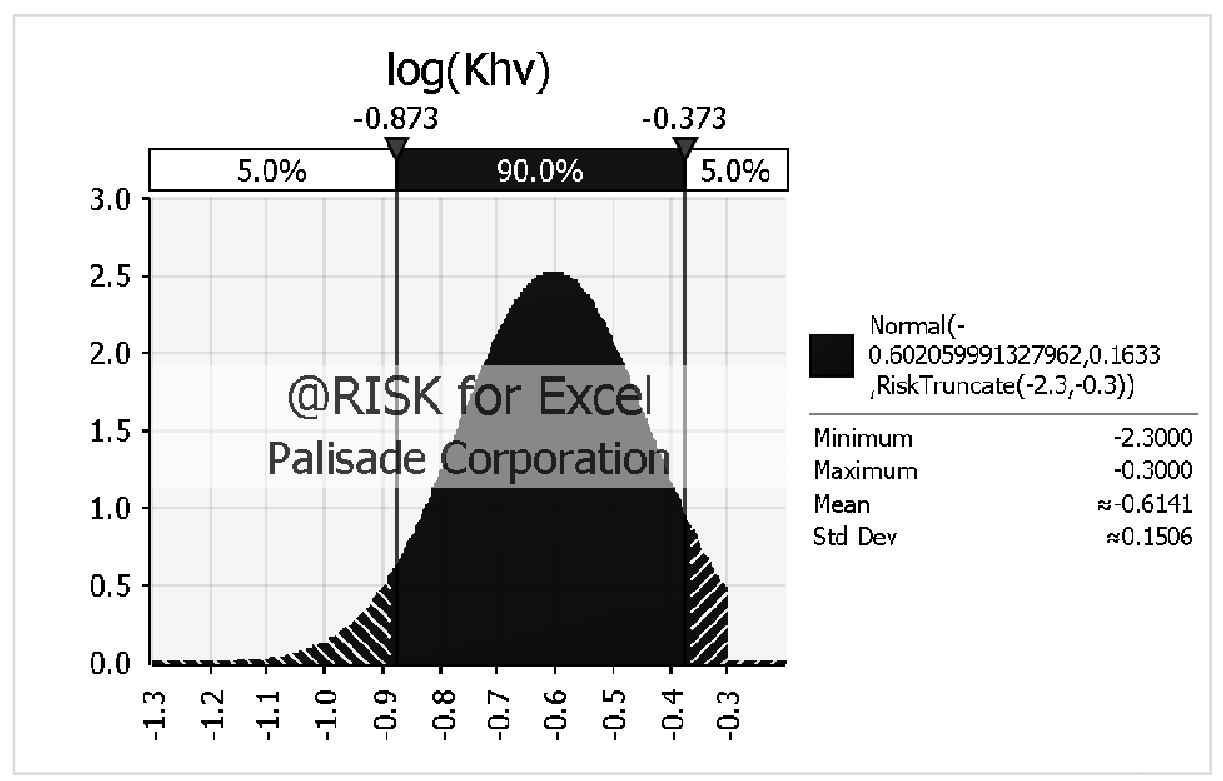

Figure A.66 Probability Density Function for soil variable Khv. 


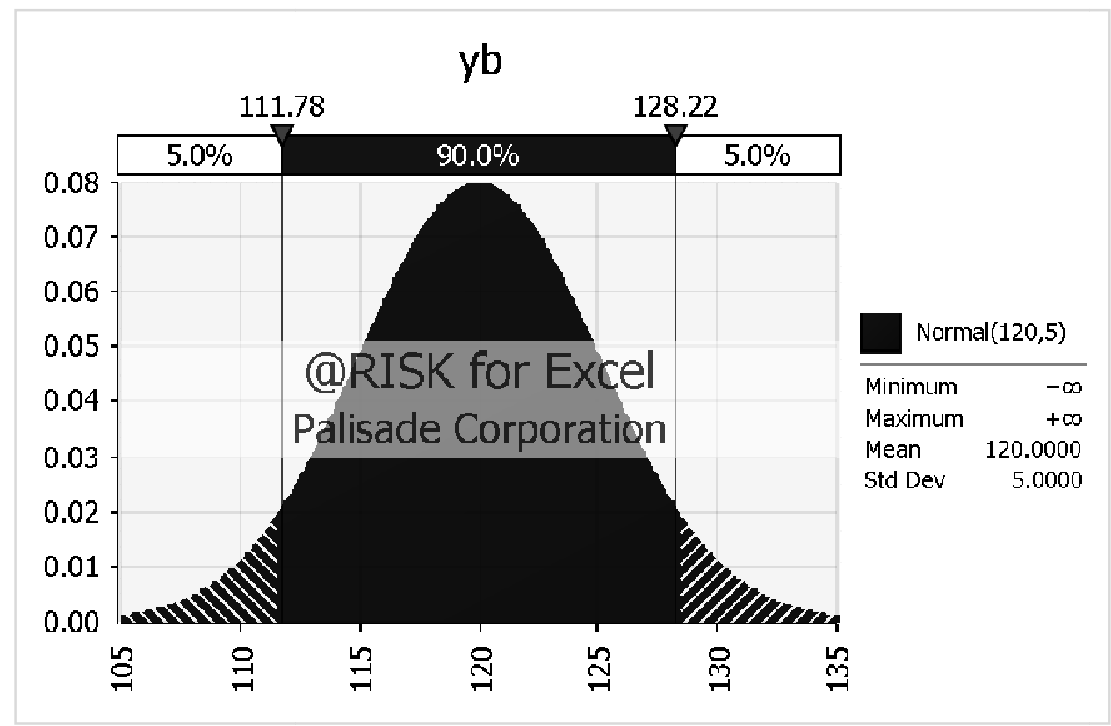

Figure A.67 Probability Density Function for soil variable $\gamma_{\mathrm{b}}$.

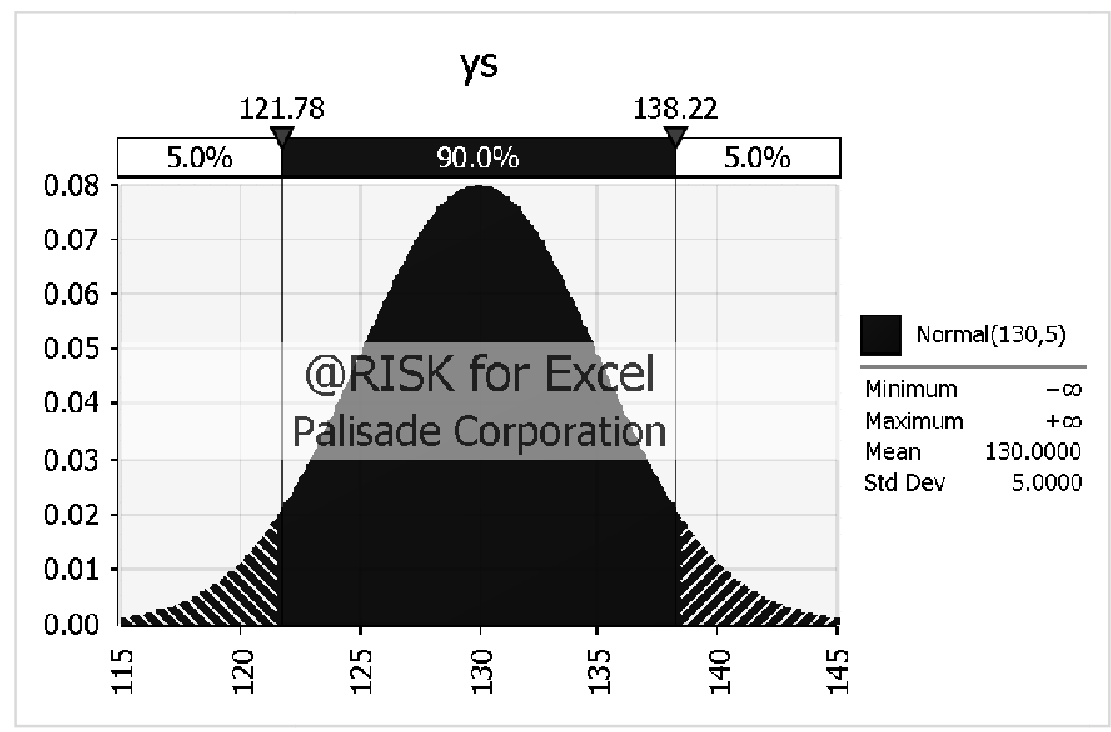

Figure A.68 Probability Density Function for soil variable $\gamma_{\mathrm{s}}$. 
Appendix B. Analysis 2 
Table B.1 Exit gradient $\mathrm{i}_{\mathrm{e}}$ SAND as a function of $\mathrm{A}, \mathrm{Ksb}$ and $\mathrm{Khv}=0.50$

\begin{tabular}{|c|c|c|c|c|c|}
\hline \multirow{2}{*}{$\mathbf{A}$} & \multicolumn{5}{|c|}{$\mathbf{i}_{\mathbf{e}}$ SAND } \\
\cline { 2 - 6 } & $\mathbf{K s b}=\mathbf{2 0}$ & $\mathbf{K s b}=\mathbf{6 5}$ & $\mathbf{K s b}=\mathbf{2 0 0}$ & $\mathbf{K s b}=\mathbf{1 3 0 0}$ & $\mathbf{K s b}=\mathbf{1 3 0 0 0}$ \\
\hline $\mathbf{- 7 6}$ & 0.419 & 0.439 & 0.453 & 0.461 & 0.462 \\
\hline $\mathbf{- 6 8 . 7 5}$ & 0.44 & 0.471 & 0.491 & 0.503 & 0.505 \\
\hline $\mathbf{- 6 1 . 5}$ & 0.477 & 0.528 & 0.561 & 0.58 & 0.583 \\
\hline $\mathbf{- 5 4 . 2 5}$ & 0.558 & 0.659 & 0.722 & 0.757 & 0.764 \\
\hline $\mathbf{- 4 7}$ & 0.809 & 1.079 & 1.252 & 1.352 & 1.371 \\
\hline $\mathbf{- 3 9}$ & 0.918 & 1.13 & 1.256 & 1.327 & 1.34 \\
\hline $\mathbf{- 3 1}$ & 1.049 & 1.281 & 1.416 & 1.491 & 1.504 \\
\hline $\mathbf{- 2 3}$ & 1.077 & 1.306 & 1.437 & 1.51 & 1.524 \\
\hline $\mathbf{- 1 5}$ & 1.194 & 1.446 & 1.591 & 1.67 & 1.685 \\
\hline
\end{tabular}

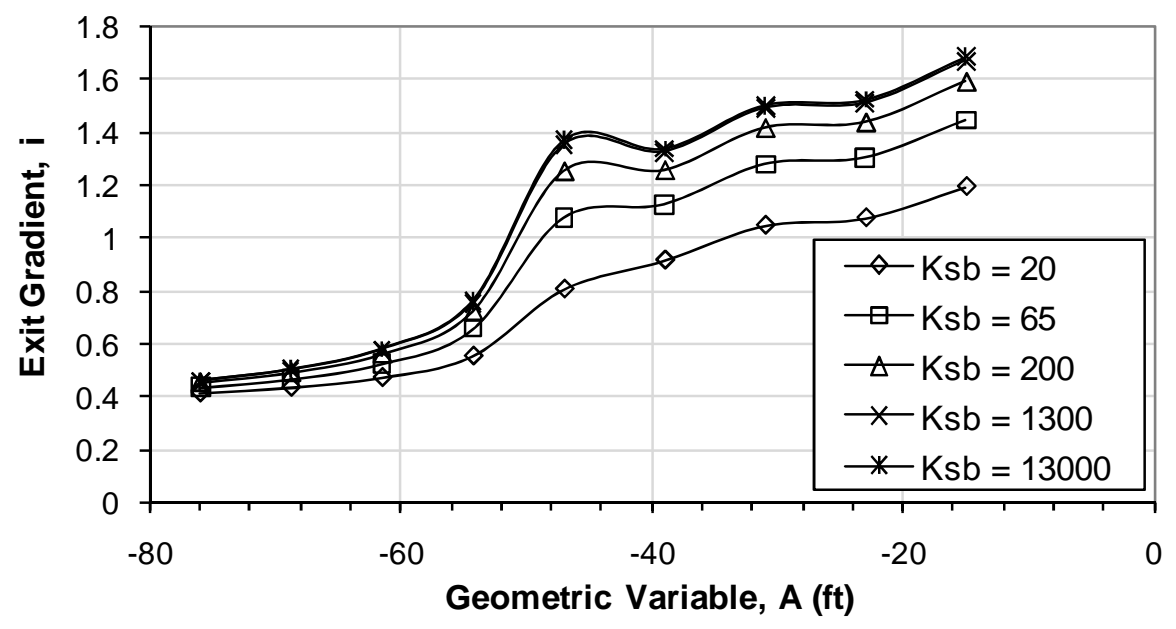

Figure B.1 Family of curves representing relationship of $\mathrm{i}_{\mathrm{e}}$ SAND, $\mathrm{A}, \mathrm{Ksb}$ and, $\mathrm{Khv}=0.50$. 


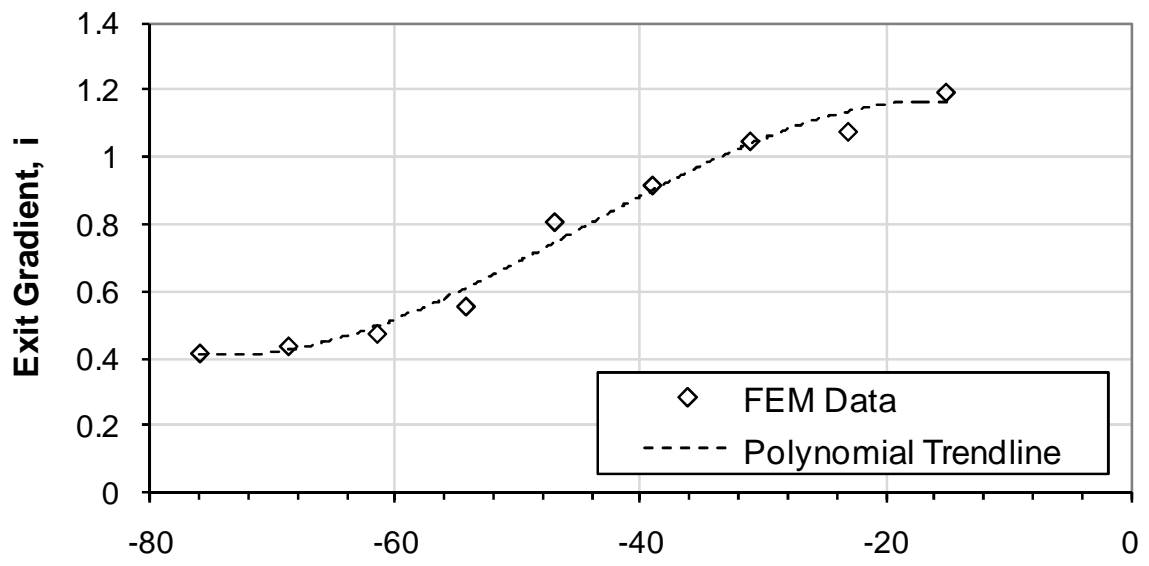

Geometric Variable, A (ft)

Figure B.2 Family of curves representing relationship of $\mathrm{i}_{\mathrm{e}}$ SAND $, \mathrm{A}, \mathrm{Ksb}=20$ and, $\mathrm{Khv}=0.50$.

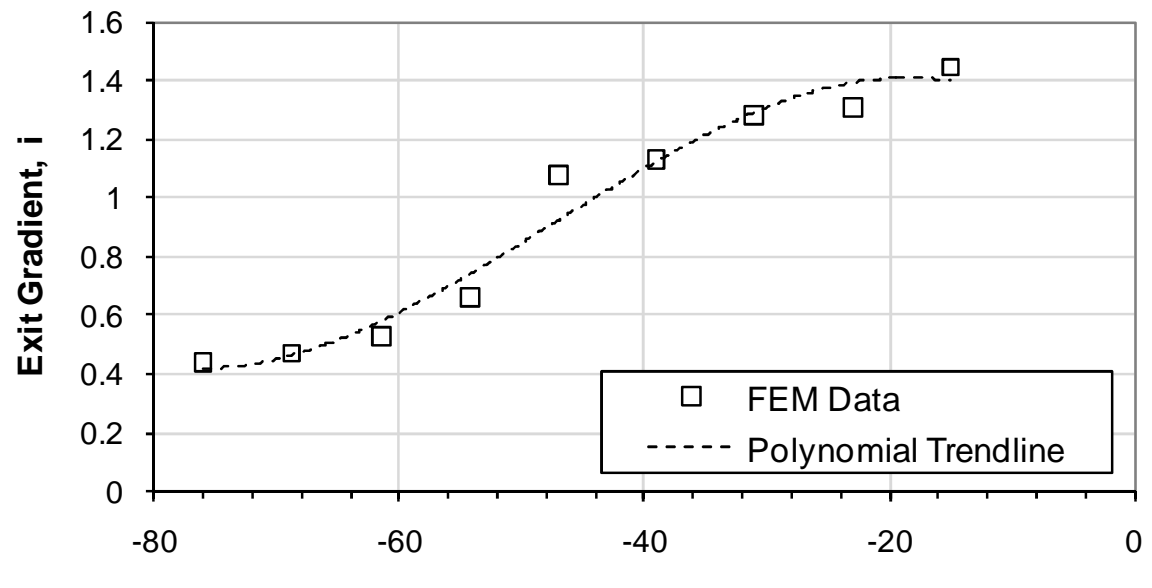

Geometric Variable, A (ft)

Figure B.3 Family of curves representing relationship of $\mathrm{i}_{\mathrm{e}}$ SAND $, \mathrm{A}, \mathrm{Ksb}=65$ and, $\mathrm{Khv}=0.50$. 


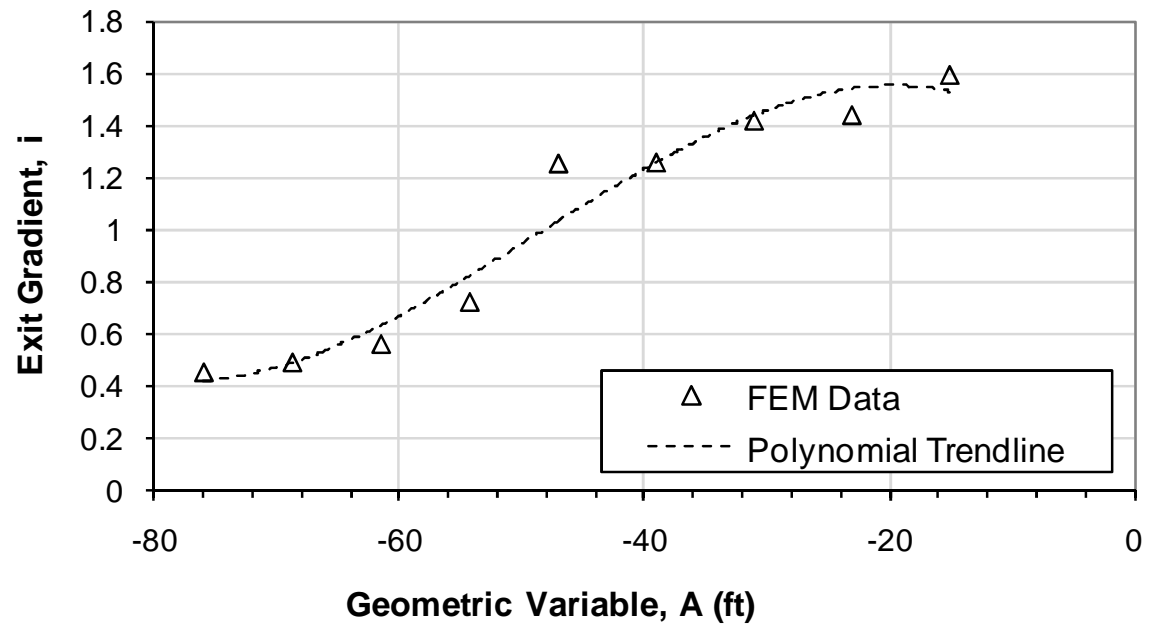

Figure B.4 Family of curves representing relationship of $\mathrm{i}_{\mathrm{e}}$ SAND, $\mathrm{A}, \mathrm{Ksb}=200$ and, $\mathrm{Khv}=0.50$.

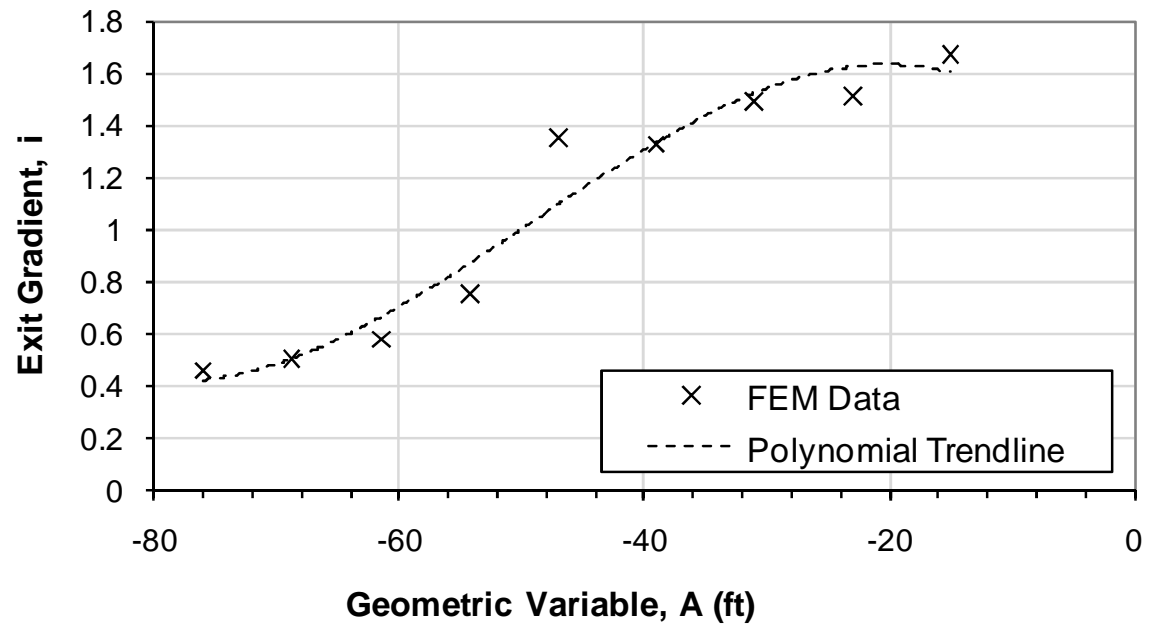

Figure B.5 Family of curves representing relationship of $\mathrm{i}_{\mathrm{e}}$ SAND, $\mathrm{A}, \mathrm{Ksb}=1300$ and, $\mathrm{Khv}=0.50$. 


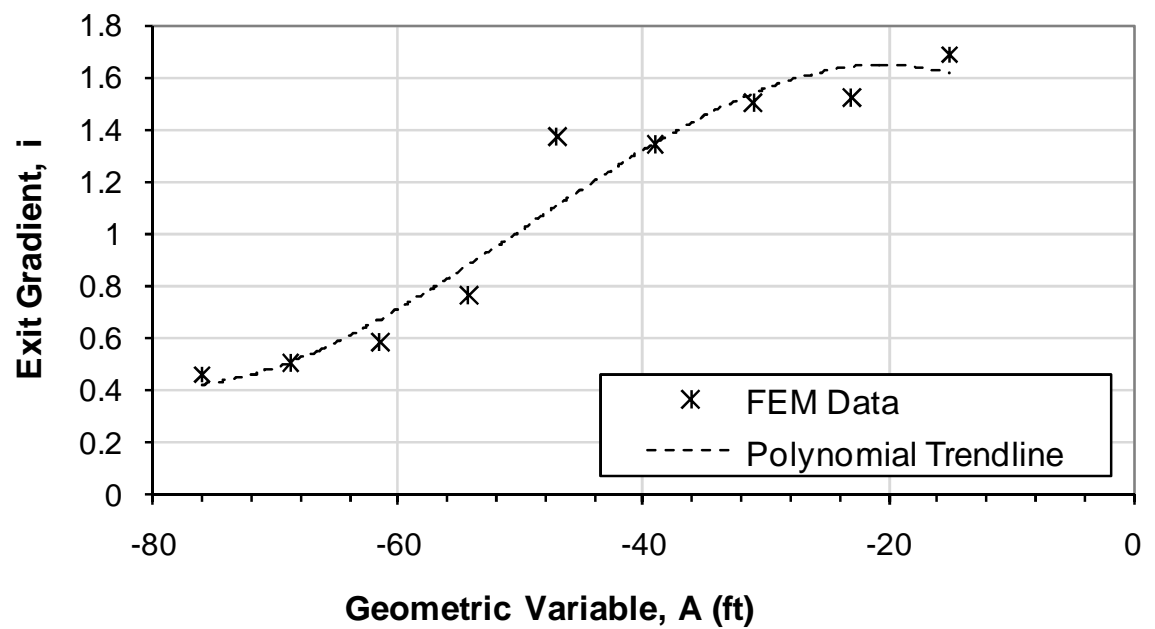

Figure B.6 Family of curves representing relationship of $\mathrm{i}_{\mathrm{e} S A N D}, \mathrm{~A}, \mathrm{Ksb}=13000$ and, $\mathrm{Khv}=0.50$.

Table B.2 Polynomial Trendline Coefficients and Coefficient of Determination $\left(\mathrm{R}^{2}\right)$ for Family of Curves in Figure B.1

\begin{tabular}{|c|c|c|c|c|c|c|}
\hline \multirow{2}{*}{$\mathbf{K s b}$} & \multicolumn{6}{|c|}{$\mathbf{i}=\mathbf{a}_{\mathbf{3}} * \mathbf{A}^{\mathbf{3}}+\mathbf{a}_{\mathbf{2}} * \mathbf{A}^{\mathbf{2}}+\mathbf{a}_{\mathbf{1}} * \mathbf{A}+\mathbf{a}_{\mathbf{0}}$} \\
\cline { 2 - 7 } & $\mathbf{a}_{\mathbf{3}}$ & $\mathbf{a}_{\mathbf{2}}$ & $\mathbf{a}_{\mathbf{1}}$ & $\mathbf{a}_{\mathbf{0}}$ & $\mathbf{R}^{\mathbf{2}}$ & $\mathbf{1 - R}^{\mathbf{2}}$ \\
\hline $\mathbf{2 0}$ & $-7.974 \mathrm{E}-06$ & $-1.073 \mathrm{E}-03$ & $-2.836 \mathrm{E}-02$ & $9.548 \mathrm{E}-01$ & 0.9839 & $1.611 \mathrm{E}-02$ \\
\hline $\mathbf{6 5}$ & $-1.035 \mathrm{E}-05$ & $-1.471 \mathrm{E}-03$ & $-4.394 \mathrm{E}-02$ & $1.035 \mathrm{E}+00$ & 0.9658 & $3.417 \mathrm{E}-02$ \\
\hline $\mathbf{2 0 0}$ & $-1.162 \mathrm{E}-05$ & $-1.696 \mathrm{E}-03$ & $-5.323 \mathrm{E}-02$ & $1.074 \mathrm{E}+00$ & 0.9524 & $4.760 \mathrm{E}-02$ \\
\hline $\mathbf{1 3 0 0}$ & $-1.236 \mathrm{E}-05$ & $-1.828 \mathrm{E}-03$ & $-5.879 \mathrm{E}-02$ & $1.089 \mathrm{E}+00$ & 0.9446 & $5.542 \mathrm{E}-02$ \\
\hline $\mathbf{1 3 0 0 0}$ & $-1.246 \mathrm{E}-05$ & $-1.848 \mathrm{E}-03$ & $-5.962 \mathrm{E}-02$ & $1.094 \mathrm{E}+00$ & 0.9431 & $5.688 \mathrm{E}-02$ \\
\hline
\end{tabular}

Table B.3 Exit gradient $\mathrm{i}_{\mathrm{e} \text { SAND }}$ as a function of $\mathrm{A}, \mathrm{Ksb}$ and $\mathrm{Khv}=0.25$

\begin{tabular}{|c|c|c|c|c|c|}
\hline \multirow{2}{*}{$\mathbf{A}$} & \multicolumn{5}{|c|}{$\mathbf{i}_{\mathbf{e} \text { SAND }}$} \\
\cline { 2 - 6 } & $\mathbf{K s b}=\mathbf{2 0}$ & $\mathbf{K s b}=\mathbf{6 5}$ & $\mathbf{K s b}=\mathbf{2 0 0}$ & $\mathbf{K s b}=\mathbf{1 3 0 0}$ & $\mathbf{K s b}=\mathbf{1 3 0 0 0}$ \\
\hline $\mathbf{- 7 6}$ & 0.506 & 0.547 & 0.578 & 0.596 & 0.599 \\
\hline $\mathbf{- 6 8 . 7 5}$ & 0.529 & 0.588 & 0.63 & 0.655 & 0.659 \\
\hline $\mathbf{- 6 1 . 5}$ & 0.569 & 0.661 & 0.724 & 0.761 & 0.768 \\
\hline $\mathbf{- 5 4 . 2 5}$ & 0.653 & 0.818 & 0.931 & 0.999 & 1.012 \\
\hline $\mathbf{- 4 7}$ & 0.87 & 1.246 & 1.516 & 1.684 & 1.716 \\
\hline $\mathbf{- 3 9}$ & 1.055 & 1.36 & 1.555 & 1.669 & 1.691 \\
\hline $\mathbf{- 3 1}$ & 1.278 & 1.625 & 1.843 & 1.97 & 1.994 \\
\hline $\mathbf{- 2 3}$ & 1.39 & 1.752 & 1.977 & 2.108 & 2.132 \\
\hline $\mathbf{- 1 5}$ & 1.511 & 1.894 & 2.132 & 2.268 & 2.294 \\
\hline
\end{tabular}




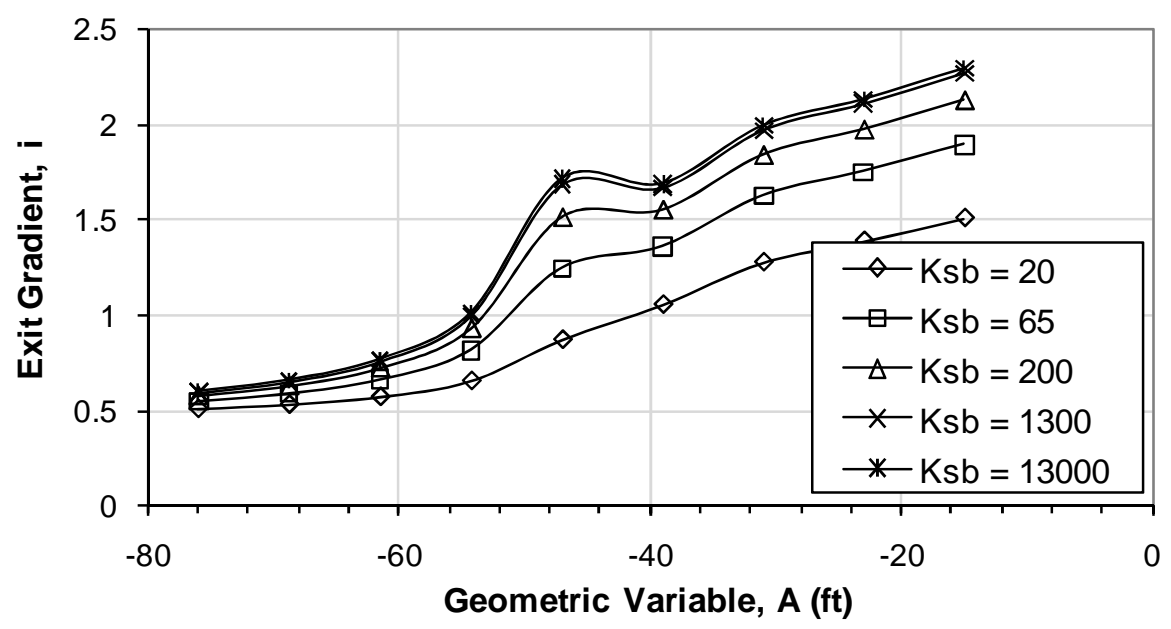

Figure B.7 Family of curves representing relationship of $\mathrm{i}_{\mathrm{e} \text { SAND }}, \mathrm{A}, \mathrm{Ksb}$ and, $\mathrm{Khv}=0.25$.

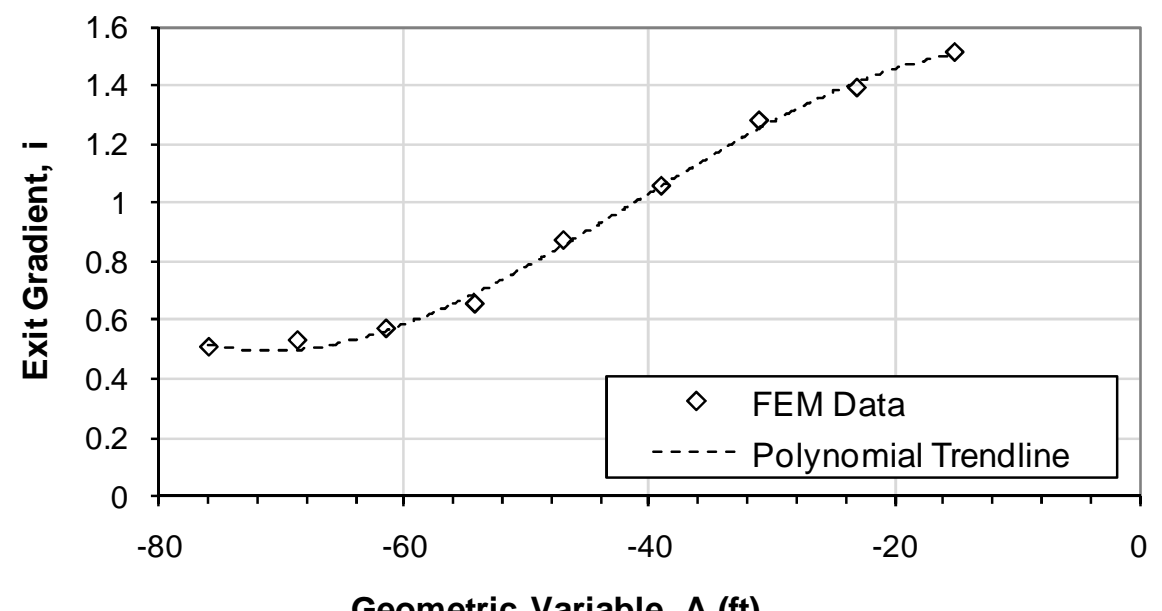

Figure B.8 Family of curves representing relationship of $\mathrm{i}_{\mathrm{e}}$ SAND $, \mathrm{A}, \mathrm{Ksb}=20$ and, $\mathrm{Khv}=0.25$. 


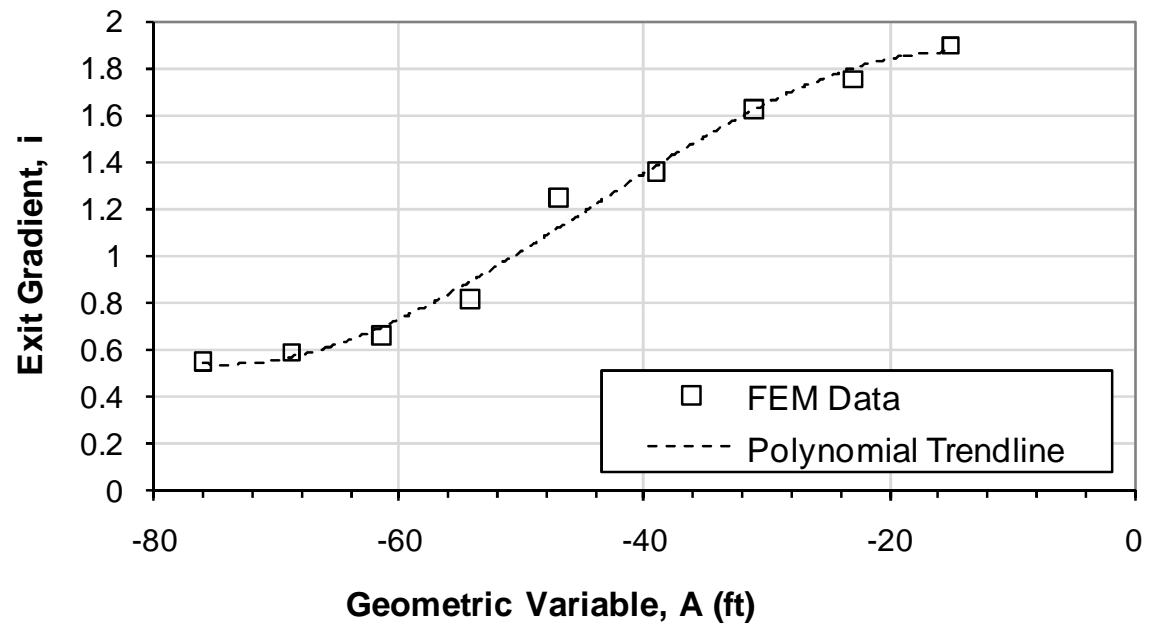

Figure B.9 Family of curves representing relationship of $\mathrm{i}_{\mathrm{e}} \mathrm{SAND}, \mathrm{A}, \mathrm{Ksb}=65$ and, $\mathrm{Khv}=0.25$.

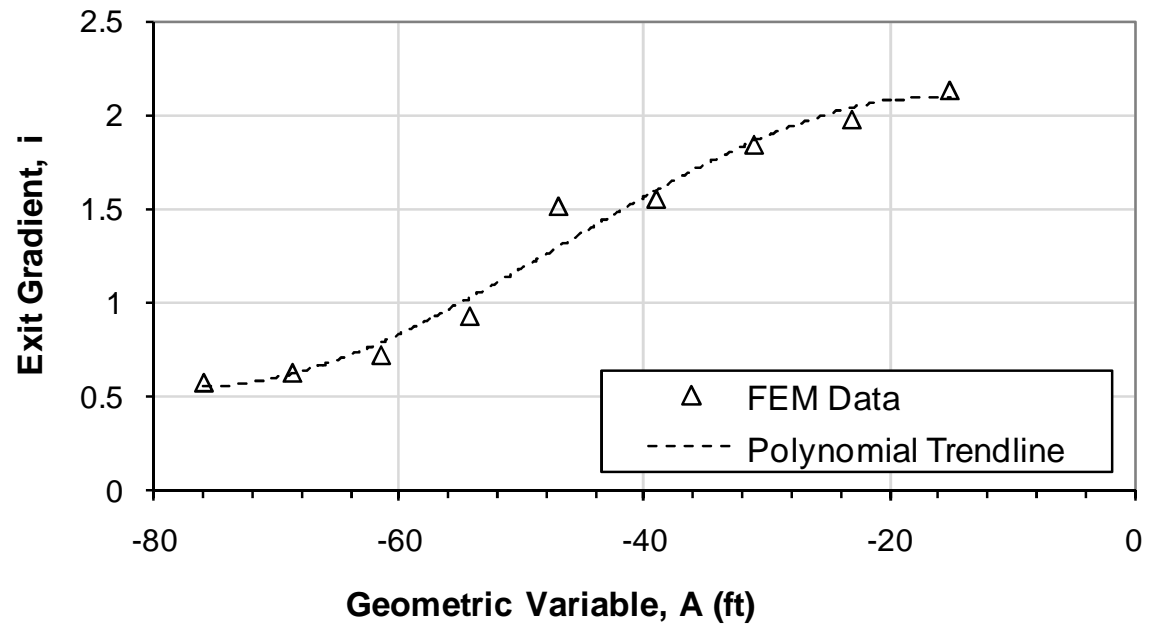

Figure B.10 Family of curves representing relationship of $\mathrm{i}_{\mathrm{e} \text { SAND }}, \mathrm{A}, \mathrm{Ksb}=200$ and, $\mathrm{Khv}=0.25$. 


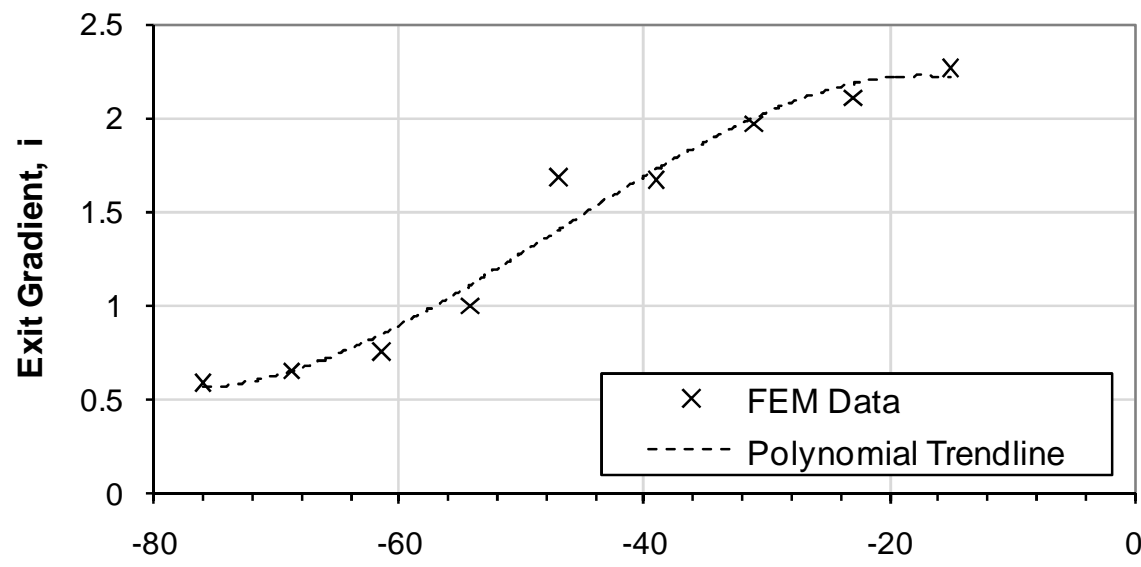

Geometric Variable, A (ft)

Figure B.11 Family of curves representing relationship of $\mathrm{i}_{\mathrm{e}} \mathrm{SAND}, \mathrm{A}, \mathrm{Ksb}=1300$ and, $\mathrm{Khv}=0.25$.

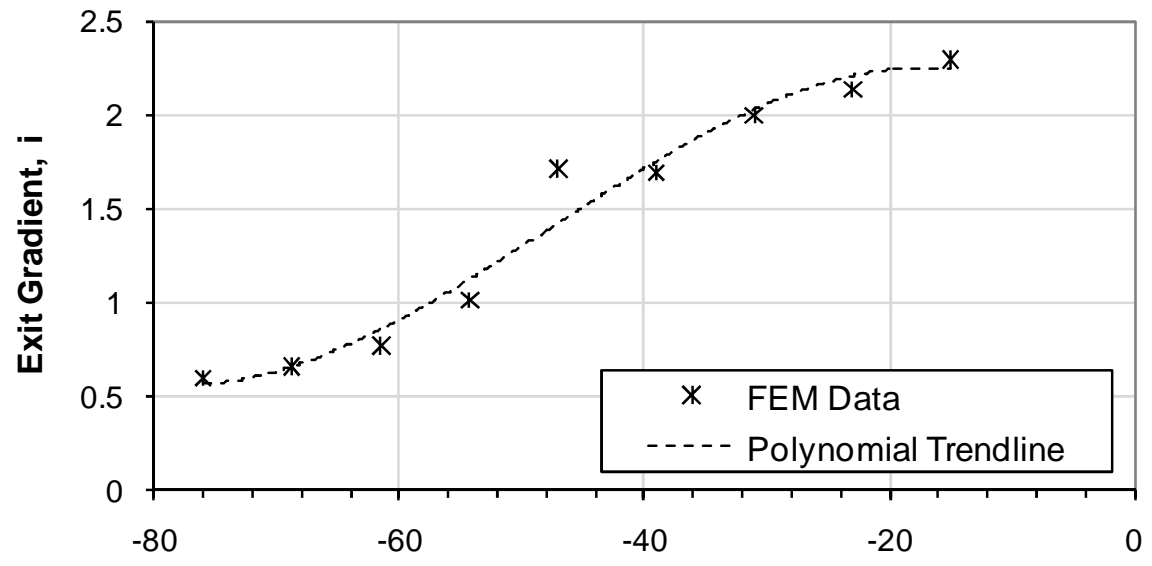

Geometric Variable, A (ft)

Figure B.12 Family of curves representing relationship of $\mathrm{i}_{\mathrm{e}} \mathrm{SAND}, \mathrm{A}, \mathrm{Ksb}=13000$ and, $\mathrm{Khv}=0.25$.

Table B.4 Polynomial Trendline Coefficients and Coefficient of Determination $\left(\mathrm{R}^{2}\right)$ for Family of Curves in Figure B.7

\begin{tabular}{|c|c|c|c|c|c|c|}
\hline \multirow{2}{*}{ Ksb } & \multicolumn{6}{|c|}{$\mathbf{i}=\mathbf{a}_{\mathbf{3}} * \mathbf{A}^{\mathbf{3}}+\mathbf{a}_{\mathbf{2}} * \mathbf{A}^{\mathbf{2}}+\mathbf{a}_{\mathbf{1}} * \mathbf{A}+\mathbf{a}_{\mathbf{0}}$} \\
\cline { 2 - 7 } & $\mathbf{a}_{\mathbf{3}}$ & $\mathbf{a}_{\mathbf{2}}$ & $\mathbf{a}_{\mathbf{1}}$ & $\mathbf{a}_{\mathbf{0}}$ & $\mathbf{R}^{\mathbf{2}}$ & $\mathbf{1 - R}^{\mathbf{2}}$ \\
\hline $\mathbf{2 0}$ & $-9.438 \mathrm{E}-06$ & $-1.160 \mathrm{E}-03$ & $-2.199 \mathrm{E}-02$ & $1.405 \mathrm{E}+00$ & 0.9970 & $3.030 \mathrm{E}-03$ \\
\hline $\mathbf{6 5}$ & $-1.253 \mathrm{E}-05$ & $-1.672 \mathrm{E}-03$ & $-4.090 \mathrm{E}-02$ & $1.589 \mathrm{E}+00$ & 0.9883 & $1.165 \mathrm{E}-02$ \\
\hline $\mathbf{2 0 0}$ & $-1.425 \mathrm{E}-05$ & $-1.979 \mathrm{E}-03$ & $-5.314 \mathrm{E}-02$ & $1.691 \mathrm{E}+00$ & 0.9767 & $2.328 \mathrm{E}-02$ \\
\hline $\mathbf{1 3 0 0}$ & $-1.525 \mathrm{E}-05$ & $-2.163 \mathrm{E}-03$ & $-6.082 \mathrm{E}-02$ & $1.741 \mathrm{E}+00$ & 0.9683 & $3.170 \mathrm{E}-02$ \\
\hline $\mathbf{1 3 0 0 0}$ & $-1.542 \mathrm{E}-05$ & $-2.196 \mathrm{E}-03$ & $-6.222 \mathrm{E}-02$ & $1.751 \mathrm{E}+00$ & 0.9667 & $3.332 \mathrm{E}-02$ \\
\hline
\end{tabular}


Table B.5 Exit gradient $\mathrm{i}_{\mathrm{e}}$ SAND as a function of A, Ksb and $\mathrm{Khv}=0.15$

\begin{tabular}{|c|c|c|c|c|c|}
\hline \multirow{2}{*}{$\mathbf{A}$} & \multicolumn{5}{|c|}{$\mathbf{i}_{\mathbf{e}}$ SAND } \\
\cline { 2 - 6 } & $\mathbf{K s b}=\mathbf{2 0}$ & $\mathbf{K s b}=\mathbf{6 5}$ & $\mathbf{K s b}=\mathbf{2 0 0}$ & $\mathbf{K s b}=\mathbf{1 3 0 0}$ & $\mathbf{K s b}=\mathbf{1 3 0 0 0}$ \\
\hline $\mathbf{- 7 6}$ & 0.56 & 0.619 & 0.667 & 0.697 & 0.703 \\
\hline $\mathbf{- 6 8 . 7 5}$ & 0.583 & 0.666 & 0.73 & 0.77 & 0.778 \\
\hline $\mathbf{- 6 1 . 5}$ & 0.62 & 0.747 & 0.84 & 0.899 & 0.91 \\
\hline $\mathbf{- 5 4 . 2 5}$ & 0.693 & 0.912 & 1.074 & 1.178 & 1.198 \\
\hline $\mathbf{- 4 7}$ & 0.865 & 1.307 & 1.66 & 1.893 & 1.94 \\
\hline $\mathbf{- 3 9}$ & 1.116 & 1.486 & 1.74 & 1.896 & 1.926 \\
\hline $\mathbf{- 3 1}$ & 1.415 & 1.851 & 2.141 & 2.319 & 2.353 \\
\hline $\mathbf{- 2 3}$ & 1.612 & 2.087 & 2.4 & 2.59 & 2.627 \\
\hline $\mathbf{- 1 5}$ & 1.737 & 2.225 & 2.546 & 2.74 & 2.777 \\
\hline
\end{tabular}

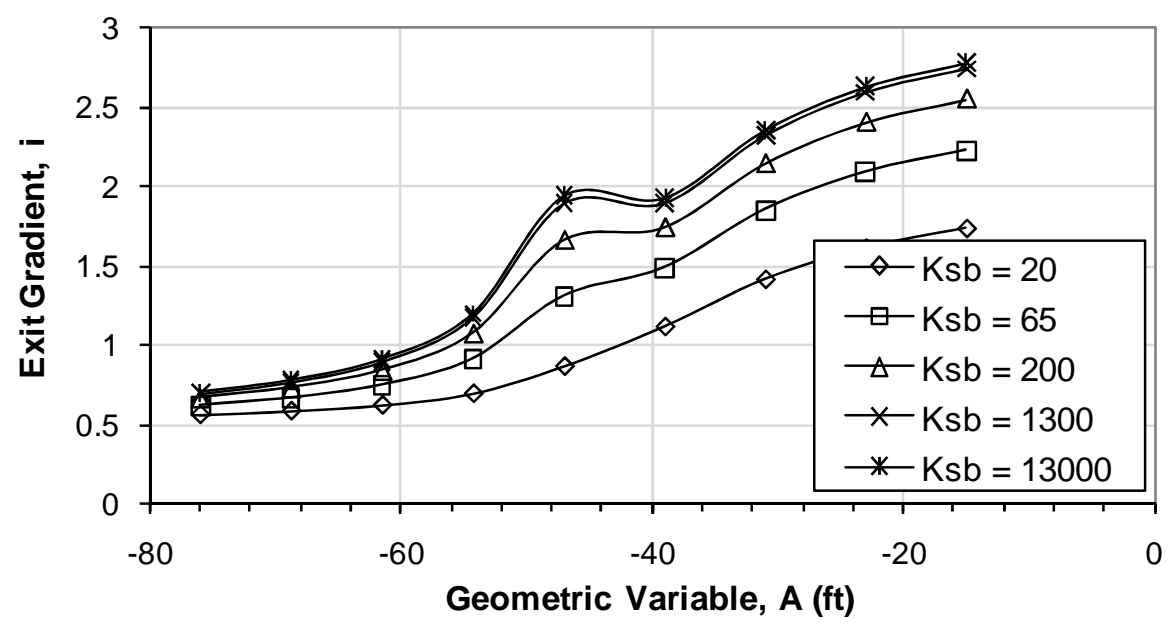

Figure B.13 Family of curves representing relationship of $\mathrm{i}_{\mathrm{e}}$ SAND $, \mathrm{A}, \mathrm{Ksb}$ and, $\mathrm{Khv}=0.15$. 


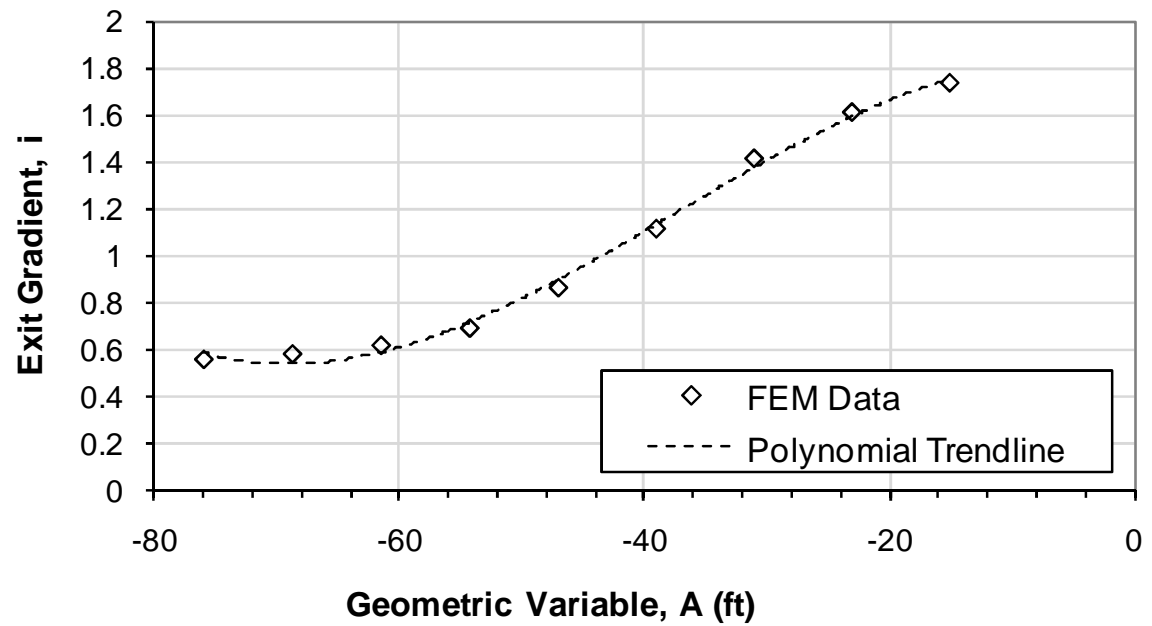

Figure B.14 Family of curves representing relationship of $\mathrm{i}_{\mathrm{e}}$ SAND $, \mathrm{A}, \mathrm{Ksb}=20$ and, $\mathrm{Khv}=0.15$.

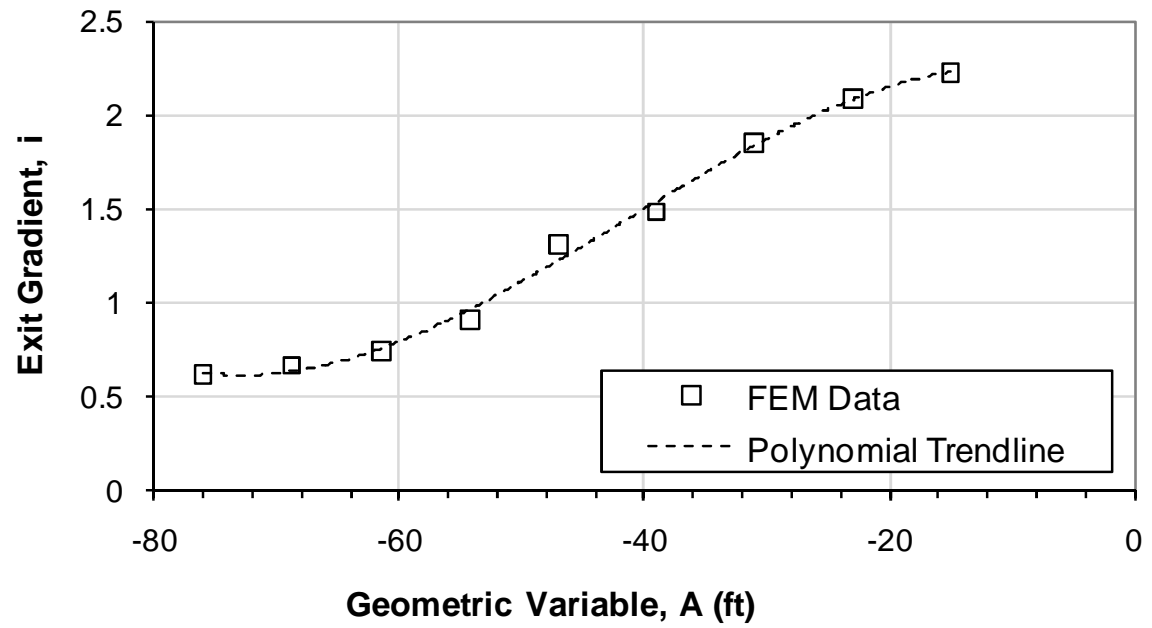

Figure B.15 Family of curves representing relationship of $\mathrm{i}_{\mathrm{e}}$ SAND, $\mathrm{A}, \mathrm{Ksb}=65$ and, $\mathrm{Khv}=0.15$. 


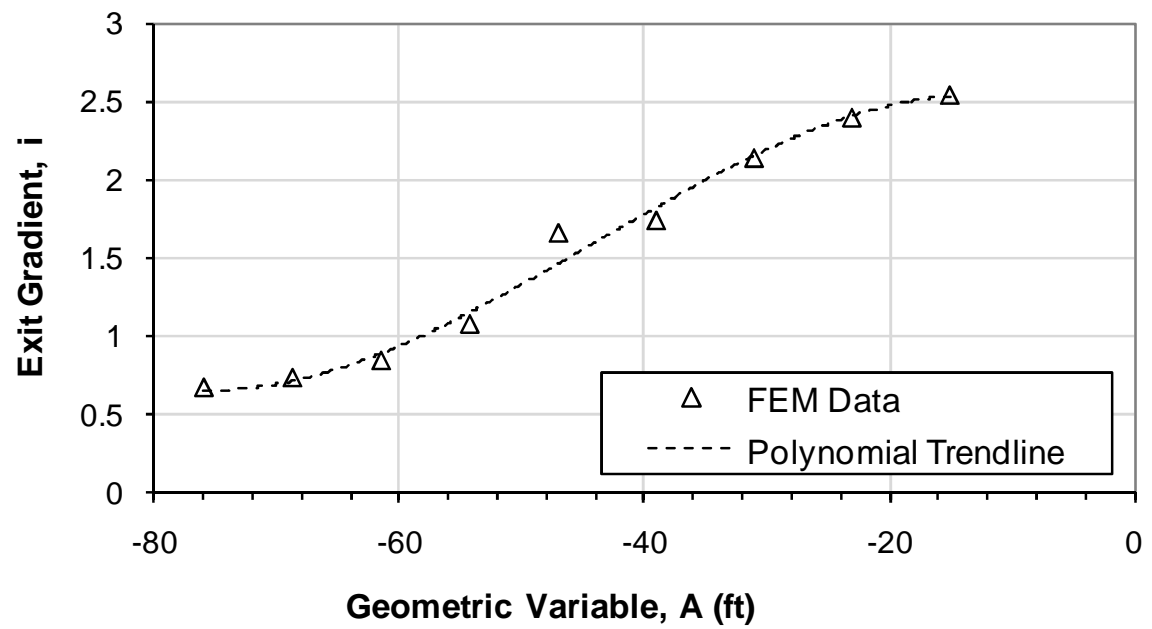

Figure B.16 Family of curves representing relationship of $\mathrm{i}_{\mathrm{e} S A N D}, \mathrm{~A}, \mathrm{Ksb}=200$ and, Khv $=0.15$.

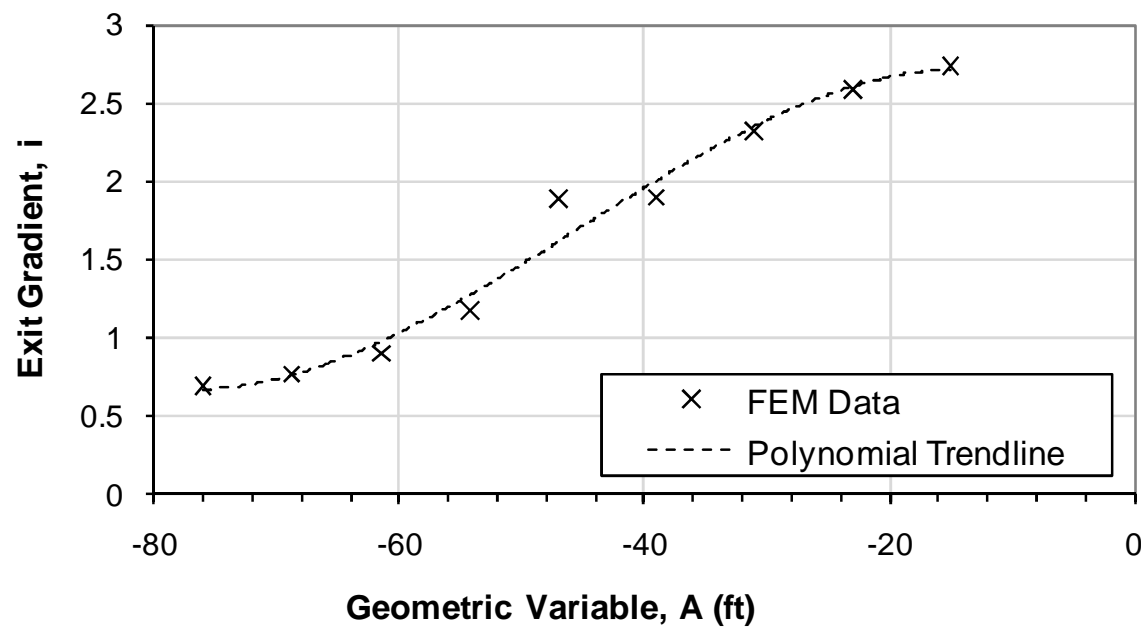

Figure B.17 Family of curves representing relationship of $\mathrm{i}_{\mathrm{e} \text { SAND }}, \mathrm{A}, \mathrm{Ksb}=1300$ and, $\mathrm{Khv}=0.15$. 


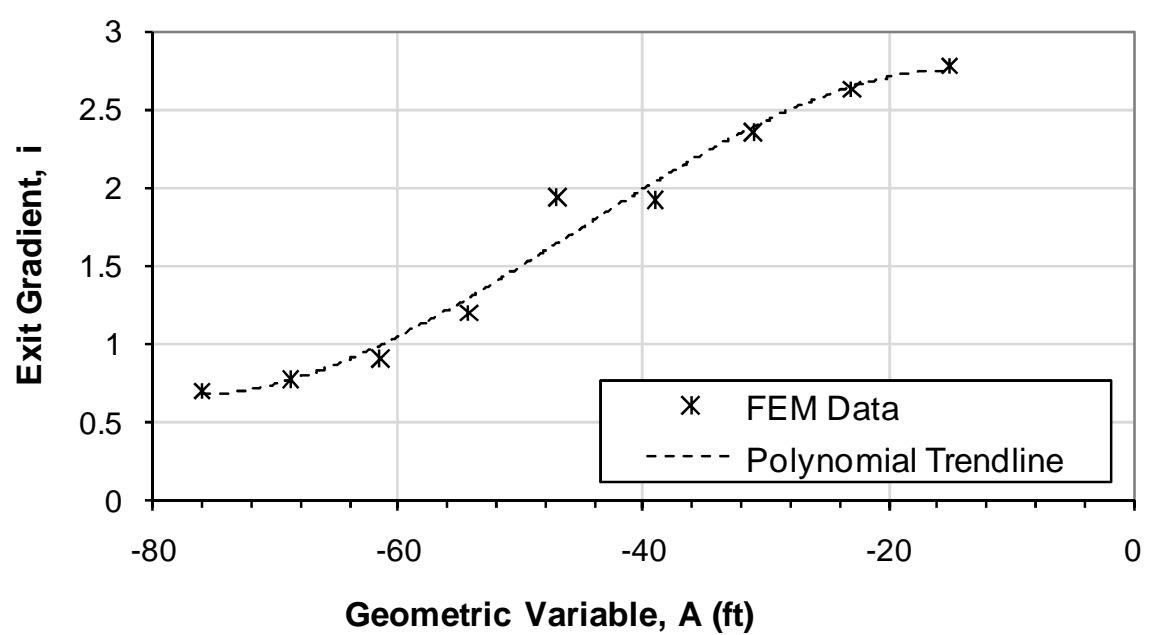

Figure B.18 Family of curves representing relationship of $\mathrm{i}_{\mathrm{e}}$ SAND, $\mathrm{A}, \mathrm{Ksb}=13000$ and, $\mathrm{Khv}=0.15$.

Table B.6 Polynomial Trendline Coefficients and Coefficient of Determination $\left(\mathrm{R}^{2}\right)$ for Family of Curves in Figure B.13

\begin{tabular}{|c|c|c|c|c|c|c|}
\hline \multirow{2}{*}{ Ksb } & \multicolumn{6}{|c|}{$\mathbf{i}=\mathbf{a}_{\mathbf{3}} * \mathbf{A}^{\mathbf{3}}+\mathbf{a}_{\mathbf{2}} * \mathbf{A}^{\mathbf{2}}+\mathbf{a}_{\mathbf{1}} * \mathbf{A}+\mathbf{a}_{\mathbf{0}}$} \\
\cline { 2 - 7 } & $\mathbf{a}_{\mathbf{3}}$ & $\mathbf{a}_{\mathbf{2}}$ & $\mathbf{a}_{\mathbf{1}}$ & $\mathbf{a}_{\mathbf{0}}$ & $\mathbf{R}^{\mathbf{2}}$ & $\mathbf{1}_{-} \mathbf{R}^{\mathbf{2}}$ \\
\hline $\mathbf{2 0}$ & $-1.010 \mathrm{E}-05$ & $-1.131 \mathrm{E}-03$ & $-1.168 \mathrm{E}-02$ & $1.801 \mathrm{E}+00$ & 0.9954 & $4.602 \mathrm{E}-03$ \\
\hline $\mathbf{6 5}$ & $-1.359 \mathrm{E}-05$ & $-1.698 \mathrm{E}-03$ & $-3.131 \mathrm{E}-02$ & $2.095 \mathrm{E}+00$ & 0.9957 & $4.325 \mathrm{E}-03$ \\
\hline $\mathbf{2 0 0}$ & $-1.556 \mathrm{E}-05$ & $-2.054 \mathrm{E}-03$ & $-4.512 \mathrm{E}-02$ & $2.267 \mathrm{E}+00$ & 0.9872 & $1.275 \mathrm{E}-02$ \\
\hline $\mathbf{1 3 0 0}$ & $-1.665 \mathrm{E}-05$ & $-2.266 \mathrm{E}-03$ & $-5.385 \mathrm{E}-02$ & $2.363 \mathrm{E}+00$ & 0.9794 & $2.064 \mathrm{E}-02$ \\
\hline $\mathbf{1 3 0 0 0}$ & $-1.687 \mathrm{E}-05$ & $-2.309 \mathrm{E}-03$ & $-5.567 \mathrm{E}-02$ & $2.380 \mathrm{E}+00$ & 0.9775 & $2.247 \mathrm{E}-02$ \\
\hline
\end{tabular}

Table B.7 Exit gradient $\mathrm{i}_{\mathrm{e} \text { SAND }}$ as a function of A, Ksb and $\mathrm{Khv}=0.05$

\begin{tabular}{|c|c|c|c|c|c|}
\hline \multirow{2}{*}{$\mathbf{A}$} & \multicolumn{5}{|c|}{$\mathbf{i}_{\mathbf{e}}$ SAND } \\
\cline { 2 - 6 } & $\mathbf{K s b}=\mathbf{2 0}$ & $\mathbf{K s b}=\mathbf{6 5}$ & $\mathbf{K s b}=\mathbf{2 0 0}$ & $\mathbf{K s b}=\mathbf{1 3 0 0}$ & $\mathbf{K s b}=\mathbf{1 3 0 0 0}$ \\
\hline $\mathbf{- 7 6}$ & 0.623 & 0.72 & 0.816 & 0.885 & 0.899 \\
\hline $\mathbf{- 6 8 . 7 5}$ & 0.628 & 0.767 & 0.896 & 0.986 & 1.005 \\
\hline $\mathbf{- 6 1 . 5}$ & 0.637 & 0.841 & 1.024 & 1.155 & 1.182 \\
\hline $\mathbf{- 5 4 . 2 5}$ & 0.651 & 0.97 & 1.258 & 1.476 & 1.522 \\
\hline $\mathbf{- 4 7}$ & 0.681 & 1.201 & 1.717 & 2.128 & 2.217 \\
\hline $\mathbf{- 3 9}$ & 1.107 & 1.574 & 1.956 & 2.221 & 2.275 \\
\hline $\mathbf{- 3 1}$ & 1.582 & 2.169 & 2.632 & 2.948 & 3.012 \\
\hline $\mathbf{- 2 3}$ & 2.017 & 2.726 & 3.271 & 3.642 & 3.717 \\
\hline $\mathbf{- 1 5}$ & 1.737 & 2.225 & 2.546 & 2.74 & 2.777 \\
\hline
\end{tabular}




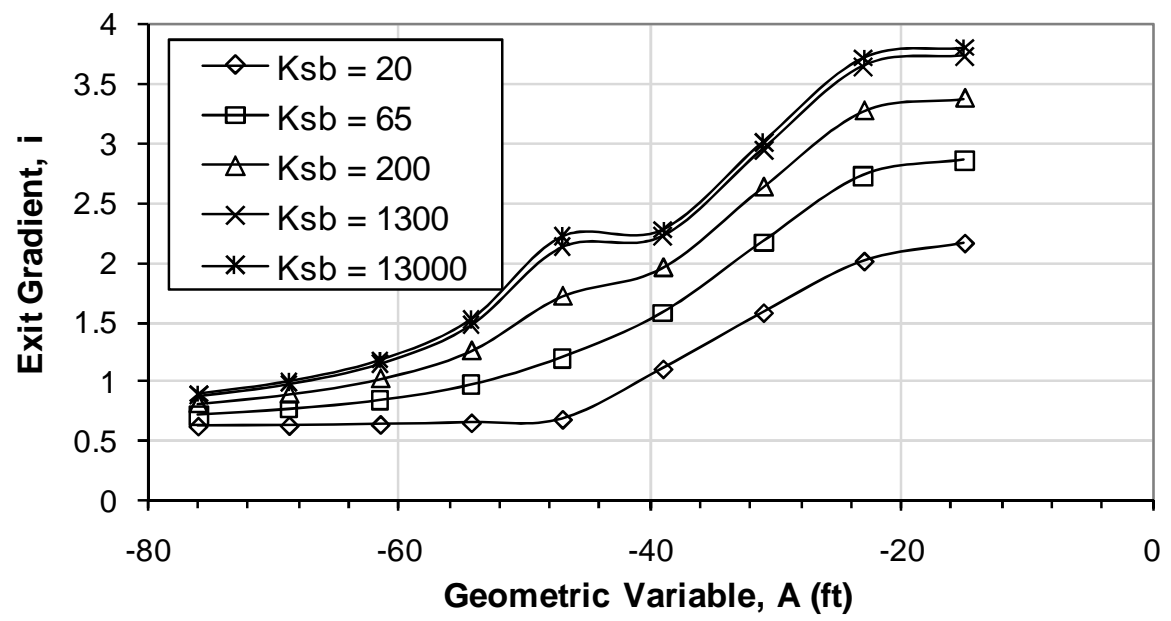

Figure B.19 Family of curves representing relationship of $\mathrm{i}_{\mathrm{e} S A N D}, \mathrm{~A}, \mathrm{Ksb}$ and, Khv $=0.05$.

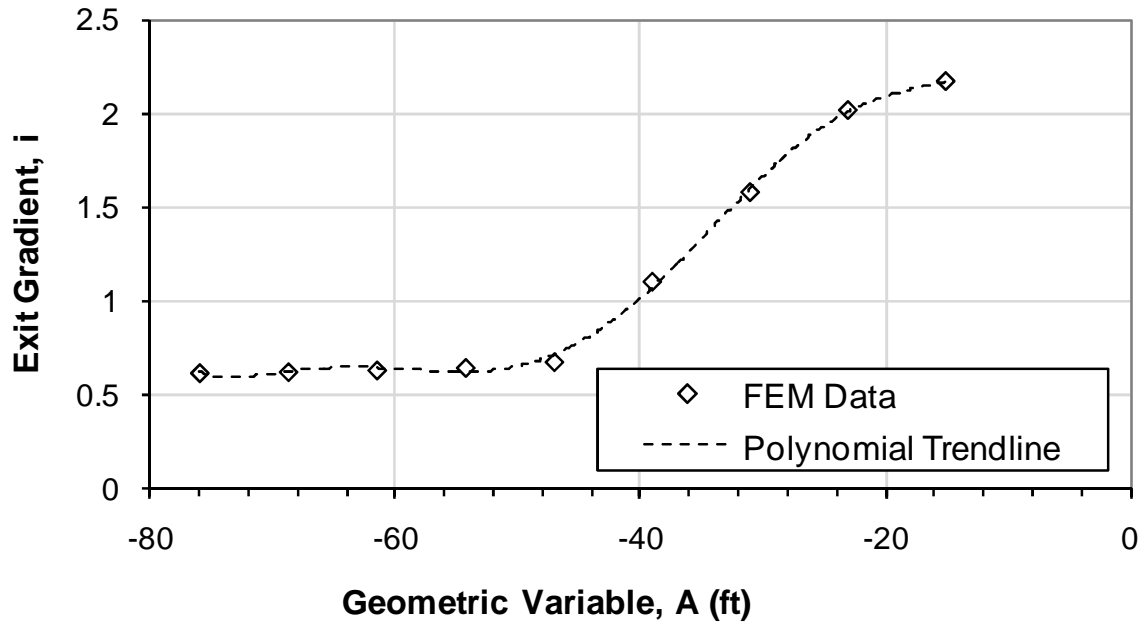

Figure B.20 Family of curves representing relationship of $\mathrm{i}_{\mathrm{e}} \mathrm{SAND}, \mathrm{A}, \mathrm{Ksb}=20$ and, $\mathrm{Khv}=0.05$. 


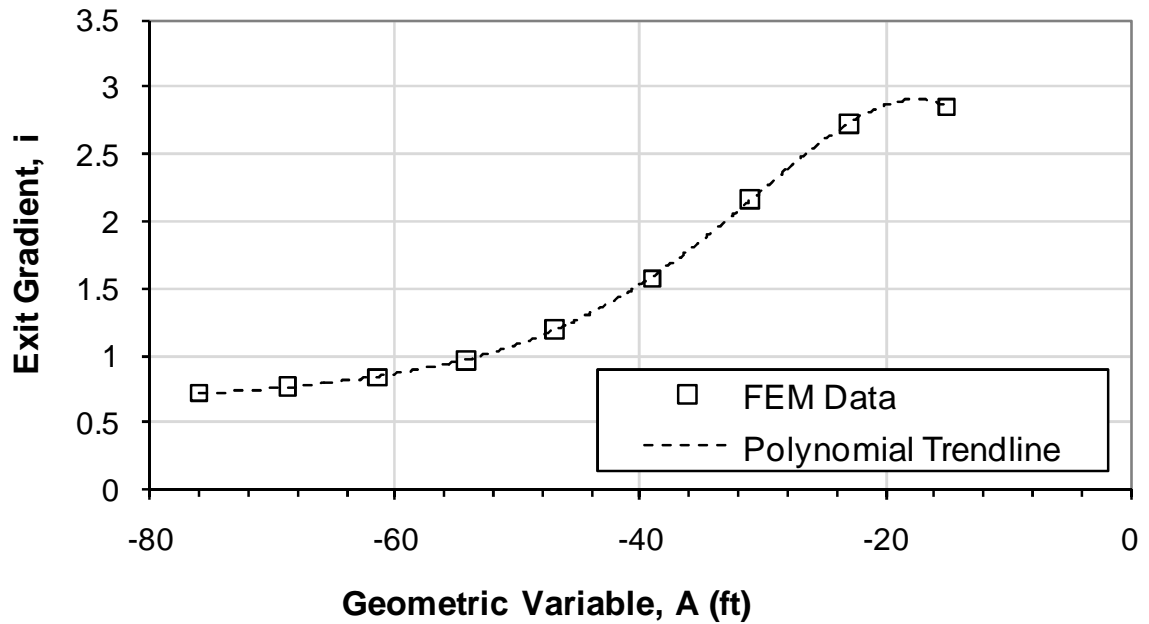

Figure B.21 Family of curves representing relationship of $\mathrm{i}_{\mathrm{e}} \mathrm{SAND}, \mathrm{A}, \mathrm{Ksb}=65$ and, $\mathrm{Khv}=0.05$.

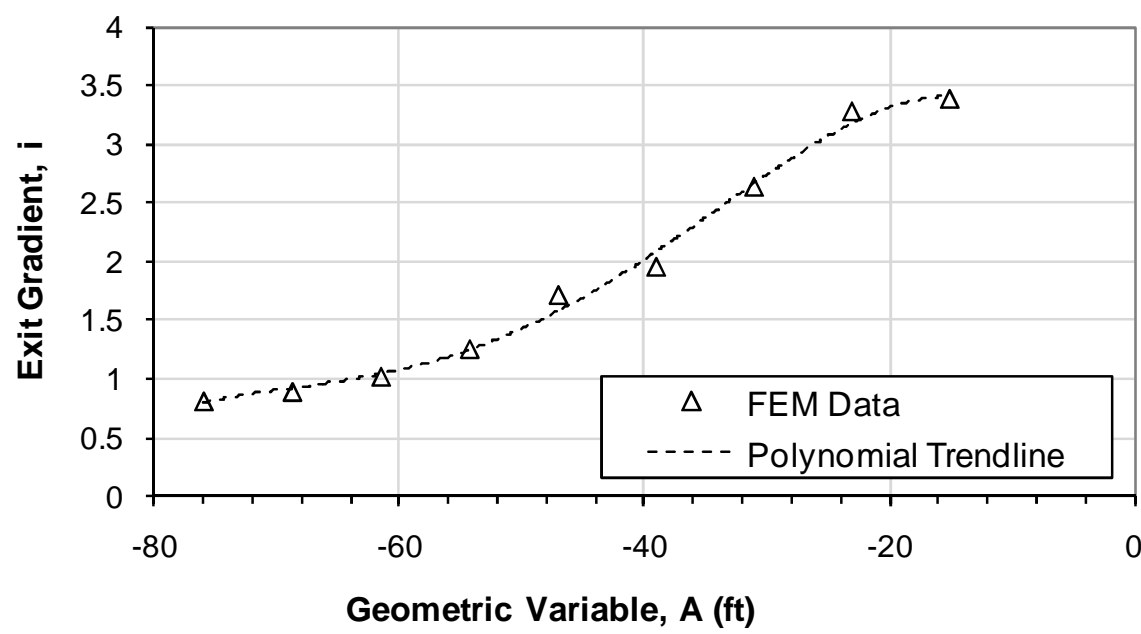

Figure B.22 Family of curves representing relationship of

$$
\mathrm{i}_{\mathrm{e}} \mathrm{SAND}, \mathrm{A}, \mathrm{Ksb}=200 \text { and, } \mathrm{Khv}=0.05 \text {. }
$$




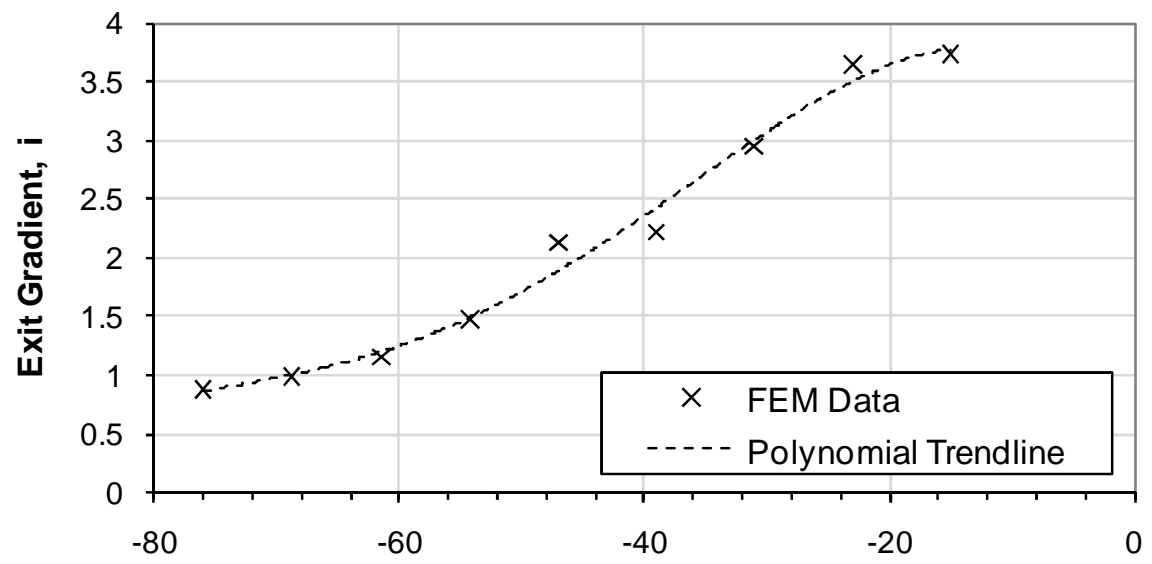

Geometric Variable, A (ft)

Figure B.23 Family of curves representing relationship of $\mathrm{i}_{\mathrm{e}} \mathrm{SAND}, \mathrm{A}, \mathrm{Ksb}=1300$ and, $\mathrm{Khv}=0.05$.

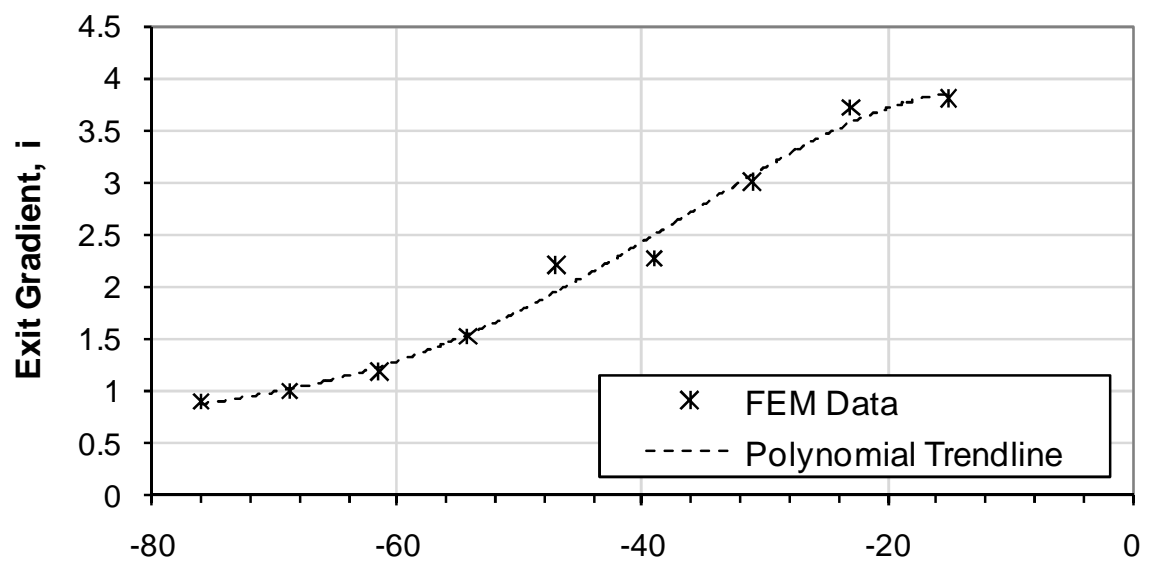

Geometric Variable, A (ft)

Figure B.24 Family of curves representing relationship of $\mathrm{i}_{\mathrm{e} \text { SAND }}, \mathrm{A}, \mathrm{Ksb}=13000$ and, $\mathrm{Khv}=0.05$.

Table B.8 Polynomial Trendline Coefficients and Coefficient of Determination $\left(\mathrm{R}^{2}\right)$ for Family of Curves in Figure B.19

\begin{tabular}{|c|c|c|c|c|c|c|c|c|c|}
\hline \multirow{2}{*}{ Ksb } & \multicolumn{9}{|c|}{$\mathbf{i}=\mathbf{a}_{6} * \mathbf{A}^{6}+\mathbf{a}_{5} * \mathbf{A}^{5}+\mathbf{a}_{4} * \mathbf{A}^{4}+\mathbf{a}_{3} * \mathbf{A}^{3}+\mathbf{a}_{2} * \mathbf{A}^{2}+\mathbf{a}_{1} * A+\mathbf{a}_{0}$} \\
\hline & $\mathbf{a}_{6}$ & $\mathbf{a}_{5}$ & $\mathbf{a}_{4}$ & $\mathbf{a}_{3}$ & $\mathbf{a}_{2}$ & $\mathbf{a}_{1}$ & $\mathbf{a}_{0}$ & $\mathbf{R}^{2}$ & $1-R^{2}$ \\
\hline 20 & $1.419 \mathrm{E}-09$ & $3.812 \mathrm{E}-07$ & $3.964 \mathrm{E}-05$ & $1.992 \mathrm{E}-03$ & $4.960 \mathrm{E}-02$ & $6.056 \mathrm{E}-01$ & $5.082 \mathrm{E}+00$ & 0.9989 & $1.075 \mathrm{E}-03$ \\
\hline 65 & $-1.42 \mathrm{E}-10$ & $-6.206 \mathrm{E}-08$ & $-1.047 \mathrm{E}-05$ & $-8.751 \mathrm{E}-04$ & $-3.732 \mathrm{E}-02$ & $-6.993 \mathrm{E}-01$ & $-1.706 \mathrm{E}+00$ & 0.9999 & $1.075 \mathrm{E}-03$ \\
\hline 200 & - & - & $-7.135 \mathrm{E}-07$ & $-1.466 \mathrm{E}-04$ & $-1.001 \mathrm{E}-02$ & $-2.112 \mathrm{E}-01$ & $2.034 \mathrm{E}+00$ & 0.9940 & $1.075 \mathrm{E}-03$ \\
\hline 1300 & - & - & $-4.512 \mathrm{E}-07$ & $-9.978 \mathrm{E}-05$ & $-7.234 \mathrm{E}-03$ & $-1.445 \mathrm{E}-01$ & $2.921 \mathrm{E}+00$ & 0.9870 & $1.075 \mathrm{E}-03$ \\
\hline 13000 & - & - & $-3.900 \mathrm{E}-07$ & $-8.877 \mathrm{E}-05$ & $-6.574 \mathrm{E}-03$ & $-1.286 \mathrm{E}-01$ & $3.119 \mathrm{E}+00$ & 0.9852 & $1.075 \mathrm{E}-03$ \\
\hline
\end{tabular}


Table B.9 Exit gradient $\mathrm{i}_{\mathrm{e}}$ SAND as a function of $\mathrm{A}, \mathrm{Ksb}$ and $\mathrm{Khv}=0.005$

\begin{tabular}{|c|c|c|c|c|c|}
\hline \multirow{2}{*}{$\mathbf{A}$} & \multicolumn{5}{|c|}{$\mathbf{i}_{\mathbf{e} \text { SAND }}$} \\
\cline { 2 - 6 } & $\mathbf{K s b}=\mathbf{2 0}$ & $\mathbf{K s b}=\mathbf{6 5}$ & $\mathbf{K s b}=\mathbf{2 0 0}$ & $\mathbf{K s b}=\mathbf{1 3 0 0}$ & $\mathbf{K s b}=\mathbf{1 3 0 0 0}$ \\
\hline $\mathbf{- 7 6}$ & 0.648 & 0.737 & 0.786 & 0.98 & 1.029 \\
\hline $\mathbf{- 6 8 . 7 5}$ & 0.668 & 0.753 & 0.794 & 1.031 & 1.096 \\
\hline $\mathbf{- 6 1 . 5}$ & 0.687 & 0.769 & 0.806 & 1.102 & 1.186 \\
\hline $\mathbf{- 5 4 . 2 5}$ & 0.705 & 0.786 & 0.817 & 1.207 & 1.340 \\
\hline $\mathbf{- 4 7}$ & 0.724 & 0.801 & 0.829 & 1.402 & 1.603 \\
\hline $\mathbf{- 3 9}$ & 0.799 & 0.935 & 1.389 & 1.888 & 2.019 \\
\hline $\mathbf{- 3 1}$ & 1.261 & 1.795 & 2.428 & 3.050 & 3.207 \\
\hline $\mathbf{- 2 3}$ & 2.234 & 3.126 & 4.079 & 4.992 & 5.223 \\
\hline $\mathbf{- 1 5}$ & 2.655 & 3.401 & 4.21 & 5.006 & 5.209 \\
\hline
\end{tabular}

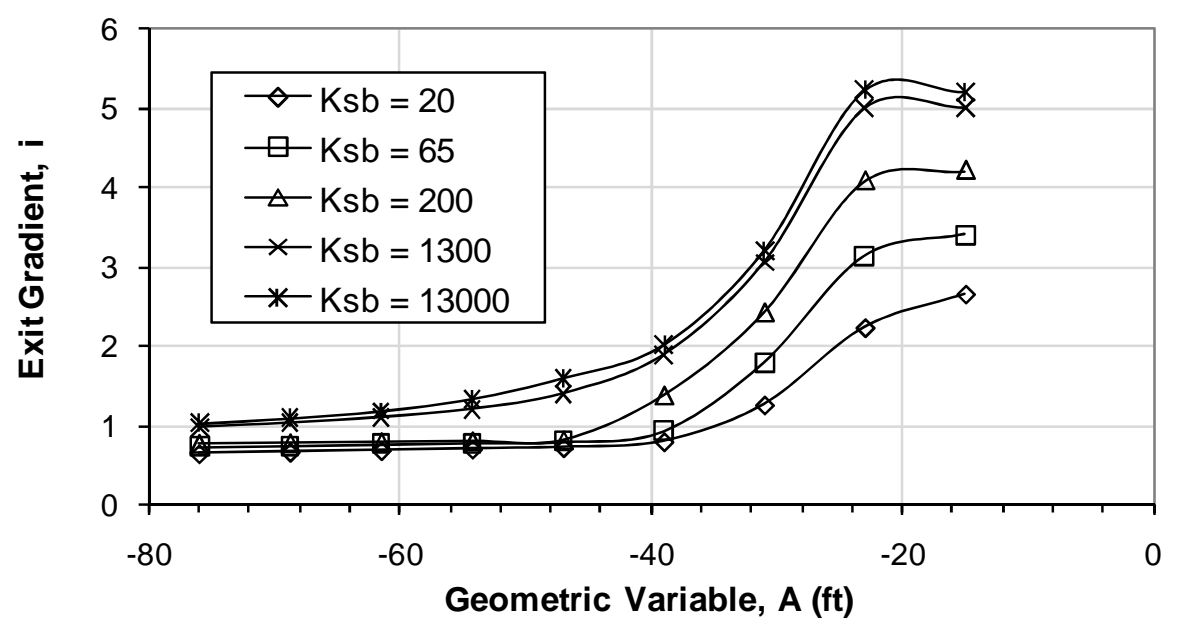

Figure B.25 Family of curves representing relationship of $\mathrm{i}_{\mathrm{e} \text { SAND, }} \mathrm{A}, \mathrm{Ksb}$ and, Khv $=0.005$. 


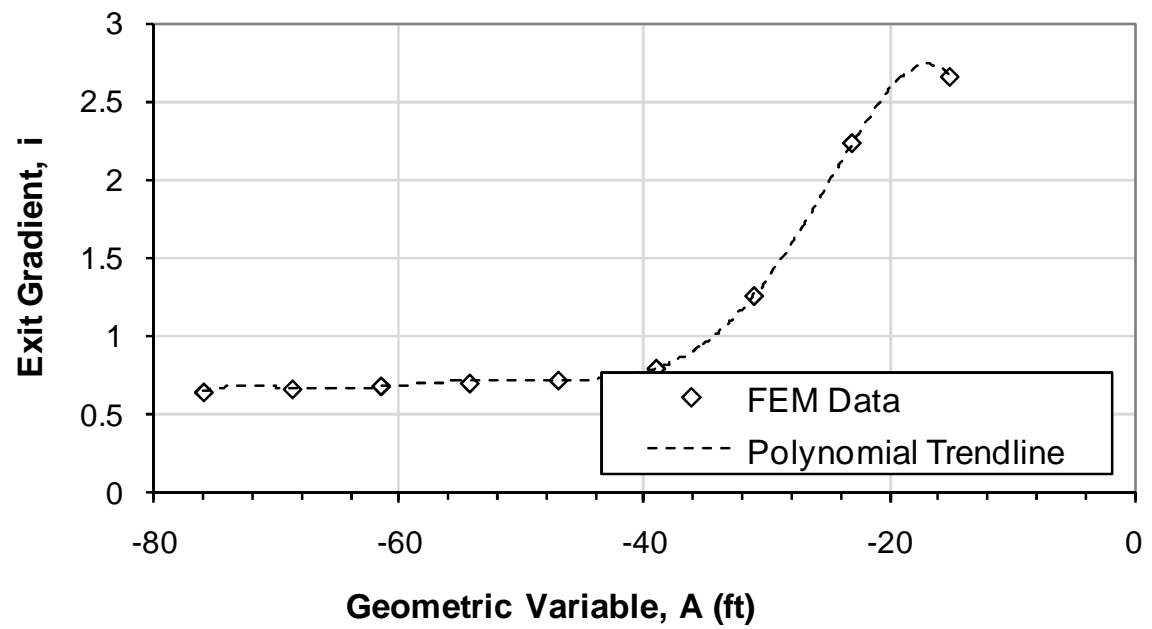

Figure B.26 Family of curves representing relationship of $\mathrm{i}_{\mathrm{e}}$ SAND, $\mathrm{A}, \mathrm{Ksb}=20$ and, $\mathrm{Khv}=0.005$.

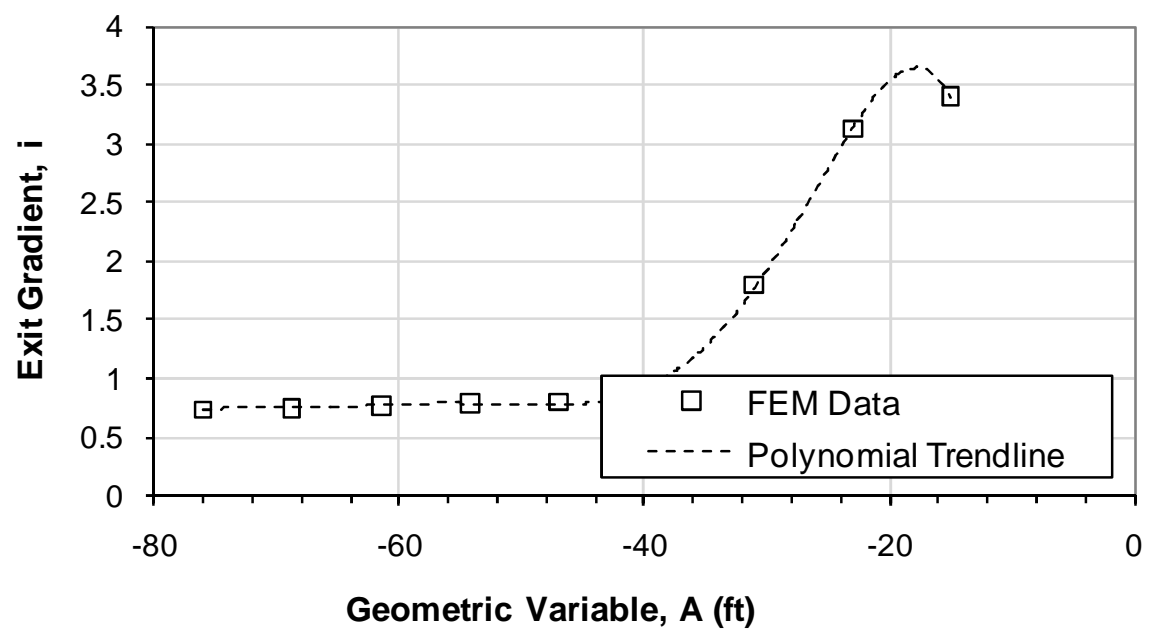

Figure B.27 Family of curves representing relationship of $\mathrm{i}_{\mathrm{e}} \mathrm{SAND}, \mathrm{A}, \mathrm{Ksb}=65$ and, $\mathrm{Khv}=0.005$. 


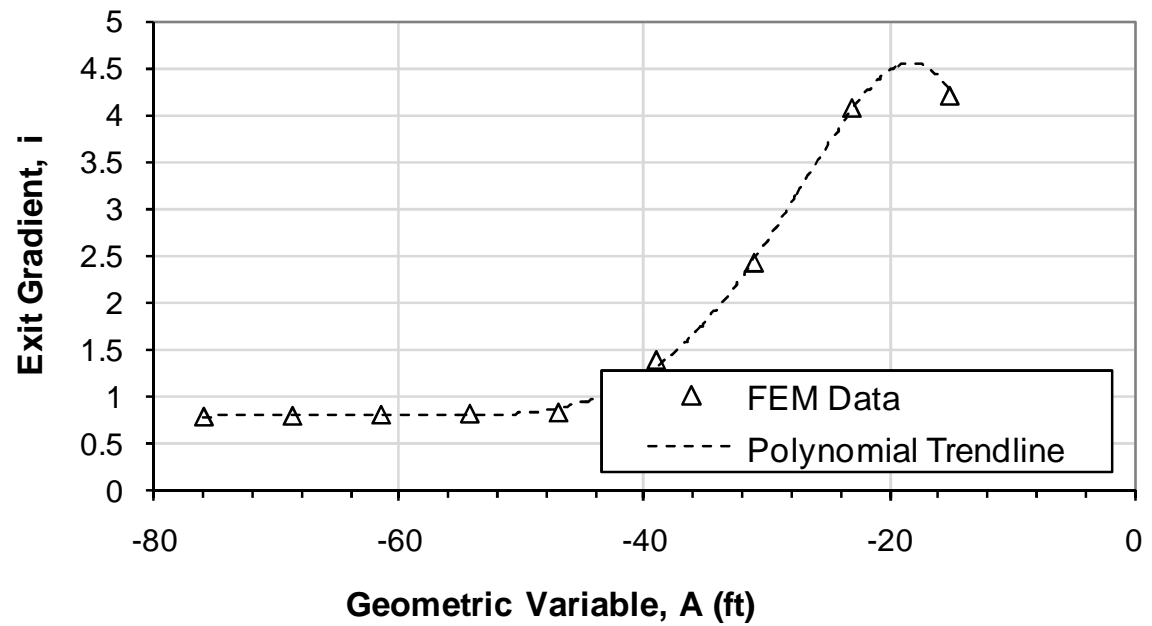

Figure B.28 Family of curves representing relationship of $\mathrm{i}_{\mathrm{e}} \mathrm{SAND}, \mathrm{A}, \mathrm{Ksb}=200$ and, $\mathrm{Khv}=0.005$.

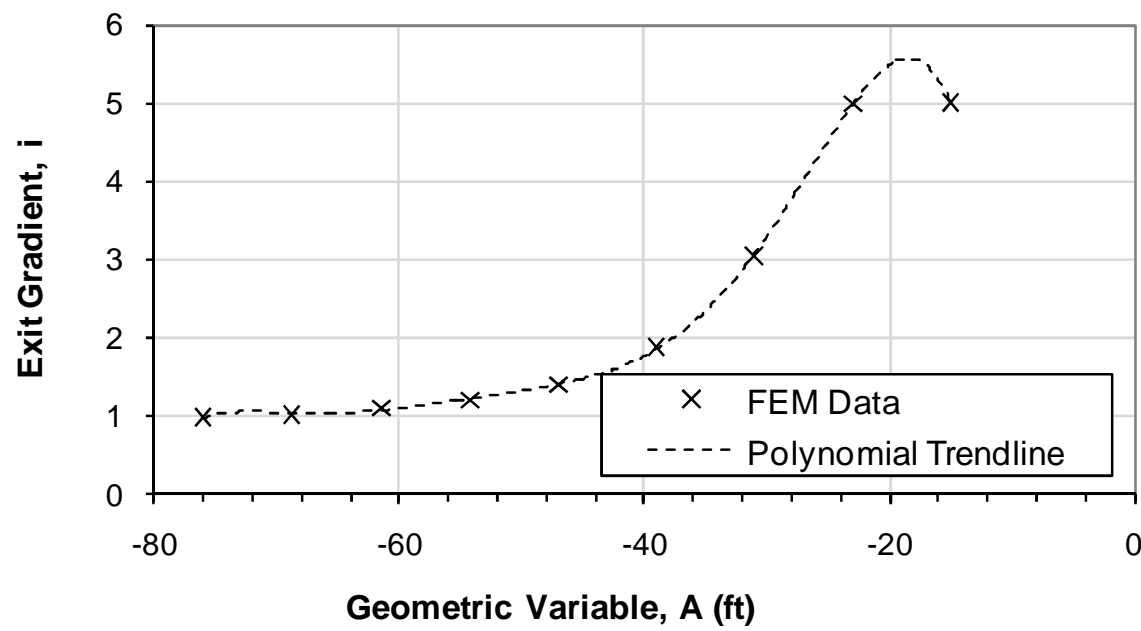

Figure B.29 Family of curves representing relationship of $\mathrm{i}_{\mathrm{e}}$ SAND, $\mathrm{A}, \mathrm{Ksb}=1300$ and, $\mathrm{Khv}=0.005$. 


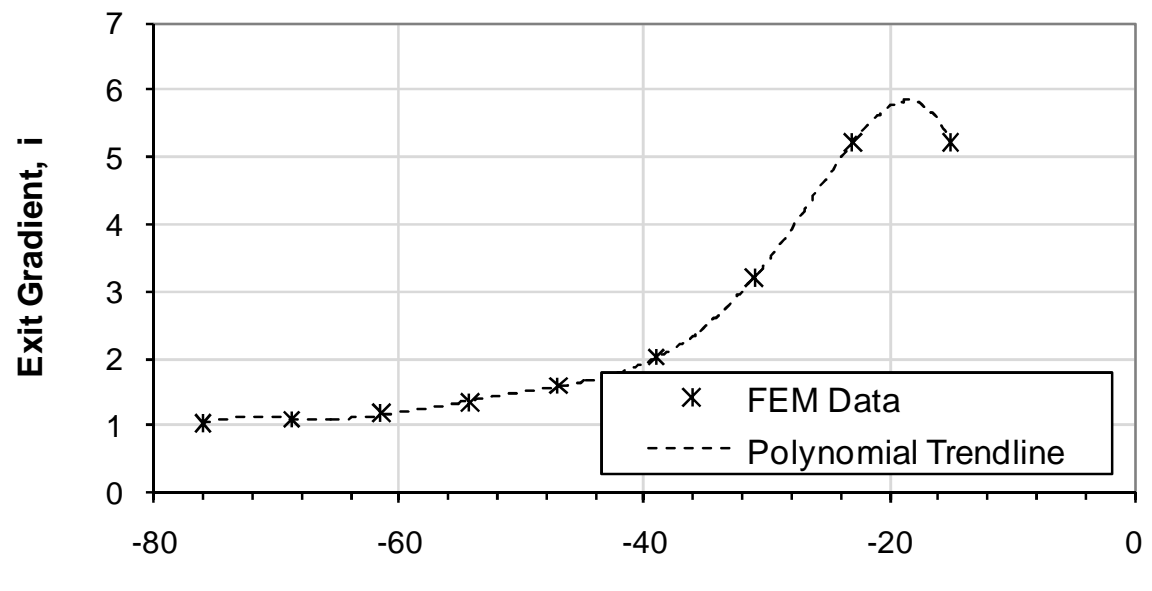

Geometric Variable, A (ft)

Figure B.30 Family of curves representing relationship of $\mathrm{i}_{\mathrm{e}} \mathrm{SAND}, \mathrm{A}, \mathrm{Ksb}=13000$ and, Khv $=0.005$.

Table B.10 Polynomial Trendline Coefficients and Coefficient of Determination $\left(\mathrm{R}^{2}\right)$ for Family of Curves in Figure B.25

\begin{tabular}{|c|c|c|c|c|c|c|c|c|c|}
\hline \multirow{2}{*}{ Ksb } & \multicolumn{9}{|c|}{$\mathbf{i}=\mathbf{a}_{6} * \mathbf{A}^{6}+\mathbf{a}_{5} * \mathbf{A}^{5}+\mathbf{a}_{4} * \mathbf{A}^{4}+\mathbf{a}_{3} * \mathbf{A}^{3}+\mathbf{a}_{2} * \mathbf{A}^{2}+\mathbf{a}_{1} * A+\mathbf{a}_{0}$} \\
\hline & $\mathbf{a}_{6}$ & $\mathbf{a}_{5}$ & $\mathbf{a}_{4}$ & $\mathbf{a}_{3}$ & $\mathbf{a}_{2}$ & $\mathbf{a}_{1}$ & $\mathbf{a}_{0}$ & $\mathbf{R}^{2}$ & $1-R^{2}$ \\
\hline 20 & $\begin{array}{c}-2.526 \mathrm{E}- \\
09 \\
\end{array}$ & $\begin{array}{c}-7.648 \mathrm{E}- \\
07 \\
\end{array}$ & $\begin{array}{c}-9.294 \mathrm{E}- \\
05\end{array}$ & $\begin{array}{c}-5.739 \mathrm{E}- \\
03\end{array}$ & $\begin{array}{c}-1.861 \mathrm{E}- \\
01\end{array}$ & $\begin{array}{c}- \\
2.874 \mathrm{E}+00\end{array}$ & $\begin{array}{c}- \\
1.380 \mathrm{E}+01\end{array}$ & $\begin{array}{c}0.999 \\
9\end{array}$ & $\begin{array}{l}5.764 \mathrm{E}- \\
05\end{array}$ \\
\hline 65 & $\begin{array}{c}-2.677 \mathrm{E}- \\
09\end{array}$ & $\begin{array}{c}-8.502 \mathrm{E}- \\
07\end{array}$ & $\begin{array}{c}-1.086 \mathrm{E}- \\
04\end{array}$ & $\begin{array}{c}-7.053 \mathrm{E}- \\
03\end{array}$ & $\begin{array}{c}-2.408 \mathrm{E}- \\
01\end{array}$ & $\begin{array}{c}- \\
3.918 \mathrm{E}+00\end{array}$ & $\begin{array}{c}- \\
2.012 \mathrm{E}+01\end{array}$ & $\begin{array}{c}0.999 \\
7\end{array}$ & $\begin{array}{c}2.514 \mathrm{E}- \\
04\end{array}$ \\
\hline 200 & $\begin{array}{c}-2.353 \mathrm{E}- \\
09\end{array}$ & $\begin{array}{c}-7.655 \mathrm{E}- \\
07\end{array}$ & $\begin{array}{c}-1.007 \mathrm{E}- \\
04\end{array}$ & $\begin{array}{c}-6.781 \mathrm{E}- \\
03\end{array}$ & $\begin{array}{c}-2.407 \mathrm{E}- \\
01\end{array}$ & $\begin{array}{c}- \\
4.059 \mathrm{E}+00\end{array}$ & $\begin{array}{c}- \\
2.085 \mathrm{E}+01\end{array}$ & $\begin{array}{c}0.999 \\
5\end{array}$ & $\begin{array}{c}5.418 \mathrm{E}- \\
04\end{array}$ \\
\hline 1300 & $\begin{array}{c}-4.989 \mathrm{E}- \\
09\end{array}$ & $\begin{array}{c}-1.524 \mathrm{E}- \\
06\end{array}$ & $\begin{array}{c}-1.880 \mathrm{E}- \\
04\end{array}$ & $\begin{array}{c}-1.188 \mathrm{E}- \\
02\end{array}$ & $\begin{array}{c}-3.986 \mathrm{E}- \\
01\end{array}$ & $\begin{array}{c}- \\
6.482 \mathrm{E}+00\end{array}$ & $\begin{array}{c}- \\
3.420 \mathrm{E}+01\end{array}$ & $\begin{array}{c}0.999 \\
9\end{array}$ & $\begin{array}{c}1.396 \mathrm{E}- \\
04\end{array}$ \\
\hline $\begin{array}{c}1300 \\
0\end{array}$ & $\begin{array}{c}-6.060 \mathrm{E}- \\
09\end{array}$ & $\begin{array}{c}-1.831 \mathrm{E}- \\
06\end{array}$ & $\begin{array}{c}-2.230 \mathrm{E}- \\
04\end{array}$ & $\begin{array}{c}-1.389 \mathrm{E}- \\
02\end{array}$ & $\begin{array}{c}-4.600 \mathrm{E}- \\
01\end{array}$ & $\begin{array}{c}- \\
7.406 \mathrm{E}+00\end{array}$ & $\begin{array}{c}- \\
3.930 \mathrm{E}+01\end{array}$ & $\begin{array}{c}0.999 \\
9\end{array}$ & $\begin{array}{c}1.029 \mathrm{E}- \\
04\end{array}$ \\
\hline
\end{tabular}




\begin{tabular}{|c|c|c|c|c|}
\hline Variable & MLV & $\sigma$ & MAX & MIN \\
\hline $\log (K b)$ & -6.00 & 0.67 & -5.10 & -7.00 \\
\hline $\log (\mathrm{Ks})$ & -3.00 & 0.67 & -2.00 & -3.80 \\
\hline $\log (K h v)$ & -0.60 & 0.097 & -0.30 & -2.30 \\
\hline$A$ & -47 & - & -15 & -76 \\
\hline ys & 130 & 5.200 & 140 & 120 \\
\hline
\end{tabular}

\begin{tabular}{|c|c|c|c|c|}
\hline$A$ & $\log (\mathrm{Kb})$ & $\log (\mathrm{Ks})$ & $\log (\mathrm{Khv})$ & $\mathrm{ys}$ \\
\hline-26.80225011 & -6.226748 & -2.277653 & -0.592031 & 129.20 \\
\hline
\end{tabular}

\begin{tabular}{|c|c|c|c|c|}
\hline$A$ & $\log (\mathrm{Kb})$ & $\log (\mathrm{Ks})$ & $\log (\mathrm{Khv})$ & $\mathrm{ys}$ \\
\hline-26.80225011 & -6.226748 & -2.277653 & -0.592031 & 129.20 \\
\hline
\end{tabular}

\begin{tabular}{|c|c|c|c|c|}
\hline $\mathrm{A}$ & $\mathrm{Kb}$ & $\mathrm{Ks}$ & $\mathrm{Khv}$ & $\mathrm{ys}$ \\
\hline-27 & $5.93 \mathrm{E}-07$ & $5.28 \mathrm{E}-03$ & 0.26 & 129.20 \\
\hline
\end{tabular}

\begin{tabular}{|c|c|c|c|}
\hline Khv SP & $\mathrm{Kb}(\mathrm{ft} / \mathrm{s})$ & $\mathrm{Ksp}(\mathrm{ft} / \mathrm{s})$ & \\
\hline 0.50 & $6.50 \mathrm{E}-05$ & $1.30 \mathrm{E}-03$ & 20 \\
\hline 0.25 & $2.00 \mathrm{E}-05$ & & 65 \\
\hline 0.15 & $6.50 \mathrm{E}-06$ & & 200 \\
\hline 0.05 & $1.00 \mathrm{E}-06$ & & 1300 \\
\hline 0.005 & $1.00 \mathrm{E}-07$ & & 13000 \\
\hline
\end{tabular}

$$
\begin{aligned}
\mathrm{yw} & =62.4 \\
\mathrm{ic} & =1.07 \\
\mathrm{i} & =1.86 \\
\mathrm{FS} & =0.58
\end{aligned}
$$

Figure B.31 Excel spreadsheet for Analysis 2. 


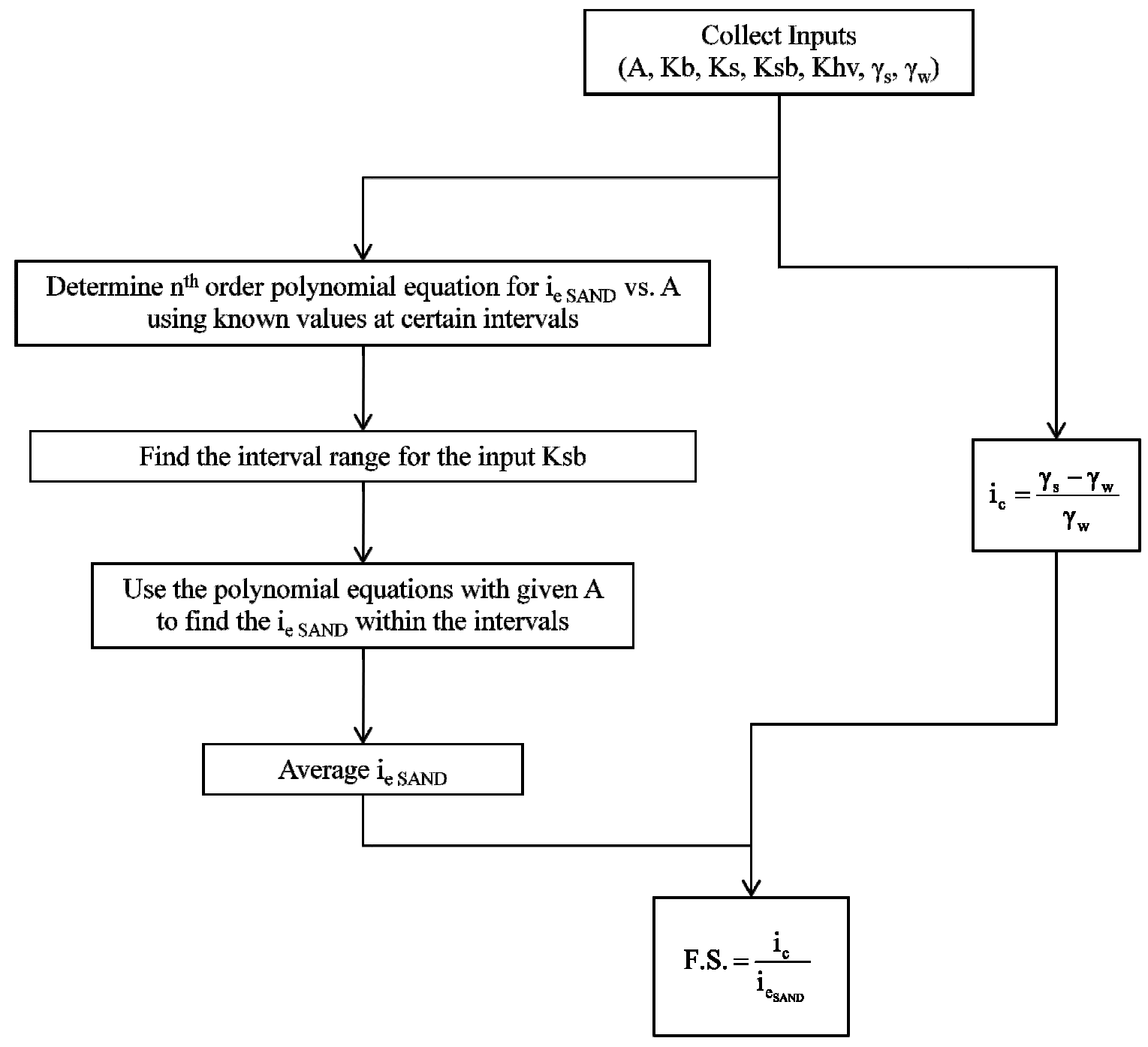

Figure B.32 Flow Chart for Excel Spreadsheet for Analysis 2. 


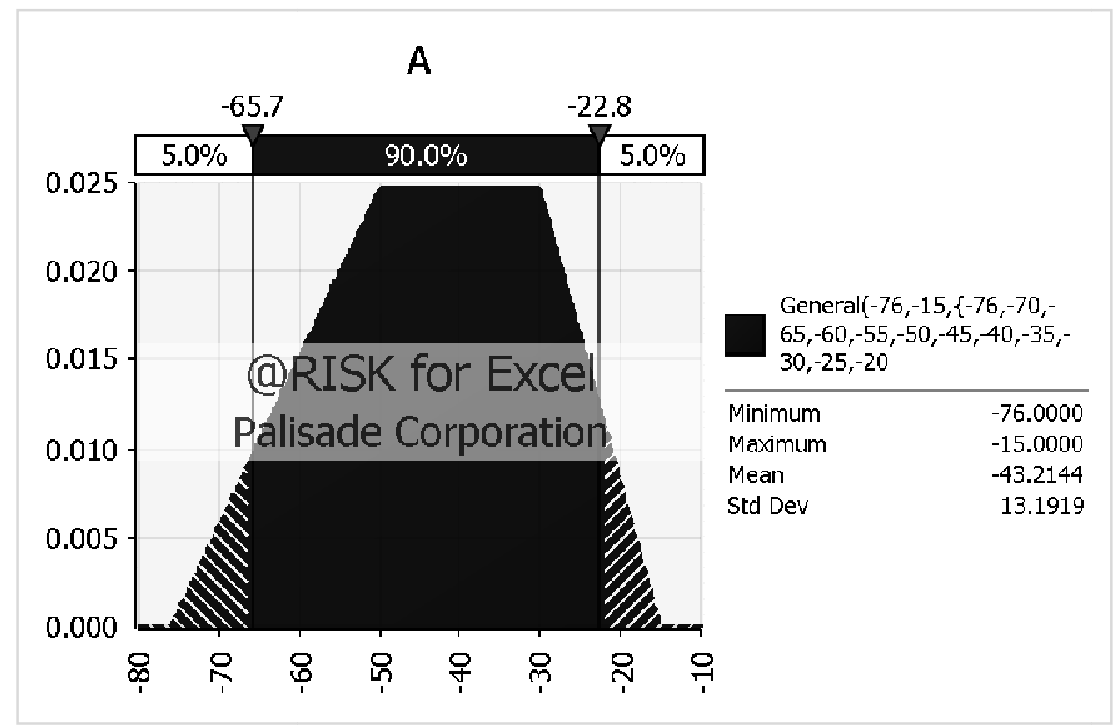

Figure B.33 Probability Density Function for geometric variable A.

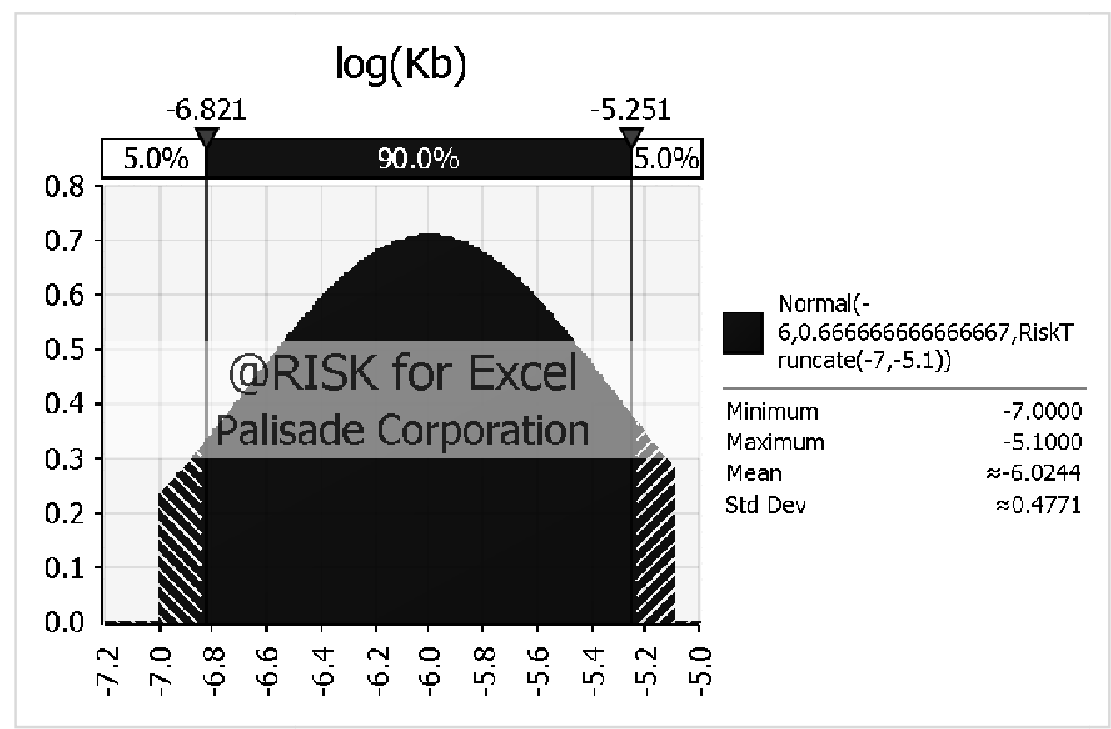

Figure B.34 Probability Density Function for soil variable Kb. 


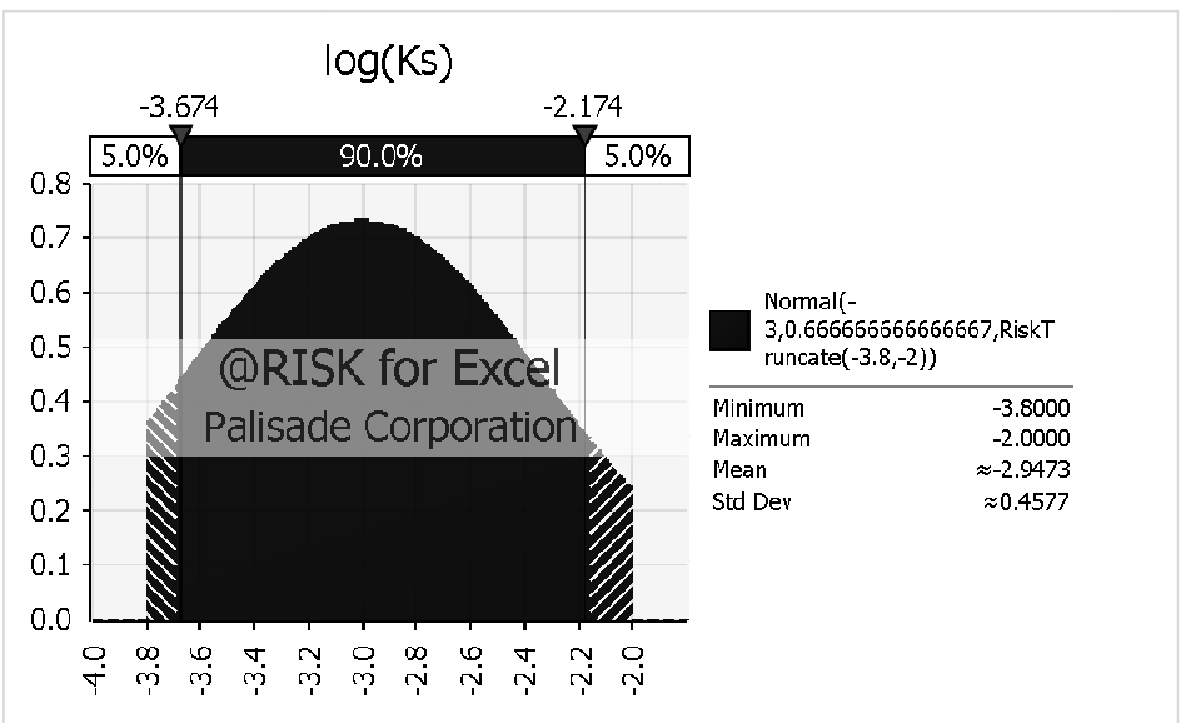

Figure B.35 Probability Density Function for soil variable Ks.

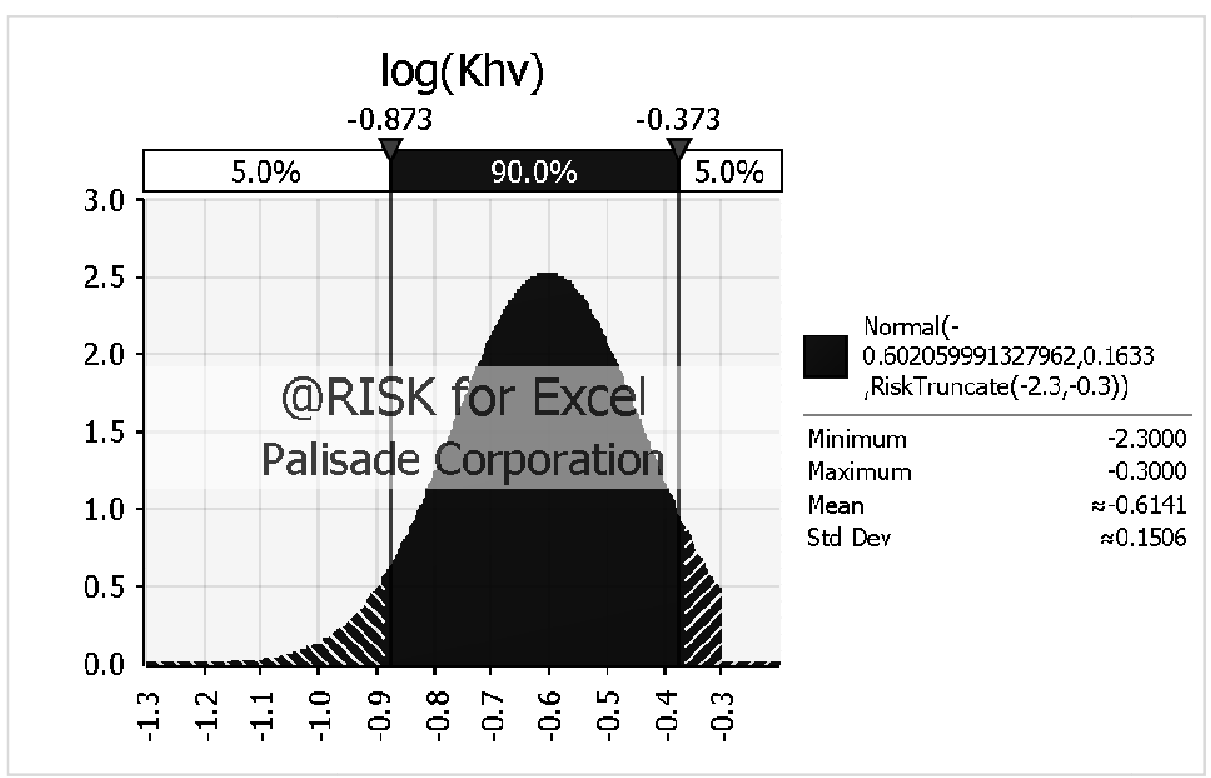

Figure B.36 Probability Density Function for soil variable Khv. 


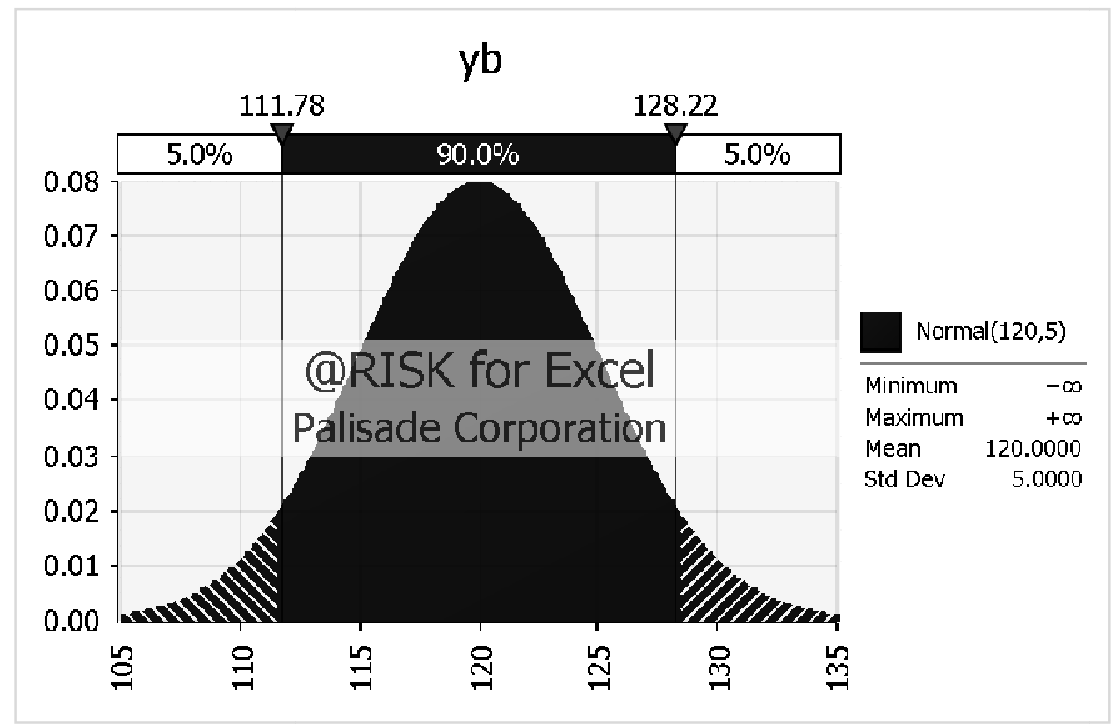

Figure B.37 Probability Density Function for soil variable $\gamma_{b}$.

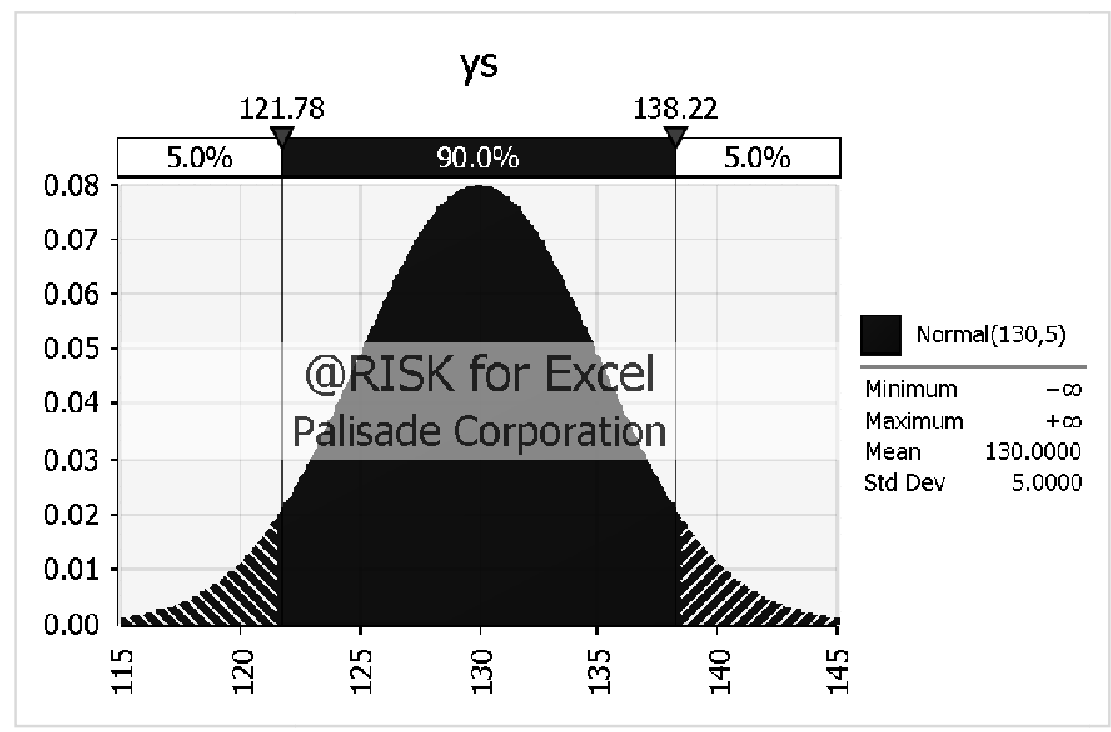

Figure B.38 Probability Density Function for soil variable $\gamma_{\mathrm{s}}$. 
Appendix C. Analysis 3 
Table C. 1 Exit gradient $\mathrm{i}_{\mathrm{e} \text { BLANKET }}$ as a function of $\mathrm{H}, \mathrm{Ksb}$ and $\mathrm{Khv}=0.25$

\begin{tabular}{|c|c|c|c|c|c|}
\hline & \multicolumn{5}{|c|}{$\mathbf{i}_{\text {e,blanket }}$} \\
\hline $\mathbf{H}$ & $\mathbf{K s b}=\mathbf{2 0}$ & $\mathbf{K s b}=\mathbf{6 3}$ & $\mathbf{K s b}=\mathbf{2 0 1}$ & $\mathbf{K s b}=\mathbf{6 3 4}$ & $\mathbf{K s b}=\mathbf{2 0 0 6}$ \\
\hline $\mathbf{2}$ & 1.278 & 2.163 & 3.076 & 3.693 & 3.976 \\
\hline $\mathbf{4}$ & 0.881 & 1.344 & 1.721 & 1.922 & 2.000 \\
\hline $\mathbf{6}$ & 0.688 & 0.985 & 1.194 & 1.293 & 1.329 \\
\hline $\mathbf{8}$ & 0.570 & 0.779 & 0.912 & 0.97 & 0.991 \\
\hline $\mathbf{1 0}$ & 0.489 & 0.645 & 0.738 & 0.776 & 0.790 \\
\hline $\mathbf{1 2}$ & 0.429 & 0.550 & 0.618 & 0.645 & 0.654 \\
\hline $\mathbf{1 4}$ & 0.383 & 0.480 & 0.532 & 0.552 & 0.559 \\
\hline $\mathbf{1 6}$ & 0.345 & 0.425 & 0.466 & 0.481 & 0.487 \\
\hline $\mathbf{1 8}$ & 0.315 & 0.382 & 0.415 & 0.428 & 0.432 \\
\hline $\mathbf{2 0}$ & 0.289 & 0.346 & 0.373 & 0.384 & 0.387 \\
\hline $\mathbf{2 2}$ & 0.268 & 0.317 & 0.34 & 0.349 & 0.351 \\
\hline $\mathbf{2 4}$ & 0.249 & 0.292 & 0.311 & 0.319 & 0.321 \\
\hline $\mathbf{2 6}$ & 0.233 & 0.270 & 0.288 & 0.294 & 0.296 \\
\hline
\end{tabular}

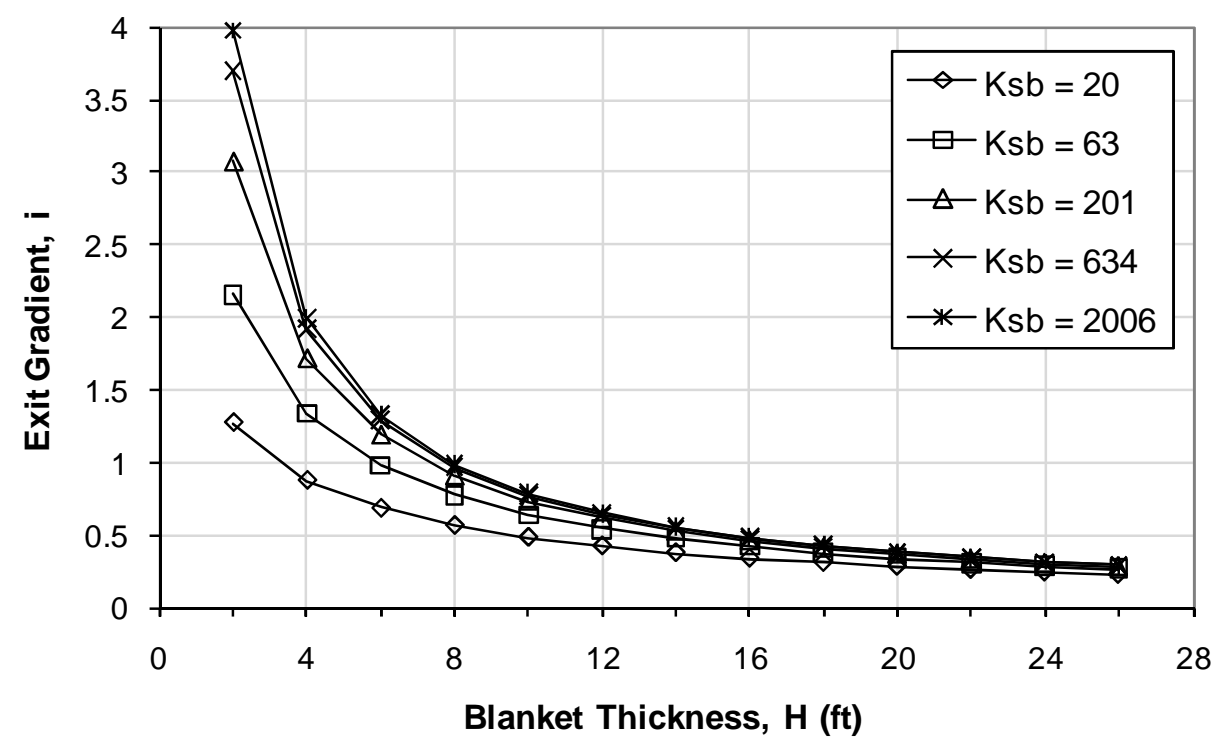

Figure C.1 Family of curves representing relationship of $\mathrm{i}_{\mathrm{e} \text { BLANKET, }} \mathrm{H}, \mathrm{Ksb}$ and, Khv $=0.25$. 


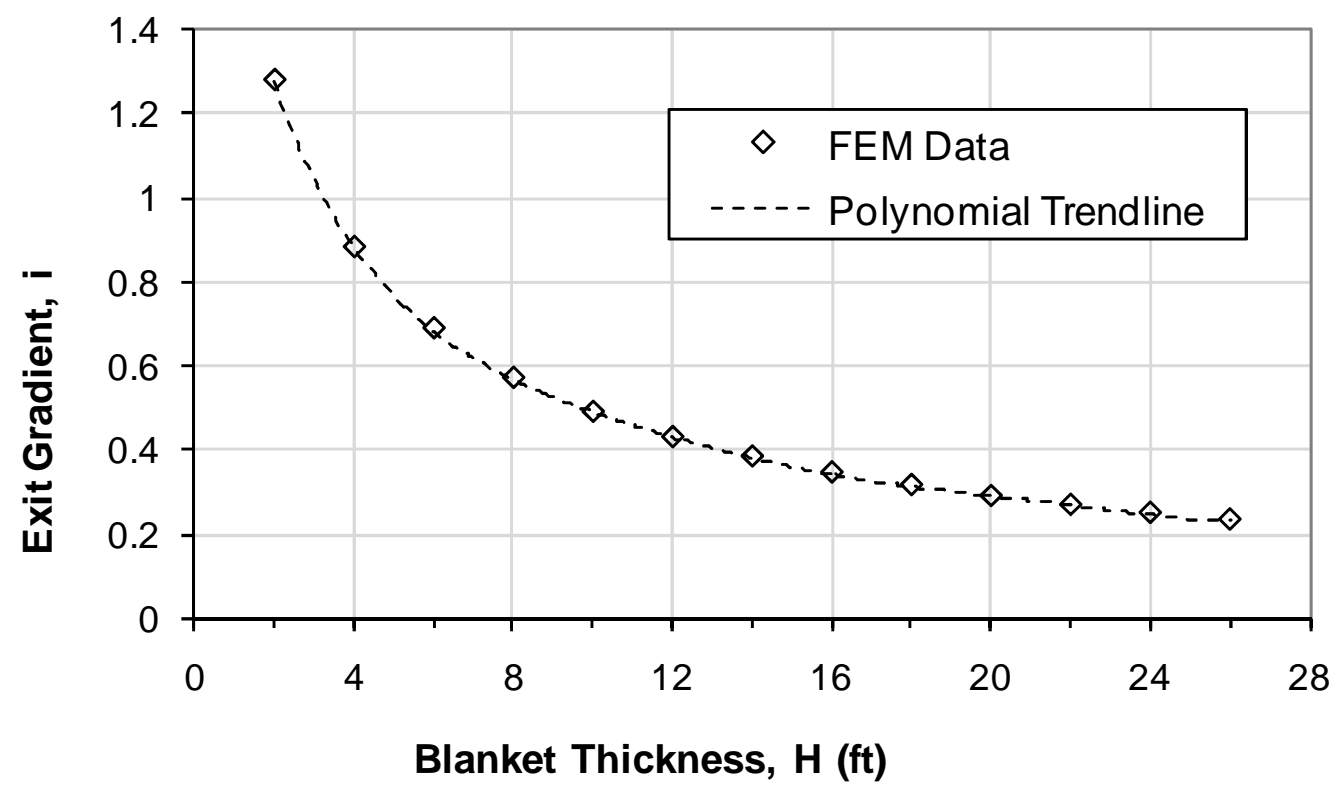

Figure C.2 Exit Gradient ( $i_{\text {e BLANKET }}$ ) vs. Blanket Thickness $(H)$ for $\mathrm{Ksb}=20$ and $\mathrm{Khv}=0.25$.

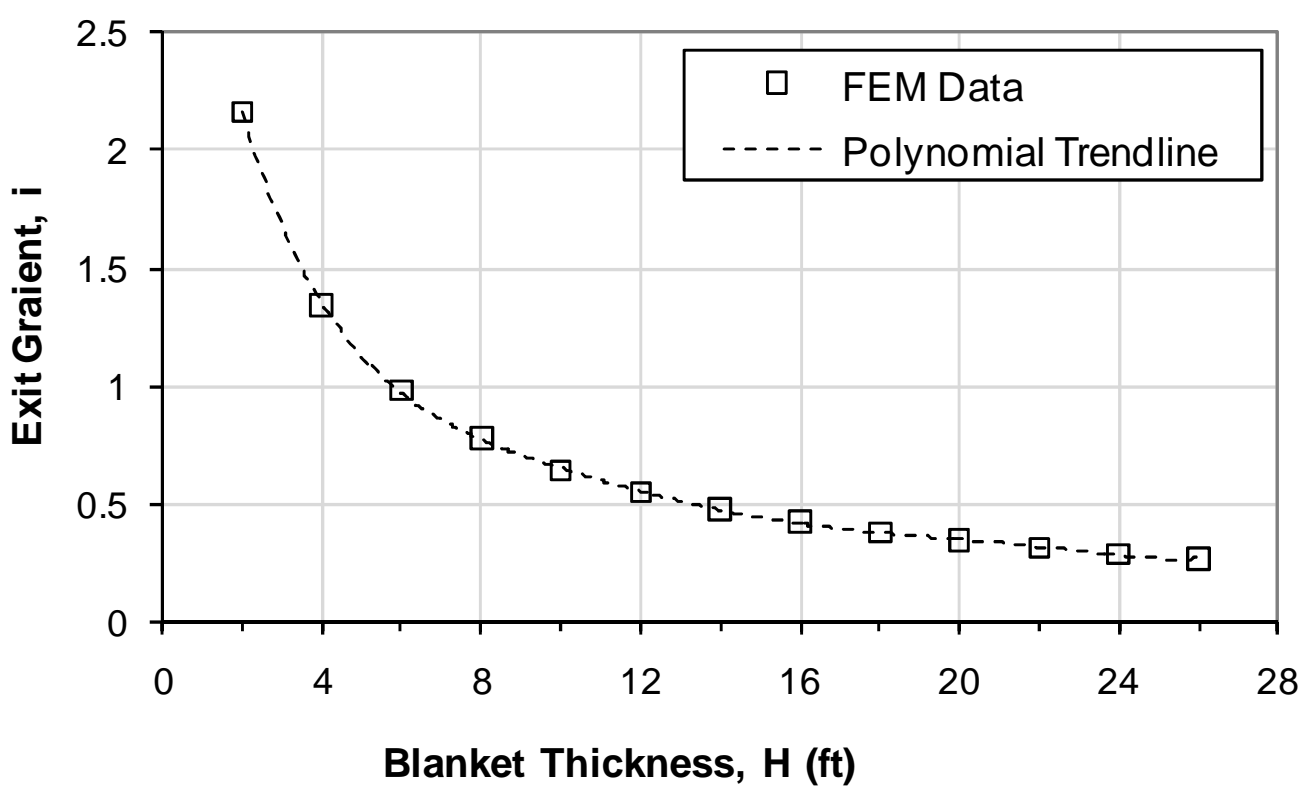

Figure C.3 Exit Gradient ( $\mathrm{i}_{\mathrm{e}}$ BLANKET) vs. Blanket Thickness $(\mathrm{H})$ for $\mathrm{Ksb}=63$ and $\mathrm{Khv}=0.25$. 


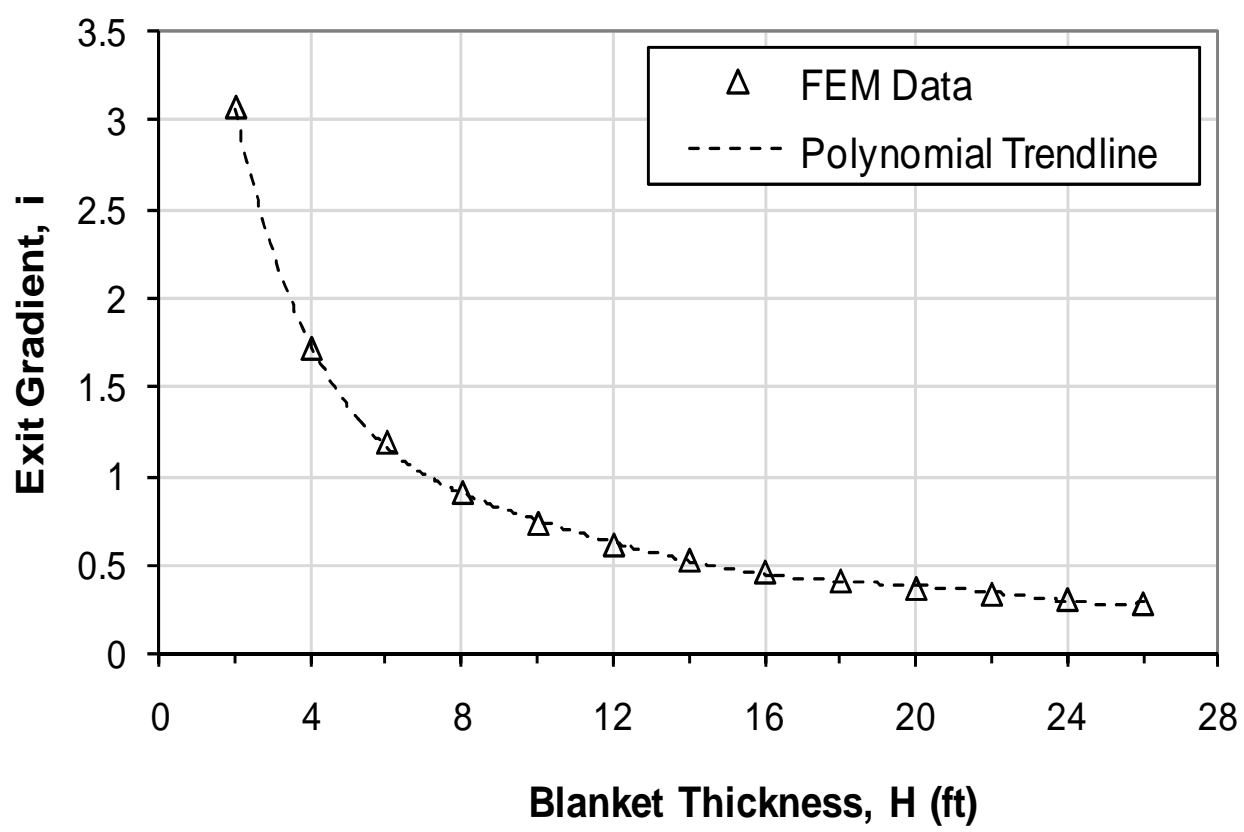

Figure C.4 Exit Gradient ( $\mathrm{i}_{\mathrm{e}}$ BLANKET) vs. Blanket Thickness $(\mathrm{H})$ for $\mathrm{Ksb}=201$ and $\mathrm{Khv}=0.25$.

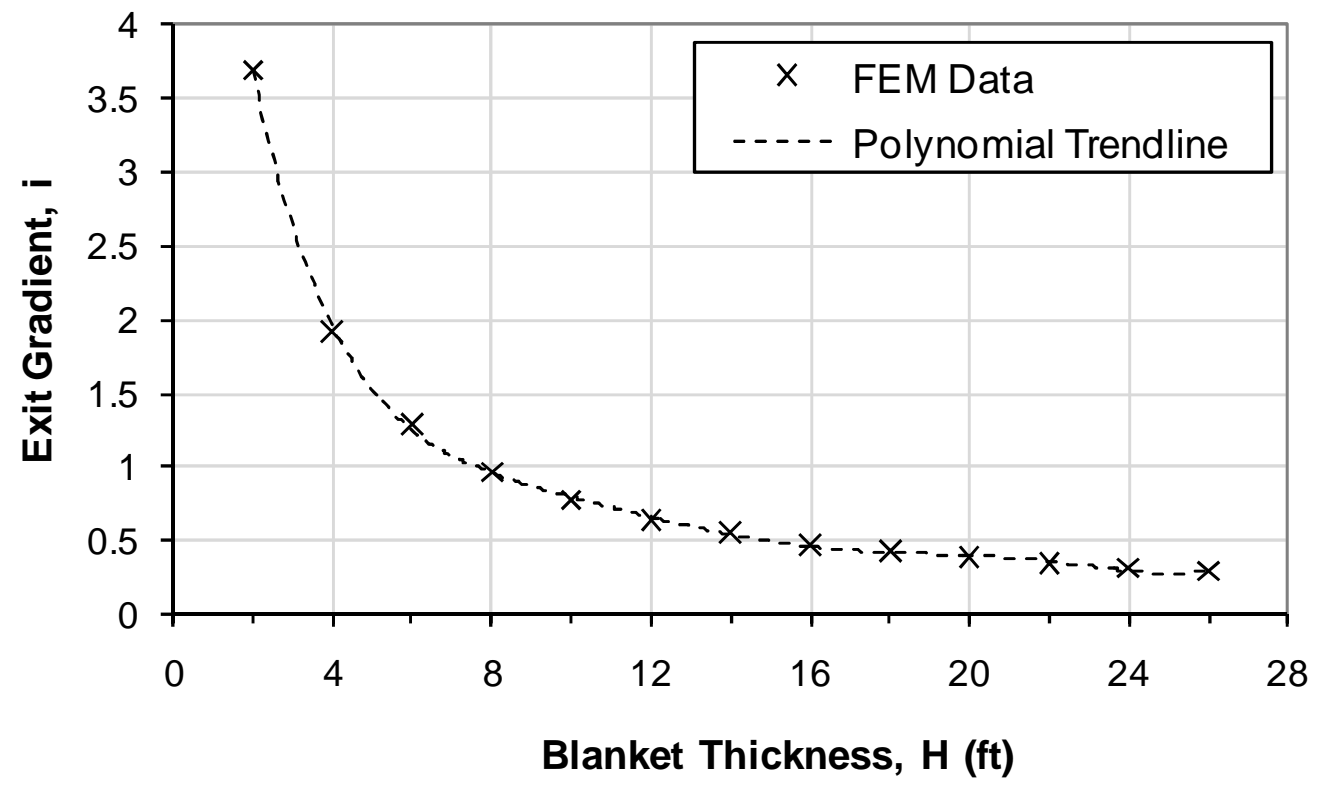

Figure C.5 Exit Gradient ( $\mathrm{i}_{\mathrm{e}}$ BLANKET) vs. Blanket Thickness $(\mathrm{H})$ for $\mathrm{Ksb}=634$ and $\mathrm{Khv}=0.25$. 


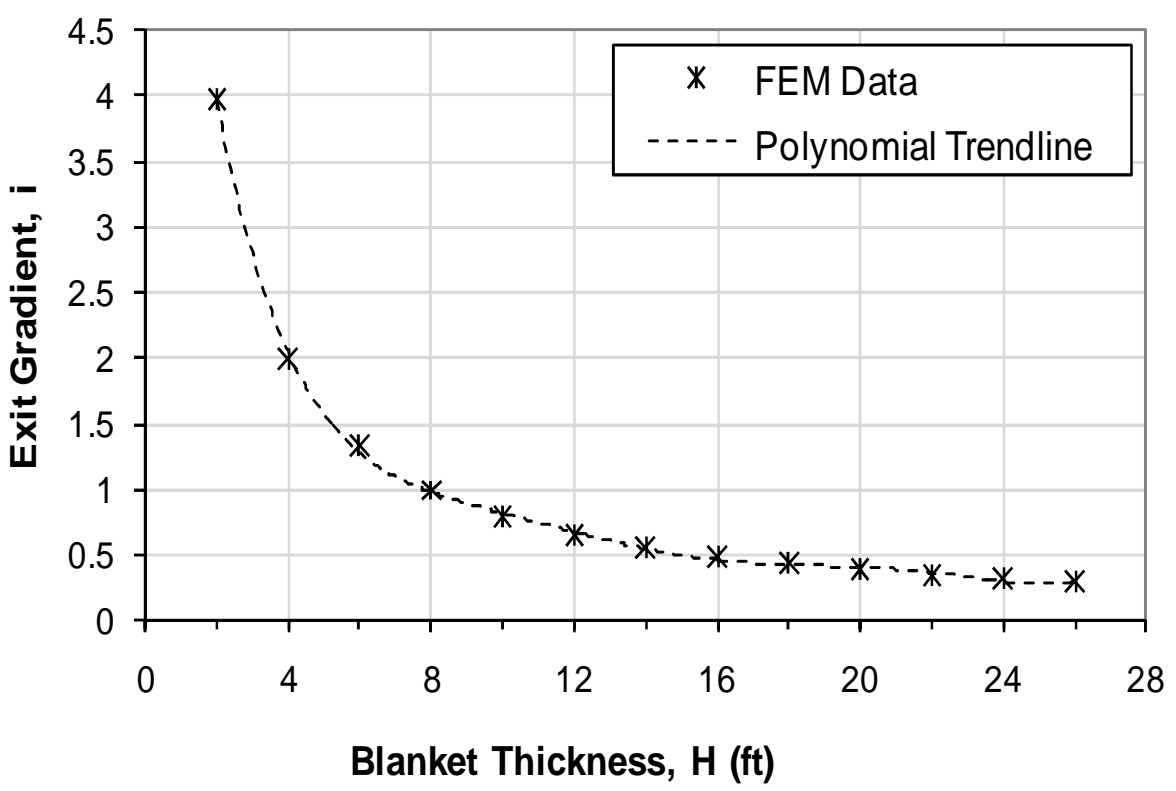

Figure C.6 Exit Gradient ( $\mathrm{i}_{\mathrm{e}}$ BLANKET) vs. Blanket Thickness $(\mathrm{H})$ for $\mathrm{Ksb}=2006$ and $\mathrm{Khv}=0.25$.

Table C.2 Polynomial Trendline Coefficients and Coefficient of Determination $\left(\mathrm{R}^{2}\right)$

\begin{tabular}{|c|c|c|c|c|c|c|c|c|c|}
\hline \multicolumn{8}{|c|}{$i=a_{6} * H^{6}+a_{5} * H^{5}+a_{4} * H^{4}+a_{3} * H^{3}+a_{2} * H^{2}+a_{1} * H+a_{0}$} & \multirow[b]{2}{*}{$\mathbf{R}^{2}$} & \multirow[b]{2}{*}{$1-R^{2}$} \\
\hline Ksb & $a_{6}$ & $a_{5}$ & $a_{4}$ & $a_{3}$ & $a_{2}$ & $a_{1}$ & $a_{0}$ & & \\
\hline 20 & 8.617E-08 & $-8.378 \mathrm{E}-06$ & $3.291 \mathrm{E}-04$ & $-6.724 \mathrm{E}-03$ & 7.694E-02 & $-5.045 E-01$ & $2.027 \mathrm{E}+00$ & 0.999918361 & 8.164E-05 \\
\hline 63 & $2.093 \mathrm{E}-07$ & $-2.024 \mathrm{E}-05$ & 7.886E-04 & $-1.591 \mathrm{E}-02$ & $1.781 \mathrm{E}-01$ & $-1.110 \mathrm{E}+00$ & $3.783 \mathrm{E}+00$ & 0.999829959 & $1.700 \mathrm{E}-04$ \\
\hline 201 & 4.092E-07 & $-3.932 E-05$ & 1.519E-03 & $-3.025 \mathrm{E}-02$ & 3.307E-01 & $-1.963 E+00$ & $5.893 \mathrm{E}+00$ & 0.999679851 & 3.201E-04 \\
\hline 634 & 5.948E-07 & $-5.693 \mathrm{E}-05$ & $2.187 \mathrm{E}-03$ & $-4.315 \mathrm{E}-02$ & $4.645 \mathrm{E}-01$ & $-2.677 E+00$ & $7.492 \mathrm{E}+00$ & 0.999503679 & 4.963E-04 \\
\hline 2006 & 6.963E-07 & $-6.651 E-05$ & $2.548 \mathrm{E}-03$ & $-5.005 \mathrm{E}-02$ & $5.351 \mathrm{E}-01$ & $-3.044 E+00$ & $8.275 \mathrm{E}+00$ & 0.999392385 & 6.076E-04 \\
\hline
\end{tabular}




\begin{tabular}{|c|c|c|c|c|}
\hline Variable & MLV & $\sigma$ & MAX & MIN \\
\hline $\log (\mathrm{Kb})$ & -6.00 & 1.00 & -5.10 & -7.00 \\
\hline $\log (\mathrm{Ks})$ & -3.00 & 1.00 & -2.00 & -3.80 \\
\hline $\mathrm{H}$ & 14 & 8.00 & 26 & 2 \\
\hline$\gamma_{\mathrm{b}}$ & 120 & 5.00 & 130 & 110 \\
\hline
\end{tabular}

\begin{tabular}{|c|c|c|c|}
\hline $\mathrm{H}$ & $\log (\mathrm{Kb})$ & $\log (\mathrm{Ks})$ & $\gamma_{\mathrm{b}}$ \\
\hline 20.621 & -6.820 & -2.753 & 118.361 \\
\hline
\end{tabular}

\begin{tabular}{|c|c|c|c|}
\hline$H$ & $\log (\mathrm{Kb})$ & $\log (\mathrm{Ks})$ & $\gamma_{\mathrm{b}}$ \\
\hline 20.621 & -6.820 & -2.753 & 118.361 \\
\hline
\end{tabular}

\begin{tabular}{|c|c|c|c|}
\hline $\mathrm{H}(\mathrm{ft})$ & $\mathrm{Kb}(\mathrm{ft} / \mathrm{s})$ & $\mathrm{Ks}(\mathrm{ft} / \mathrm{s})$ & $\gamma_{\mathrm{b}}(\mathrm{pcf})$ \\
\hline 21 & $1.51 \mathrm{E}-07$ & $1.77 \mathrm{E}-03$ & 118.36 \\
\hline
\end{tabular}

\begin{tabular}{|c|c|c|}
\hline Khv SP & $\mathrm{Kb}(\mathrm{ft} / \mathrm{s})$ & $\mathrm{Ksp}(\mathrm{ft} / \mathrm{s})$ \\
\hline \multirow[t]{5}{*}{0.25} & $6.60 \mathrm{E}-05$ & $1.30 \mathrm{E}-03$ \\
\hline & $2.05 \mathrm{E}-05$ & \\
\hline & $6.48 \mathrm{E}-06$ & \\
\hline & $2.05 \mathrm{E}-06$ & \\
\hline & $6.48 \mathrm{E}-07$ & \\
\hline
\end{tabular}

$$
\begin{aligned}
\mathrm{yw} & =62.4 \\
\mathrm{ic} & =0.90 \\
\mathrm{i} & =0.40 \\
\mathrm{FS} & =2.25
\end{aligned}
$$

Figure C. 7 Excel spreadsheet for Analysis 3. 


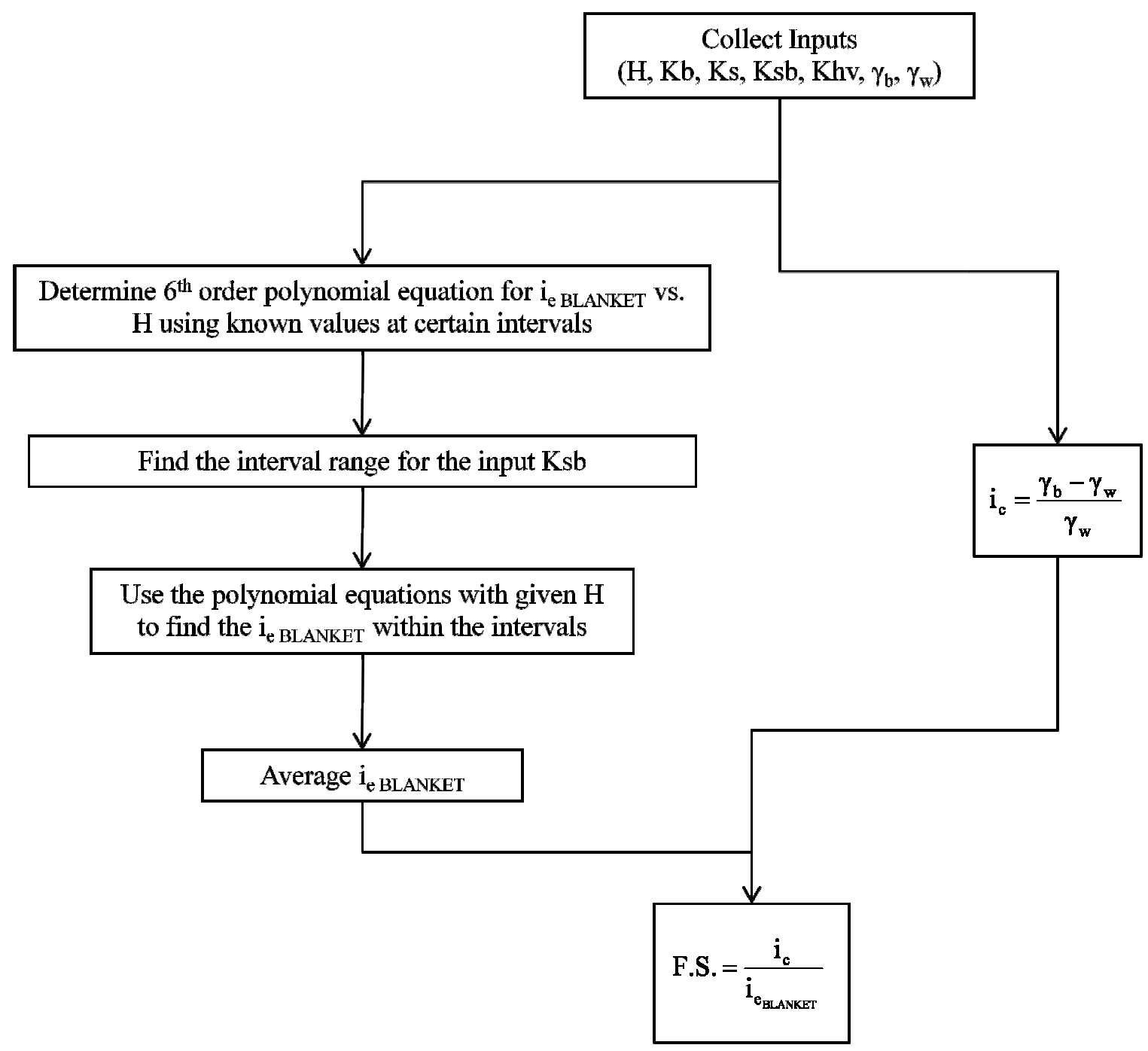

Figure C.8 Flow Chart for Excel Spreadsheet for Analysis 3. 


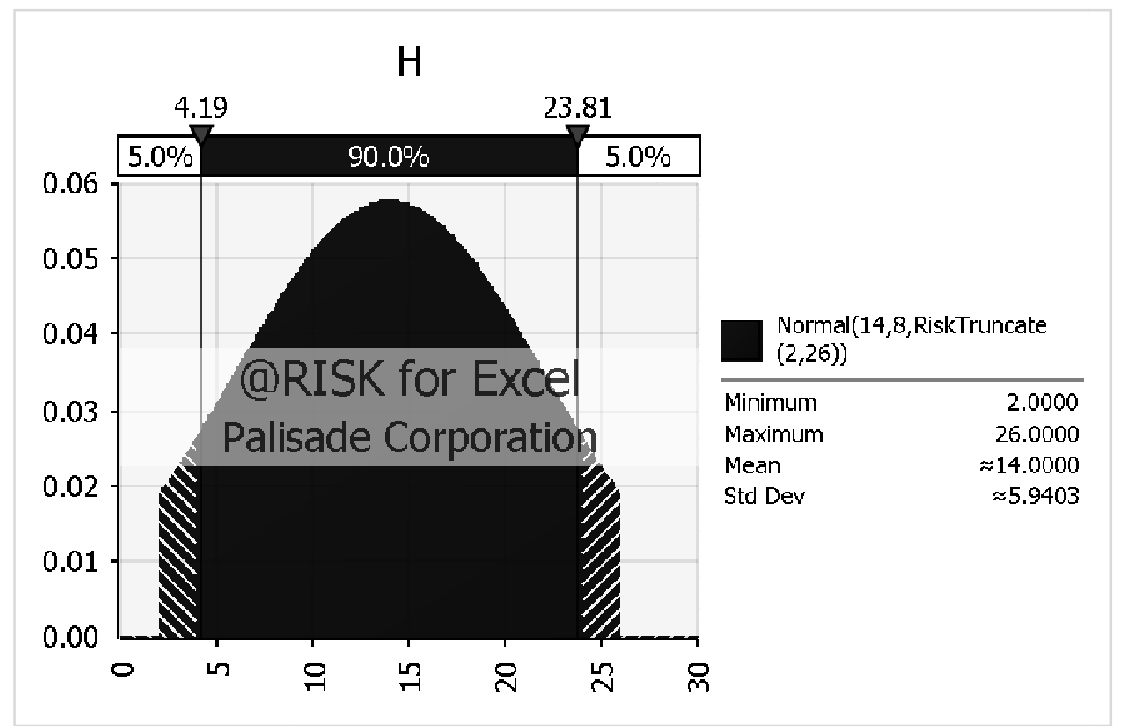

Figure C.9 Probability Density Function for geometric variable H.

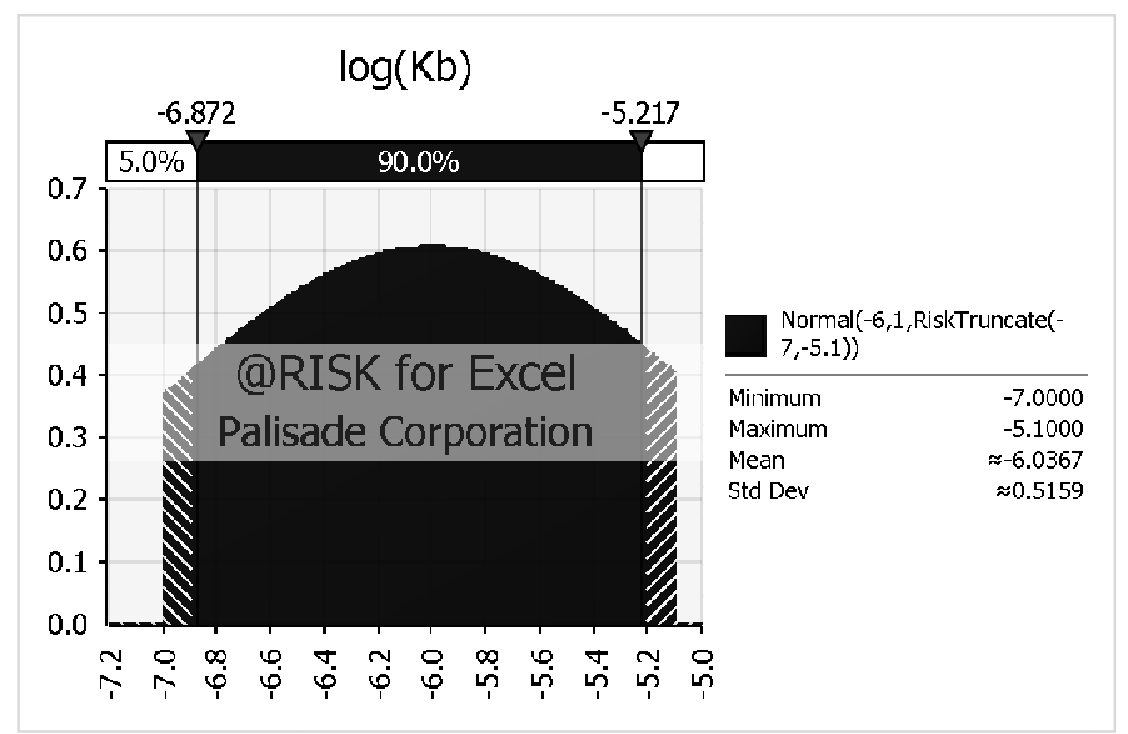

Figure C.10 Probability Density Function for soil variable Kb. 


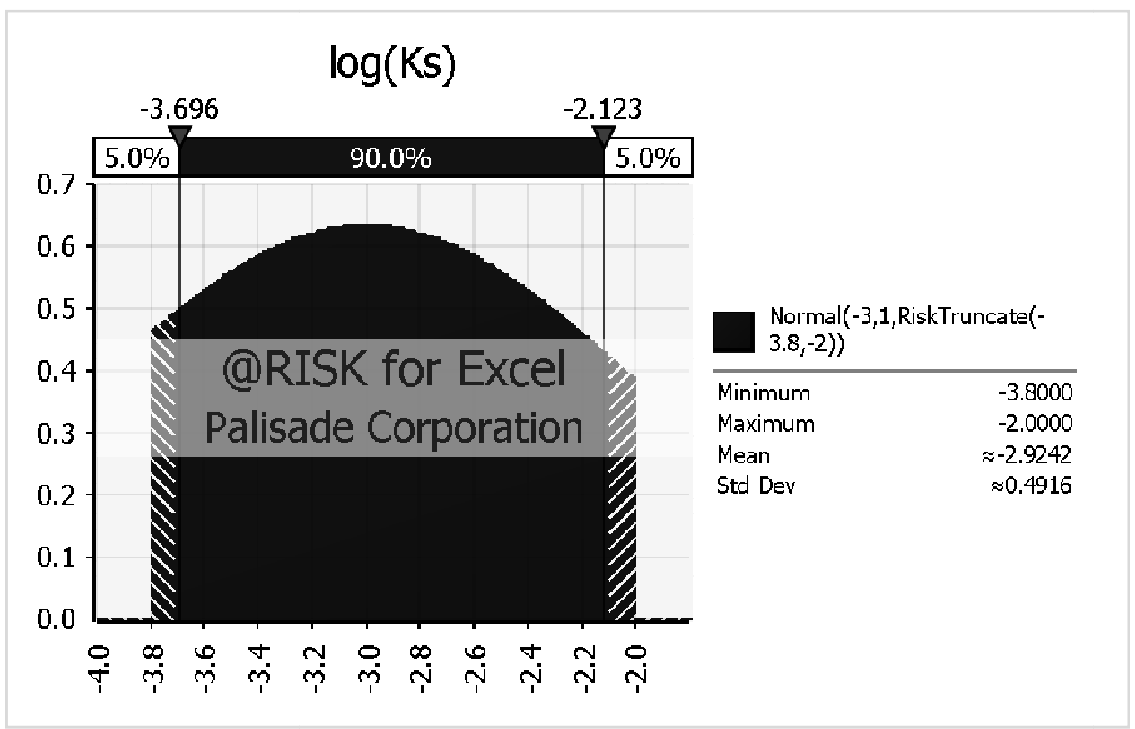

Figure C.11 Probability Density Function for soil variable Ks.

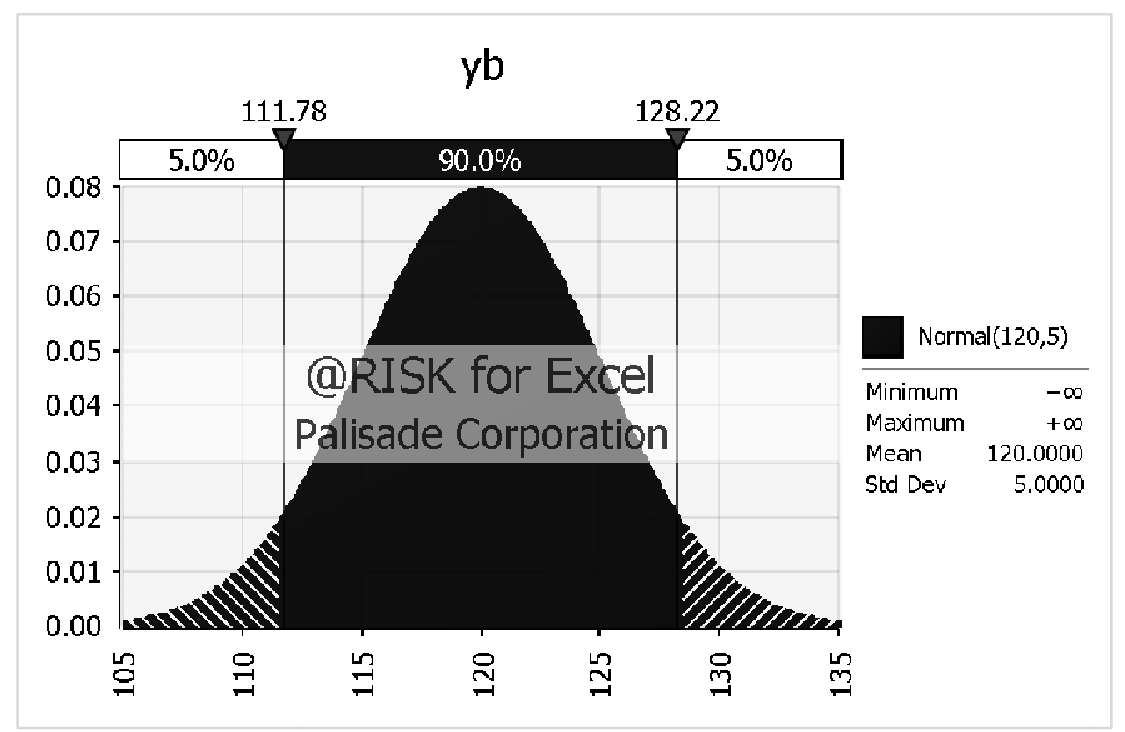

Figure C.12 Probability Density Function for soil variable $\gamma_{b}$. 
Appendix D. Analysis 4 
Table D.1 Uplift (Pore) Pressure $\mu_{\text {SAND }}$ as a function of h, Ksb, Khv $=0.25$ and d $=175$ '

\begin{tabular}{|c|c|c|c|c|c|}
\hline \multirow{2}{*}{$\mathbf{h}$} & \multicolumn{5}{|c|}{$\boldsymbol{\mu}_{\text {SAND }}$} \\
\cline { 2 - 6 } & $\mathbf{K s b}=\mathbf{2 0}$ & $\mathbf{K s b}=\mathbf{6 5}$ & $\mathbf{K s b}=\mathbf{2 0 0}$ & $\mathbf{K s b}=\mathbf{1 3 0 0}$ & $\mathbf{1 3 0 0 0}$ \\
\hline $\mathbf{0}$ & 1068.09 & 1195.561 & 1398.96 & 1627.446 & 1795.561 \\
\hline $\mathbf{3}$ & 869.674 & 997.523 & 1202.75 & 1434.369 & 1605.458 \\
\hline $\mathbf{6}$ & 666.893 & 793.066 & 1000.014 & 1236.518 & 1412.831 \\
\hline $\mathbf{9}$ & 458.315 & 577.966 & 785.034 & 1029.177 & 1215.068 \\
\hline $\mathbf{1 2}$ & 240.478 & 339.431 & 536.154 & 791.686 & 999.758 \\
\hline
\end{tabular}

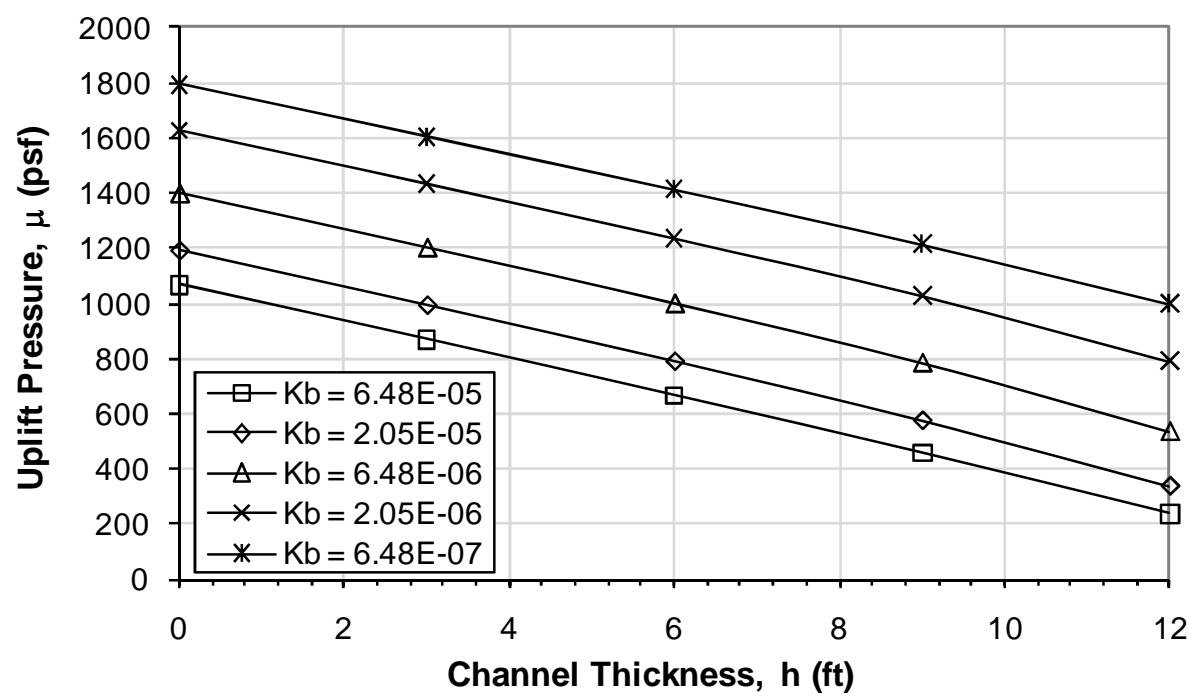

Figure D.1 Family of curves representing relationship of $\mu_{\text {SAND }}, h, K s b, K h v=0.25$ and $d=175$ '.

Table D.2 Polynomial Trendline Coefficients and Coefficient of Determination $\left(\mathrm{R}^{2}\right)$ for Family of Curves in Figure D.1

\begin{tabular}{|c|c|c|c|c|c|}
\hline \multirow{2}{*}{ Ksb } & \multicolumn{5}{|c|}{$\mathbf{u}=\mathbf{H}_{\mathbf{3}} * \mathbf{h}^{\mathbf{3}}+\mathbf{H}_{\mathbf{2}} * \mathbf{h}^{\mathbf{2}}+\mathbf{H}_{\mathbf{1}} * \mathbf{h}+\mathbf{H}_{\mathbf{0}}$} \\
\cline { 2 - 6 } & $\mathbf{H}_{\mathbf{3}}$ & $\mathbf{H}_{\mathbf{2}}$ & $\mathbf{H}_{\mathbf{1}}$ & $\mathbf{H}_{\mathbf{0}}$ & $\mathbf{R}^{\mathbf{2}}$ \\
\hline $\mathbf{2 0}$ & $-1.510 \mathrm{E}-02$ & $-8.239 \mathrm{E}-02$ & $-6.580 \mathrm{E}+01$ & $1.068 \mathrm{E}+03$ & 1.00 \\
\hline $\mathbf{6 5}$ & $-5.252 \mathrm{E}-02$ & $2.181 \mathrm{E}-01$ & $-6.640 \mathrm{E}+01$ & $1.196 \mathrm{E}+03$ & 1.00 \\
\hline $\mathbf{2 0 0}$ & $-8.449 \mathrm{E}-02$ & $5.876 \mathrm{E}-01$ & $-6.679 \mathrm{E}+01$ & $1.399 \mathrm{E}+03$ & 1.00 \\
\hline $\mathbf{1 3 0 0}$ & $-7.832 \mathrm{E}-02$ & $6.295 \mathrm{E}-01$ & $-6.592 \mathrm{E}+01$ & $1.628 \mathrm{E}+03$ & 1.00 \\
\hline $\mathbf{1 3 0 0 0}$ & $-4.637 \mathrm{E}-02$ & $3.937 \mathrm{E}-01$ & $-6.436 \mathrm{E}+01$ & $1.796 \mathrm{E}+03$ & 1.00 \\
\hline
\end{tabular}


Table D.3 Uplift (Pore) Pressure $\mu_{\text {SAND }}$ as a function of h, Ksb, Khv $=0.25$ and d $=150$ '

\begin{tabular}{|c|c|c|c|c|c|}
\hline \multirow{2}{*}{$\mathbf{h}$} & \multicolumn{5}{|c|}{$\boldsymbol{\mu}_{\text {SAND }}$} \\
\cline { 2 - 6 } & $\mathbf{K s b}=\mathbf{2 0}$ & $\mathbf{K s b}=\mathbf{6 5}$ & $\mathbf{K s b}=\mathbf{2 0 0}$ & $\mathbf{K s b}=\mathbf{1 3 0 0}$ & $\mathbf{1 3 0 0 0}$ \\
\hline $\mathbf{0}$ & 1089.123 & 1213.428 & 1408.645 & 1626.035 & 1785.491 \\
\hline $\mathbf{3}$ & 887.111 & 1012.199 & 1209.595 & 1430.195 & 1592.485 \\
\hline $\mathbf{6}$ & 680.479 & 804.408 & 1004.096 & 1229.767 & 1397.089 \\
\hline $\mathbf{9}$ & 467.844 & 585.916 & 786.673 & 1020.368 & 1196.931 \\
\hline $\mathbf{1 2}$ & 245.639 & 343.84 & 536.102 & 782.361 & 980.476 \\
\hline
\end{tabular}

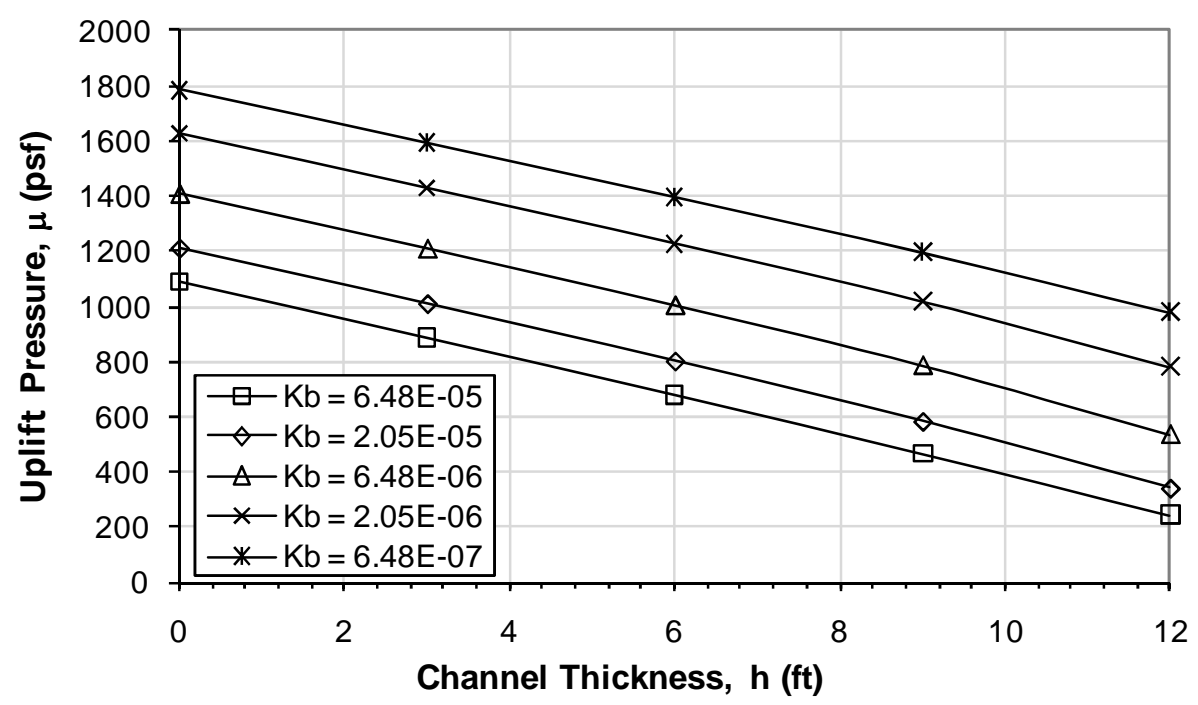

Figure D.2 Family of curves representing relationship of $\mu_{\text {SAND }}, \mathrm{h}, \mathrm{Ksb}, \mathrm{Khv}=0.25$ and $\mathrm{d}=150$ '.

Table D.4 Polynomial Trendline Coefficients and Coefficient of Determination $\left(\mathrm{R}^{2}\right)$ for Family of Curves in Figure D.2

\begin{tabular}{|c|c|c|c|c|c|}
\hline \multirow{2}{*}{ Ksb } & \multicolumn{5}{|c|}{$\mathbf{u}=\mathbf{H}_{\mathbf{3}} * \mathbf{h}^{\mathbf{3}}+\mathbf{H}_{\mathbf{2}} * \mathbf{h}^{\mathbf{2}}+\mathbf{H}_{\mathbf{1}} * \mathbf{h}+\mathbf{H}_{\mathbf{0}}$} \\
\cline { 2 - 6 } & $\mathbf{H}_{\mathbf{3}}$ & $\mathbf{H}_{\mathbf{2}}$ & $\mathbf{H}_{\mathbf{1}}$ & $\mathbf{H}_{\mathbf{0}}$ & $\mathbf{R}^{\mathbf{2}}$ \\
\hline $\mathbf{2 0}$ & $-1.528 \mathrm{E}-02$ & $-9.317 \mathrm{E}-02$ & $-6.697 \mathrm{E}+01$ & $1.089 \mathrm{E}+03$ & 1.00 \\
\hline $\mathbf{6 5}$ & $-5.254 \mathrm{E}-02$ & $2.124 \mathrm{E}-01$ & $-6.745 \mathrm{E}+01$ & $1.214 \mathrm{E}+03$ & 1.00 \\
\hline $\mathbf{2 0 0}$ & $-8.240 \mathrm{E}-02$ & $5.708 \mathrm{E}-01$ & $-6.770 \mathrm{E}+01$ & $1.409 \mathrm{E}+03$ & 1.00 \\
\hline $\mathbf{1 3 0 0}$ & $-7.414 \mathrm{E}-02$ & $5.939 \mathrm{E}-01$ & $-6.676 \mathrm{E}+01$ & $1.626 \mathrm{E}+03$ & 1.00 \\
\hline $\mathbf{1 3 0 0 0}$ & $-4.292 \mathrm{E}-02$ & $3.626 \mathrm{E}-01$ & $-6.526 \mathrm{E}+01$ & $1.786 \mathrm{E}+03$ & 1.00 \\
\hline
\end{tabular}


Table D.5 Uplift (Pore) Pressure $\mu_{\text {SAND }}$ as a function of $h, K s b, K h v=0.25$ and d $=125$ '

\begin{tabular}{|c|c|c|c|c|c|}
\hline \multirow{2}{*}{$\mathbf{h}$} & \multicolumn{5}{|c|}{$\boldsymbol{\mu}_{\text {SAND }}$} \\
\cline { 2 - 6 } & $\mathbf{K s b}=\mathbf{2 0}$ & $\mathbf{K s b}=\mathbf{6 5}$ & $\mathbf{K s b}=\mathbf{2 0 0}$ & $\mathbf{K s b}=\mathbf{1 3 0 0}$ & $\mathbf{1 3 0 0 0}$ \\
\hline $\mathbf{0}$ & 1112.528 & 1230.554 & 1415.446 & 1620.319 & 1770.316 \\
\hline $\mathbf{3}$ & 904.738 & 1023.622 & 1210.769 & 1418.737 & 1571.313 \\
\hline $\mathbf{6}$ & 692.55 & 810.434 & 1000.039 & 1212.931 & 1370.138 \\
\hline $\mathbf{9}$ & 474.774 & 587.173 & 778.241 & 998.991 & 1164.721 \\
\hline $\mathbf{1 2}$ & 248.205 & 341.782 & 525.672 & 759.129 & 944.834 \\
\hline
\end{tabular}

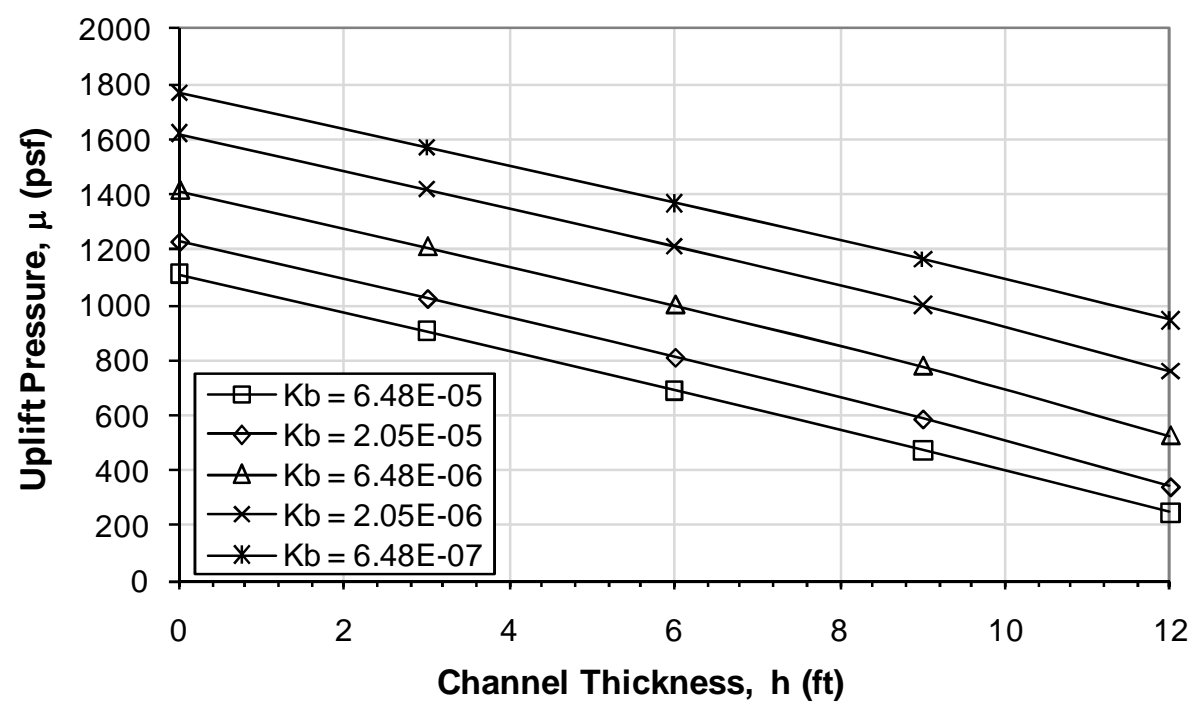

Figure D.3 Family of curves representing relationship of $\mu_{\mathrm{SAND}}, \mathrm{h}, \mathrm{Ksb}, \mathrm{Khv}=0.25$ and d $=125$ '.

Table D.6 Polynomial Trendline Coefficients and Coefficient of Determination $\left(\mathrm{R}^{2}\right)$ for Family of Curves in Figure D.3

\begin{tabular}{|c|c|c|c|c|c|}
\hline \multirow{2}{*}{ Ksb } & \multicolumn{5}{|c|}{$\mathbf{u}=\mathbf{H}_{\mathbf{3}} * \mathbf{h}^{\mathbf{3}}+\mathbf{H}_{\mathbf{2}} * \mathbf{h}^{\mathbf{2}}+\mathbf{H}_{\mathbf{1}} * \mathbf{h}+\mathbf{H}_{\mathbf{0}}$} \\
\cline { 2 - 6 } & $\mathbf{H}_{\mathbf{3}}$ & $\mathbf{H}_{\mathbf{2}}$ & $\mathbf{H}_{\mathbf{1}}$ & $\mathbf{H}_{\mathbf{0}}$ & $\mathbf{R}^{\mathbf{2}}$ \\
\hline $\mathbf{2 0}$ & $-1.356 \mathrm{E}-02$ & $-9.826 \mathrm{E}-02$ & $-6.889 \mathrm{E}+01$ & $1.113 \mathrm{E}+03$ & 1.00 \\
\hline $\mathbf{6 5}$ & $-4.899 \mathrm{E}-02$ & $1.915 \mathrm{E}-01$ & $-6.931 \mathrm{E}+01$ & $1.231 \mathrm{E}+03$ & 1.00 \\
\hline $\mathbf{2 0 0}$ & $-7.629 \mathrm{E}-02$ & $5.252 \mathrm{E}-01$ & $-6.946 \mathrm{E}+01$ & $1.416 \mathrm{E}+03$ & 1.00 \\
\hline $\mathbf{1 3 0 0}$ & $-6.697 \mathrm{E}-02$ & $5.333 \mathrm{E}-01$ & $-6.852 \mathrm{E}+01$ & $1.621 \mathrm{E}+03$ & 1.00 \\
\hline $\mathbf{1 3 0 0 0}$ & $-3.796 \mathrm{E}-02$ & $3.181 \mathrm{E}-01$ & $-6.714 \mathrm{E}+01$ & $1.770 \mathrm{E}+03$ & 1.00 \\
\hline
\end{tabular}


Table D.7 Uplift (Pore) Pressure $\mu_{\text {SAND }}$ as a function of h, Ksb, Khv $=0.25$ and d $=100$ '

\begin{tabular}{|c|c|c|c|c|c|}
\hline \multirow{2}{*}{$\mathbf{h}$} & \multicolumn{5}{|c|}{$\boldsymbol{\mu}_{\text {SAND }}$} \\
\cline { 2 - 6 } & $\mathbf{K s b}=\mathbf{2 0}$ & $\mathbf{K s b}=\mathbf{6 5}$ & $\mathbf{K s b}=\mathbf{2 0 0}$ & $\mathbf{K s b}=\mathbf{1 3 0 0}$ & $\mathbf{1 3 0 0 0}$ \\
\hline $\mathbf{0}$ & 1142.305 & 1252.111 & 1424.941 & 1615.984 & 1755.739 \\
\hline $\mathbf{3}$ & 928.325 & 1039.39 & 1214.645 & 1408.664 & 1550.737 \\
\hline $\mathbf{6}$ & 709.935 & 820.587 & 998.626 & 1197.448 & 1343.76 \\
\hline $\mathbf{9}$ & 486.066 & 592.151 & 772.311 & 978.884 & 1133.028 \\
\hline $\mathbf{1 2}$ & 253.632 & 342.572 & 517.339 & 736.909 & 909.532 \\
\hline
\end{tabular}

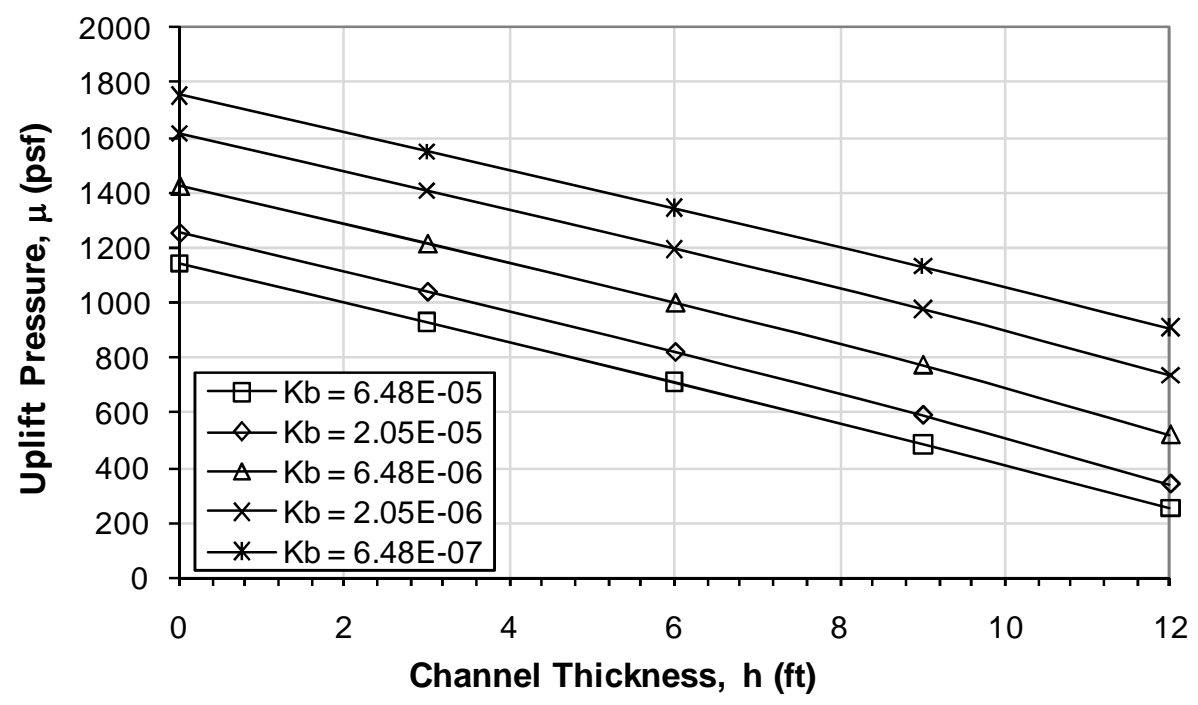

Figure D.4 Family of curves representing relationship of $\mu_{\text {SAND }}, \mathrm{h}, \mathrm{Ksb}, \mathrm{Khv}=0.25$ and d $=100$ '.

Table D.8 Polynomial Trendline Coefficients and Coefficient of Determination $\left(\mathrm{R}^{2}\right)$ for Family of Curves in Figure D.4

\begin{tabular}{|c|c|c|c|c|c|}
\hline \multirow{2}{*}{ Ksb } & \multicolumn{5}{|c|}{$\mathbf{u}=\mathbf{H}_{\mathbf{3}} * \mathbf{h}^{\mathbf{3}}+\mathbf{H}_{\mathbf{2}} * \mathbf{h}^{\mathbf{2}}+\mathbf{H}_{\mathbf{1}} * \mathbf{h}+\mathbf{H}_{\mathbf{0}}$} \\
\cline { 2 - 6 } & $\mathbf{H}_{\mathbf{3}}$ & $\mathbf{H}_{\mathbf{2}}$ & $\mathbf{H}_{\mathbf{1}}$ & $\mathbf{H}_{\mathbf{0}}$ & $\mathbf{R}^{\mathbf{2}}$ \\
\hline $\mathbf{2 0}$ & $-1.282 \mathrm{E}-02$ & $-1.056 \mathrm{E}-01$ & $-7.094 \mathrm{E}+01$ & $1.142 \mathrm{E}+03$ & 1.00 \\
\hline $\mathbf{6 5}$ & $-4.648 \mathrm{E}-02$ & $1.752 \mathrm{E}-01$ & $-7.120 \mathrm{E}+01$ & $1.252 \mathrm{E}+03$ & 1.00 \\
\hline $\mathbf{2 0 0}$ & $-7.078 \mathrm{E}-02$ & $4.833 \mathrm{E}-01$ & $-7.124 \mathrm{E}+01$ & $1.425 \mathrm{E}+03$ & 1.00 \\
\hline $\mathbf{1 3 0 0}$ & $-6.023 \mathrm{E}-02$ & $4.758 \mathrm{E}-01$ & $-7.029 \mathrm{E}+01$ & $1.616 \mathrm{E}+03$ & 1.00 \\
\hline $\mathbf{1 3 0 0 0}$ & $-3.330 \mathrm{E}-02$ & $2.760 \mathrm{E}-01$ & $-6.903 \mathrm{E}+01$ & $1.756 \mathrm{E}+03$ & 1.00 \\
\hline
\end{tabular}


Table D.9 Uplift (Pore) Pressure $\mu_{\text {SAND }}$ as a function of $h, K s b, K h v=0.25$ and $d=75$,

\begin{tabular}{|c|c|c|c|c|c|}
\hline \multirow{2}{*}{$\mathbf{h}$} & \multicolumn{5}{|c|}{$\boldsymbol{\mu}_{\text {SAND }}$} \\
\cline { 2 - 6 } & $\mathbf{K s b}=\mathbf{2 0}$ & $\mathbf{K s b}=\mathbf{6 5}$ & $\mathbf{K s b}=\mathbf{2 0 0}$ & $\mathbf{K s b}=\mathbf{1 3 0 0}$ & $\mathbf{1 3 0 0 0}$ \\
\hline $\mathbf{0}$ & 1178.144 & 1277.707 & 1436.811 & 1612.831 & 1741.665 \\
\hline $\mathbf{3}$ & 960.314 & 1062.068 & 1223.967 & 1402.929 & 1533.89 \\
\hline $\mathbf{6}$ & 737.795 & 840.692 & 1005.966 & 1189.62 & 1324.415 \\
\hline $\mathbf{9}$ & 509.626 & 609.793 & 778.406 & 969.778 & 1111.687 \\
\hline $\mathbf{1 2}$ & 271.604 & 357.773 & 524.194 & 729.232 & 888.018 \\
\hline
\end{tabular}

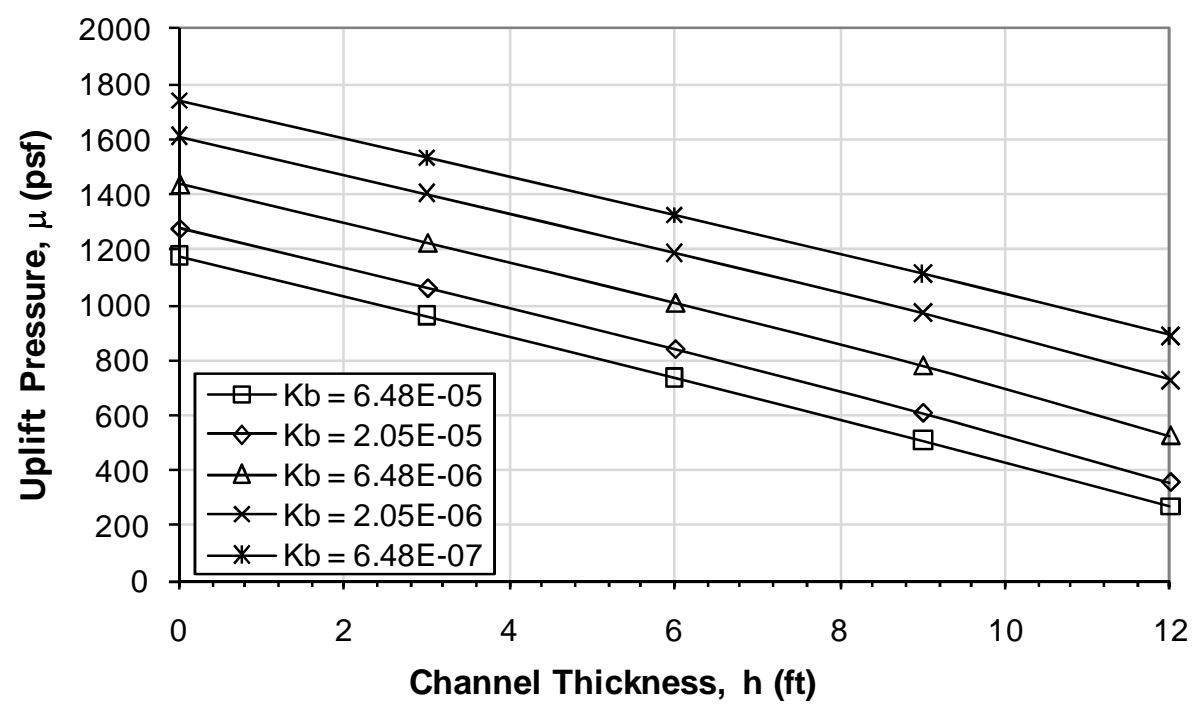

Figure D.5 Family of curves representing relationship of $\mu_{\text {SAND }}, \mathrm{h}, \mathrm{Ksb}, \mathrm{Khv}=0.25$ and d $=75$ '.

Table D.10 Polynomial Trendline Coefficients and Coefficient of Determination $\left(\mathrm{R}^{2}\right)$ for Family of Curves in Figure D.5

\begin{tabular}{|c|c|c|c|c|c|}
\hline \multirow{2}{*}{$\mathbf{K s b}$} & \multicolumn{5}{|c|}{$\mathbf{u}=\mathbf{H}_{\mathbf{3}} * \mathbf{h}^{\mathbf{3}}+\mathbf{H}_{\mathbf{2}} * \mathbf{h}^{\mathbf{2}}+\mathbf{H}_{\mathbf{1}} * \mathbf{h}+\mathbf{H}_{\mathbf{0}}$} \\
\cline { 2 - 6 } & $\mathbf{H}_{\mathbf{3}}$ & $\mathbf{H}_{\mathbf{2}}$ & $\mathbf{H}_{\mathbf{1}}$ & $\mathbf{H}_{\mathbf{0}}$ & $\mathbf{R}^{\mathbf{2}}$ \\
\hline $\mathbf{2 0}$ & $-1.594 \mathrm{E}-02$ & $-7.846 \mathrm{E}-02$ & $-7.231 \mathrm{E}+01$ & $1.178 \mathrm{E}+03$ & 1.00 \\
\hline $\mathbf{6 5}$ & $-4.748 \mathrm{E}-02$ & $2.016 \mathrm{E}-01$ & $-7.224 \mathrm{E}+01$ & $1.278 \mathrm{E}+03$ & 1.00 \\
\hline $\mathbf{2 0 0}$ & $-6.634 \mathrm{E}-02$ & $4.617 \mathrm{E}-01$ & $-7.204 \mathrm{E}+01$ & $1.437 \mathrm{E}+03$ & 1.00 \\
\hline $\mathbf{1 3 0 0}$ & $-5.339 \mathrm{E}-02$ & $4.227 \mathrm{E}-01$ & $-7.102 \mathrm{E}+01$ & $1.613 \mathrm{E}+03$ & 1.00 \\
\hline $\mathbf{1 3 0 0 0}$ & $-2.852 \mathrm{E}-02$ & $2.353 \mathrm{E}-01$ & $-6.985 \mathrm{E}+01$ & $1.742 \mathrm{E}+03$ & 1.00 \\
\hline
\end{tabular}


Table D.11 Uplift (Pore) Pressure $\mu$ SAND as a function of $h, K s b, K h v=0.25$ and $d=50$ '

\begin{tabular}{|c|c|c|c|c|c|}
\hline \multirow{2}{*}{$\mathbf{h}$} & \multicolumn{5}{|c|}{$\boldsymbol{\mu}_{\text {SAND }}$} \\
\cline { 2 - 6 } & $\mathbf{K s b}=\mathbf{2 0}$ & $\mathbf{K s b}=\mathbf{6 5}$ & $\mathbf{K s b}=\mathbf{2 0 0}$ & $\mathbf{K s b}=\mathbf{1 3 0 0}$ & $\mathbf{1 3 0 0 0}$ \\
\hline $\mathbf{0}$ & 1258.291 & 1342.254 & 1484.948 & 1644.596 & 1761.953 \\
\hline $\mathbf{3}$ & 1022.49 & 1108.451 & 1252.859 & 1414.091 & 1532.685 \\
\hline $\mathbf{6}$ & 806.615 & 894.108 & 1040.478 & 1204.054 & 1324.795 \\
\hline $\mathbf{9}$ & 587.001 & 675.045 & 823.621 & 990.979 & 1115.391 \\
\hline $\mathbf{1 2}$ & 359.963 & 444.851 & 595.277 & 769.659 & 901.803 \\
\hline
\end{tabular}

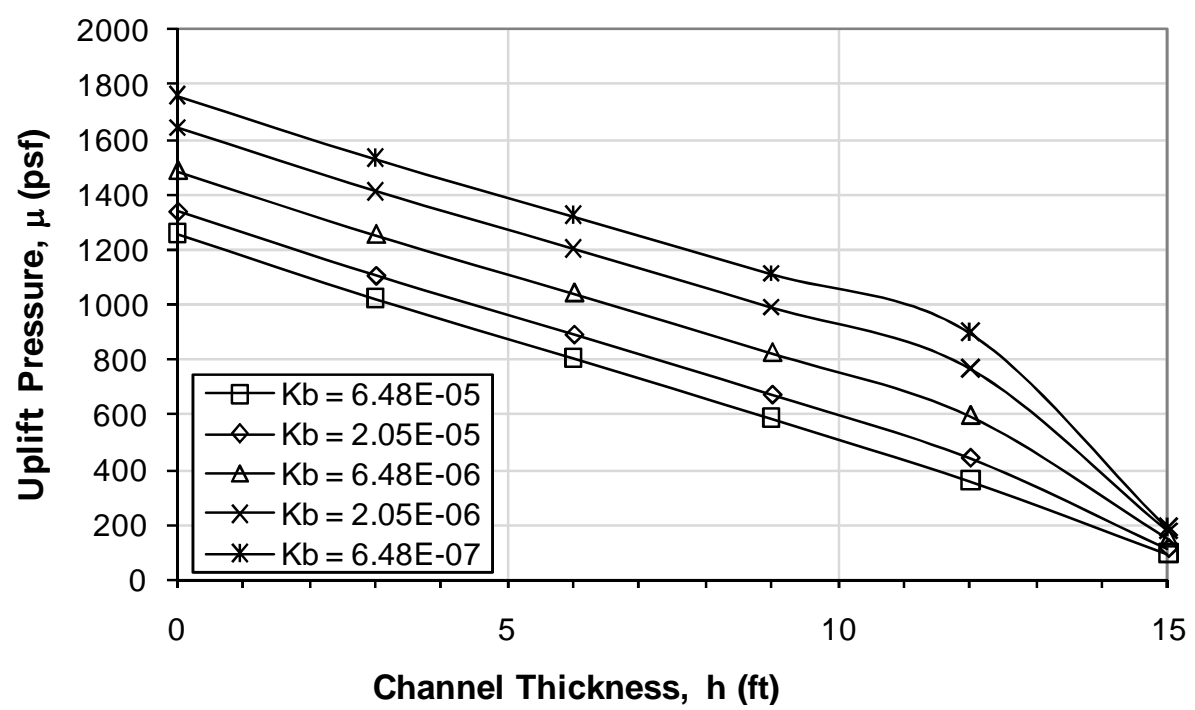

Figure D.6 Family of curves representing relationship of $\mu_{\mathrm{SAND}}, \mathrm{h}, \mathrm{Ksb}, \mathrm{Khv}=0.25$ and d $=50^{\prime}$.

Table D.12 Polynomial Trendline Coefficients and Coefficient of Determination $\left(\mathrm{R}^{2}\right)$ for Family of Curves in Figure D.6

\begin{tabular}{|c|c|c|c|c|c|c|}
\hline \multirow{2}{*}{ Ksb } & \multicolumn{7}{|c|}{$\mathbf{u}=\mathbf{H}_{\mathbf{4}} * \mathbf{h}^{\mathbf{4}}+\mathbf{H}_{\mathbf{3}} * \mathbf{h}^{\mathbf{3}}+\mathbf{H}_{\mathbf{2}} * \mathbf{h}^{\mathbf{2}}+\mathbf{H}_{\mathbf{1}} * \mathbf{h}+\mathbf{H}_{\mathbf{0}}$} \\
\cline { 2 - 7 } & $\mathbf{H}_{\mathbf{4}}$ & $\mathbf{H}_{\mathbf{3}}$ & $\mathbf{H}_{\mathbf{2}}$ & $\mathbf{H}_{\mathbf{1}}$ & $\mathbf{H}_{\mathbf{0}}$ & $\mathbf{R}^{\mathbf{2}}$ \\
\hline $\mathbf{2 0}$ & - & $-1.018 \mathrm{E}-01$ & $1.919 \mathrm{E}+00$ & $-8.337 \mathrm{E}+01$ & $1.258 \mathrm{E}+03$ & 1.00 \\
\hline $\mathbf{6 5}$ & - & $-2.106 \mathrm{E}-01$ & $3.661 \mathrm{E}+00$ & $-8.929 \mathrm{E}+01$ & $1.344 \mathrm{E}+03$ & 1.00 \\
\hline $\mathbf{2 0 0}$ & $-4.683 \mathrm{E}-02$ & $9.906 \mathrm{E}-01$ & $-5.872 \mathrm{E}+00$ & $-6.568 \mathrm{E}+01$ & $1.484 \mathrm{E}+03$ & 1.00 \\
\hline $\mathbf{1 3 0 0}$ & $-8.675 \mathrm{E}-02$ & $1.929 \mathrm{E}+00$ & $-1.249 \mathrm{E}+01$ & $-5.141 \mathrm{E}+01$ & $1.643 \mathrm{E}+03$ & 1.00 \\
\hline $\mathbf{1 3 0 0 0}$ & $-1.207 \mathrm{E}-01$ & $2.730 \mathrm{E}+00$ & $-1.814 \mathrm{E}+01$ & $-3.928 \mathrm{E}+01$ & $1.760 \mathrm{E}+03$ & 1.00 \\
\hline
\end{tabular}


Table D.13 Uplift (Pore) Pressure $\mu$ SAND as a function of $h, K s b, K h v=0.25$ and $d=25$ '

\begin{tabular}{|c|c|c|c|c|c|}
\hline \multirow{2}{*}{$\mathbf{h}$} & \multicolumn{5}{|c|}{$\boldsymbol{\mu}_{\text {SAND }}$} \\
\cline { 2 - 6 } & $\mathbf{K s b}=\mathbf{2 0}$ & $\mathbf{K s b}=\mathbf{6 5}$ & $\mathbf{K s b}=\mathbf{2 0 0}$ & $\mathbf{K s b}=\mathbf{1 3 0 0}$ & $\mathbf{1 3 0 0 0}$ \\
\hline $\mathbf{0}$ & 1258.291 & 1342.254 & 1484.948 & 1644.596 & 1761.953 \\
\hline $\mathbf{3}$ & 1022.49 & 1108.451 & 1252.859 & 1414.091 & 1532.685 \\
\hline $\mathbf{6}$ & 806.615 & 894.108 & 1040.478 & 1204.054 & 1324.795 \\
\hline $\mathbf{9}$ & 587.001 & 675.045 & 823.621 & 990.979 & 1115.391 \\
\hline $\mathbf{1 2}$ & 359.963 & 444.851 & 595.277 & 769.659 & 901.803 \\
\hline
\end{tabular}

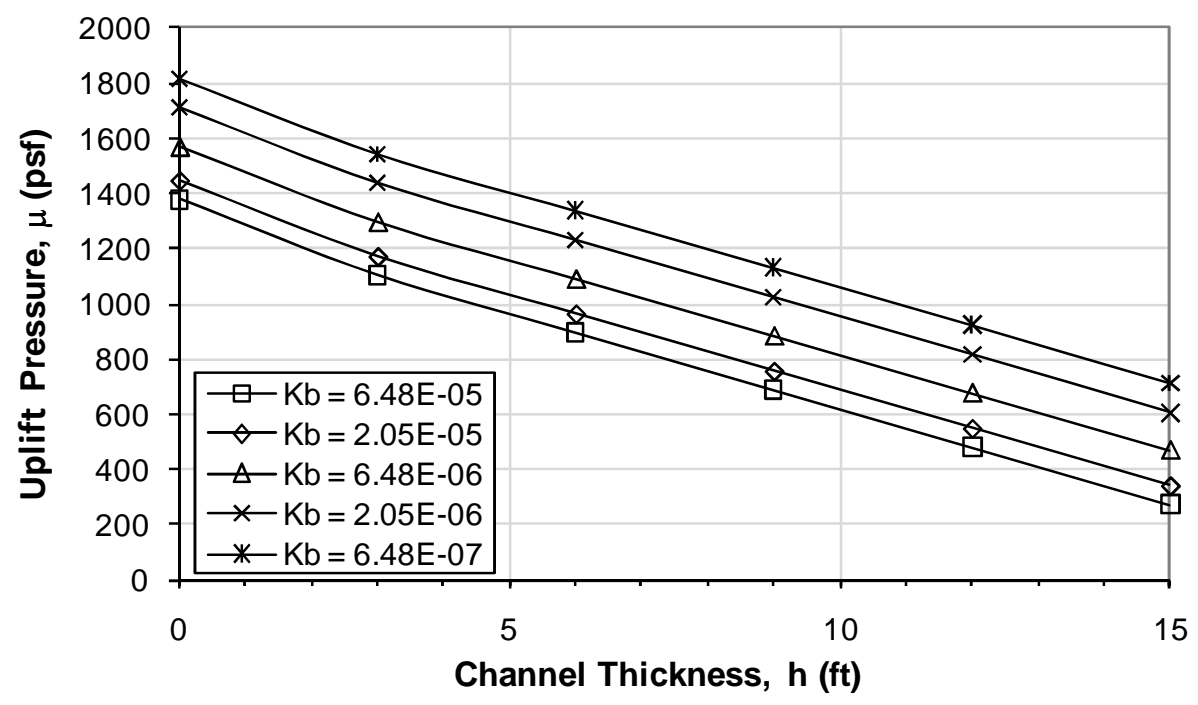

Figure D.7 Family of curves representing relationship of $\mu_{\mathrm{SAND}}, \mathrm{h}, \mathrm{Ksb}, \mathrm{Khv}=0.25$ and $\mathrm{d}=25$.

Table D.14 Polynomial Trendline Coefficients and Coefficient of Determination $\left(\mathrm{R}^{2}\right)$ for Family of Curves in Figure D.7

\begin{tabular}{|c|c|c|c|c|c|}
\hline \multirow{2}{*}{ Ksb } & \multicolumn{5}{|c|}{$\mathbf{u}=\mathbf{H}_{\mathbf{3}} * \mathbf{h}^{\mathbf{3}}+\mathbf{H}_{2} * \mathbf{h}^{\mathbf{2}}+\mathbf{H}_{\mathbf{1}} * \mathbf{h}+\mathbf{H}_{\mathbf{0}}$} \\
\cline { 2 - 6 } & $\mathbf{H}_{\mathbf{3}}$ & $\mathbf{H}_{\mathbf{2}}$ & $\mathbf{H}_{\mathbf{1}}$ & $\mathbf{H}_{\mathbf{0}}$ & $\mathbf{R}^{\mathbf{2}}$ \\
\hline $\mathbf{2 0}$ & $-1.153 \mathrm{E}-01$ & $3.272 \mathrm{E}+00$ & $-9.678 \mathrm{E}+01$ & $1.377 \mathrm{E}+03$ & 1.00 \\
\hline $\mathbf{6 5}$ & $-1.148 \mathrm{E}-01$ & $3.254 \mathrm{E}+00$ & $-9.639 \mathrm{E}+01$ & $1.443 \mathrm{E}+03$ & 1.00 \\
\hline $\mathbf{2 0 0}$ & $-1.160 \mathrm{E}-01$ & $3.255 \mathrm{E}+00$ & $-9.619 \mathrm{E}+01$ & $1.568 \mathrm{E}+03$ & 1.00 \\
\hline $\mathbf{1 3 0 0}$ & $-1.167 \mathrm{E}-01$ & $3.255 \mathrm{E}+00$ & $-9.617 \mathrm{E}+01$ & $1.710 \mathrm{E}+03$ & 1.00 \\
\hline $\mathbf{1 3 0 0 0}$ & $-1.180 \mathrm{E}-01$ & $3.280 \mathrm{E}+00$ & $-9.620 \mathrm{E}+01$ & $1.815 \mathrm{E}+03$ & 1.00 \\
\hline
\end{tabular}




\begin{tabular}{|c|c|c|c|c|}
\hline Variable & MLV & $\sigma$ & MAX & MIN \\
\hline $\log (K b)$ & -6.00 & 0.67 & -5.10 & -7.00 \\
\hline $\log (\mathrm{Ks})$ & -3.00 & 0.67 & -2.00 & -3.80 \\
\hline$y b$ & 120 & 4.800 & 130 & 110 \\
\hline d & - & - & 175 & 25 \\
\hline $\mathrm{h}$ & - & - & 12 & 0 \\
\hline
\end{tabular}

\begin{tabular}{|c|c|c|c|c|}
\hline $\mathrm{d}$ & $\mathrm{h}$ & $\mathrm{yb}$ & $\log (\mathrm{Kb})$ & $\log (\mathrm{Ks})$ \\
\hline 81.04 & 5.56 & 118.99 & -6.10 & -3.14 \\
\hline
\end{tabular}

\begin{tabular}{|c|c|c|c|c|}
\hline $\mathrm{d}$ & $\mathrm{h}$ & $\mathrm{yb}$ & $\log (\mathrm{Kb})$ & $\log (\mathrm{Ks})$ \\
\hline 81.04 & 5.56 & 118.99 & -6.10 & -3.14 \\
\hline
\end{tabular}

\begin{tabular}{|c|c|c|c|c|}
\hline $\mathrm{d}$ & $\mathrm{h}$ & $\mathrm{yb}$ & $\mathrm{Kb}$ & $\mathrm{Ks}$ \\
\hline 81.04 & 5.56 & 118.99 & $8.00 \mathrm{E}-07$ & $7.16 \mathrm{E}-04$ \\
\hline
\end{tabular}

\begin{tabular}{|c|c|c|c|}
\hline $\mathrm{Kh} / \mathrm{Kv} \mathrm{SP}$ & $\mathrm{Kb}(\mathrm{ft} / \mathrm{s})$ & $\mathrm{Ksp}(\mathrm{ft} / \mathrm{s})$ & Khv \\
\hline 0.50 & $6.60 \mathrm{E}-05$ & 1.30E-03 & 0.25 \\
\hline 0.25 & $2.05 \mathrm{E}-05$ & & \\
\hline 0.15 & $6.48 \mathrm{E}-06$ & & \\
\hline 0.10 & $2.05 \mathrm{E}-06$ & & \\
\hline 0.05 & $6.48 \mathrm{E}-07$ & & \\
\hline 0.005 & & & \\
\hline
\end{tabular}

\begin{tabular}{|c|c|}
\hline & \\
$\mathrm{d}(\mathrm{ft})$ & $\mathrm{h}(\mathrm{ft})$ \\
\hline 175 & 0 \\
\hline 150 & 3 \\
\hline 125 & 6 \\
\hline 100 & 9 \\
\hline 75 & 12 \\
\hline 50 & 15 \\
\hline 25 & \multicolumn{2}{|c}{} \\
\cline { 1 - 1 } &
\end{tabular}

\begin{tabular}{|c|c|c|}
\hline $\begin{array}{c}z(\mathrm{ft})(\mathrm{d} \\
\text { between } \\
175^{\prime} \text { and } \\
\left.75^{\prime}\right)\end{array}$ & $\begin{array}{c}\mathrm{z}(\mathrm{ft}) \\
\left(\mathrm{d}=50^{\prime}\right)\end{array}$ & $\begin{array}{c}\mathrm{z}(\mathrm{ft}) \\
\left(\mathrm{d}=25^{\prime}\right)\end{array}$ \\
\hline 15 & 19.60 & 26.00 \\
\hline 12 & 15.95 & 21.62 \\
\hline 9 & 12.65 & 18.32 \\
\hline 6 & 9.35 & 15.02 \\
\hline 3 & 6.05 & 11.72 \\
\hline 0 & 2.75 & 8.42 \\
\hline
\end{tabular}

$$
\begin{aligned}
\mathrm{yw} & =62.4 \\
\mathrm{FS} & =0.83
\end{aligned}
$$

Figure D.8 Excel spreadsheet for Analysis 4. 


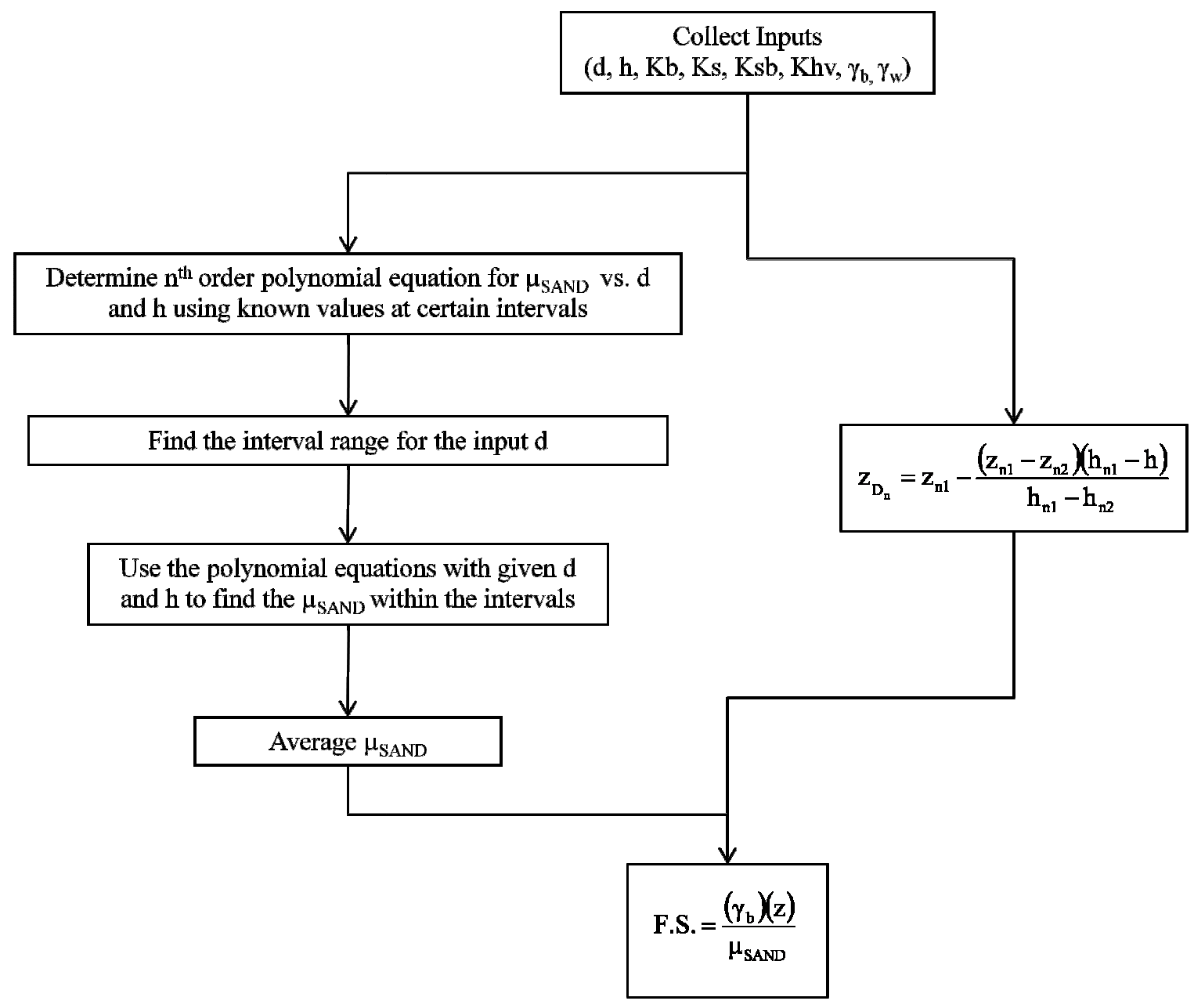

Figure D.9 Flow Chart for Excel Spreadsheet for Analysis 4. 


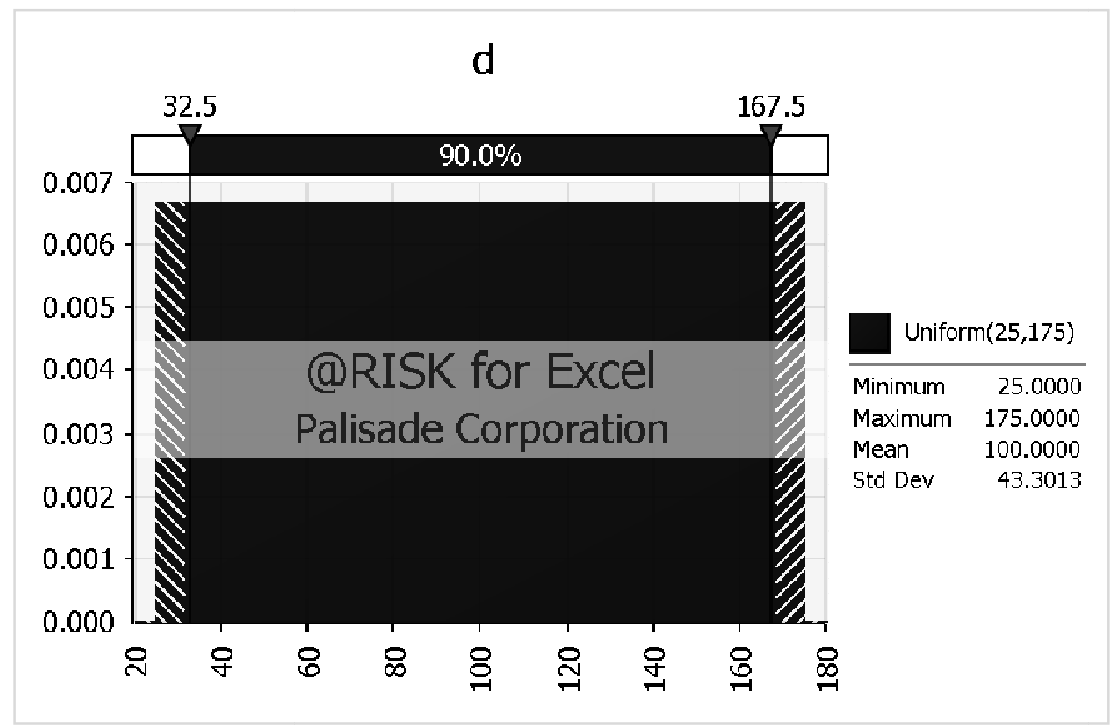

Figure D.10 Probability Density Function for geometric variable d.

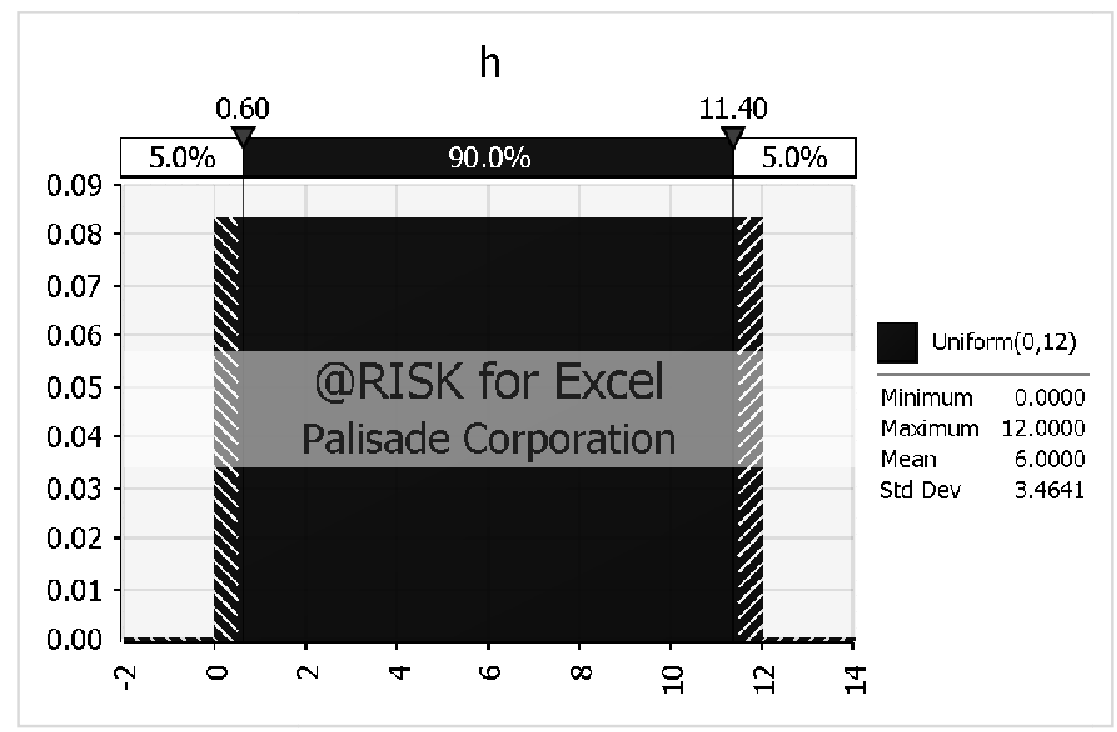

Figure D.11 Probability Density Function for geometric variable h. 


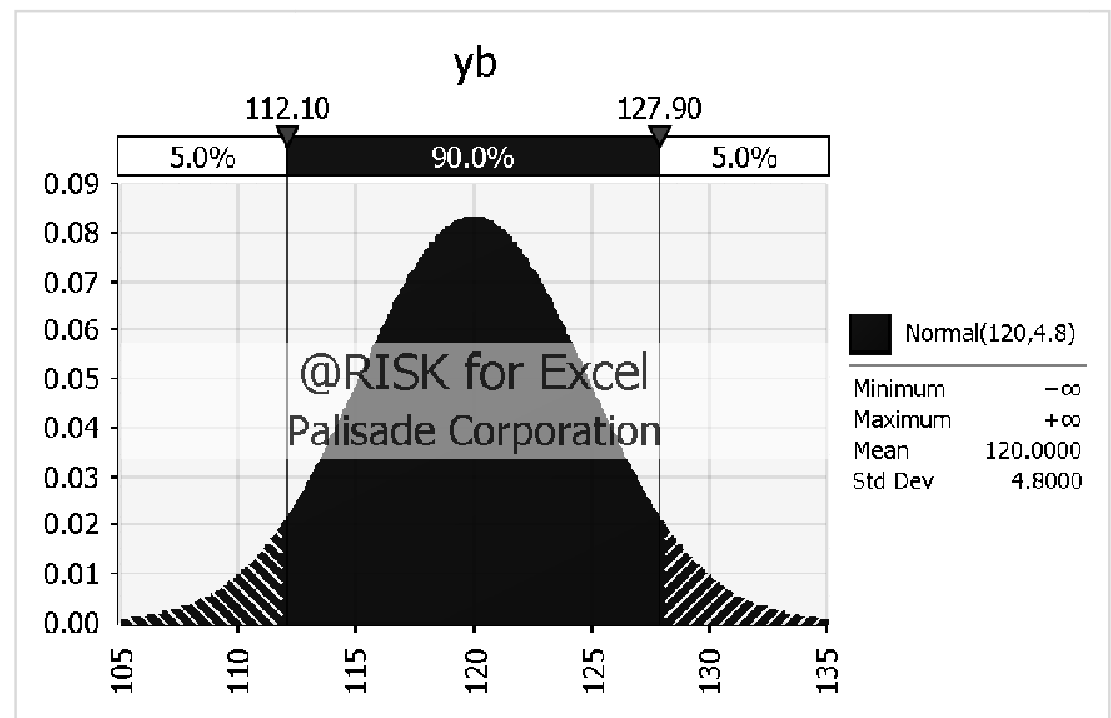

Figure D.12 Probability Density Function for soil variable $\gamma_{b}$.

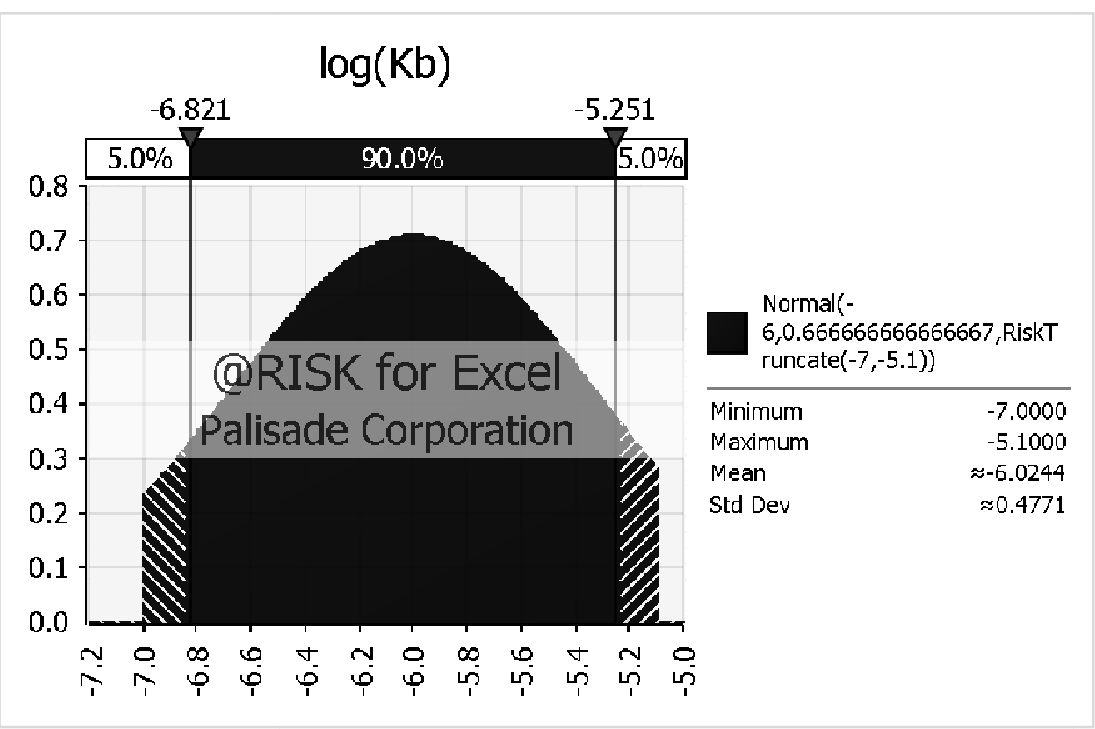

Figure D.13 Probability Density Function for soil variable Kb. 


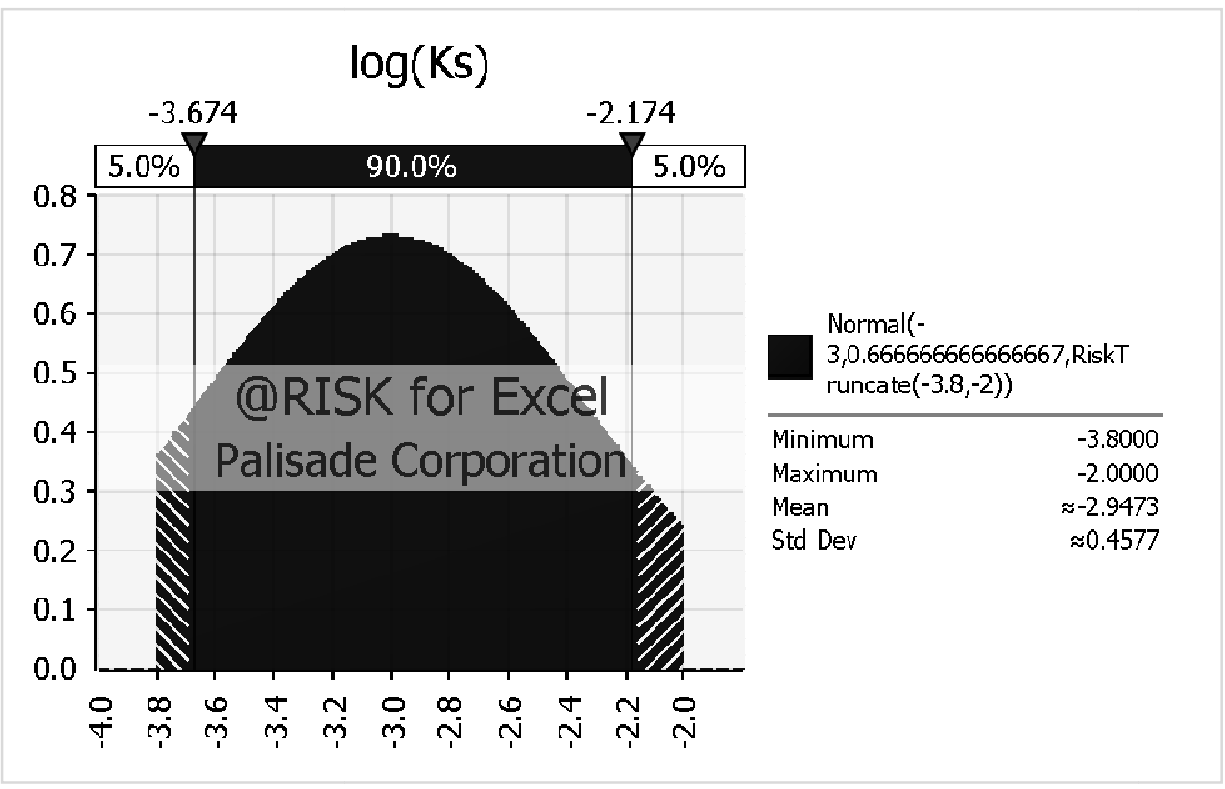

Figure D.14 Probability Density Function for soil variable Ks. 